INTERNATIONAL PHASE OF OCEAN DRILLING (IPOD)

DEEP SEA DRILLING PROJECT

DEVELOPMENT ENGINEERING

TECHNICAL REPORT NO. 14

\title{
DRILL STRING FAILURE ANALYSES
}

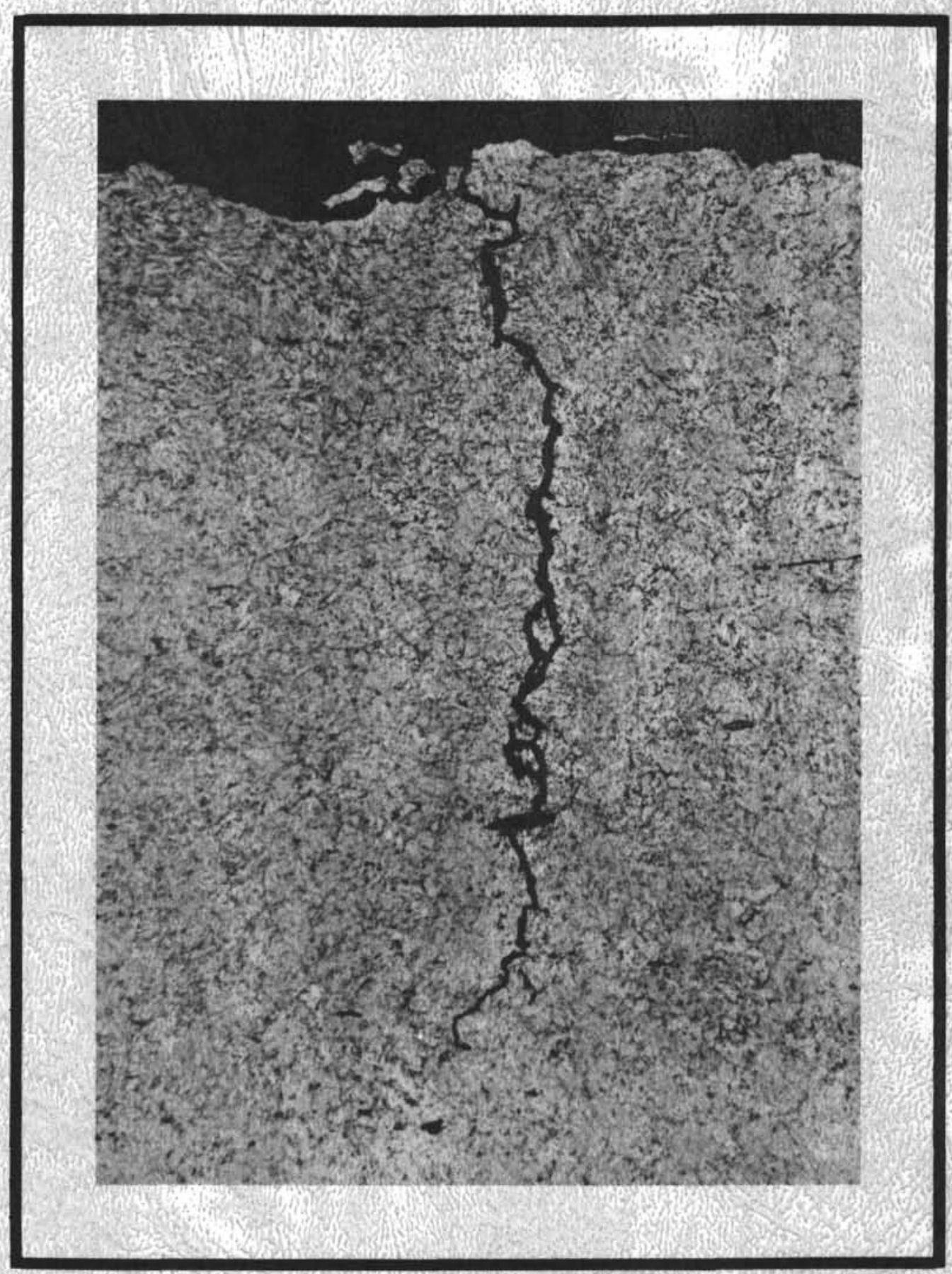

SCRIPPS INSTITUTION OF OCEANOGRAPHY UNIVERSITY OF CALIFORNIA AT SAN DIEGO CONTRACT NSF C-482

PRIME CONTRACTOR: THE REGENTS, UNIVERSITY OF CALIFORNIA 
DISCLAIMER

This report was prepared by the Deep Sea Drilling Project, University of California, San Diego as an account of work sponsored by the United States Government's National Science Foundation. Neither the University nor any of their employees, nor any of their contractors, subcontractors, or their employees, makes any warranty, express or implied, or assumes any legal liability or responsibility for the accuracy, completeness or usefulness of any information, apparatus, product or process disclosed, or represents that its use would nct infringe privacely owned rights. 
THE COVER PICTURE

The fatigue crack (shown in $300 x$ magnification) has originated at the exterior surface of the drill pipe and has propagated to a depth of .017 inch. Fatigue cracks, in combination with the ever present corrosion problem, have been the major cause of failure of the drill pipe during the history of the Deep Sea Drilling Project. 
TECHNICAL REPORT NO. 14

\title{
DRILL STRING FAILURE ANALYSES
}

\author{
Prepared for the \\ NATIONAL SCIENCE FOUNDATION \\ National Ocean Sediment Coring Program \\ Under Contract $\mathrm{C}-482$ \\ by the \\ UNIVERSITY OF CALIFORNIA \\ Scripps Institution of Oceanography \\ Prime Contractor for the Project
}

November 1983

W. A. Nierenberg, Director

Scripps Institution of Oceanography
M.N.A. Peterson

Principal Investigator and Project Manager Deep Sea Drilling Project Scripps Institution of Oceanography 
The Deep Sea Drilling Project (DSDP) became operational in August 1968 with the successful sea trials of the drillship GLOMAR CHALLENGER. The vessel's mission was to recover cores of sediments and basement rock from the deep ocean for scientific study. During the 15 years of exploration, a total penetration of $1,032,707$ feet was accummulated in the course of drilling and coring 1072 holes at 614 sites. The deepest penetration beneath the sea floor was 5712 feet and the maximum penetration into basaltic crust was 3,543 feet. Wireline coring operations were undertaken with drill string lengths to 23,111 feet.

For this demanding work, the project employed drill strings of 5 -inch, 19.5 lbs/ft, S-135 drill pipe with a minimum yield strength of 135,000 psi. A 4-inch minimum bore provided for high speed wireline coring and high loads could be carried within the drill pipe's 712,000 pound minimum yield load. Normal design loads were at $90 \%$ of minimum load.

During the 15 years of deep water operation, the high drill string loads, vessel positioning losses, hard seafloors and a corrosive environment have all contributed to a number of major drill string losses. Technical Report No. 14 is a summary and analysis of these drill string and bottom hole assembly failures. Operating practices and means of failure reduction are also discussed. Copies of formal metallurgical failure analyses by U. S. Steel Research and Battelle Houston Operations are included in the appendix. 


\section{ACKNOWLEDGEMENTS}

Technical Report No. 14 contains analyses of major drill string failures incurred during 15 years of Deep Sea Drilling Project (DSDP) wireline coring operations. Operating experience and means to reduce such losses is also described. This operational experience and failure analyses should be of interest to other operators in designing for similar deep water work.

The Project acknowledges the prompt and thorough failure analyses provided, under contract, by U. S. Steel Research and Battelle Houston Operations.

This report was prepared by Mr. Don Bellows, Senior Design Engineer with the Project's Development Engineering Department.

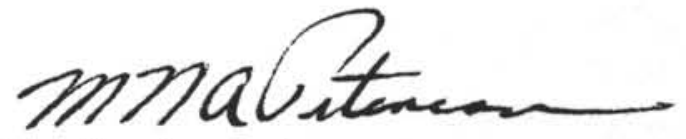

M. N. A. Peterson

Principal Investigator

and Project Manager 
CONTENTS

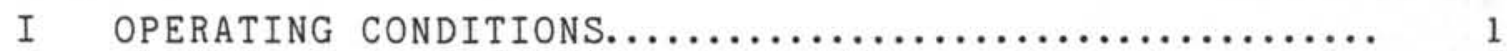

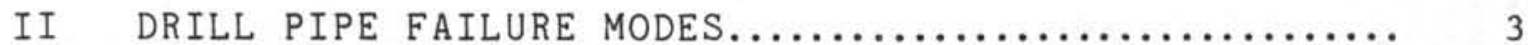

II BOTTOM HOLE ASSEMBLY FAILURE MODES $\ldots \ldots \ldots \ldots \ldots \ldots \ldots . . \ldots 1$

IV FAILURE PREVENTION-INSPECTION AND OPERATIONAL

PROCEDURES.................................. 12

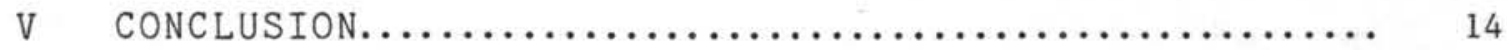

VI APPENDICES

A. FAILURES OF DRILL PIPE AND BOTTOM HOLE

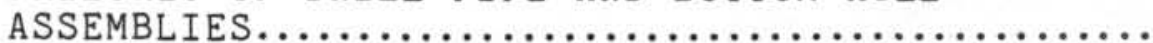

B. DRILL PIPE FAILURE ANALYSES

B-1 FAILURE ANALYSIS OF DRILL PIPE TOOL

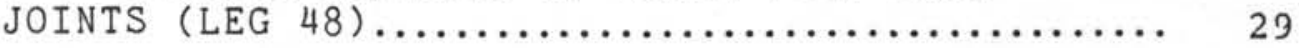

B-2 FAILURE ANALYSIS OF S-135 DRILL PIPE USED IN DEEP SEA DRILLING (LEG 53) ............ 55

B-3 DOCKSIDE PRELIMINARY EXAMINATION OF FAILED S-135 STEEL DRILL PIPE FROM D/V GLOMAR CHALLENGER AND ASSOCIATED METALLURICAL FAILURE ANALYSIS OF FRACTURED DRILL PIPE,

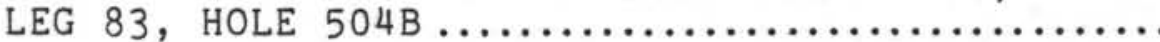

B-4 FINAL REPORT-FAILURE OF DRILL STRING,

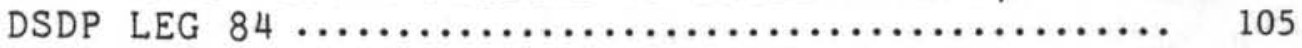

B-5 FAILURE ANALYSIS OF KELLY COCK SUB

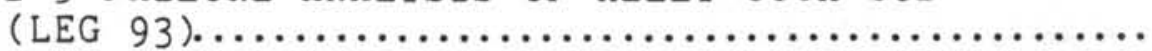

C. FAILURE ANALYSIS OF DRILL PIPE FROM HOLE

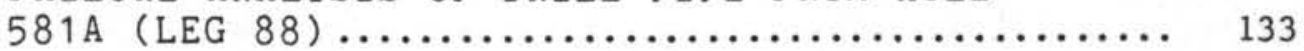

D. OPERATIONS DURING SEVERE WEATHER $\ldots \ldots \ldots \ldots \ldots \ldots \ldots . . . \ldots \ldots$

E. MECHANICAL AND METALLURGICAL EVALUATION OF

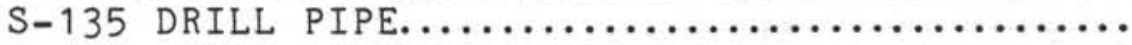




\section{LIST OF FIGURES}

1. Configuration of Drill String

2. Bending Stress in Drill Pipe

3. Corrosion on Interior Surface of Drill Pipe

4. Typical Bottom Hole Assembly (BHA)

5. Bumper Sub in Fully Stroked Out Condition

\section{LIST OF TABLES}

I. Properties of S-135 Steel 
Figure 1 shows, schematically, the configuration of a typical drill string used in the Deep Sea Drilling Project (DSDP). The string varies in length dependent upon water depth and depth drilled below the sea floor. The longest 5-inch drill string deployed thus far has reached 23,111 feet. The drill pipe material is $\mathrm{S}-135 \mathrm{steel}$. Some mechanical and chemical properties of this steel are given in Table $I$.

The most highly stressed region in the string is at the upper end. The weight of the string, as much as 450,000 pounds in water, produces a high static axial stress. The heave motion of the ship produces a dynamic axial stress, which usually is relatively low, but which near resonance of the string can reach three times its normal value. A bending load, caused by the pitch and roll of the ship, is imposed on the drill string as it passes thru the guide shoe. A typical bending stress pattern, as obtained from a strain gaged section of drill pipe, is shown in Figure 2. The envelope of the record corresponds to the pitch or roll of the ship, whereas the individual cycles correspond to the rotation of the drill string as it is lowered thru the guide shoe. The periods of zero stress represent the time when the pipe is not bent, but is swinging from one side of the guide shoe to the other. While the drill string is being rotated, the torsion is closely monitored to prevent a twist-off of the pipe.

For a 21,000 foot long, 5-inch drill string, the static axial stress is on the order of 80,000 psi. The dynamic axial stress is about 8,000 psi and the bending stress is approximately 25,000 psi. The total load is monitored during drilling operations to insure that the load does not continuously exceed the design limit of $90 \%$ of the yield strength. Stress levels are increased when re-entry cones or casing is lowered on the drill string. The submerged re-entry cone becomes a large intertial mass responding to vessel heave motion during lowering. Drill string stresses are also increased when drill pipe is used to lower long casing strings into boreholes. The additional static loads due to casing have reached 80,000 pounds during such operations. This load is equivalent to the weight of 4,300 feet of $51 / 2$-inch drill pipe.

Normally the point of highest stress and vulnerability is at the top of the drill string. However, under certain conditions, the bottom of the string can also be severely stressed. The bottom hole assembly (BHA) or drill pipe can be buckled during attempts to start hole on a hard bottom without lateral support. During drilling, the drill pipe immediately above the drill collars can be buckled if the drill pipe is not kept in tension, or if there is insufficient bumper sub stroke to compensate for drill string vertical oscillation. Losses of dynamic positioning during drilling pose an additional risk to drill pipe. With dynamic 
positioning lost, even for a brief period, the vessel can drift off location, bending the drill string at the sea bottom. The conditions described above have resulted in losses of drill pipe and bottom hole assemblies.

Corrosion is also a factor which has a bearing on the magnitude of stress in the drill pipe. While drilling into the ocean bottom, seawater is pumped down the string and out of the bit to flush cuttings out of the hole. This flow of water in the string erodes the inner diameter of the pipe. Also, since the water is taken from the surface, it is rich in oxygen which sets up the conditions for oxygen concentration cells on the inside surface of the pipe. The effects of corrosion and fatigue "feed on each other". A corrosion pit is frequently the initiation point for a fatigue crack. Then corrosion proceeds into the crack, further weakening that area and causing the crack to propagate at a faster rate than it would without the corrosive seawater environment. Many of the failures have resulted from fatigue cracks which have originated at erosion/corrosion pits on the inside of the pipe. Figure 3 shows a typical case of corrosion on the interior surface of the pipe. In 1977, an independent inspection was conducted by a corrosion consultant on approximately 12 joints of the drill pipe which had been coated internally with an inorganic zinc compound and had been in service for 12 months. The inspection showed the internally coated pipe to have significantly lower corrosion as compared to uncoated pipe. Based upon these findings, the 1978 purchase of drill pipe included coating on both the interior and exterior surfaces with inorganic zinc. Previous to this, only the exterior of the pipe had been coated with the zinc. 
II DRILL PIPE FAILURE MODES

The failures of the 5-inch drill pipe are summarized below.

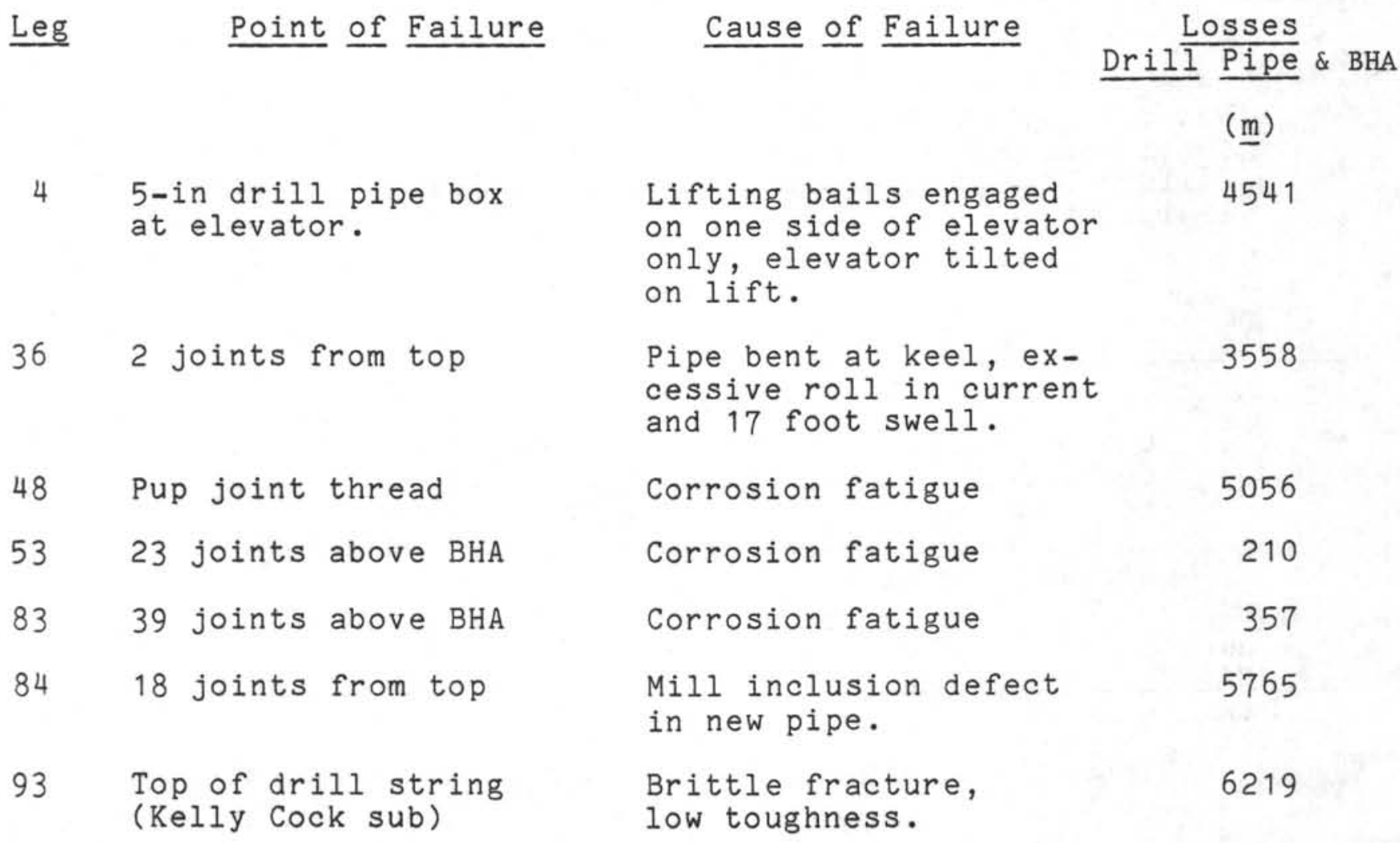

Table A-1 in Appendix A lists the major drill pipe failures that have occurred during the course of the Project. Details of the seven pipe failures and the results of the failure analyses are described on the following pages. Complete reports, including metallurgical analyses, for the failures on Legs $48,53,83,84$, and 93 , are contained in Appendices B-1 through B-5, respectively. A formal report is also included for a bottom hole assembly loss on one Leg 88 (Appendix C).

Specification RP-7G of the American Petroleum Institute (API) states the conditions for inspection and classification of drill pipe. Some of the items mentioned are wear, fatigue cracks, cuts, gouges, and corrosion on the exterior and corrosive pitting, erosion, wear, and fatigue cracks on the interior. From the experience to date on the Project it appears that the exterior condition of the pipe is seldom the cause of a failure, except in the case of material defects. The principal cause of failure of the drill pipe has been corrosion fatigue which originates on the interior and propagates through the pipe wall. 
LEG 4 - HOLE 24

Failure Statistics

Date of Failure: $\quad 2 / 8 / 69$

Water Depth (m): 5149

Total Depth $(m)$ : above mud line

Failure Depth (m): at the derrick floor

Equipment Lost: $4541 \mathrm{~m}$ of drill pipe + $\mathrm{BHA}$

Results of Analysis

1. One of the bails on the travelling block failed to fully engage in position in the elevator during a trip out of the hole. As a result, the other bail took the full weight of the string breaking the pipe in the elevator.

\section{Corrective Action Taken}

1. Insure full elevator/bail engagement before picking up pipe. 


\section{LEG $36-$ HOLE 326}

Failure Statistics

$\begin{array}{ll}\text { Date of Failure: } & 4 / 6 / 74 \\ \text { Water Depth (m): } & 3822 \\ \text { Total Depth (m): } & 3831 \\ \text { Failure Depth (m): } & 18 \\ \text { Equipment Lost: } & 3558 \mathrm{~m} \text { drill pipe + BHA }\end{array}$

Results of Analysis

1. The drill pipe failure was caused by the sharp bending of the drill string beyond the limits of the restraining member (guide shoe) as the ship rolled in response to the severe weather conditions in the Antarctic.

Corrective Action Taken

Established the following operational limits:

1. Drill pipe shall not be run when anticipated sea conditions will cause the ship to pitch and/or roll in excess of 7 degrees single amplitude.*

2. Drilling operations, including running of drill pipe, may continue on the basis of a maximum pitch and/or roll of 7 degrees single amplitude.*

3. The drill string shall be pulled if occasional pitch and/or roll exceeds 9 degrees single amplitude.

*Limitation is 5 degrees for drill strings in excess of $6860 \mathrm{~m}$. A more complete description of severe weather operational limits and procedures is contained in Appendix E. 


\section{LEG $48-$ HOLE $400 \mathrm{~A}$}

Failure Statistics

$\begin{array}{ll}\text { Date of Failure: } & 6 / 3 / 76 \\ \text { Water Depth (m): } & 4399 \\ \text { Total Depth (m): } & 5176 \\ \text { Failure Depth (m): } & \text { above rig floor in pup joint } \\ \text { Equipment Lost: } & 5056 \mathrm{~m} \text { drill pipe + BHA }\end{array}$

Results of Failure Analysis by U.S. Steel

1. Fracture was initiated by corrosion fatigue in root of pup joint thread.

2. Chemical composition of failed pup joint corresponded to that specified for AISI 4150 steel.

3. Mechanical properties of failed joint were within those specified for AISI 4150 steel.

\section{Corrective Action Taken}

1. Procedure was set up for frequent inspections of pup joint threads using flourescent magnetic particle examination. Any joints showing cracks in threads are removed from service. 


\section{LEG $53-$ HOLE $418 \mathrm{~A}$}

Failure Statistics

$\begin{array}{ll}\text { Date of Failure: } & 4 / 6 / 77 \\ \text { Water Depth }(\mathrm{m}): & 5519 \\ \text { Total Depth }(\mathrm{m}): & 5816 \\ \text { Failure Depth }(\mathrm{m}): & 5519 \\ \text { Equipment Lost: } & 210 \mathrm{~m} \text { drill pipe + BHA }\end{array}$

Results of Failure Analysis by U. S. Steel

1. Fracture was result of corrosion fatigue initiated on external surface of pipe.

2. Chemical composition of failed pipe corresponded to that given in API Specification $5 \mathrm{AX}$.

3. Mechanical properties of failed pipe were within those given in API Specification $5 \mathrm{AX}$.

Corrective Action Taken

1. A policy was established whereby only premium class drill pipe was to be used. in any further drilling operations. The Project has followed this policy.

2. The interval for periodic inspection of the drill pipe was set at 4 to 6 months. 


\section{LEG $83-$ HOLE 504B}

Failure Statistics

Date of Failure:

Water Depth (m):

Total Depth (m): $\quad 4535,4763$

Failure Depth (m): 4033, 4543

Equipment Lost: $\quad 357 \mathrm{~m} \mathrm{drill} \mathrm{pipe} \mathrm{+} \mathrm{BHA} \mathrm{(first} \mathrm{failure)}$

$100 \mathrm{~m}$ drill pipe + BHA (second failure)

Results of Failure Analysis by Battelle

1. Failure was due to corrosion fatigue.

2. Fatigue cracks originated at deep broad corrosion pits on inside surface of pipe.

3. Mechanical properties of drill pipe met API Specification 5AX.

4. Chemical composition of drill pipe met API Specification 5AX.

5. Basic cause of failures was inability of internal inspection system to detect advanced corrosion damage on interior surface of drill pipe.

\section{Corrective Action Taken}

1. All suspect pipe ( 588 joints) was removed from ship and inspected by External Sonoscope and ultrasonic wall

thickness measuring instruments. 


\section{LEG $84-$ HOLE $567 \mathrm{~A}$}

\section{Failure Statistics}

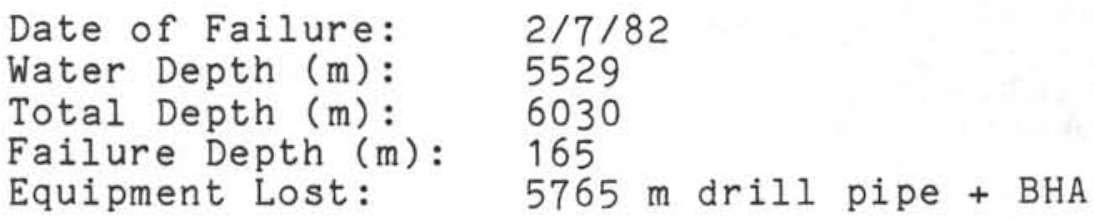

Results of Failure Analysis by Battelle

1. Lap defect, at fracture point, probably produced during tube rolling operation, and which was rejectable according to API Specification $5 \mathrm{AX}$.

2. Yield strength of 170,800 psi was higher than that allowed $(165,000 \mathrm{psi})$ in API Specification 5AX.

3. Hydrogen embrittlement was contributing factor in failure, especially since yield strength was higher than allowed.

\section{Corrective Action Taken}

1. Hardness of Rc 38.5 corresponds to yield strength of 165,000 psi. Joints of pipe with hardness in excess of Rc 38 were removed from service. 


\section{LEG $93-$ HOLE 603B}

\section{Failure Statistics}

$\begin{array}{ll}\text { Date of Failure: } & 6 / 1 / 83 \\ \text { Water of Depth (m) } & 4644 \\ \text { Total Depth (m): } & 6229 \\ \text { Failure Depth (m): } & \text { at rig floor } \\ \text { Equipment Lost: } & 6219 \text { m drill pipe + BHA }\end{array}$

Results of Failure Analysis by Battelle

1. Kelly Cock sub failed by brittle fracture initiated at fatigue cracks which began at corrosion pits in the root of the last engaged thread.

2. Thoughness of Kelly Cock sub was low due to presence of mixed microstructure.

\section{Corrective Action Taken}

1. Recommendation from Battelle is to specify a tougher material such as quenched and tempered 4340 steel for replacement subs. Also, there should be a programmed replacement of the sub, say every five years. 


\section{BOTTOM HOLE ASSEMBLY FAILURE MODES}

A schematic representation of a typical bottom hole assembly (BHA) is shown in Figure 4. A detailed listing of the failures in, or near, the BHA is given in Table A-2 of Appendix A. Conparison with Table A-1 reveals that the vast majority of the failures have occurred at the BHA. Although the top of the drill string is the most highly stressed region during normal operations, the bottom of the string is also vulnerable to damage since the driller must be guided only by the weight indicator reading which fluctuates irregularly by 50,000 to 100,000 pounds. The drill string must always be kept in tension--if it goes into compression it is susceptible to buckling which can produce damaging stresses. The driller must carefully monitor the weight on bottom to insure that buckling does not take place. This becomes especially critical when spudding in (starting a hole) on a hard bottom where the sediment cover is not thick enough to give lateral support to the 400-foot long BHA.

Once the drill string has been deployed and drilling into the bottom has started, the ship must maintain position over the site until the string is pulled out of the hole. The ship's dynamic positioning system is computer controlled and can maintain a watch circle of 50-60 feet diameter when operating in water depths up to 20,000 feet. If the ship loses dynamic positioning capability and drifts off site while the drill string is in the hole, the string may be subjected to excessive bending stresses at the mudline. Table A-2 indicates that this has happened several times resulting in the loss of part or all of the BHA.

The bumper subs are heave compensating telescoping joints interspersed among the drill collars in the BHA. They prevent the heave motion of the ship from being transmitted to the drill bit. Without the bumper subs (or some other heave compensating device) the bit would be alternately lifted off the bottom of the hole, then slammed into the bottom. Figure 5 shows a fully stroked out bumper sub which is slightly bent as a result of overstressing. The drill collars are thick wall weight members--therefore, the bumper subs are the weak link in the BHA. This is evident from the number of bumper sub failures listed in Table A-2.

During the early years of the Project, failures in the BHA were quite common. However, as experience was gained and improvements made, the frequency of BHA failures decreased. One such improvement was a transition from 6-5/8 API regular threads to $6-5 / 8$ API full hole modified threads. 
Various methods are used to inspect the drill pipe and determine its suitability for continued service. Visual inspection of the exterior will detect any obvious problems such as cuts, gouges, and corrosion pitting. A visual inspection of the interior must be done with a borescope, an optical device which can be passed through the bore. Wall thickness and uniformity are measured with an ultrasonic thickness gage which passes sound waves through the wall of the pipe and measures the time interval for the waves to be reflected from the interior steel-air interface. Cracks caused by fatigue or overstressing, even though imperceptible to the unaided eye, may be revealed by magnetic flux leakage inspection. It is the practice of DSDP to perform a complete pipe inspection using these methods at intervals of four months. The BHA is inspected at intervals of two months. Tool joints are inspected at four month intervals. The shoulder diameter is measured with a micrometer gage. Gages are also used to determine the swell of the box (female threaded section) and the stretch of the pin (male threaded section). Profile gages show any discrepancy in the thread profile.

API specification RP-7G provides the criteria for classifying the drill pipe as a result of an inspection. The classes starting with the best are:

$\begin{array}{lr}\text { Class } 1 & \text { New } \\ \text { Premium Class } & 80 \% \text { wall } \\ \text { Class 2 } & 65 \% \text { wall } \\ \text { Class } 3 & =55 \% \text { wall } \\ \text { Class } 4 & <55 \% \text { wall }\end{array}$

At the present time DSDP normally uses nothing lower than premium class drill pipe in its operations. The inspection of the drill pipe on board the ship is usually conducted with the pipe in the mechanized racker. Consideration should be given to an annual inspection where the pipe is racked out on the dock for a more complete inspection.

Analytical and computer studies have been made which indicate that various options may be used to obtain long drill strings and maintain stresses within a safe level. One option is to use a tapered drill string, i.e., made up of larger diameter pipe at the top tapering to smaller diameter pipe at the bottom. Another option is a mixed string using pipe of different materials, e.g., steel and aluminum.

As previously stated, the drill pipe experiences bending stresses due to pitch and roll of the ship while rotating the drill string. One way of restricting the severity of the bending is the use of rubber spacers installed at intervals along the drill string. This lowers the bending stress from about 100,000 psi to approximately 25,000 psi for a 20,000 foot, 5-inch diameter steel 
string. Another way of reducing stress in the critical guide shoe area is the use of heavy wall drill pipe. The pipe is 5.5inch diameter with 7-3/4 inch diameter knobs at intervals of about 5-feet machined integrally as part of the pipe. Operating procedures call for the use of these "knobbies" under certain conditions of drill string length, rate of penetration, and pitch and roll angle of the ship (see Appendix D). The knobbie is used in the guide shoe. The knobs produce the same effect as the rubber spacers on the regular drill pipe, i.e., they cause a reduction of the bending stress. The larger cross sectional area associated with the 5.5 inch diameter produces a decrease in the static stress.

It is important that the drill string components be inspected after regular intervals of use. It is equally important that new pipe be inspected to determine if it is adequate for service. New pipe is inspected by the quality control group at the manufacturer's plant. The Project also conducts its own inspection of new pipe before taking delivery. The items that are considered in this type of non-destructive inspection are:

1) Seams, overlaps

2) Rolled-in slugs (or pits resulting from same)

3) Cracks

4) Eccentricity

5) Hardness and hardness variations

6) Threads - gaging for fit, checking for cracks

7) Wall thickness spot testing

8) Drifting to check bore

The same methods as mentioned for inspection of used pipe are also utilized to inspect new pipe. Appendix $E$ is a report by Battelle giving complete mechanical and metallurgical properties of the most recent order of new pipe which was put on board in September of 1982 . 


\section{CONCLUSION}

Coring operations in deep oceanic basins may present increased risk of drill string loss due to high stresses coupled with adverse weather, current, and drilling conditions. The risk of failure can be reduced through operational and inspection procedures. DSDP precautions against loss include the following:

1. The use of special 5-1/2 inch heavy wall drilling joints at the top of the string. The joints are used when drilling rates are less than 16 feet per hour or for very long drill string deployments. Integral 7-3/4 inch O.D. hubs at 5-foot spacing insure a smooth radius as the drilling joint bears against the 350-foot radius bending restraint during the vessel's roll/pitch motion.

2. Programmed replacement of heavy wall drilling joints and pup joints at the upper end of the drill string.

3. A minimum of 100 meters of soft sediment is normally required for lateral support of the bottom hole assembly.

4. Vessel roll/pitch motion limits have been set to prevent excessive pipe bending in the moon pool area.

5. Normally, only premium grade pipe is to be in the drill string (Class 2 pipe is used lower in the string if insufficient premium pipe is aboard).

6. All drill collars and subs that make up the BHA are to be inspected by magnetic particle methods at two month intervals. The top pup joint is to be magnafluxed at least once each month and pin connection recut after six months. After an additional six months, the top pup joint is retired.

7. The drill pipe is to be inspected at four month intervals using an internal sonde magnetic flux leakage device, borescope, and ultrasonic methods.

8. In addition to the vendor's mill inspection of new pipe, the Project will also have a third party inspection made prior to acceptance. 


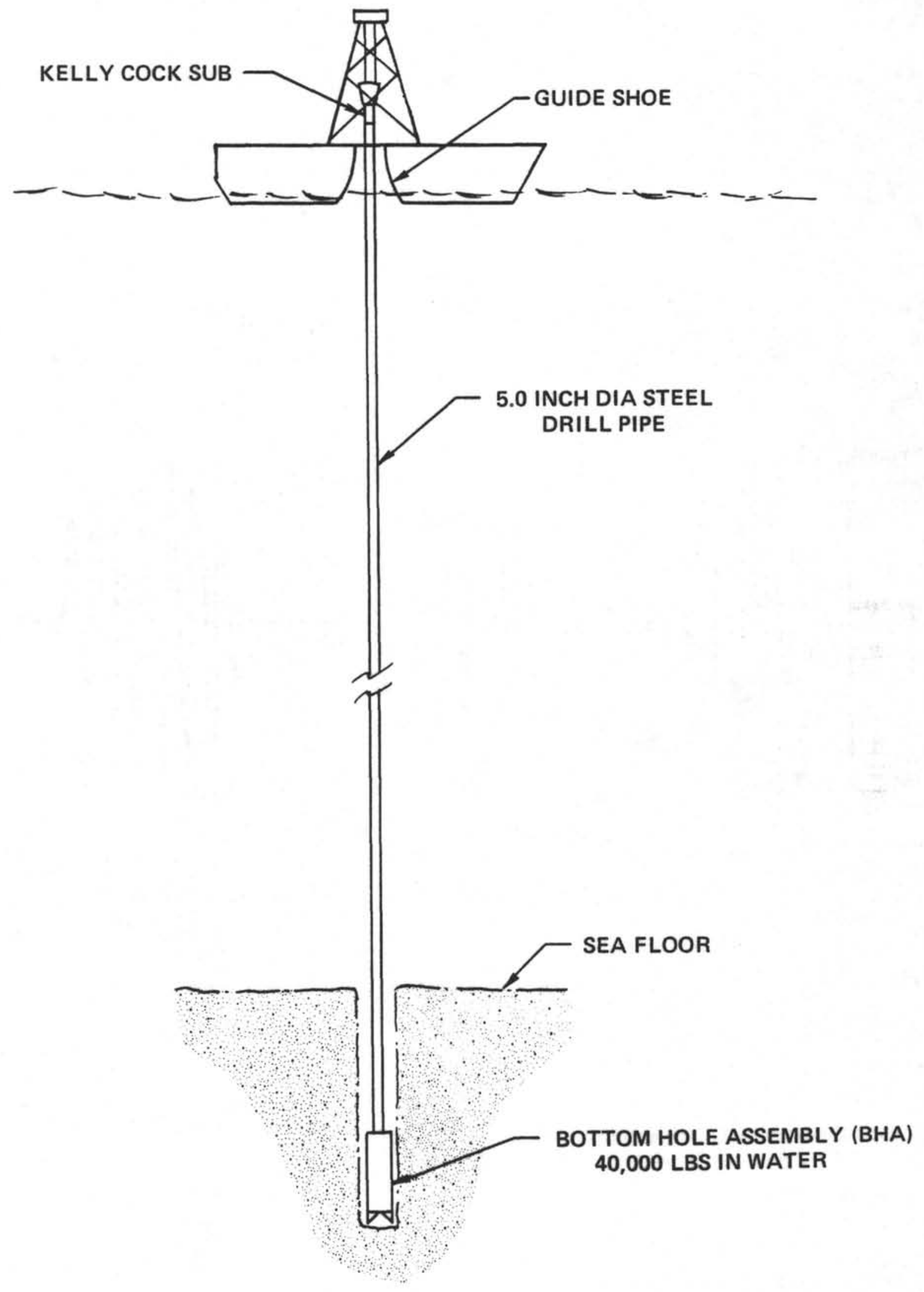

CONFIGURATION OF DRILL STRING

FIGURE 1 


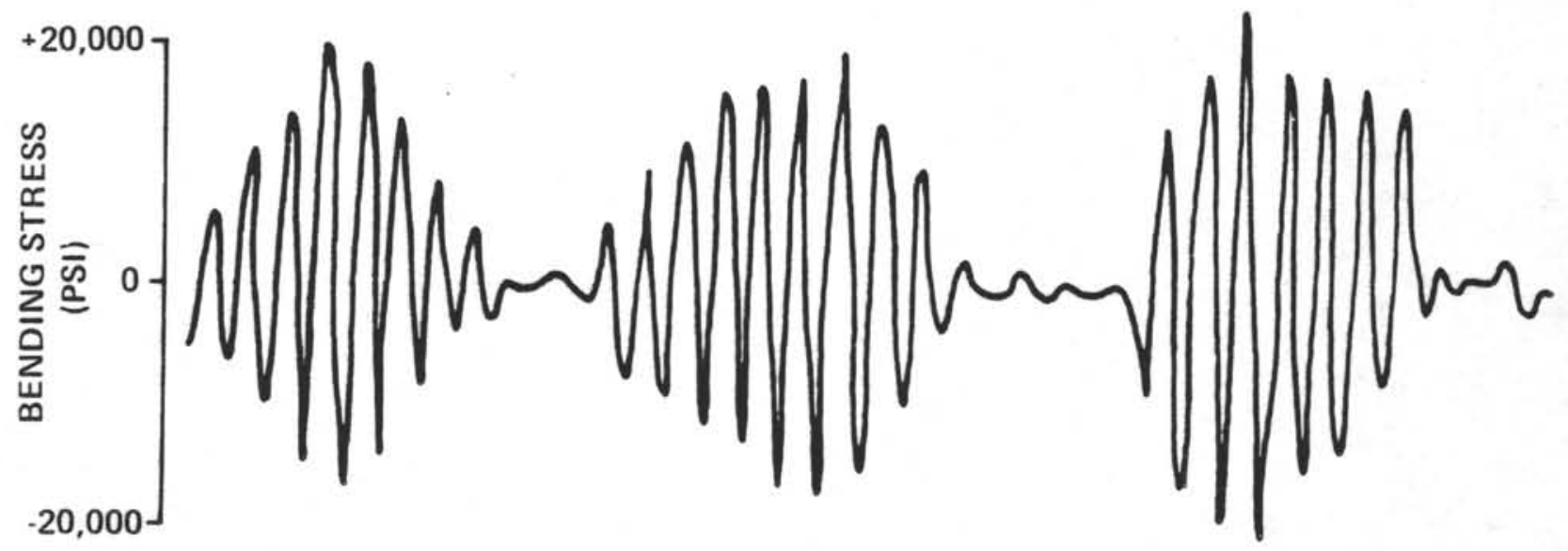

BENDING STRESS IN DRILL PIPE FIGURE 2 


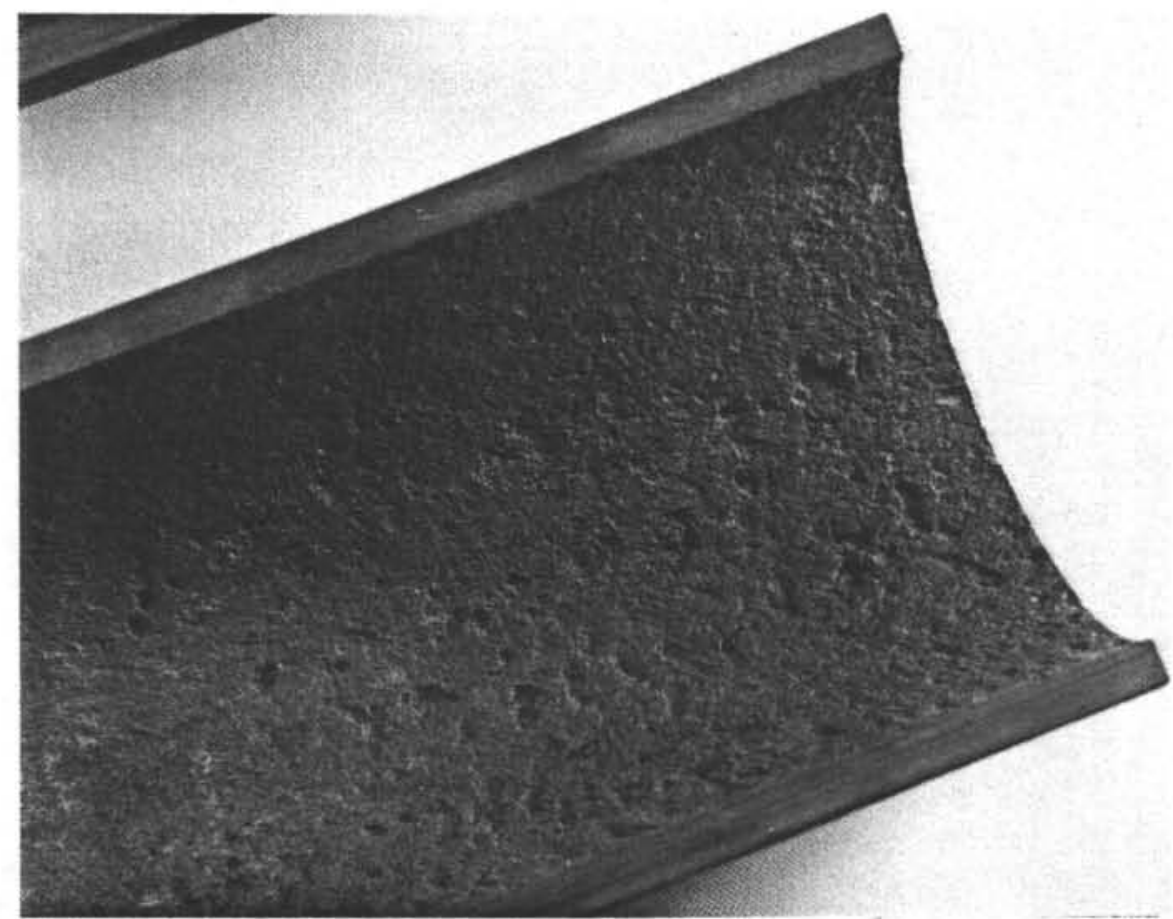

CORROSION ON INTERIOR SURFACE OF DRILL PIPE FIGURE 3 


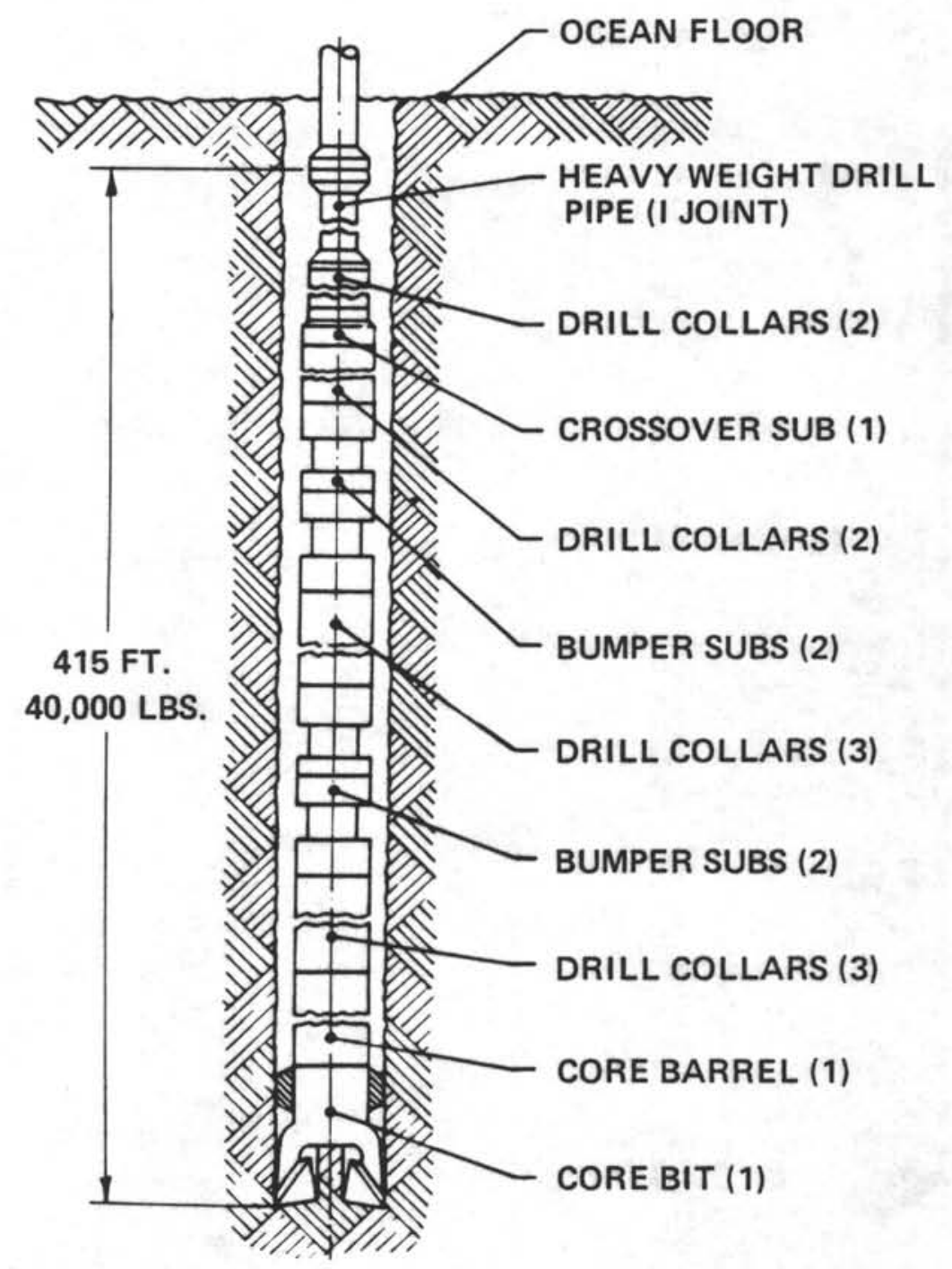

TYPICAL BOTTOM HOLE ASSEMBLY (BHA) FIGURE 4 


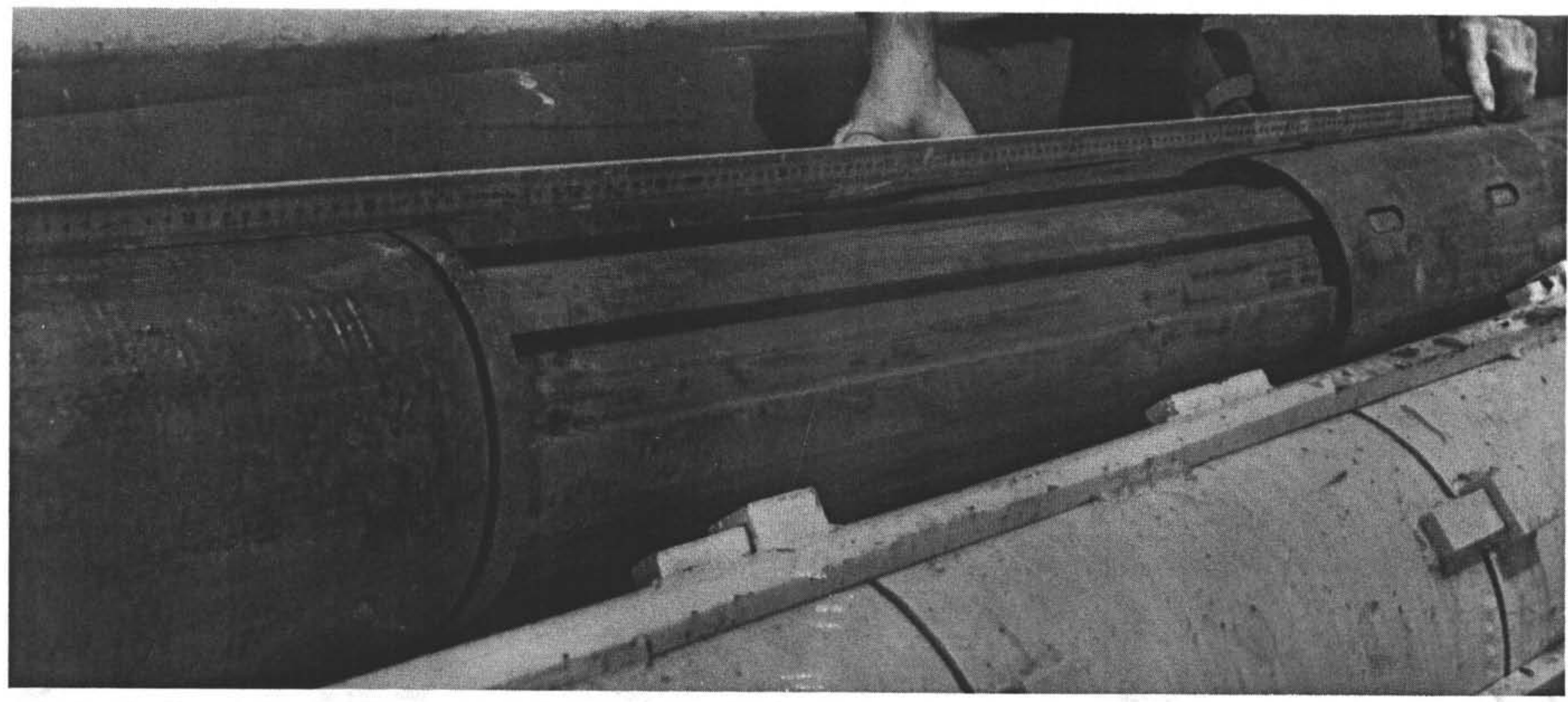

BUMPER SUB IN FULLY STROKED OUT CONDITION FIGURE 5 
TABLE I - PROPERTIES OF S-135 STEEL

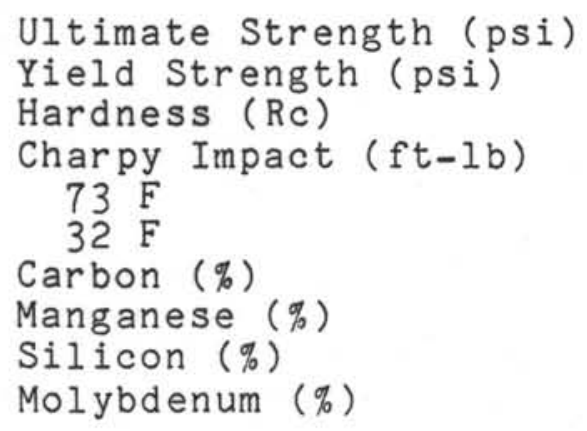

150,000

135,000

38

40

30

.25

1.50

.25

.55 
APPENDIX A

FAILURES OF DRILL PIPE AND BOTTOM HOLE ASSEMBLIES 
TABLE A-1 MAJOR DRILL PIPE FAILURES

\begin{tabular}{|c|c|c|c|c|c|c|c|c|c|}
\hline Leg & Site & Hole & $\frac{\frac{\text { Water }}{\text { Depth }}}{(\underline{m})}$ & $\frac{B S F}{(\underline{m})}$ & $\frac{\frac{\text { Total }}{\text { Depth }}}{\text { (m) }}$ & $\frac{\text { Location }}{\text { Failure }}$ & Remarks & & \\
\hline 4 & 24 & 24 & 5149 & 0 & 4541 & $\begin{array}{l}\text { Box at } \\
\text { Elevator }\end{array}$ & Lost 496 & Jts & $+\mathrm{BHA}$ \\
\hline 36 & 326 & 326 & 3822 & 9 & 3831 & ${\underset{t o p}{j t s} \text { from }}^{2 j \mathrm{~s}}$ & Lost 389 & jts. & $+\mathrm{BHA}$ \\
\hline $\begin{array}{l}48 \\
53\end{array}$ & $\begin{array}{l}400 \\
418\end{array}$ & $\begin{array}{l}400 \mathrm{~A} \\
418 \mathrm{~A}\end{array}$ & $\begin{array}{l}4399 \\
5519\end{array}$ & $\begin{array}{l}777 \\
297\end{array}$ & $\begin{array}{l}5176 \\
5816\end{array}$ & $\begin{array}{l}\text { Pup Joint } \\
23 \text { jts } \\
\text { above BHA }\end{array}$ & $\begin{array}{lr}\text { Lost } & 553 \\
\text { Lost } & 23\end{array}$ & $\begin{array}{l}\text { jts } \\
\text { jts }\end{array}$ & $\begin{array}{l}+\mathrm{BHA} \\
+\mathrm{BHA}\end{array}$ \\
\hline $\begin{array}{l}83 \\
83 \\
84\end{array}$ & $\begin{array}{l}504 \\
504 \\
567\end{array}$ & $\begin{array}{l}504 \mathrm{~B} \\
504 \mathrm{~B} \\
567 \mathrm{~A}\end{array}$ & $\begin{array}{l}3473 \\
3473 \\
5529\end{array}$ & $\begin{array}{l}226 \\
451 \\
501\end{array}$ & $\begin{array}{l}4535 \\
4763 \\
6030\end{array}$ & $\begin{array}{l}5 " \text { D.P. } \\
5 " \text { D.P. } \\
18 \text { jts } \\
\text { from top }\end{array}$ & $\begin{array}{lr}\text { Lost } & 39 \\
\text { Lost } & 11 \\
\text { Lost } & 630\end{array}$ & $\begin{array}{l}\text { jts } \\
\text { jts } \\
\text { jts }\end{array}$ & $\begin{array}{l}+ \text { BHA } \\
+ \text { BHA } \\
+ \text { BHA }\end{array}$ \\
\hline 93 & 603 & $603 B$ & 4644 & 1585 & 6229 & Kelly Cock & Lost 680 & jts. & $+\mathrm{BHA}$ \\
\hline
\end{tabular}

BSF - Below Sea Floor

D.P. - Drill Pipe

Jts - Joints (30 feet long)

BHA - Bottom Hole Assembly

Kelly Cock - Valve at upper end of drill string 
TABLE A-2 FAILURES IN BOTTOM HOLE ASSEMBLIES

\begin{tabular}{|c|c|c|c|c|c|c|c|c|}
\hline$\underline{\mathrm{Leg}}$ & Site & Hole & Date & $\frac{\frac{\text { Water }}{\text { Depth }}}{(\underline{m})}$ & $\frac{B S F}{(\underline{m})}$ & $\frac{\frac{\text { Total }}{\text { Depth }}}{\frac{(\mathrm{m})}{}}$ & $\frac{\text { Location }}{\text { Failure }}$ & Remarks \\
\hline 2 & 12 & 12 & $12 / 18 / 68$ & 4555 & 35 & 4590 & D.C.Tool Jt & $\begin{array}{l}\text { Lost Posit- } \\
\text { ioning }\end{array}$ \\
\hline $\begin{array}{l}3 \\
4\end{array}$ & $\begin{array}{l}20 \\
24\end{array}$ & $\begin{array}{l}20 \\
24 \mathrm{~A}\end{array}$ & $\begin{array}{l}01 / 12 / 69 \\
02 / 08 / 69\end{array}$ & $\begin{array}{l}4500 \\
5175\end{array}$ & $\begin{array}{r}44 \\
559\end{array}$ & $\begin{array}{l}4544 \\
5734\end{array}$ & $\begin{array}{l}\text { Top Sub-B.S. } \\
\text { Top Sub-B.S. }\end{array}$ & \\
\hline 4 & 25 & $25 \mathrm{~A}$ & $02 / 11 / 69$ & 1939 & 66 & 2005 & Top Sub-B.S. & \\
\hline 4 & 26 & 26 & $02 / 15 / 69$ & 5198 & 9 & 5207 & D.C.Tool Jt. & \\
\hline 5 & 35 & 35 & $05 / 03 / 69$ & 3283 & 390 & 3673 & B.S.Tool Jt. & \\
\hline 6 & 44 & 44 & $06 / 14 / 69$ & 1483 & 82 & 1565 & D.C.Tool Jt. & \\
\hline 6 & 45 & 45 & $06 / 19 / 69$ & 5522 & 31 & 5553 & B.S.Tool Jt. & \\
\hline 6 & 45 & $45 \mathrm{~A}$ & $06 / 22 / 69$ & 5522 & 104 & 5626 & $\begin{array}{l}\text { Just above } \\
\text { BHA }\end{array}$ & $\begin{array}{l}\text { No.B.S.in } \\
\text { string }\end{array}$ \\
\hline 6 & 46 & 46 & $06 / 25 / 69$ & 5783 & 21 & 5804 & D.C.Tool Jt. & \\
\hline 8 & 68 & 68 & $10 / 11 / 69$ & 5481 & 24 & 5505 & D.C.Tool Jt. & Little sedi- \\
\hline 9 & 76 & 76 & $12 / 09 / 69$ & 4601 & 27 & 4628 & D.C.Tool Jt. & $\begin{array}{l}\text { ment cover } \\
\text { Little sedi- } \\
\text { ment cover }\end{array}$ \\
\hline 10 & 93 & 93 & $03 / 02 / 70$ & 973 & 6 & 679 & B.S.Tool Jt. & \\
\hline 10 & 93 & 93 & $03 / 20 / 70$ & 973 & 6 & 979 & B.S.Tool Jt. & \\
\hline 10 & 93 & $93 \mathrm{~A}$ & $03 / 21 / 70$ & 969 & 2 & 971 & B.S.Tool Jt. & \\
\hline 11 & 100 & 100 & $04 / 24 / 70$ & 5331 & 335 & 5666 & B.S.Tool Jt. & \\
\hline 14 & 143 & $143 C$ & $11 / 22 / 70$ & 3517 & 43 & 3560 & D.C.Tool Jt. & \\
\hline 17 & 168 & 168 & $05 / 07 / 71$ & 5430 & 75 & 5505 & B.S. & $\begin{array}{l}\text { B.S.backed } \\
\text { off }\end{array}$ \\
\hline 18 & 176 & 176 & $06 / 22 / 71$ & 197 & 36 & 233 & B.S.Tool Jt. & $\begin{array}{l}\text { Ship } 150 \text { ' off } \\
\text { site }\end{array}$ \\
\hline 18 & 177 & $177 \mathrm{~A}$ & $06 / 22 / 71$ & 2013 & 467 & 2480 & B.S. & $\begin{array}{l}\text { Lock nut } \\
\text { backed off } \\
\text { bottom }\end{array}$ \\
\hline 23 & 226 & 226 & $04 / 18 / 72$ & 2208 & 14 & 2222 & B.S.Tool Jt. & \\
\hline 25 & 244 & 244 & $07 / 29 / 72$ & 3847 & 27 & 3874 & $\mathrm{BHA}$ & \\
\hline 29 & 275 & 275 & $03 / 07 / 73$ & 2837 & 62 & 2899 & B.S. & \\
\hline 29 & 280 & 280 & $03 / 27 / 73$ & 4191 & 42 & 4233 & $\mathrm{BHA}$ & D.C.Backoff \\
\hline 30 & 285 & 285 & $04 / 30 / 73$ & 4674 & 102 & 4776 & B.S. & \\
\hline 31 & 298 & $298 \mathrm{~A}$ & $07 / 23 / 73$ & 4628 & 129 & 4757 & D.C.Tool Jt & $\begin{array}{l}\text { Ship } 2500^{\prime} \\
\text { off site }\end{array}$ \\
\hline 32 & 309 & 309 & $09 / 18 / 73$ & 1470 & 12 & 1482 & B.S. & \\
\hline 32 & 311 & 311 & $09 / 25 / 73$ & 5280 & 46 & 5326 & B.S.Tool Jt. & \\
\hline 33 & 315 & 315 & $11 / 14 / 73$ & 4164 & 85 & 4249 & B.S. & \\
\hline 34 & 321 & 321 & $01 / 30 / 74$ & 4827 & 134 & 4961 & Just above BHA & \\
\hline 45 & 395 & $395 \mathrm{~A}$ & $12 / 19 / 75$ & 4485 & 0 & 4485 & B.S. & $\begin{array}{l}\text { Ran into } \\
\text { bottom }\end{array}$ \\
\hline $51 \mathrm{~B}$ & 417 & $417 \mathrm{C}$ & $12 / 29 / 26$ & 5489 & 26 & 5515 & B.S.Tool Jt. & \\
\hline 52 & 417 & $417 \mathrm{D}$ & $03 / 05 / 77$ & 5489 & 176 & 5665 & Just above BHA & \\
\hline 55 & 431 & 431 & $08 / 06 / 77$ & 1714 & 19 & 1733 & B.S. & \\
\hline
\end{tabular}




\begin{tabular}{|c|c|c|c|c|c|c|c|c|}
\hline Leg & Site & Hole & Date & $\frac{\text { Water }}{\frac{\text { Depth }}{(\underline{m})}}$ & $\frac{\mathrm{BSF}}{(\underline{\mathrm{m}})}$ & $\frac{\frac{\text { Total }}{\text { Depth }}}{(\underline{\text { m })}}$ & $\frac{\text { Location }}{\text { Fai of }}$ & Remarks \\
\hline $\begin{array}{l}55 \\
55 \\
55\end{array}$ & $\begin{array}{l}431 \\
432 \\
432\end{array}$ & $\begin{array}{l}431 \mathrm{~A} \\
432 \\
432 \mathrm{~A}\end{array}$ & $\begin{array}{l}08 / 07 / 77 \\
08 / 08 / 77 \\
08 / 09 / 77\end{array}$ & $\begin{array}{l}1713 \\
1320 \\
1320\end{array}$ & $\begin{array}{l}26 \\
15 \\
74\end{array}$ & $\begin{array}{l}.1739 \\
1335 \\
1394\end{array}$ & $\begin{array}{l}\text { B.S. } \\
\text { B.S. } \\
\text { B.S.Tool Jt. }\end{array}$ & \multirow{2}{*}{$\begin{array}{l}\text { Working } \\
\text { stuck pipe } \\
\text { Ran into } \\
\text { bottom }\end{array}$} \\
\hline 60 & 452 & 452 & $03 / 25 / 78$ & 5838 & 28 & 5866 & D.C.Tool Jt. & \\
\hline $\begin{array}{l}65 \\
65\end{array}$ & $\begin{array}{l}483 \\
484\end{array}$ & $\begin{array}{l}483 \mathrm{~B} \\
484 \mathrm{~A}\end{array}$ & $\begin{array}{l}03 / 02 / 79 \\
03 / 04 / 79\end{array}$ & $\begin{array}{l}3084 \\
2906\end{array}$ & $\begin{array}{r}267 \\
62\end{array}$ & $\begin{array}{l}3351 \\
2968\end{array}$ & $\begin{array}{ll}\text { Pin-Head Sub } \\
\text { Top-Head Subs }\end{array}$ & \multirow[t]{2}{*}{ Backed off } \\
\hline $\begin{array}{l}77 \\
78 \mathrm{~A} \\
87 \mathrm{~A}\end{array}$ & $\begin{array}{l}535 \\
541 \\
582\end{array}$ & $\begin{array}{l}535 \\
541 \\
582\end{array}$ & $\begin{array}{l}01 / 07 / 81 \\
02 / 14 / 81 \\
06 / 29 / 82\end{array}$ & $\begin{array}{l}3455 \\
4961 \\
4892\end{array}$ & $\begin{array}{r}714 \\
0 \\
39\end{array}$ & $\begin{array}{l}4169 \\
4961 \\
4931\end{array}$ & $\begin{array}{l}\text { Just above BHA } \\
\text { Top-Head Subs } \\
\text { Top-Head Subs }\end{array}$ & \\
\hline $\begin{array}{l}88 \\
93\end{array}$ & $\begin{array}{l}581 \\
603\end{array}$ & $\begin{array}{l}581 \mathrm{~A} \\
6038\end{array}$ & $\begin{array}{l}08 / 25 / 82 \\
05 / 20 / 83\end{array}$ & $\begin{array}{l}5490 \\
4644\end{array}$ & $\begin{array}{l}380 \\
616\end{array}$ & $\begin{array}{l}5870 \\
5260\end{array}$ & $\begin{array}{l}\text { Just above BHA } \\
\text { B.S. }\end{array}$ & \multirow{2}{*}{$\begin{array}{l}\text { Wash Pipe } \\
\text { broke loose } \\
\text { Mandrel } \\
\text { pin parted }\end{array}$} \\
\hline 94 & 606 & $606 \mathrm{~B}$ & $07 / 05 / 83$ & 3024 & 164 & 3188 & B.S. & \\
\hline
\end{tabular}

BSF - Below Seafloor

D.C. - Drill Collar

B.S. - Bumper Sub

BHA - Bottom Hole Assembly 
APPENDIX B-1

FAILURE ANALYSIS OF DRILL PIPE TOOL JOINTS (LEG 48) 


\title{
Bulletin
}

\author{
Research \\ United States Steel Corporation \\ Monroeville, Pennsylvania \\ December 29,1976
}

Failure Analysis of Drill Pipe Tool Joints

\section{Summary}

Scripps Institute of Oceanography contracted with U. S. Steel Research to conduct a failure analysis on two sections of drill pipe that failed during service in the scripps Deep Sea Drilling Project. The results of the investigation showed that fracture occurred in the pin end of the AISI 4150 steel tool joints causing the loss of several thousands of feet of pipe string. Fractographic and metallographic examination showed that the failure was a result of corrosion fatigue. It is believed that fracture occurred a short time (relative to the total life time of the components) after the cracks initiated at the root of the threads. Thus, the useful life of the component was governed primarily by the initiation of cracks rather than by their propagation to failure. Frequent inspection of tool joint pins is suggested to serve as a basis for replacing cracked joints.

(Discussion attached) 
FAILURE ANALYSIS OF

DRILL PIPE TOOL JOINTS

December 29, 1976

Discussion

Introduction

Recently the Scripps Institute of Oceanography (University of California) experienced failure of a drill pipe used in the Deep Sea Drilling Project being conducted for the National Science Foundation. The failure occurred in the pin end threads of a tool joint in the uppermost length of pipe (pup joint) in the derrick. Because of its location, this joint is not immersed in seawater. The pipe was placed on board the drill ship GLOMAR CHALLENGER on May 1, 1972, and the pin end fractured in May 1976 thereby sending the remaining 16,300 feet of drill pipe to the ocean floor.

According to information provided by Scripps, two pup joints were alternated in the drill string during four years of service. The total rotating time of both joints was 3930 hours, and although the rotating time for each joint is not known, it is assumed that each joint was exposed to about one half of the total rotating hours. The average rotation speed was 60 revolutions per minute, corresponding to about $7 \times 10^{6}$ revolutions for each joint. During the drilling operation the joints are subjected to tension loads only (due to the weight of about 350,000 pounds of pipe in seawater) for about 90 percent of the time and to additional kending loads for about 10 percent of the time while the joint is in the guide horn of the ship. (The guide horn located below the derrick provides a radius of 350 feet for support of the drill string when the ship is rolling to prevent bending the pipe against a sharp edge. This arrangement is schematically represented in Figure 1.)

After the failure of the pin in one of the two tool joints, the failed section with the adjacent pipe as well as the pin end of the other joint were submitted for examination.

Visual Examination

of the two received sections, shown in Figure 2, one was not fractured although some threads were severely scored; the other (tool joint B, Figure 2) had fractured in the third thread course, which is considered to be an area of highest stress concentration in threads. Figure 3 shows a close-up of the broken section. There was essentially no rust on the outside surface, on the threads, and on the fracture surface. However, the inside surface of both pipe sections which was exposed to aerated seawater 


\section{Discussion (Continued)}

during the drilling operation was covered with a heavy layer of rust. The appearance of the inside surface seen in Figure 3 is typical of both pipes.

The fracture surface which extended from the root of the third thread course consisted of two distinct zones: an outer flat fracture zone and an inner slanted fracture zone, illustrated in Figures 3 and 4 . The two zones were essentially equal in area; and although they were not concentric with the pipe, the flat zone extended along the entire perimeter in the thread root. The deepest penetration of the flat zone was 0.40 inch, comprising about 73 percent of the wall thickness $(0.55$ inch) in that area. Figure 4 also shows that the flat zone contains markings roughly concentric with the pipe (called beach marks) indicating periodic crack propagation.

\section{Magnetic Particle Examination}

The pins of the tool joints were examined by a fluorescent magnetic particle technique, and typical areas were photographed with ultraviolet illumination. The nonfractured pipe (tool joint A, Figure 2) showed many disconnected cracks in the thread roots of the four thread courses adjacent to the shoulder. Two typical areas are shown in Figure 5. This type of cracking was found on more than one half of the circumference. Fiyure 6 shows schematically the distribution of the cracks. In this schematic only the first five thread courses are shown; there were no cracks in the other threads. Many short cracks were also present in the remaining threads of the fractured pin (tool joint $B, F i g-$ ure 2), and typical cracked areas are shown in Figure 7. This type of cracking was present in essentially all the remaining threads. Figure 8 shows schematically the distribution of the cracks.

Chemical Composition, Mechanical Properties, and Stress Considerations

Specimens for the determination of chemical composition and mechanical properties were removed from the tool joints at areas immediately adjacent to the threaded pin. The chemical composition of the two tool joints, given in Table I, correspond to that for AISI 4150 steel. 


\section{Discussion (Continued)}

The mechanical properties are summarized in Table II. The yield strength of tool joint $A$ was somewhat lower than that of tool joint B, although the tensile strength, elongation, and reduction of area were essentially the same for both joints.

The stress at the critical cross section (fracture area) was estimated based on the weight of the drill string, the bending in the guide horn, and the torquing effects from the makeup of the threaded joint. The greatest contribution to the total longitudinal stress came from the weight of the string (42 ksi), and the bending moment contributed about $18 \mathrm{ksi}$. The resultant maximum combined tension stress was $64 \mathrm{ksi}$, disregarding the stress concentrating effect of the thread-root curvature. Although a comprchensive stress analysis was not conducted, this elementary approach showed that, assuming a stress-concentrating factor of $2.5,1)^{*}$ a stress of $160 \mathrm{ksi}$ could occur at the thread root if the material were elastic up to that stress. Since this value exceeds the yield strength of the tool joint, localized yielding in the thread root is expected to have occurred whenever the joint was bent in conformance with the contour of the guide horn.

Fractography

The fracture face of tool joint B was examined in several areas by using a scanning electron microscope. Figure 9 shows a magnified view of the flat fracture in Area A, Figure 4, which was chosen for examination because it was expected that it would be relatively protected from accidental damage by the adjacent raised slanted fracture zone. The examination showed that the elevated portions of the fracture were flattened, as shown in Figurc 10, probably as a result of alternate opening and closing of the crack. The depressed portions were filled with corrosion product. A similar appearance was observed in all other areas examined. The partial flattening of the fracture surface resulted in a smoothed appearance as indicated in Figure 11, which also shows the beach marks mentioned previously. This view also reveals "racheting" (areas of different elevation) in the area of the thread root indicating that cracking initiated from many small areas in the thread root. These cracks then joined up as the crack propagated toward the interior of the pipe. The beach marks on the fracture

\footnotetext{
* See References
} 
FAILURE ANALYSIS OF

DRILL PIPE TOOL JOINTS

December 29, 1976

Discussion (Continued)

surface are usually caused by periodic crack propagation under different stress-fluctuation conditions.

Metallography

Examination of the cracks in cross section at several locations of the two tool joints showed that the length of the cracks that had not propagated to failure varied from about 0.001 to 0.02 inch. Generally, the cracks were filled with corrosion product and in many instances were associated with small corrosion pits, as shown in Figure 12. Multiple crack initiation shown in Figure 13 was also observed. The cracks progressed along a jagged path and showed short side branches, illustrated in Figures 12, 14, and 15. This evidence, together with the mode of loading, indicates corrosion fatigue as the mode of fracture initiation. The microstructure of the steel was that of tempered martensite, normal for AISI 4150 quenched and tempered steel, as shown in Figure 15.

\section{Discussion and Summary}

The above-presented evidence indicates that the failure of the threaded pipe (fracture of one pin and cracking of the other Din) occurred as a result of corrosion fatigue. The exact nature of the corrosive environment at the mating surface of the threaded joint is not known; however, it seems certain that seawater was involved. The environment produced corrosion pits on the thread surface which acted as initiation sites for fatigue cracks. Furthermore, the presence of the environment probably increased the crack propagation rate.

Based on the design information provided by Scripps and the air-fatigue data for this type of steel,2) it is estimated that the tool joints were stressed at or below the fatigue limit in air; thus in the absence of a corrosion environment a long service life would be expected. Technical literature $3,4,5)$ and prior experience indicate that at stress levels below the fatigue limit in air most of the total corrosion fatigue life is spent in initiating cracks, and that complete fracture occurs a short time thereafter. The references cited do not, however, provide specific information which would permit any estimate of the relative time for initiation of cracks to an inspectable size as compared with the time for propagation to failure. To make such an estimate, crack propagation rates would have to be obtained on AISI 4150 steel of the tool joints stressed at the rotation speed of the drill string (60 cycles/ 


\section{Discussion (Continued)}

minute) in an environment simulating the service condition. An alternate empirical approach would be to inspect the pins of pup joints at relatively frequent intervals to detect crack initiation (and also to serve as a basis for replacing any cracked joint).

\section{References}

1. R. E. Peterson, "Stress Concentration Factors," John Wiley \& Sons, 1974, p 42, Figure 23.

2. S. T. Rolfe and J. M. Barsom, Fracture and Fatigue Control in Structures-Applications of Fracture Mechanics, Prentice-Hall, Inc., Englewood Cliff, N. J., 1976.

3. D. W. Hoeppner, "Corrosion Fatigue Considerations in Materials Selection and Engineering Design," Corrosion Fatigue, National Association of Corrosion Engineers, 1972, pp 3-11.

4. W. E. Krupp, D. W. Hoeppner, E. K. Walker, "Crack Propagation of Aluminum Alloys in Corrosive Environments," Corrosion Fatigue, National Association of Corrosion Engineers, 1972, pp 468-483.

5. V. Rollins, B. Arnold, E. Lardner, "Corrosion Fatigue in High Carbon Steel," British Corrosion Journal, Vol. 5, 1970, pp 33-40. 
Table I

Chemical Composition of Tool Joints, percent

Tool

Joint $C$ Mn $P$ S Si Cu Ni Cr Mo (total)

A $\quad \begin{array}{llllllllll}0.49 & 0.96 & 0.023 & 0.019 & 0.29 & 0.03 & 0.03 & 1.01 & 0.21 & 0.08\end{array}$

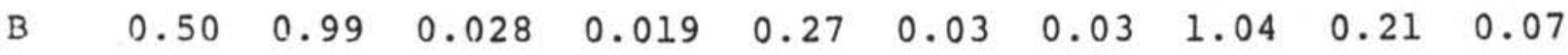

U. S. Steel Corporation, Research, Monroeville, Pennsylvania 


\section{Table II}

Mechanical Properties of Tool Joints

\begin{tabular}{|c|c|c|c|c|}
\hline $\begin{array}{l}\text { Tool } \\
\text { Joint }\end{array}$ & $\begin{array}{c}\text { Yield strength } \\
(0.28 \text { offset), } \\
\mathrm{ksi} \\
\end{array}$ & $\begin{array}{c}\text { Tensile } \\
\text { Strength, } \\
\text { ksi } \\
\end{array}$ & $\begin{array}{l}\text { Elongation } \\
\text { in } 1 \text { inch, } \\
\text { percent }\end{array}$ & $\begin{array}{l}\text { Reduction } \\
\text { in Area, } \\
\text { percent }\end{array}$ \\
\hline A & 113.8 & 152.7 & 20.3 & 56.8 \\
\hline B & 125.2 & 152.0 & 19.5 & 55.2 \\
\hline
\end{tabular}

U. S. Steel Corporation, Research, Monroeville, Pennsylvania 


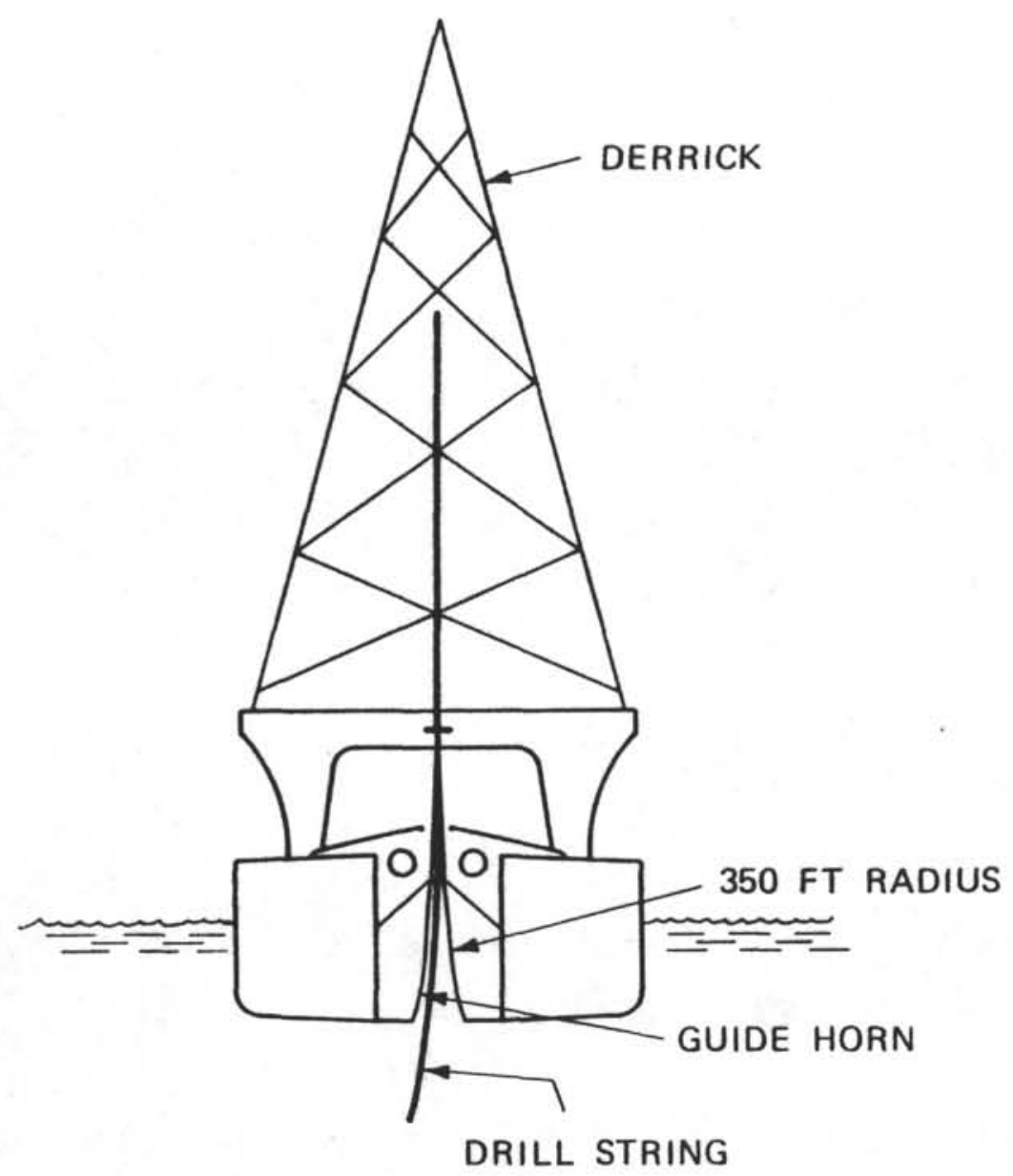

TRANSVERSE SECTION OF DRILL SHIP SHOWING DRILL PIPE GUIDE HORN 


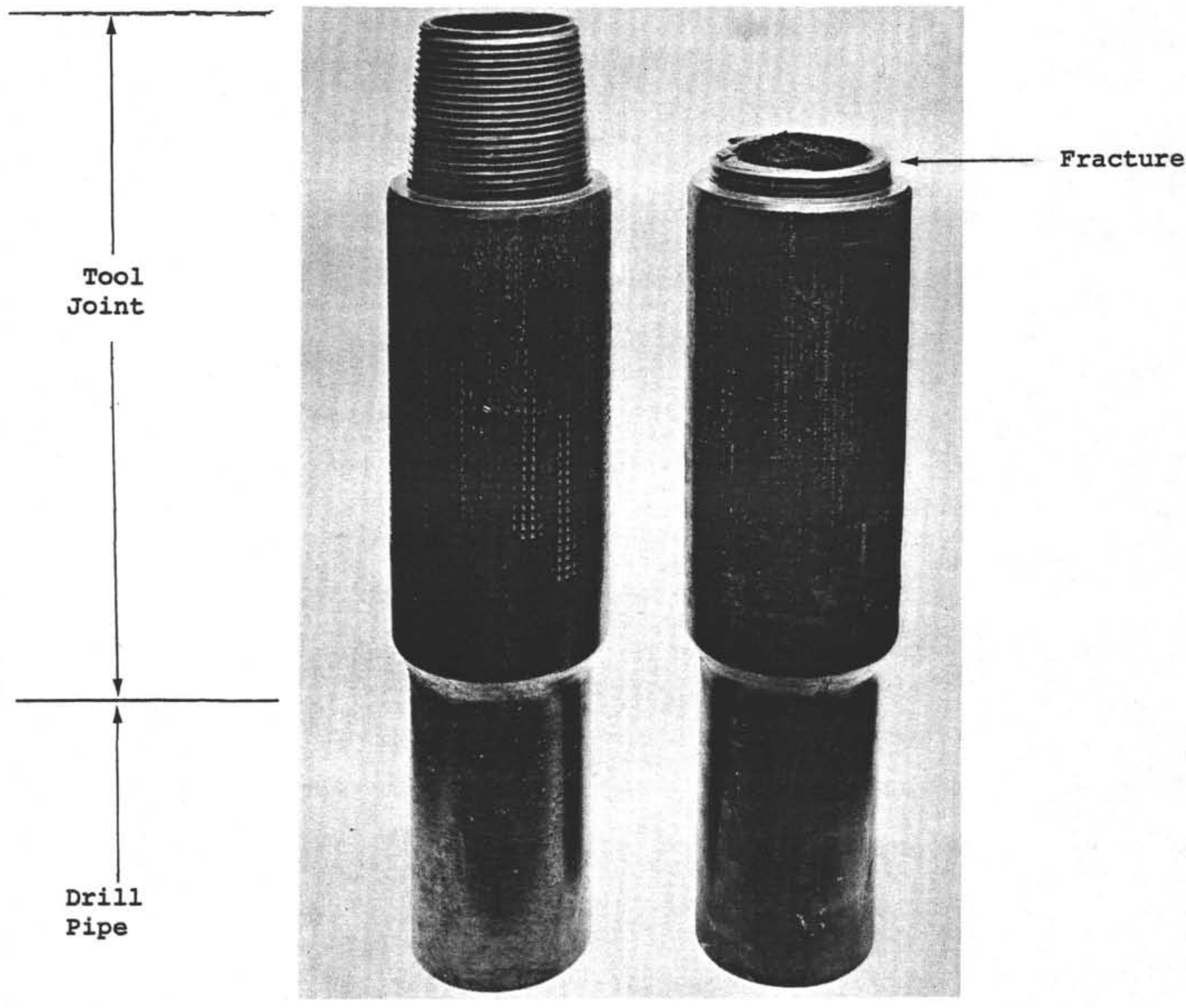

Tool joints A (left) and B (right) submitted for examination after four years service. About $1 / 5$ actual size.

Neg. No.

$\mathrm{P}-6116 \mathrm{~B}-1$ 


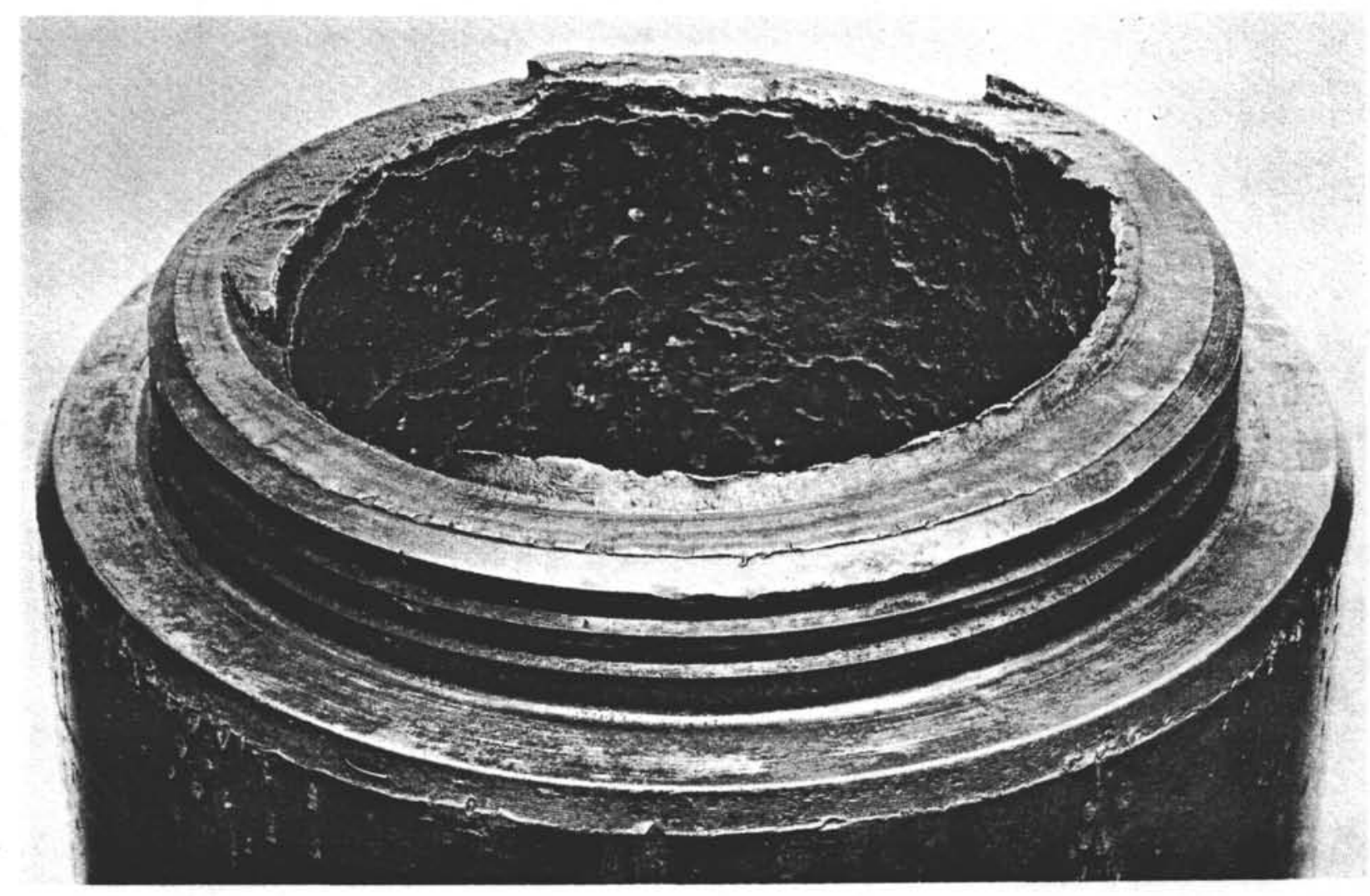

Tool joint B (Figure 2) that had fractured in the threads. Note the heavy layer of rust on the inside surface. Approximately actual size. 


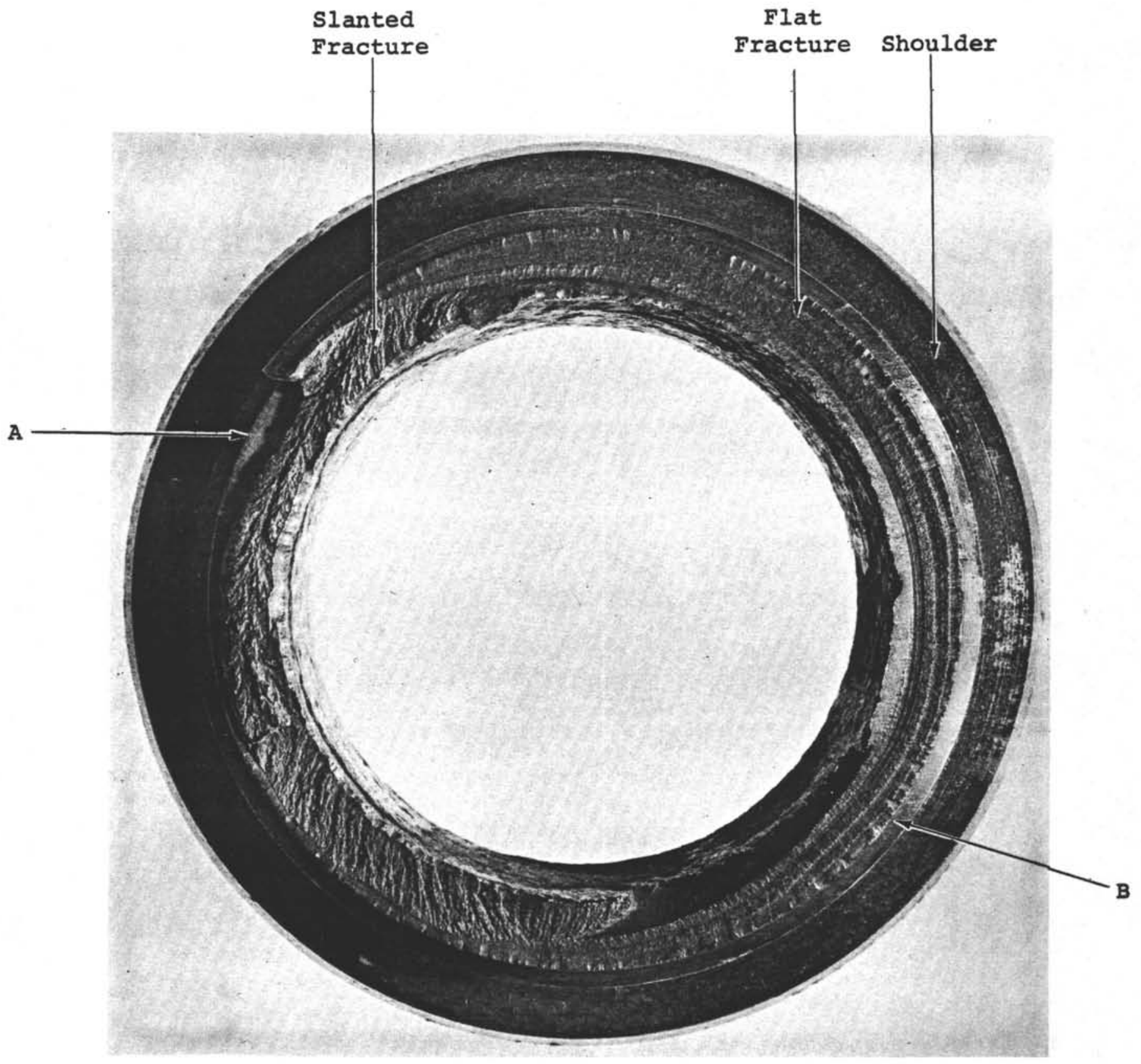

Fracture surface of tool joint B. Approximately actual size. 
Shoulder $\rightarrow$
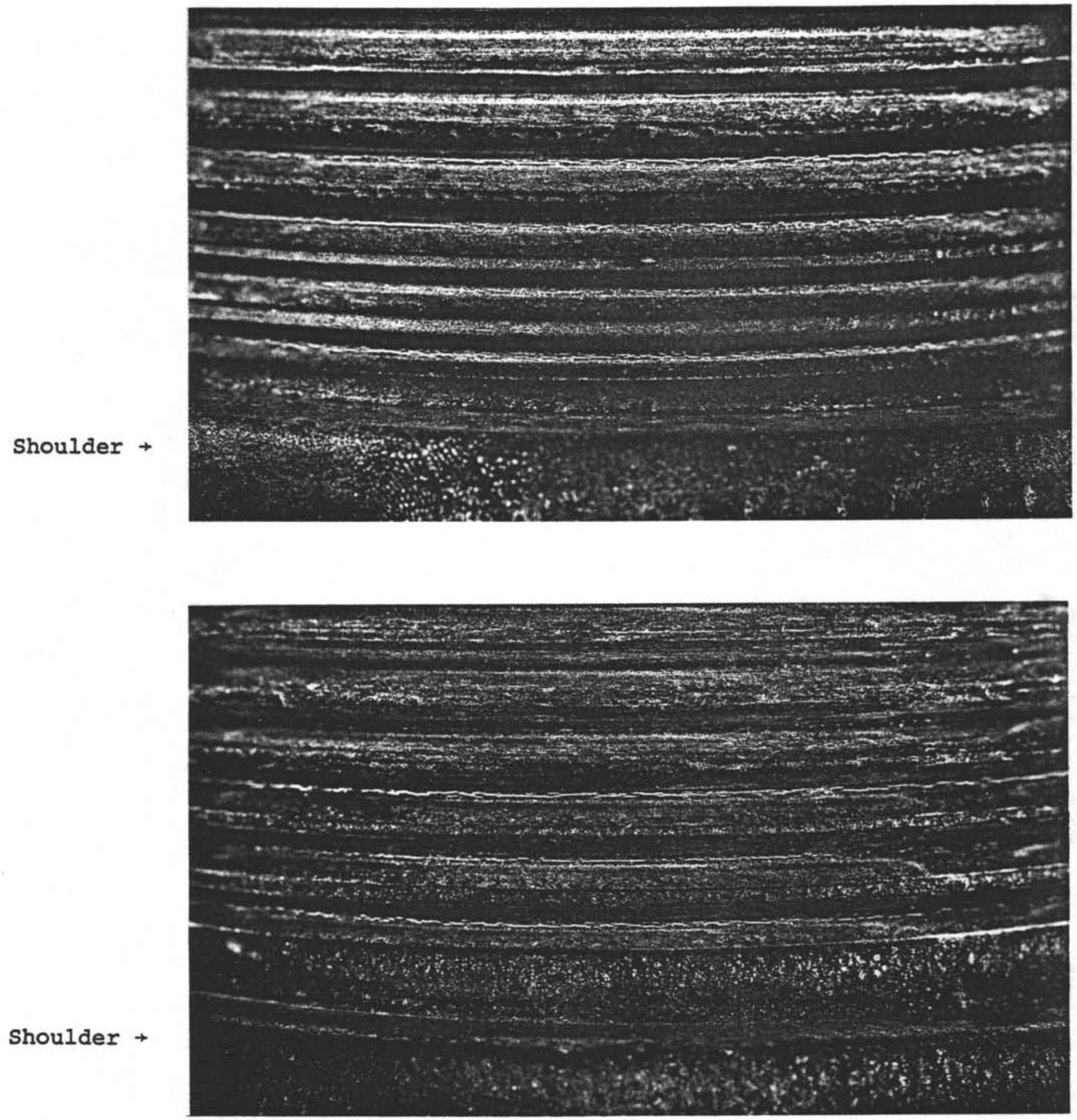

Cracks in thread roots of tool joint A (as indicated by disconnected white lines in thread roots). Cracks were revealed by fluorescent magnetic particle technique with ultraviolet illumination. X2. 


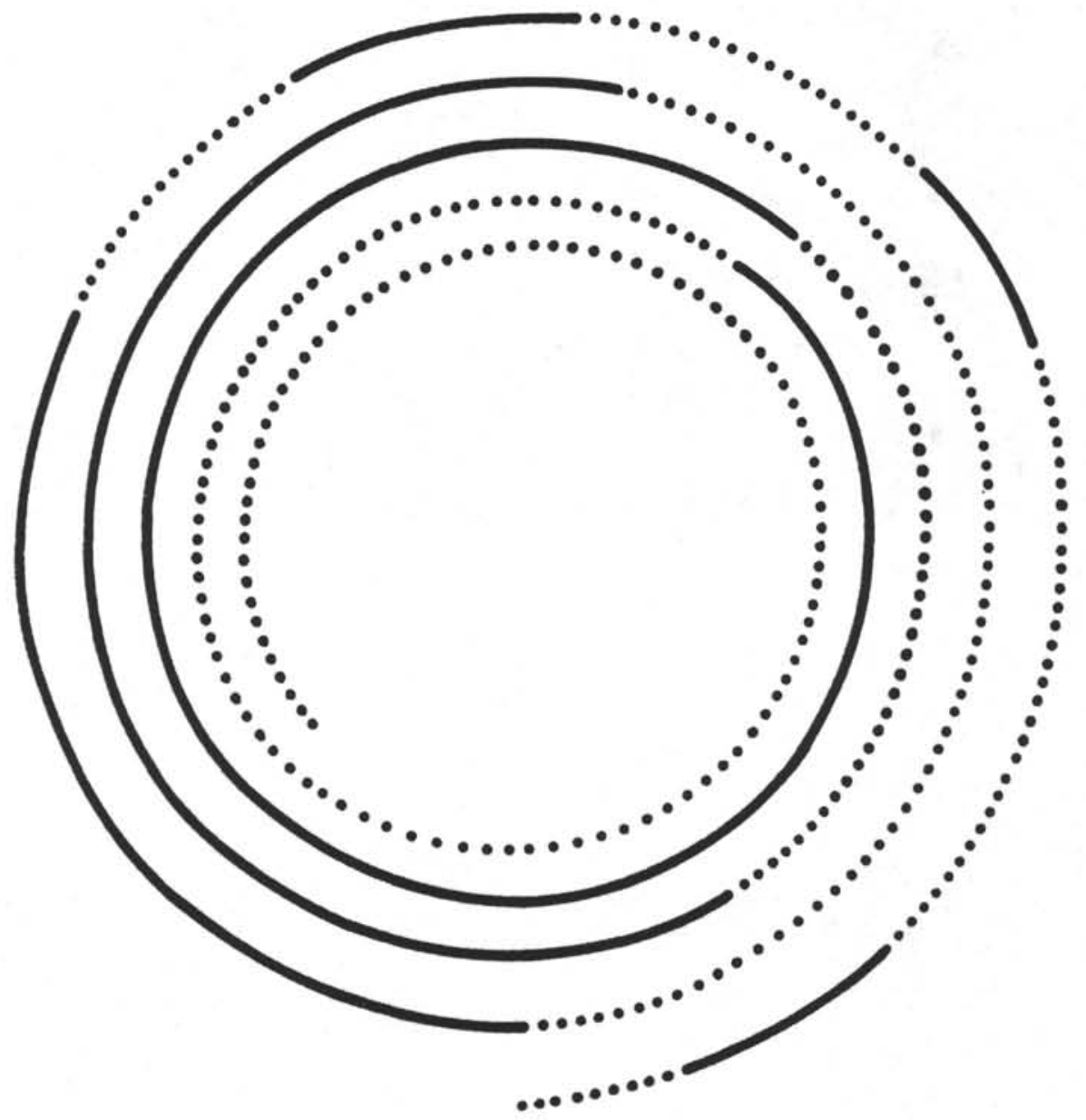

$\longrightarrow$ CRACKED

$\bullet \bullet \bullet \bullet \bullet N O T$ CRACKED

SCHEMATIC REPRESENTATION OF CRACK DISTRIBUTION IN THREAD ROOTS OF TOOL JOINT A. THE DRAWING SHOWS THREAD ROOTS AS A PROJECTION OF AN EXPANDED CONE. 
Fracture +

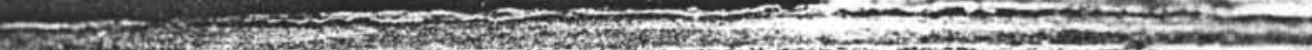
- in

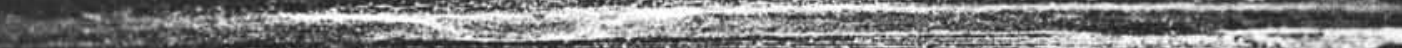

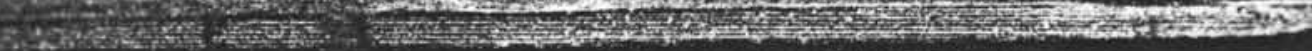

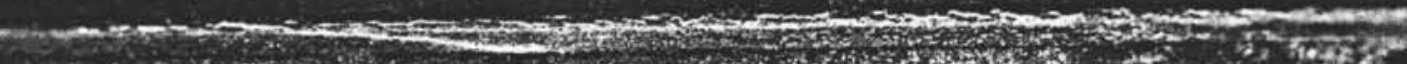

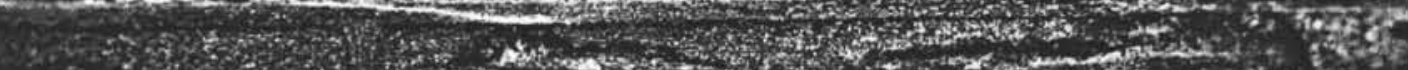

Shoulder $\rightarrow$

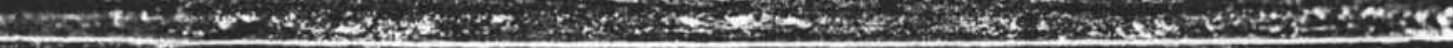

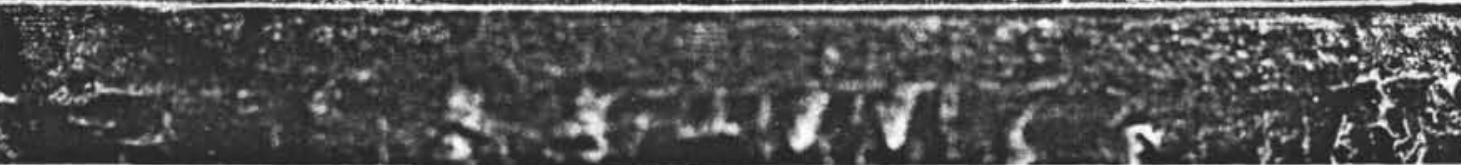
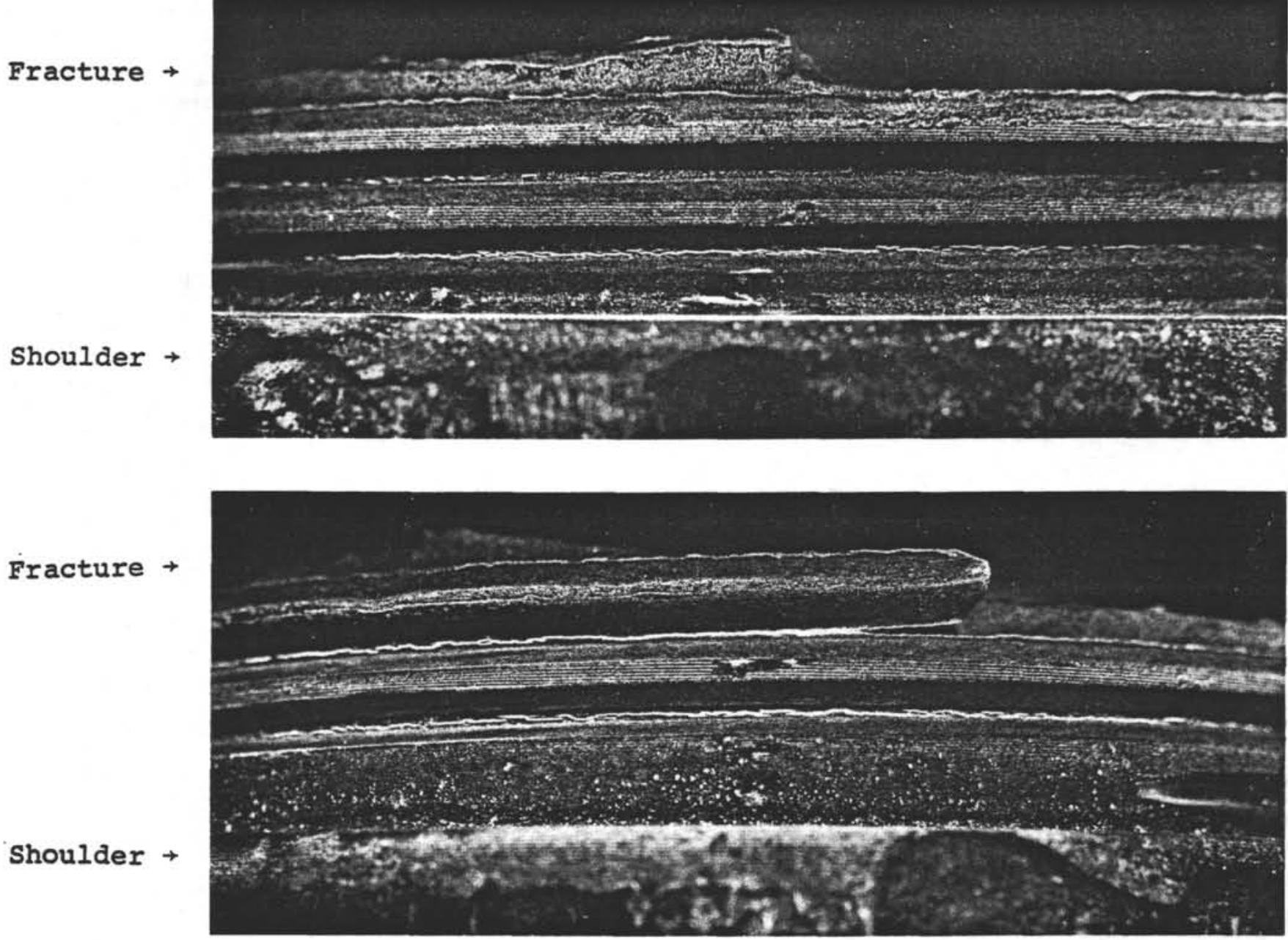

Cracks in thread roots of tool joint B (as indicated by disconnected white lines in thread roots). Cracks were revealed by fluorescent magnetic particle technique with ultraviolet illumination. $\mathrm{X} 2$.

Neg. Nos.

$\mathrm{P}-6136 \mathrm{~B}-4$

$\mathrm{P}-6136 \mathrm{~B}-3$

$\mathrm{P}-6136 \mathrm{~B}-2$ 


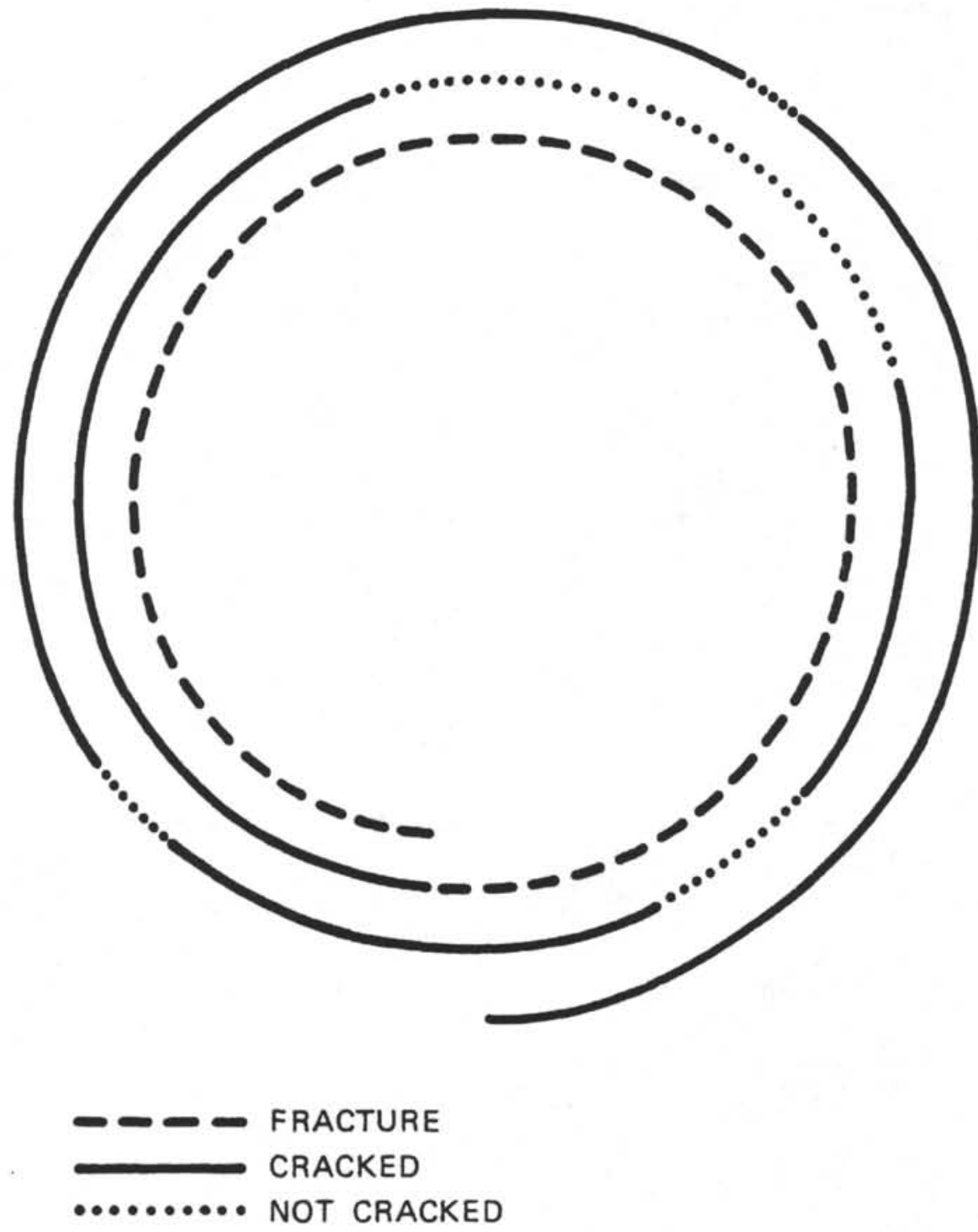

SCHEMATIC REPRESENTATION OF CRACK DISTRIBUTION IN THREAD ROOTS OF TOOL JOINT B. THE DRAWING SHOWS THREAD ROOTS AS A PROJECTION OF AN EXPANDED CONE. 


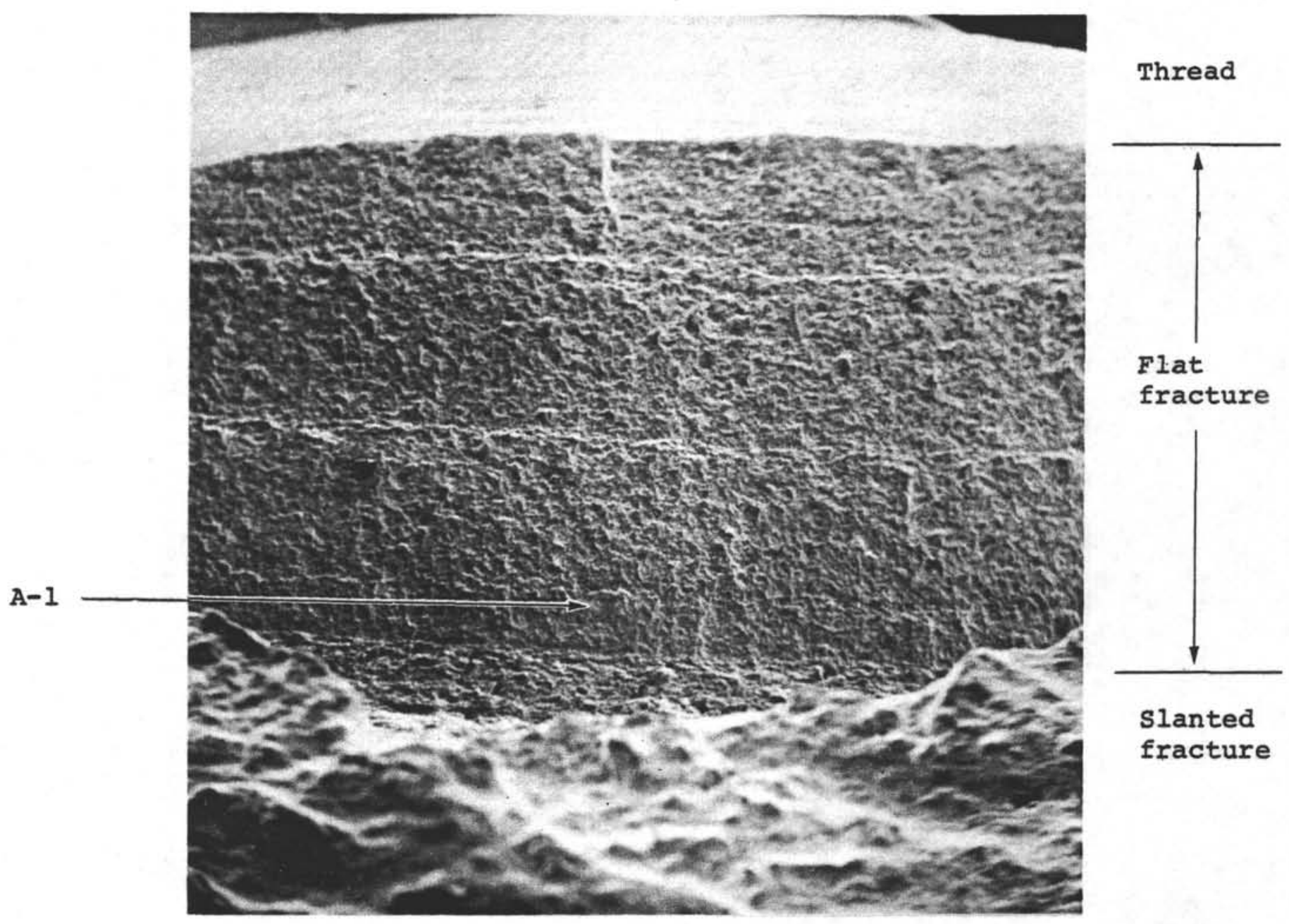

Surface of flat fracture zone in Area A, Figure 4. X25.

Neg. No. 


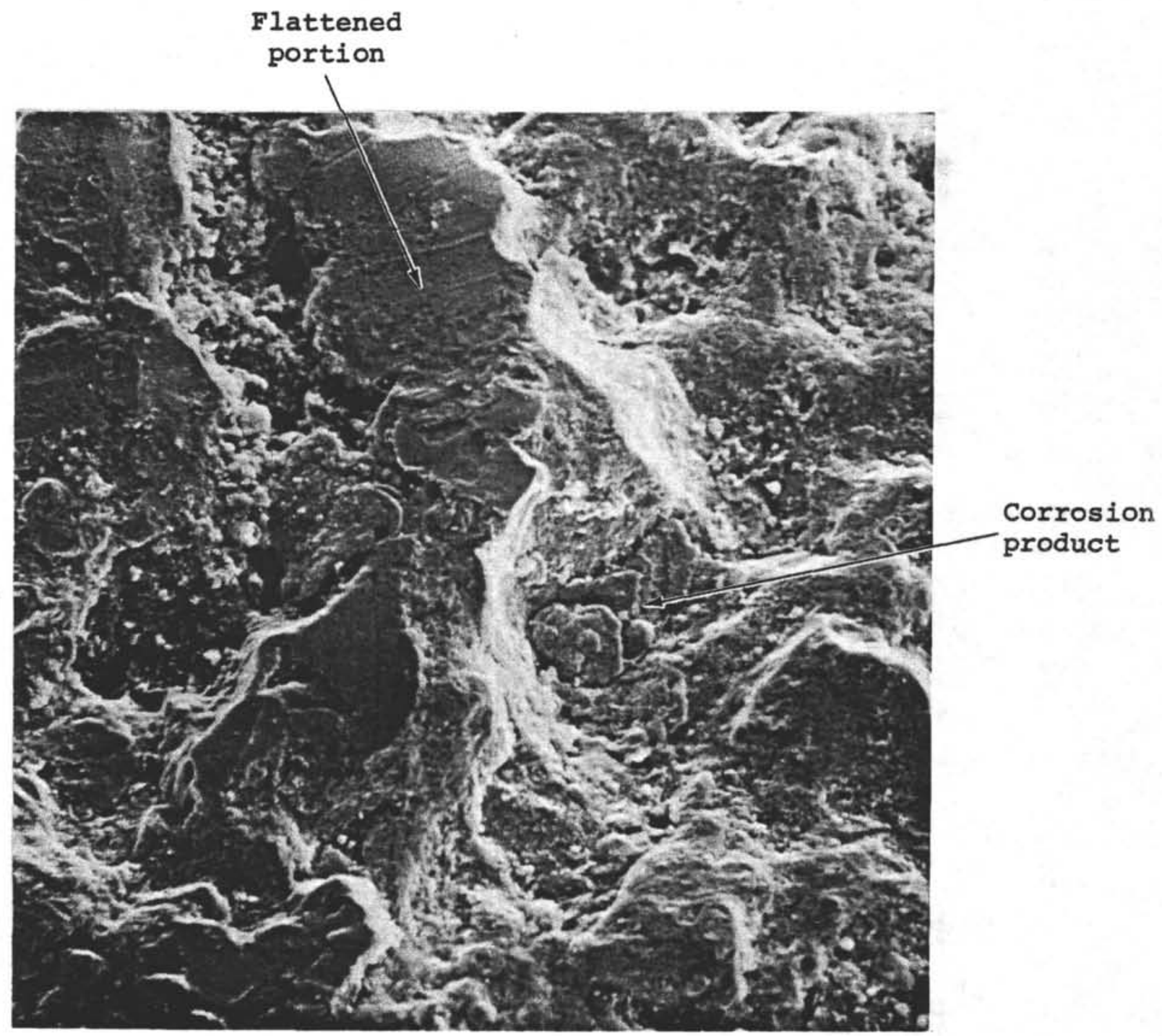

Surface of flat fracture zone in Area A-1, Figure 9, showing flattened raised portions and corrosion product in low portions. X1000. 

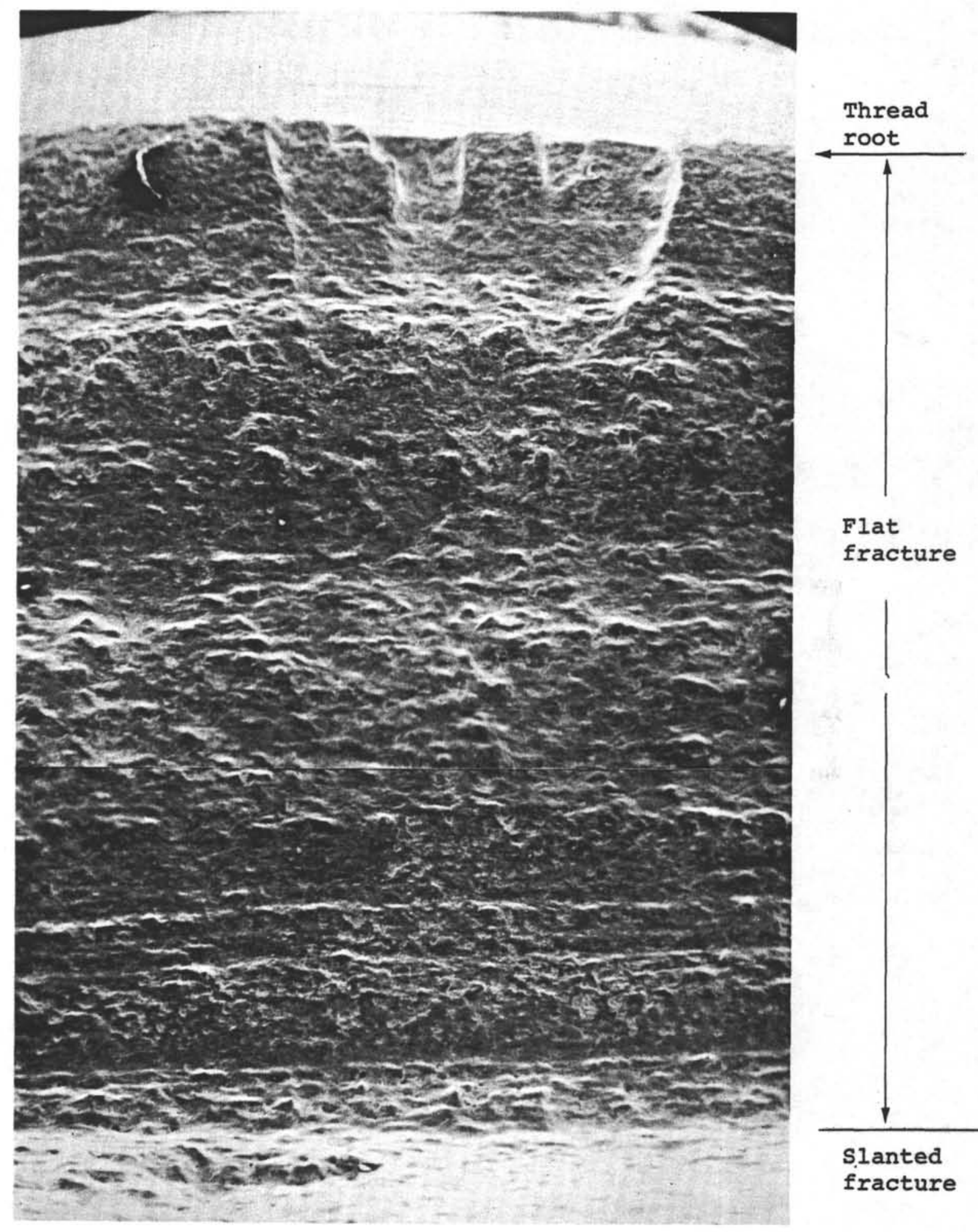

Flat

fracture

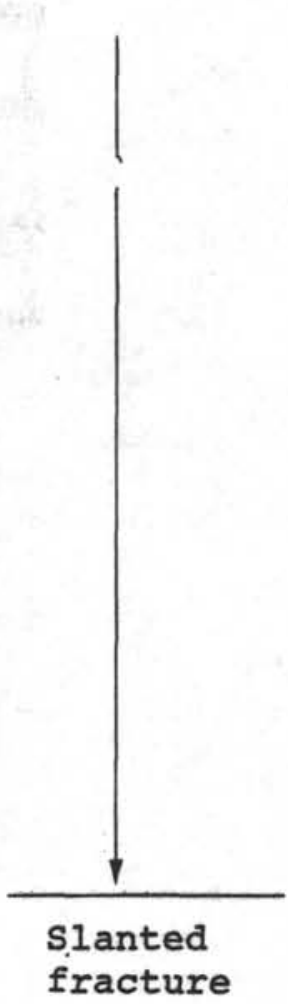

Surface of flat fracture zone in Area B, Figure 4. X25.

Neg. Nos.

2S-5961

2S-5962

Figure 11 


$$
T
$$




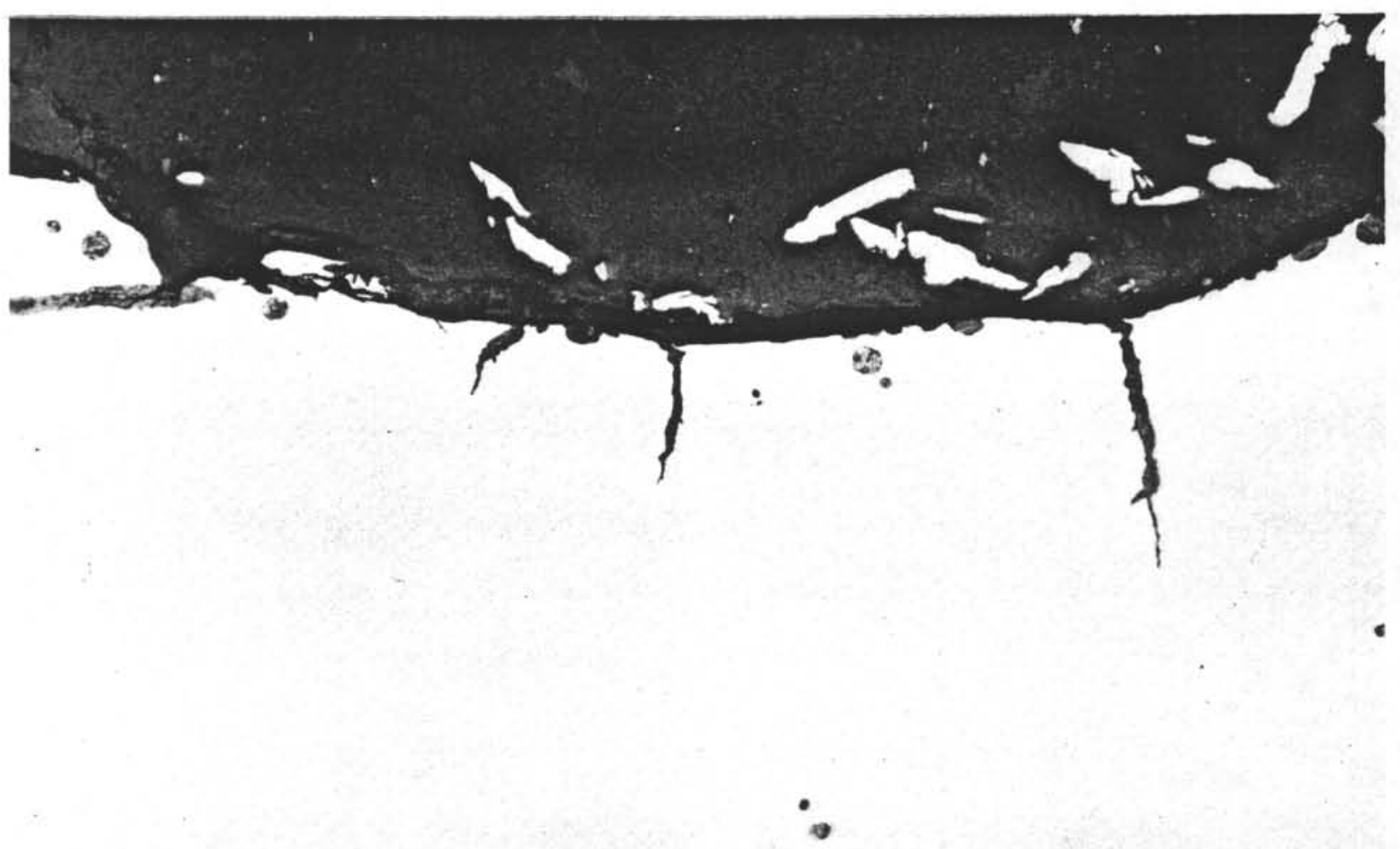

Multiple crack initiation in a thread root of tool joint A. Unetched. X250. 


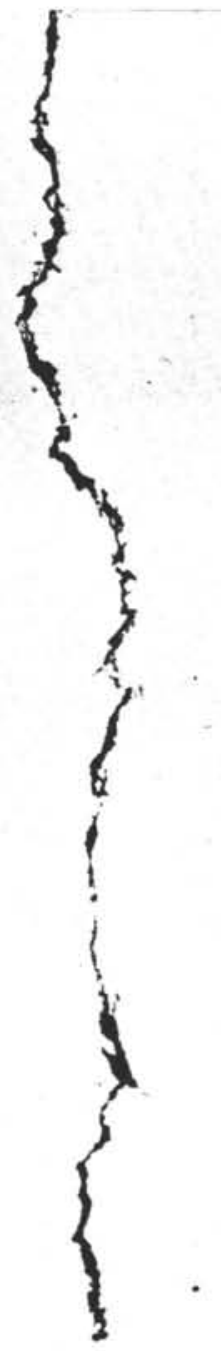

Typical crack in tool joint B. Unetched. $x 500$. 


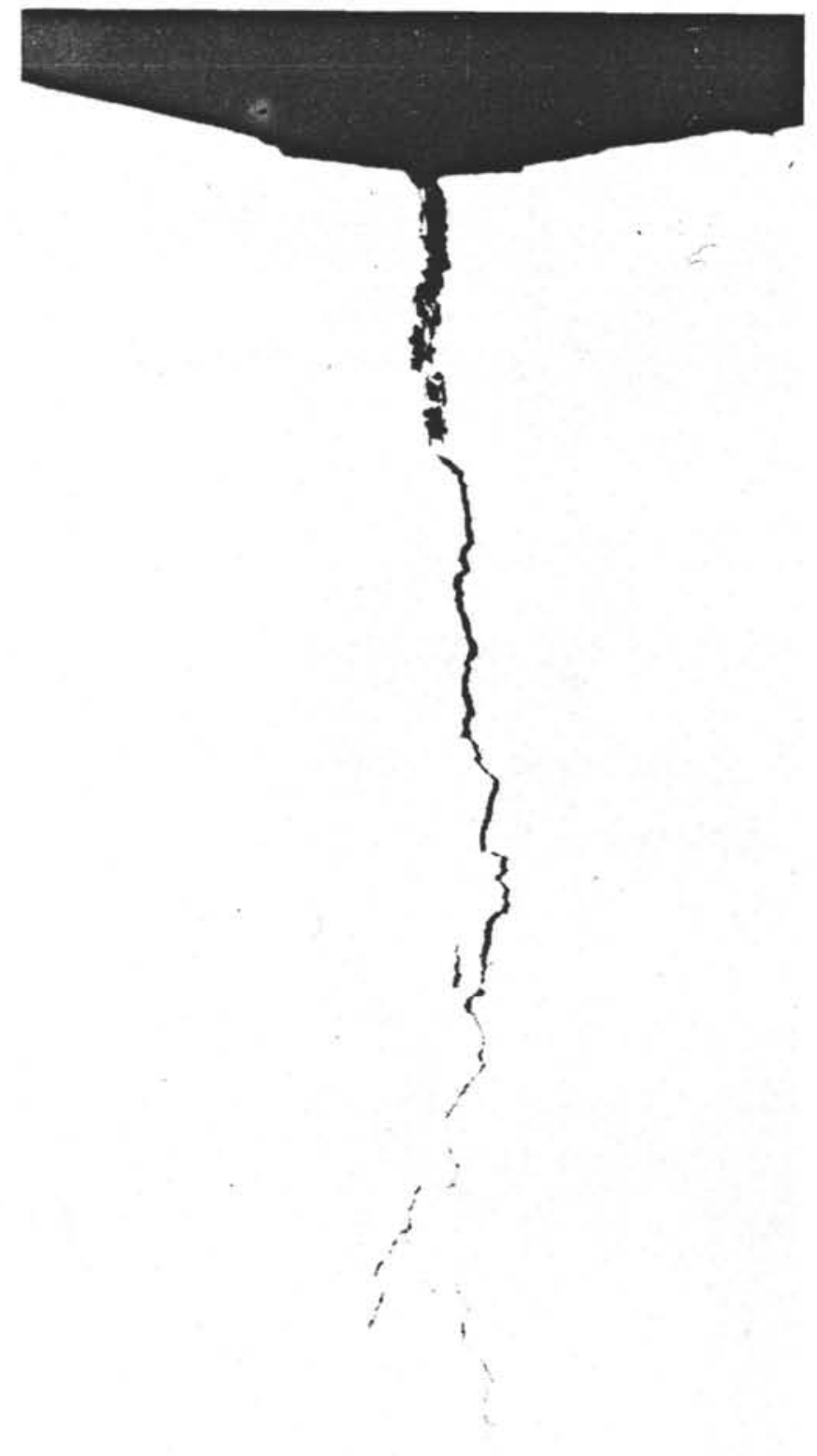

Unetched

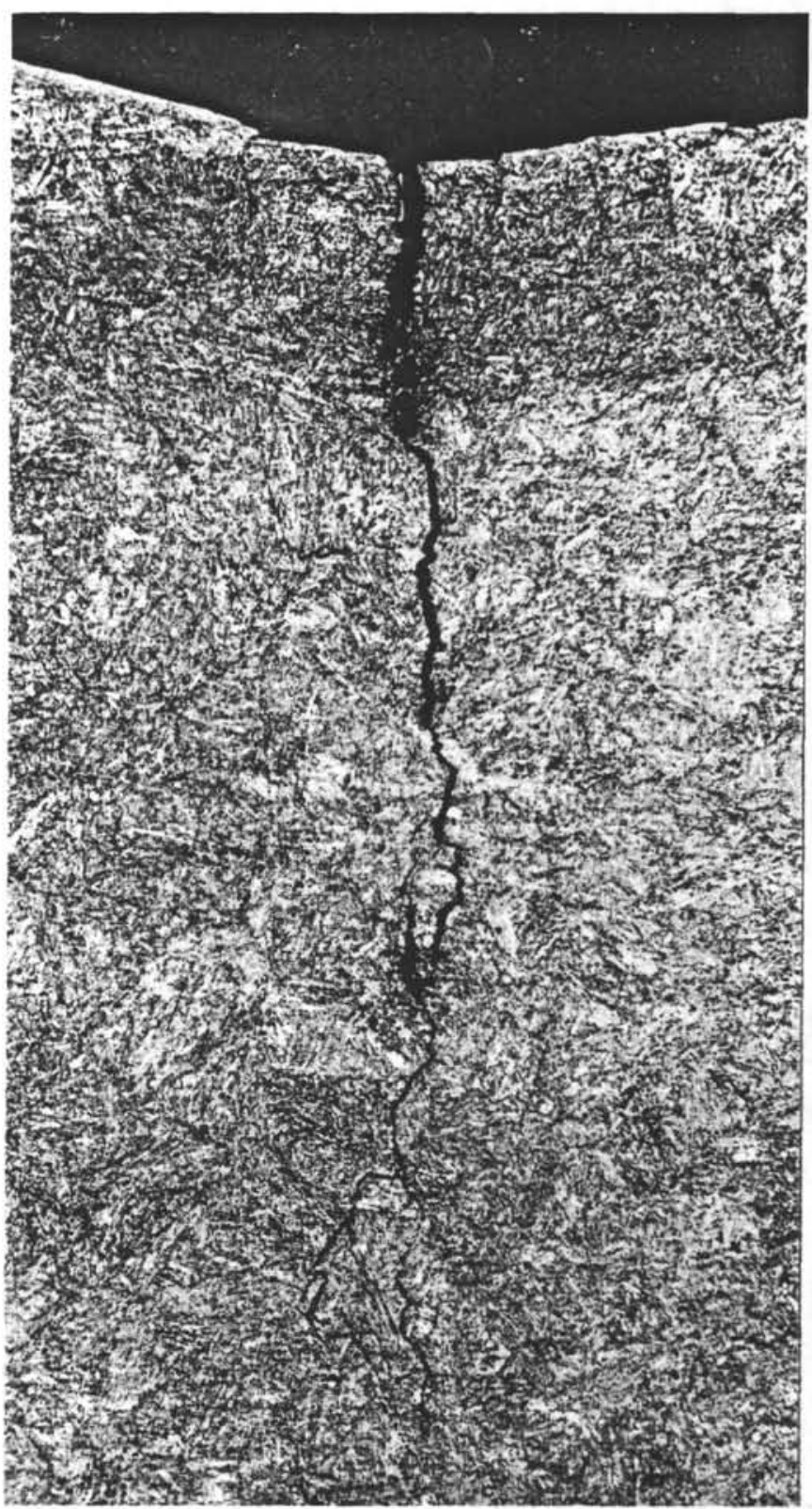

Etched in picral

Crack path and microstructure in tool joint B. $\mathrm{x} 500$. 


\section{APPENDIX B-2}

FAILURE ANALYSIS OF S-135 DRILL PIPE USED IN DEEP SEA DRILLING (LEG 53) 


\title{
BUILETIN
}

\author{
Research \\ United States Steel Corporation \\ Monroeville, Pennsylvania \\ November 8, 1977 \\ FAILURE ANALYSIS OF S-135 DRILL PIPE \\ USED IN DEEP SEA DRILIING
}

\begin{abstract}
Summary
Scripps Institution of Oceanography contracted with U. S. Steel Research to analyze failures of three sections of API Specification 5AX Grade S-135 drill pipe. The drill pipes fractured during drilling operations in seawater at considerable depths.

The study confirmed that the chemical composition, mechanical properties, and microstructure are typjcal for S-135 drill pipe. Fractographic and metallographic examinations showed that the failures occurred as a result of corrosion fatigue initiating on the external surface of the drill pipe. Corrosion pitting on the fracture surfaces of cracks that progressed partially through the pipe wall suggests that the corrosion fatigue cracks progressed relatively slowly permitting sufficient time for corrosion pits to grow on the newly exposed crack surfaces. However, specific information was not available to permit an estimate of the time-to-failure after crack initiation.

(Discussion attached)
\end{abstract}


FAILURE ANALYSIS OF

S-135 DRILL PIPE USED

IN DEEP SEA DRILLING

November 8, 1977

Discussion

Introduction

Scripps Institution of Oceanography (University of

California) experienced failure of a drill pipe (API specification

$5 \mathrm{AX}$ Grade S-135) used in the Deep sea Drilling Project being conducted for the National science Foundation. During service, the drill pipe is immersed in seawater to a considerable depth and aerated seawater is pumped through the pipe.

Three samples of failed pipes were submitted for examination. The chemical composition and mechanical properties, shown in Tables I and II, respectively, and the microstructure are typical for S-135 drill pipe. One sample received in April 1977 without identification will be referred to as Sample $A$. Two other samples received in July 1977 were identified as 53418A. One of these came in two pieces ( $2 \mathrm{~A}$ and $2 \mathrm{~B}$ ) representing mating faces of a fracture; this pipe will be referred to as sample B. The other pipe sample (53418Al) received in July contained a threaded tool joint and will be referred to as sample $C$.

\section{Sample A}

This pipe sample (5.5-inch OD, 0.42-inch wall) had a fracture on one of its ends consisting of a flat portion that extended for about one third of the circumference and of an irregular portion. Figure 1 shows a portion of the pipe containing the fracture face, and Figure 2 shows the relative positions of the flat and irregular fractures. The flat portion, extending essentially normal to the pipe axis, indicates that the initial fracture was caused by a predominantly axial load. After the initial flat fracture extended to critical size, the remaining portion failed by overload in an irregular manner. The inside surface was more severely corroded than the outside and contained many irregularly shaped pits, as is illustrated in Figure 3 . No secondary cracks were observed on the inside surface. The higher corrosion rate on the inside is believed to be the result of high oxygen concentration from some air entrapment and of high flow rate.

The outside surface was corroded to an appreciably lesser extent than the inside surface, the corrosion was more general in nature, and pitting was shallow and infrequent. In addition, many 
FAILURE ANALYSIS OF

S-135 DRILI PIPE USED

IN DEEP SEA DRILLING

November 8, 1977

Discussion (Continued)

small cracks were present on the outside surface immediately adjacent to the flat fracture. Typical cracks are shown in Figure 4. Considerable lateral corrosion also occurred in some of the cracks as depicted in Figure 5 .

The fracture surface was severely corroded, thereby obscuring the original features of the fracture face. Removal of corrosion products*) from the flat fracture section revealed small, deep pits and cracks essentially perpendicular to the fracture surface, as illustrated in Figure 6.

Sample B

Sample B represents two matching sections of a pipe (5-inch OD, 0.35-inch wall) that had fractured. The fractured ends of the pipe are shown in Figure 7. Similar to Sample A, this pipe sample also contained a flat portion in its fracture surface extending about one third of the circumference, the remainder of the fracture being irregular. Fluorescent magnetic particle examination revealed longitudinal bands of circumferential cracks adjacent to the flat fracture, as schematically indicated in Figure 7. A detailed view of one cracked zone is shown in Figure 8.

Metallographic examination showed that these cracks, about 0.01 inch deep, were filled with corrosion product as is illustrated in Figure 9. Considerable corrosion was also present on the fracture face indicating that the pipe was exposed to seawater for an appreciable time after the fracture occurred. In addition to general corrosion, deep narrow pits were present on the fracture surface, Figures 10 and 11. The fracture surface adjoining the outside diameter of the pipe revealed "ratcheting" (areas of different elevation) illustrated in Figure 12. This configuration indicates that the flat fracture initiated from many small cracks on the outside surface, such as those shown in Figure 8, which then joined up as the crack propagated. Branch cracks were also seen on the fracture surface, as is illustrated in Figures 13 and 14 , for areas at the outside and inside pipe surfaces, respectively.

*) The corrosion products were removed ultrasonically in an 18 percent HCl solution inhibited by $5 \mathrm{~g} / 1$ of $1,3-D-n-b u t y 1-2$ thiourea. This solution does not attack steel, but it removes rust and exposed sulfide inclusions. 
FAILURE ANALYSIS OF

S-135 DRILI PIPE USED

IN DEEP SEA DRILLING

November 3,1977

Discussion (Continued)

Sample C

This sample, shown in Fjgure 15, consisted of a 5-inch OD, $0.35-i n c h$ wall pipe section attached to a tool joint. About 24 inches from the pin end, the pipe contained a rather straight circumferential crack about 1.5 inches long; Figure 15 shows the location of the crack. The outside pipe surface in the vicinity of the crack was ground off before receipt of the sample. A metallographic section at about midlength of the crack showed that the crack was very straight. Although in this section the crack had not propagated through the pipe wall, in an adjacent area the crack did penetrate the crack wall. Figure 16 shows that the crack initiated on the outside surface, and that pitting corrosion occurred laterally from the crack, indicating that the crack propaqated relatively slowly. The straightness of the crack is typical of fatigue cracks. The tip of the crack follows a slightly branched, predominantly transgranular path, as illustrated in Figure 17. Although the crack initiation area could be identified, as shown in Figure 18, the grinding of the outside surface precluded linking the exact initiation site with metallographic or corrosion features.

Discussion and Sumnary

Examination of three sections of API Grade S-135 drill pipe that failed during drilling operations in seawater revealed several features which indicate that the fractures occurred as a result of corrosion fatigue. Multiple crack initiation occurred on the outside surface, the cracks propagated rather slowly, and the cracks were filled with corrosion product. The flatness of the fracture being essentially normal to the pipe axis indicates that the load was predominantly axial. The remainder of the fracture, which was irregular, was caused by overload after the fatigue crack had progressed to a critical size.

Although the inside surface of the pipe contained appreciably more and deeper corrosion pits than the outside, the corrosion fatigue cracks started from the outside surface. Lateral pitting corrosion on the fracture surfaces of cracks that progressed partially through the pipe wall indicates that the cracks progressed relatively slowly permitting sufficient time for corrosion pits to grow on the newly exposed crack surfaces. However, specific information was not availabje that would permit an estimate of the timeto-failure after crack initiation. 
Table I

Chemical Composition of Drill Pipe, percent

\begin{tabular}{|c|c|c|c|c|c|c|c|c|c|c|c|}
\hline Sample & C & $\mathrm{Mn}$ & P & $\mathrm{S}$ & $\mathrm{Si}$ & $\mathrm{Cu}$ & $\mathrm{Ni}$ & $\mathrm{Cr}$ & Mo & $\begin{array}{c}\text { Al } \\
\text { (total) } \\
\end{array}$ & V \\
\hline$A$ & 0.32 & 1.93 & 0.004 & 0.026 & 0.25 & 0.02 & 0.01 & 0.02 & 0.49 & 0.002 & 0.009 \\
\hline B & 0.29 & 1.87 & 0.018 & 0.018 & 0.23 & 0.01 & 0.01 & $<0.003$ & 0.41 & 0.003 & 0.013 \\
\hline C & 0.33 & 1.87 & 0.017 & 0.021 & 0.20 & 0.01 & 0.01 & $<0.003$ & 0.41 & 0.001 & 0.013 \\
\hline
\end{tabular}

United States Steel Corporation, Kesearch, Monroeville, Pennsylvania 
Table II

Mechanical Properties of Drill Pipe

\begin{tabular}{|c|c|c|c|c|}
\hline Sample & $\begin{array}{c}\text { Yield Strength, } \\
(0.28 \text { offset), } \\
\mathrm{ksi}\end{array}$ & $\begin{array}{c}\text { Tensile } \\
\text { Strength, } \\
\text { ksi } \\
\end{array}$ & $\begin{array}{l}\text { Elongation } \\
\text { in } 1 \text { inch, } \\
\text { percent }\end{array}$ & $\begin{array}{l}\text { Reduction } \\
\text { in Area, } \\
\text { percent } \\
\end{array}$ \\
\hline A & 149.0 & 163.5 & 17.3 & 58.0 \\
\hline B & 140.6 & 154.6 & 18.1 & 59.7 \\
\hline C & 146.1 & 160.6 & 18.0 & 57.0 \\
\hline
\end{tabular}

United States Steel Corporation, Research, Monroeville, Pa. 


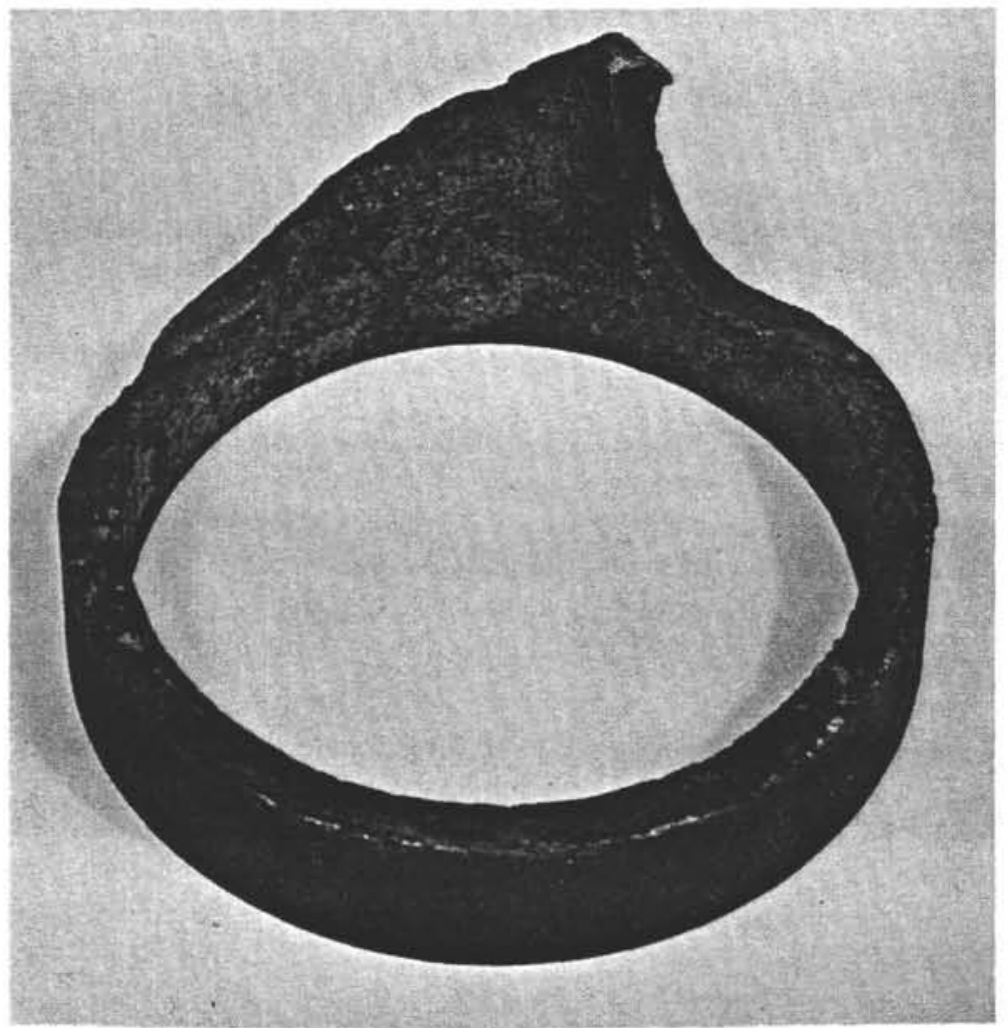

Fractured end of Sample A. Note flat portion at bottom of photograph. About 0.6 actual size. 

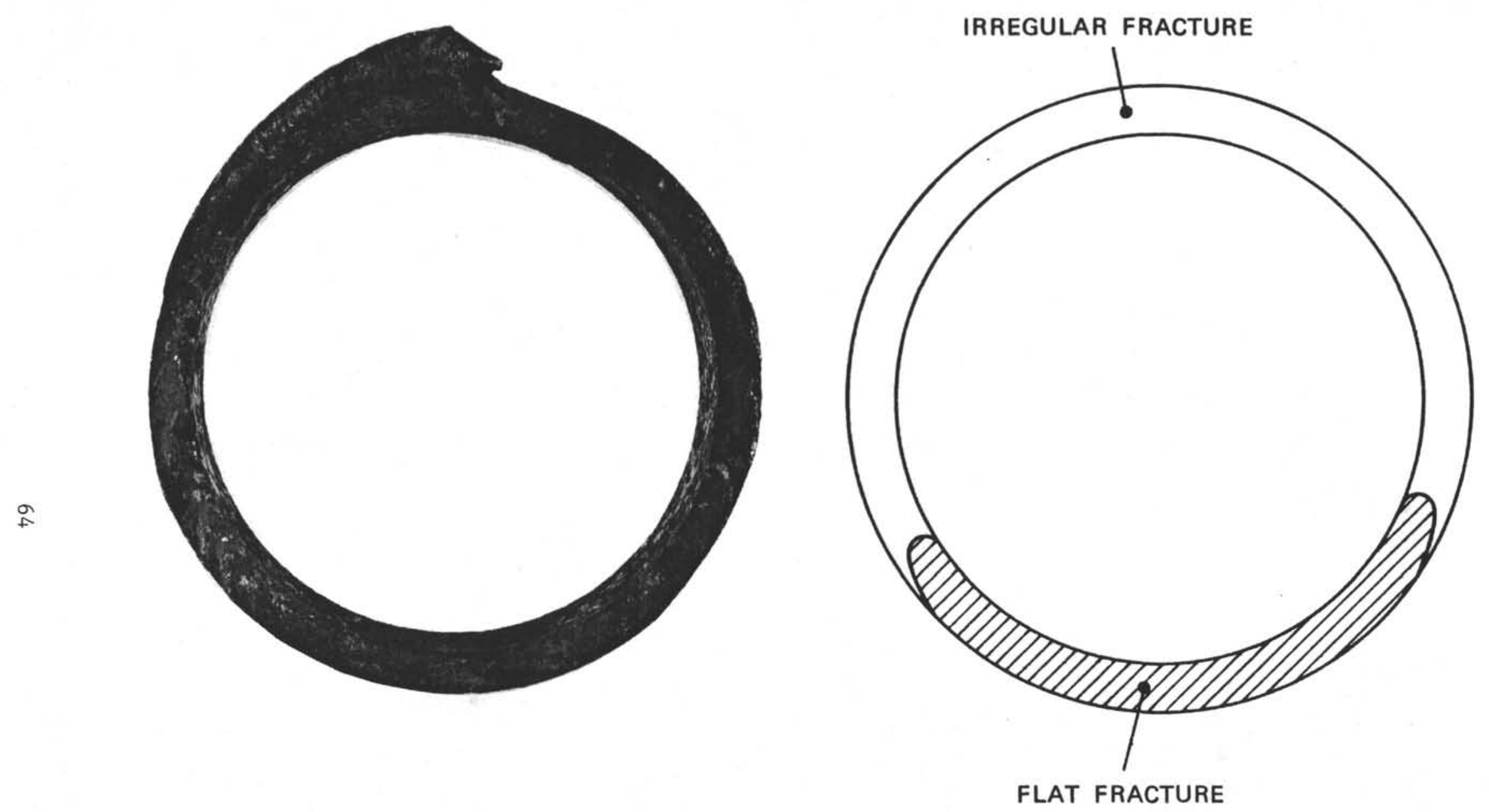

FRACTURE SURFACE OF SAMPLE A. ABOUT 0.7 ACTUAL SIZE. 


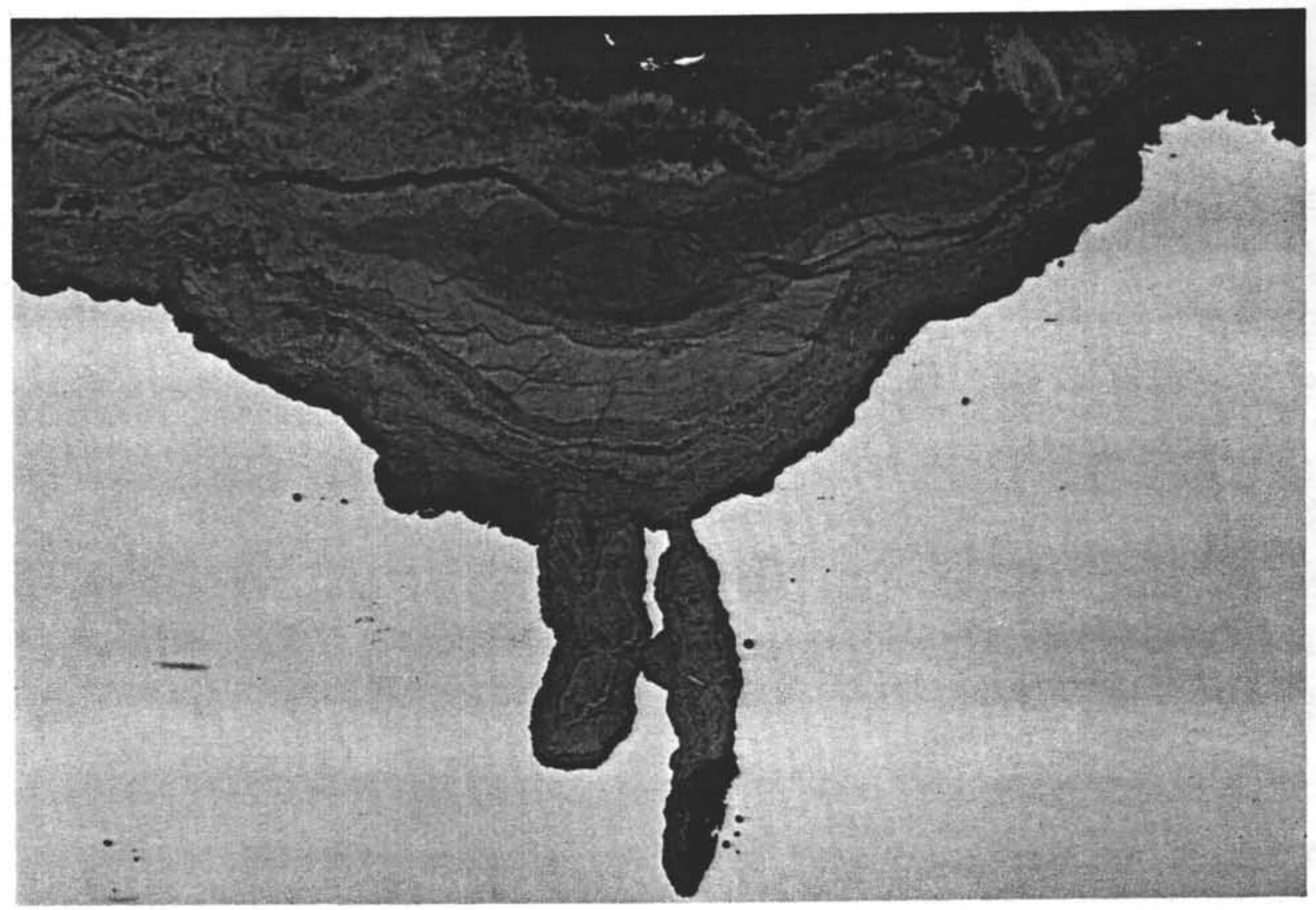

Irregularly-shaped corrosion pit on the inside surface of Sample A. Not etched. X300. 


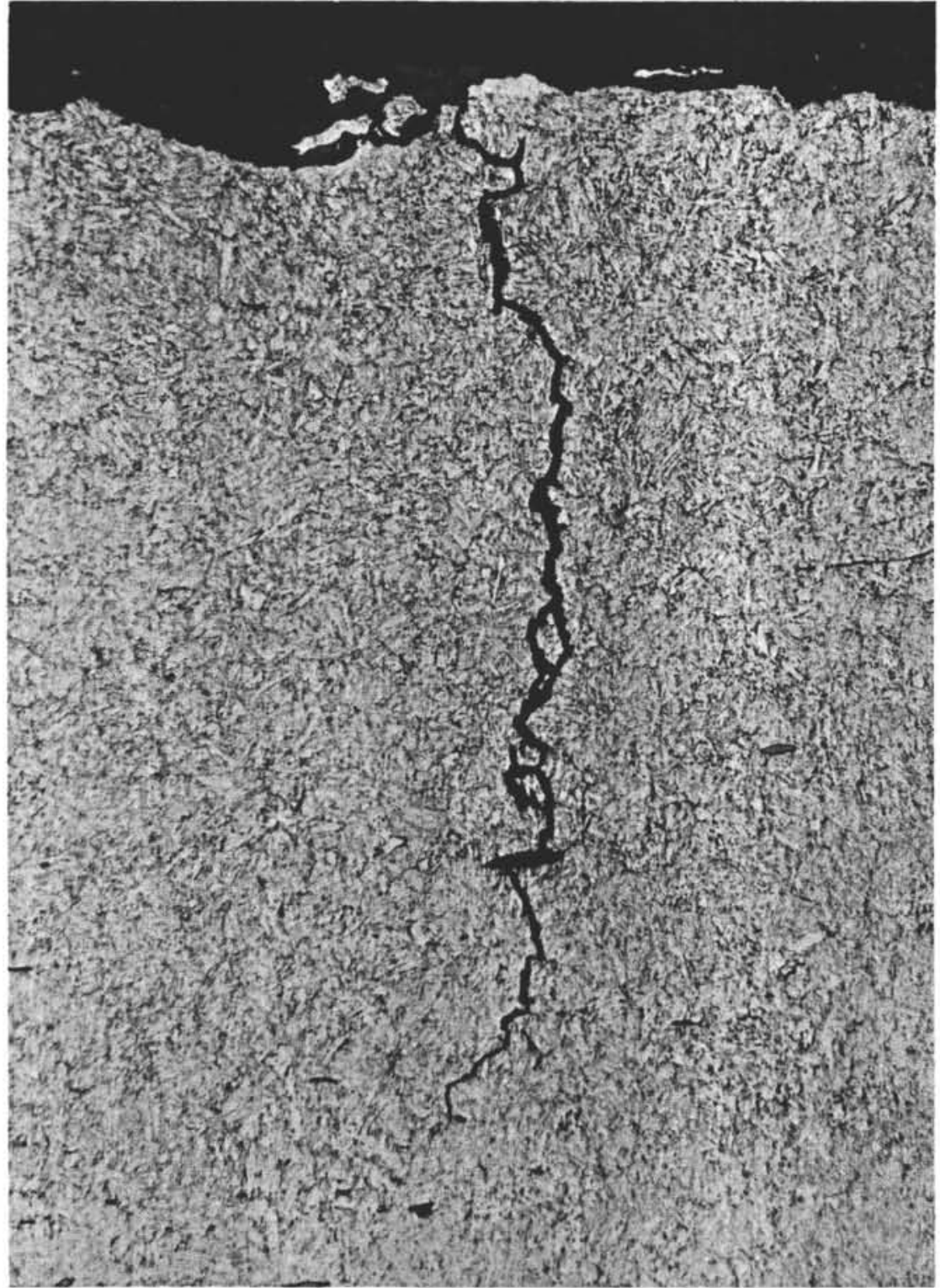

Etched in picral. $\times 300$.

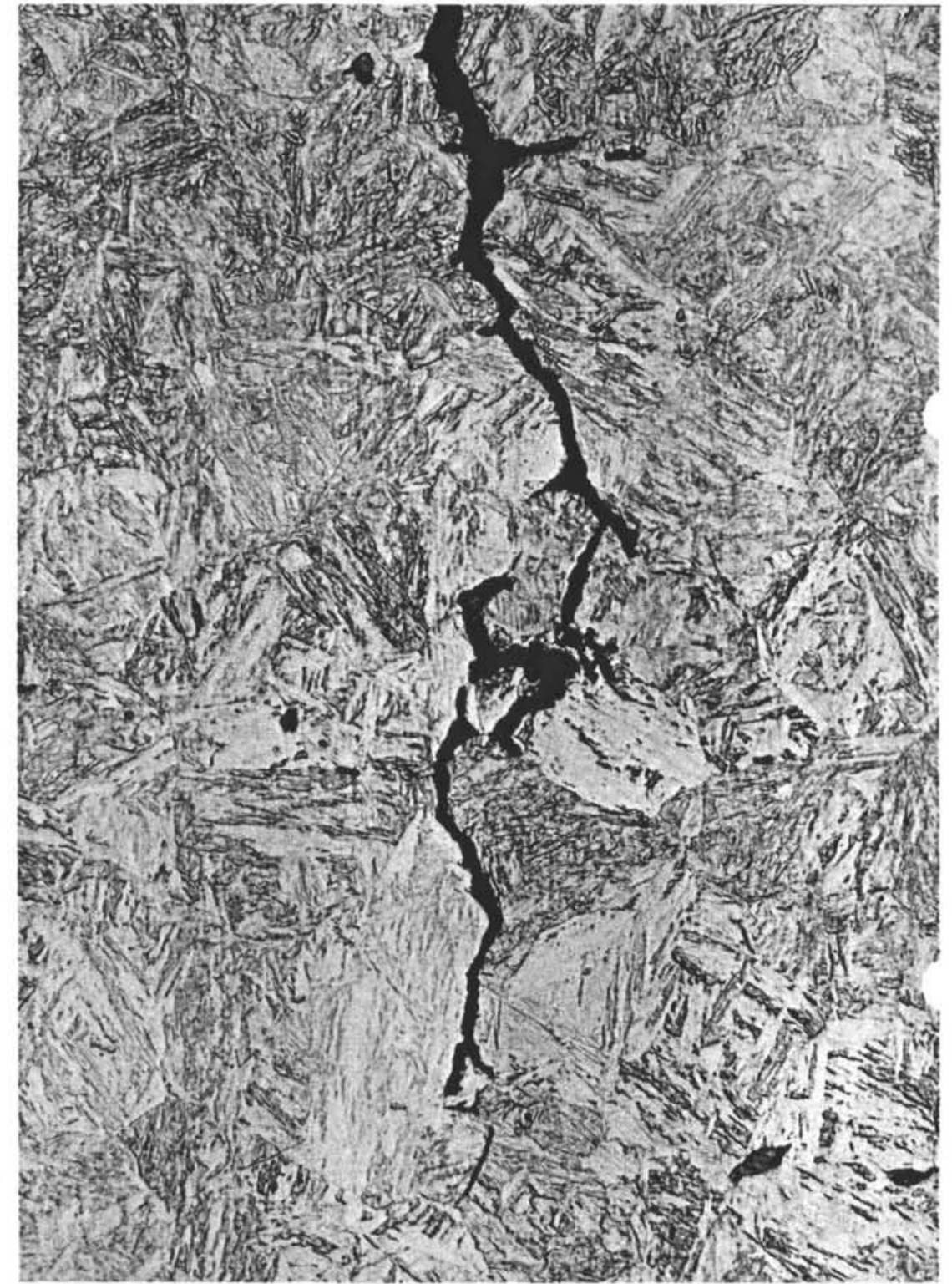

Etched in Vilella's Reagent. $\mathrm{x} 750$.

Cracks emanating from the outside surface of Sample A. 


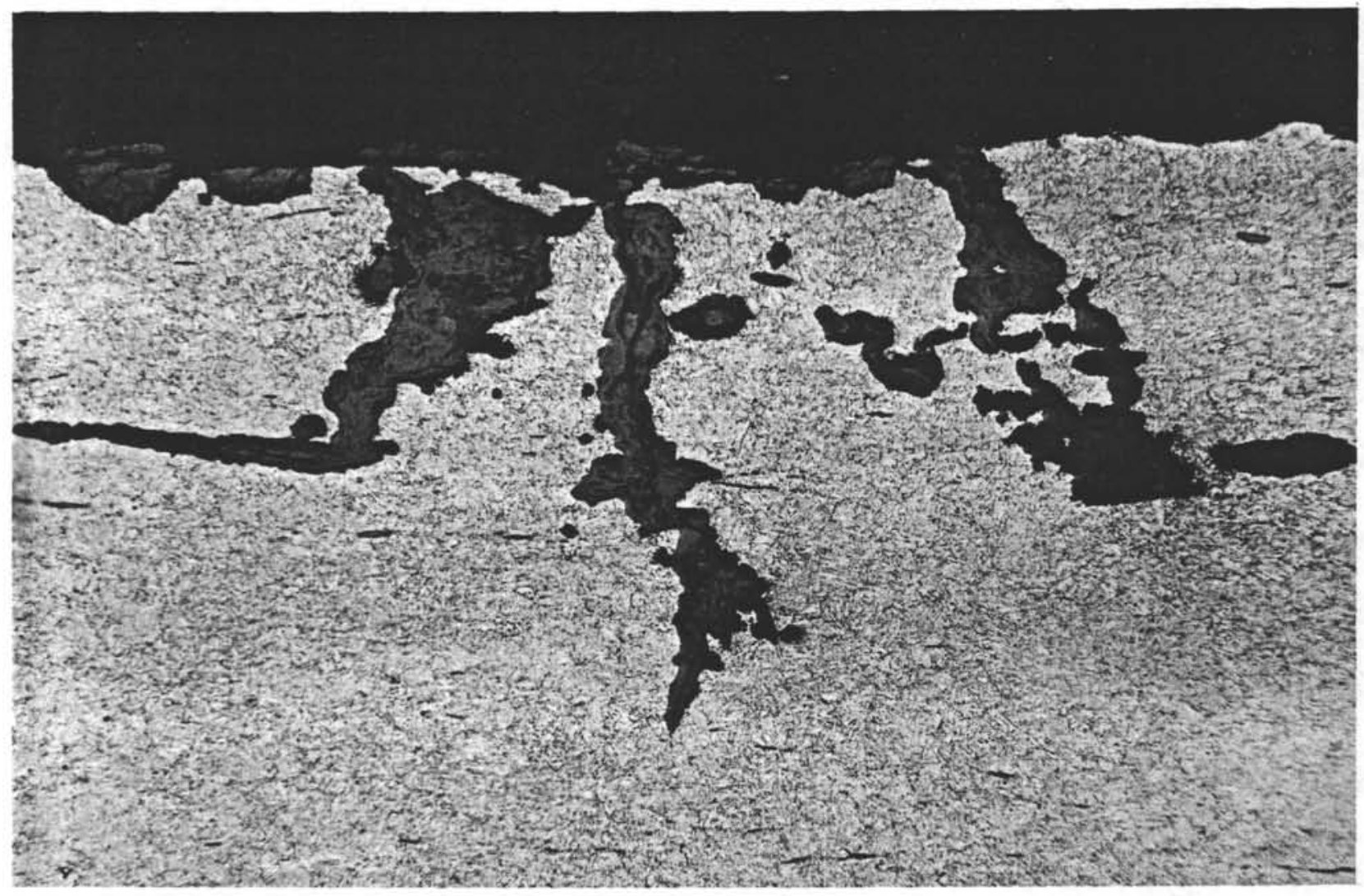

Irregular corrosion on the outside surface of Sample A. Etched in picral. $\times 200$. 


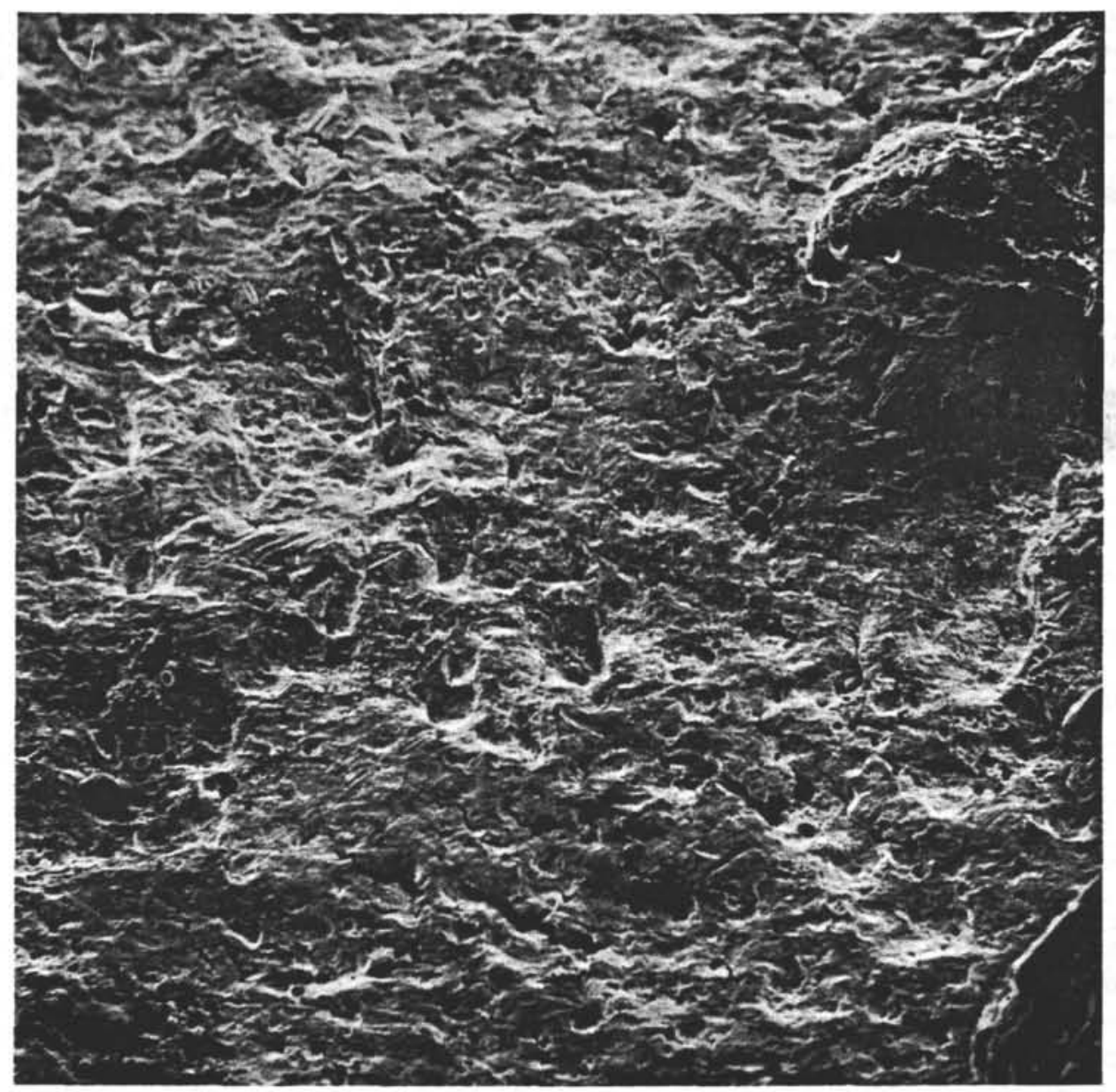

Flat fracture surface of Sample A after removal of corrosion product. Note corrosion pits and secondary cracks. $\mathrm{x} 100$. 


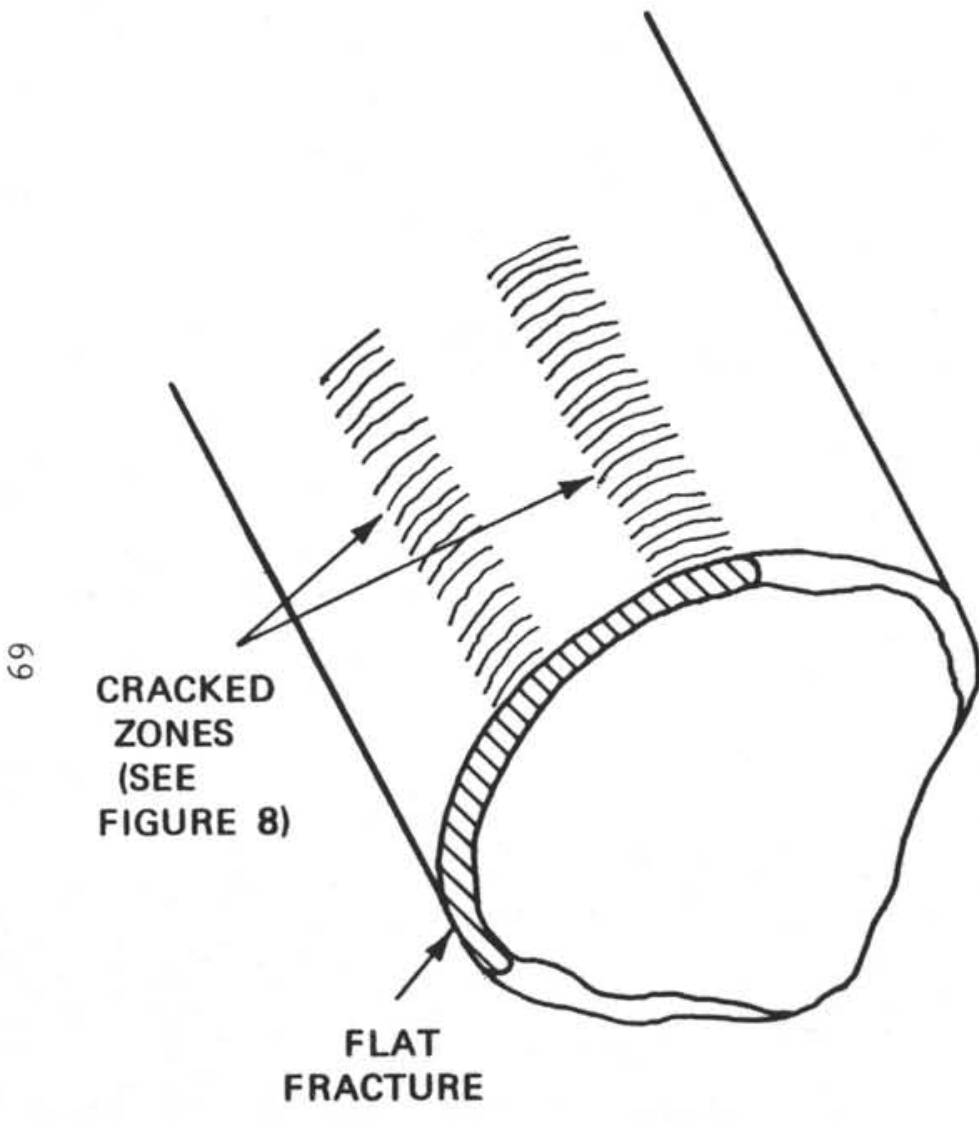

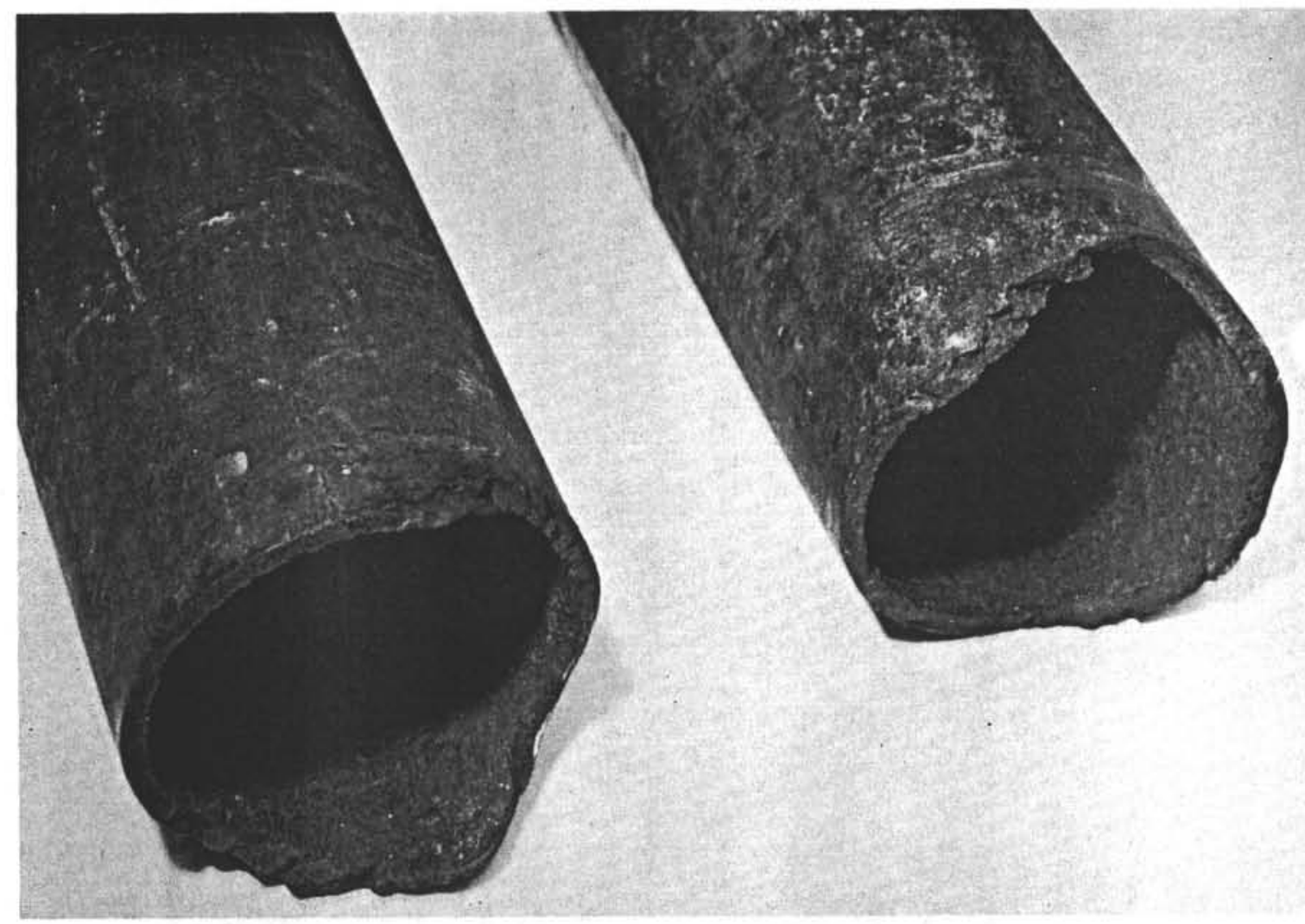

MATCHED FRACTURE FACES OF SAMPLE B. ABOUT 0.5 ACTUAL SIZE. 
Pipe Axis

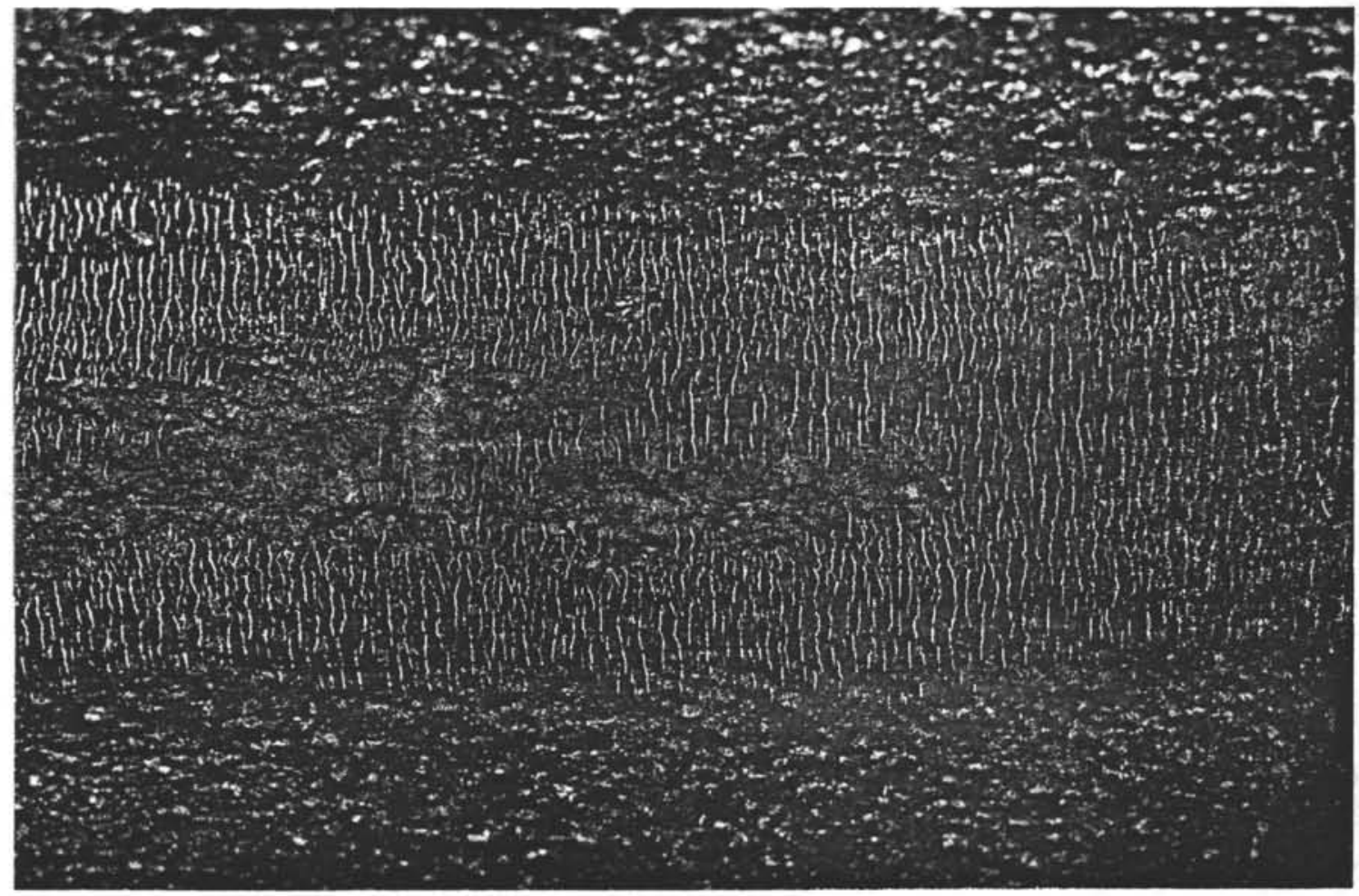

Cracked zone on the outside surface of Sample B. The cracks were revealed by fluorescent magnetic particle technique with ultraviolet illumination. X1. 3 . 


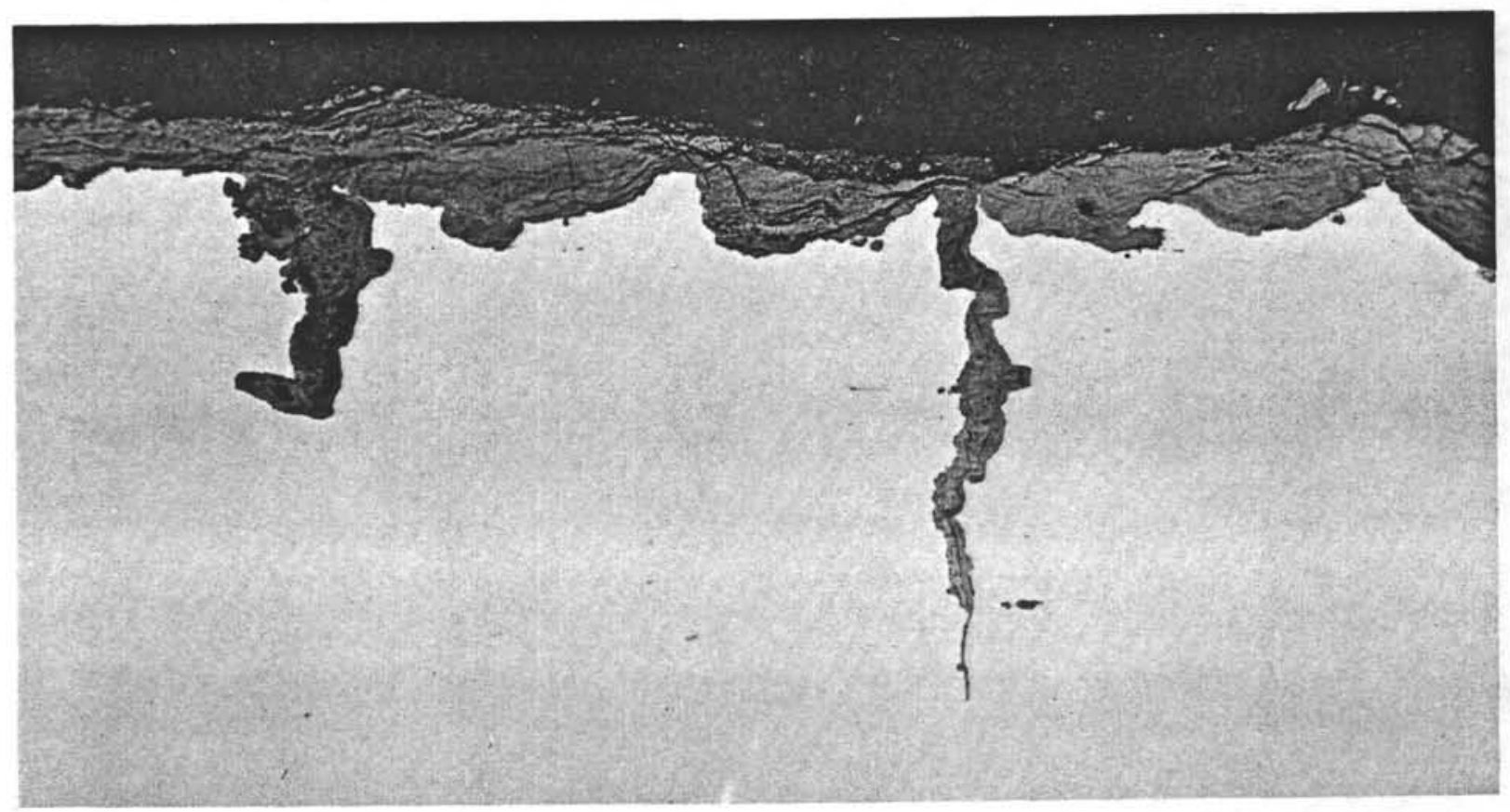

Not etched

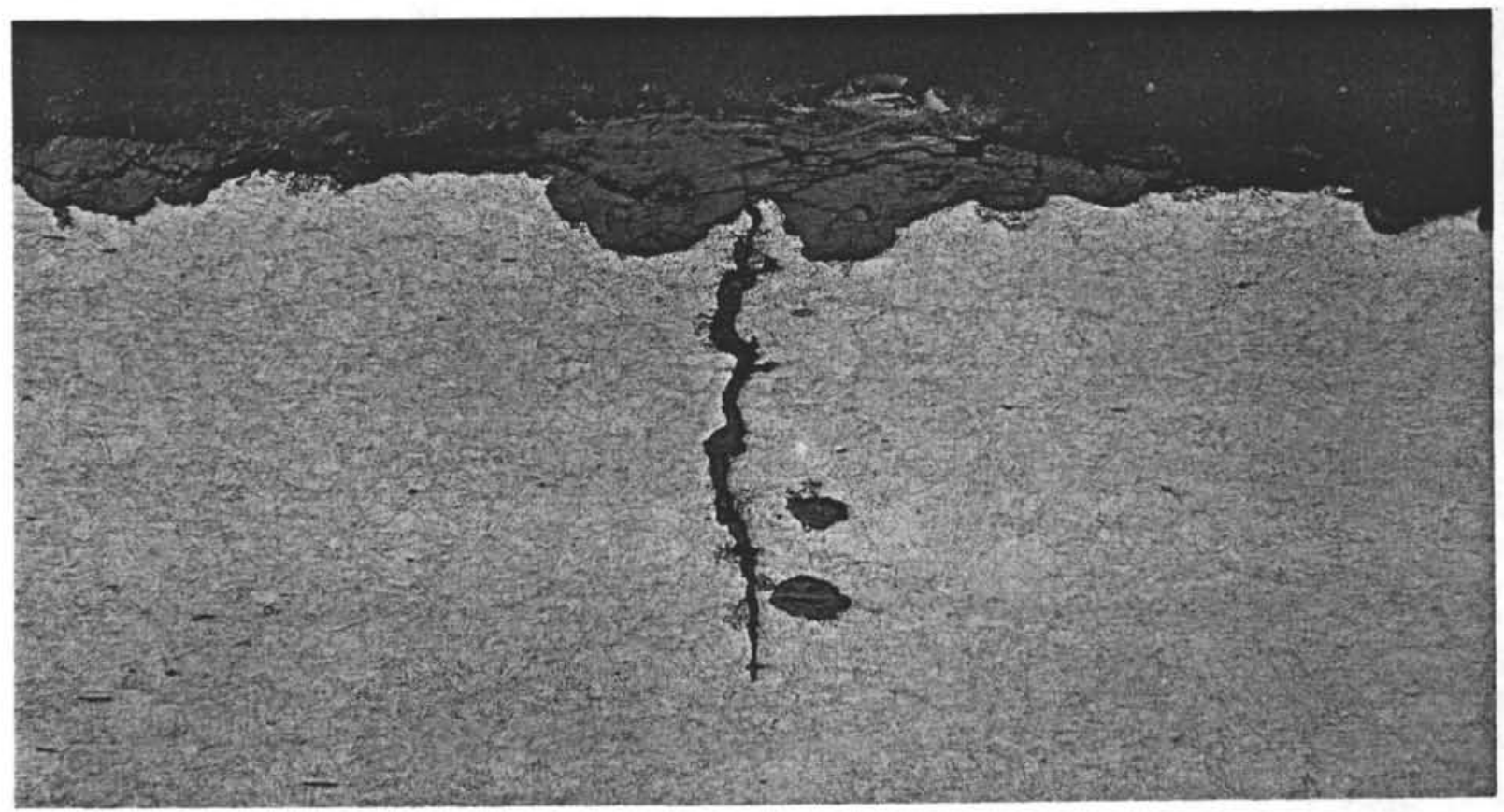

Etched in picral

Cracks on the outside surface of Sample B. X200.

1M-1870-A2-2-1

IM-1870-A2-2-3

Figure 9 


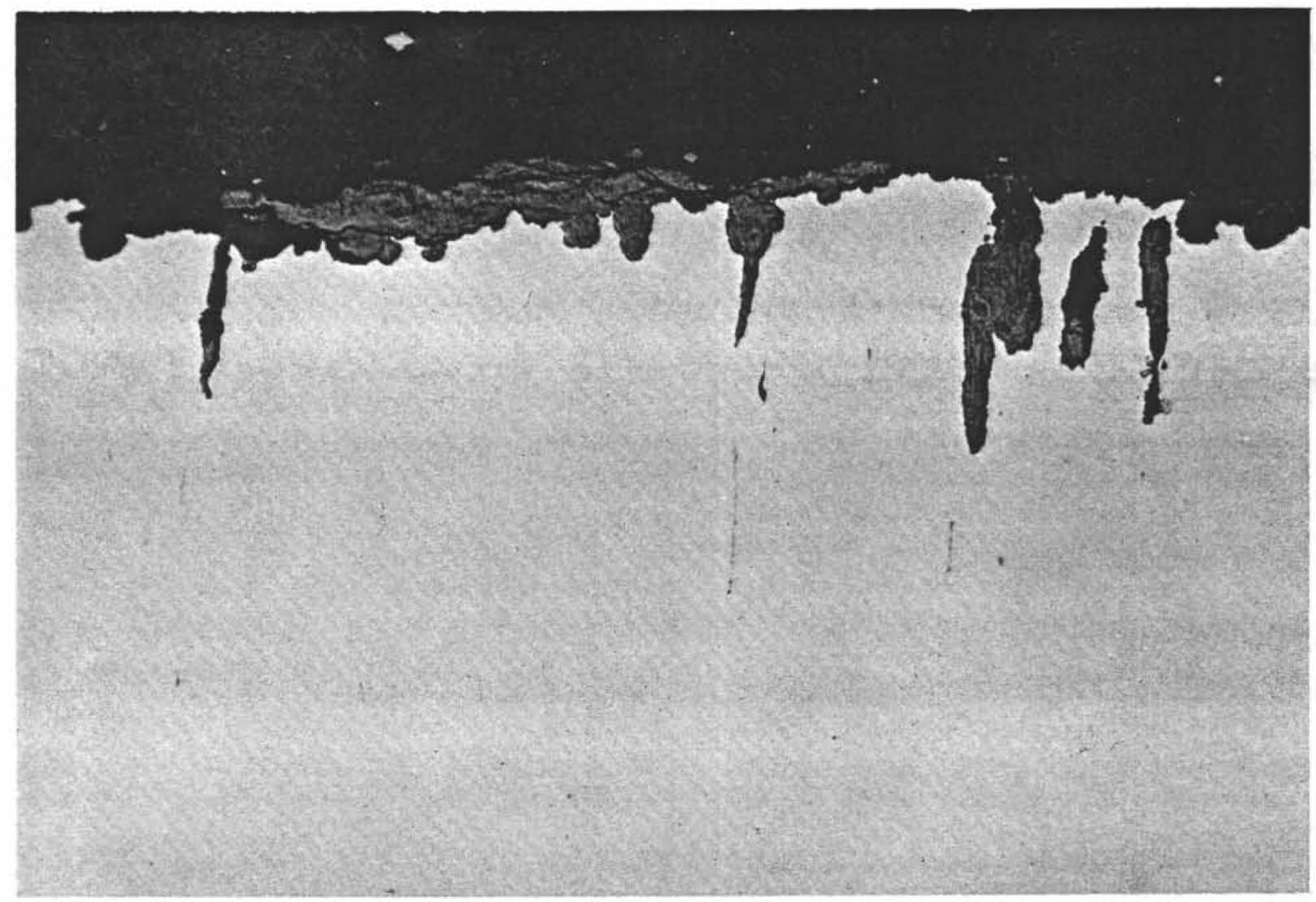

General corrosion and pitting on the flat fracture surface of Sample B. Not etched. X250. 


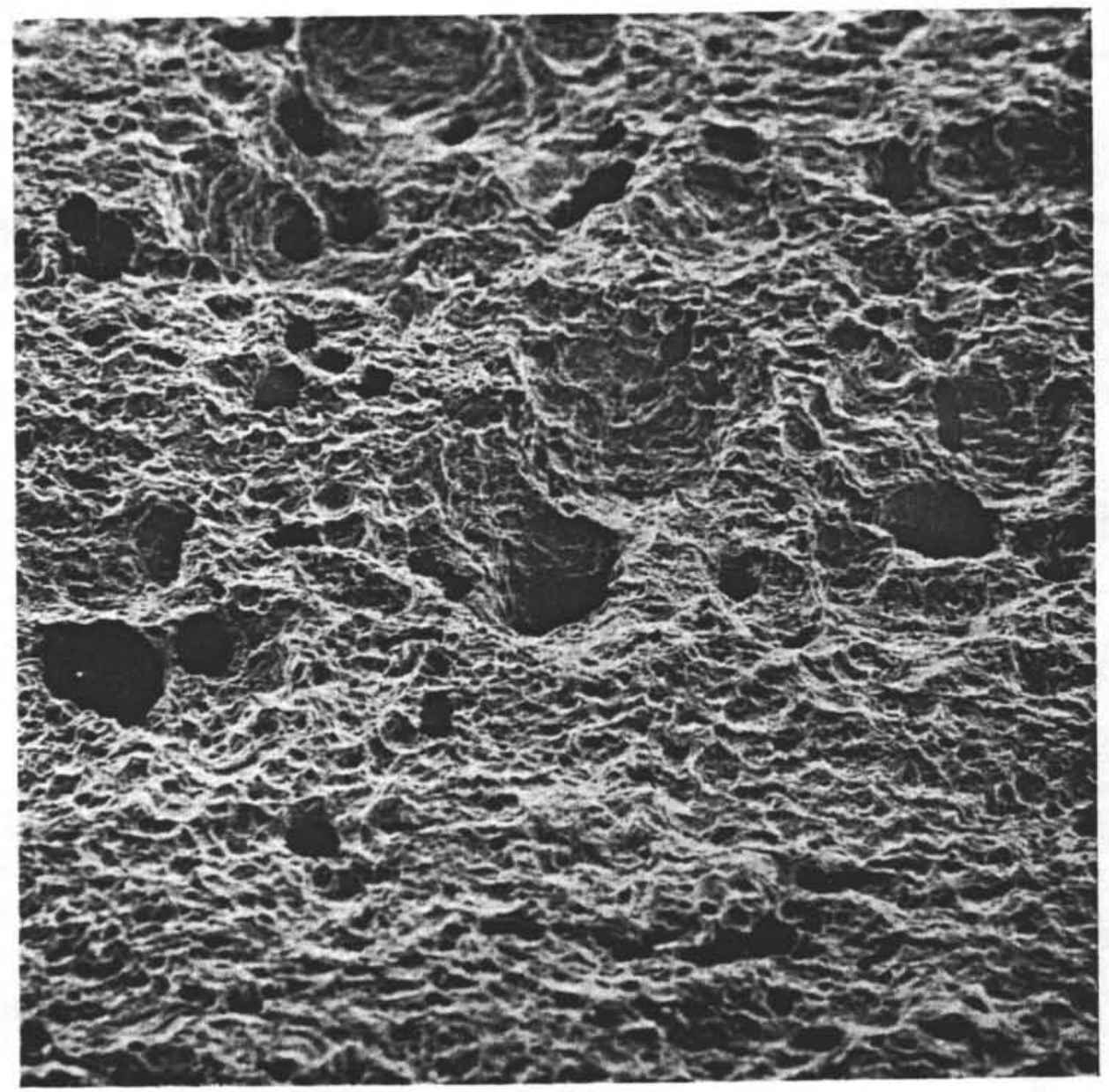

Flat fracture surface of Sample B after removal of corrosion product. $\times 250$. 


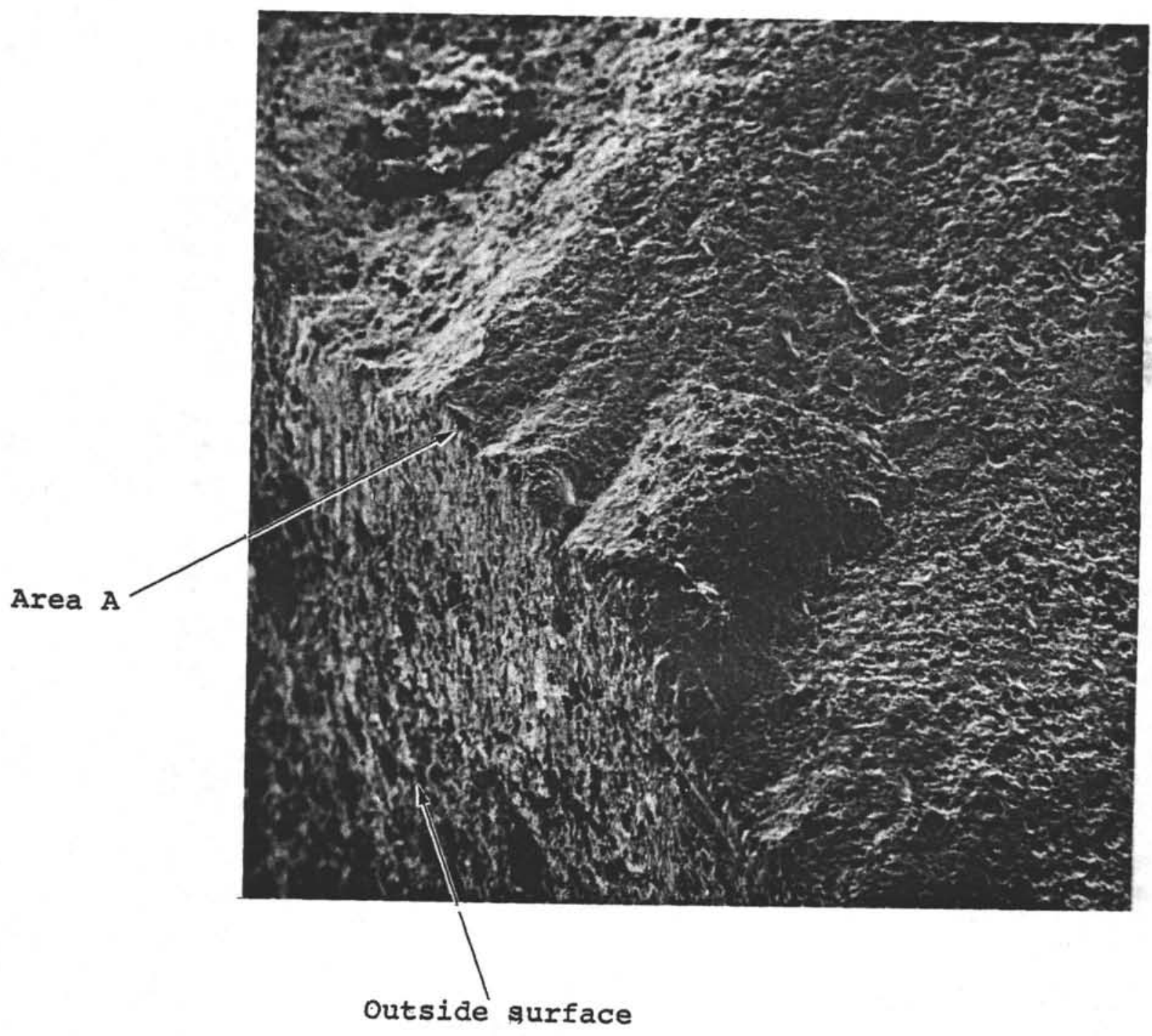

Edge of the flat fracture at the outside diameter showing ratcheting. $\mathrm{X} 50$. 


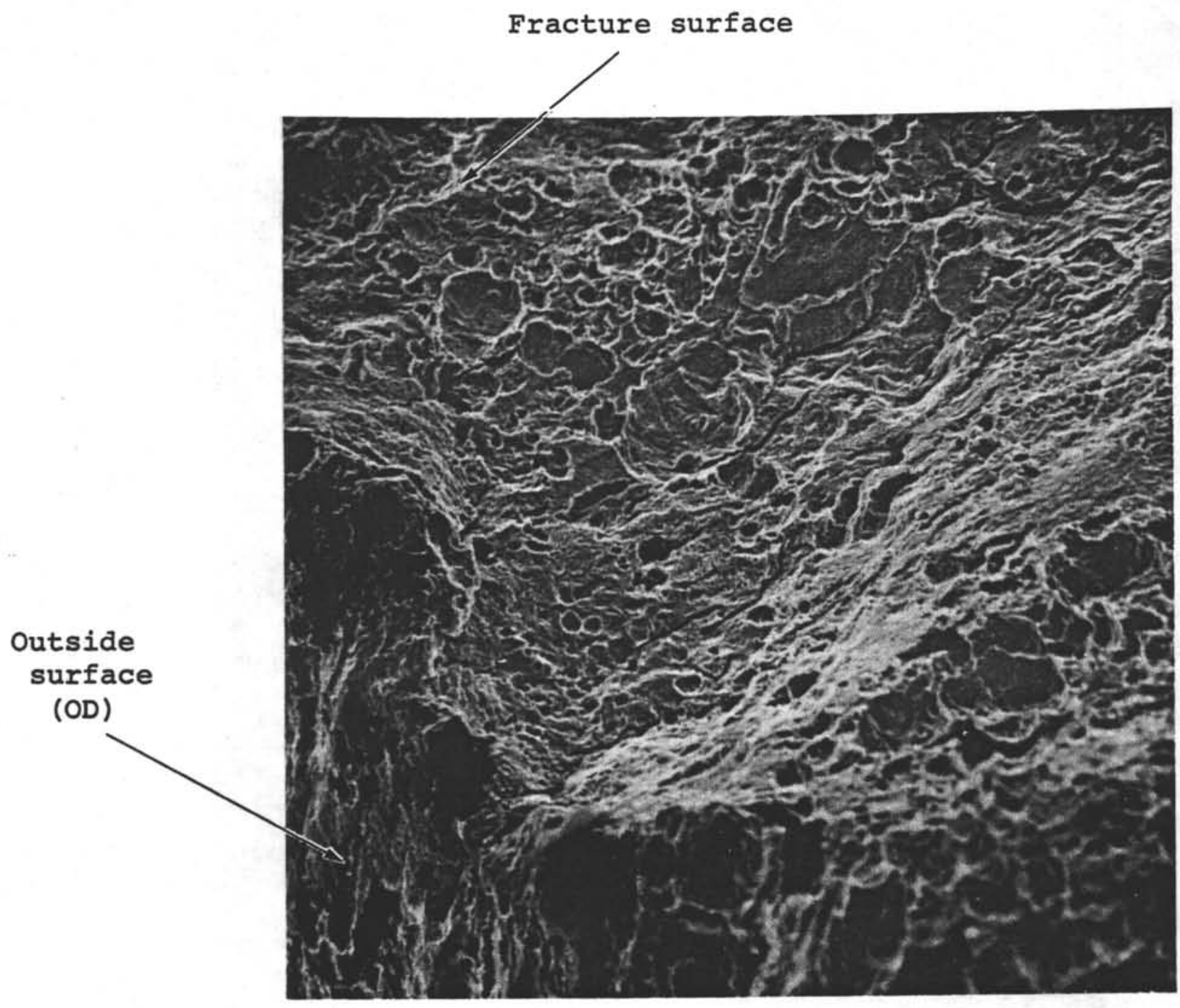

Branch cracks on flat fracture surface of Sample B. Area $A$ in Figure 12. $\times 500$. 


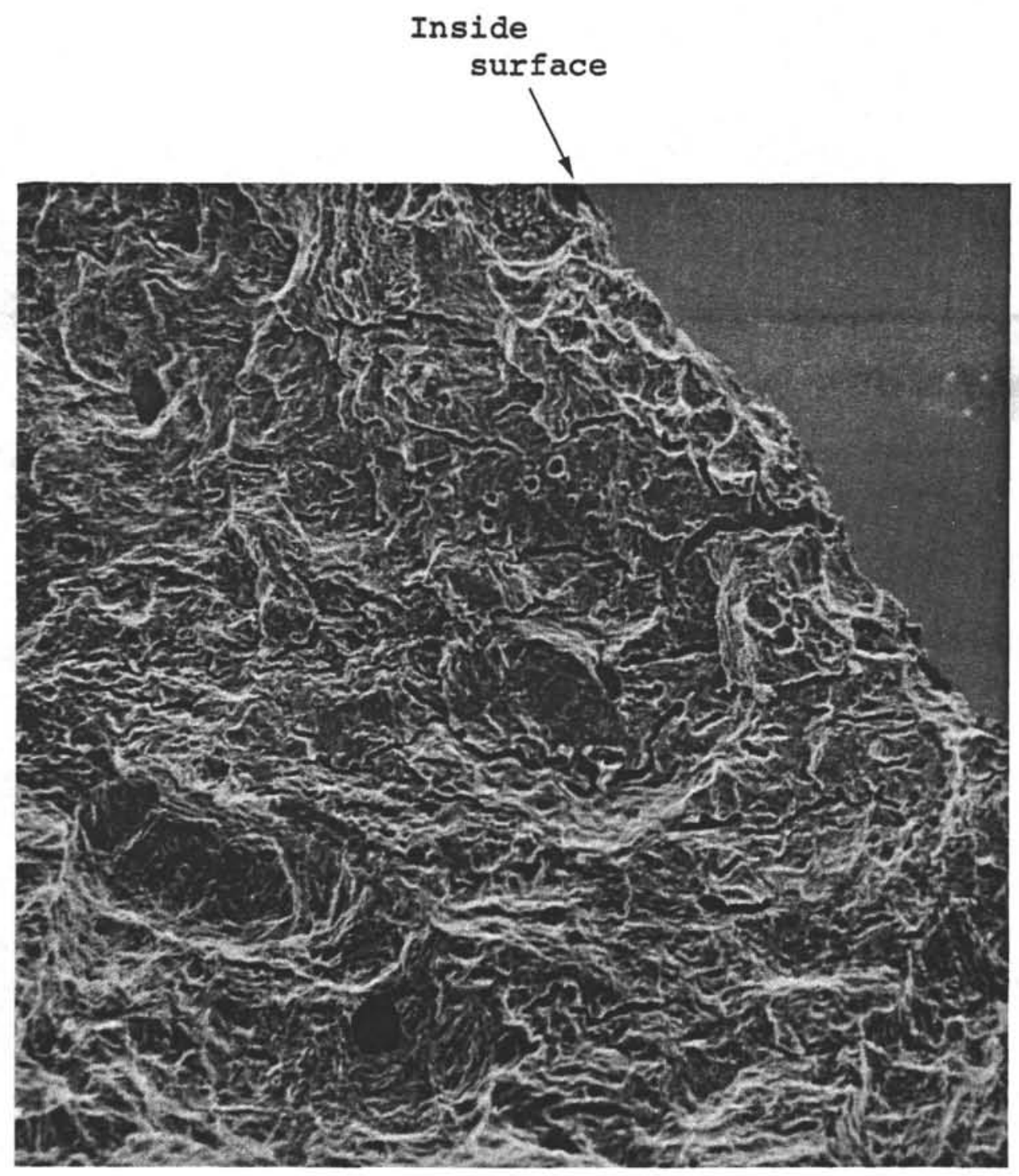

Branch cracks on flat fracture surface of Sample B. $\mathrm{x} 500$. 


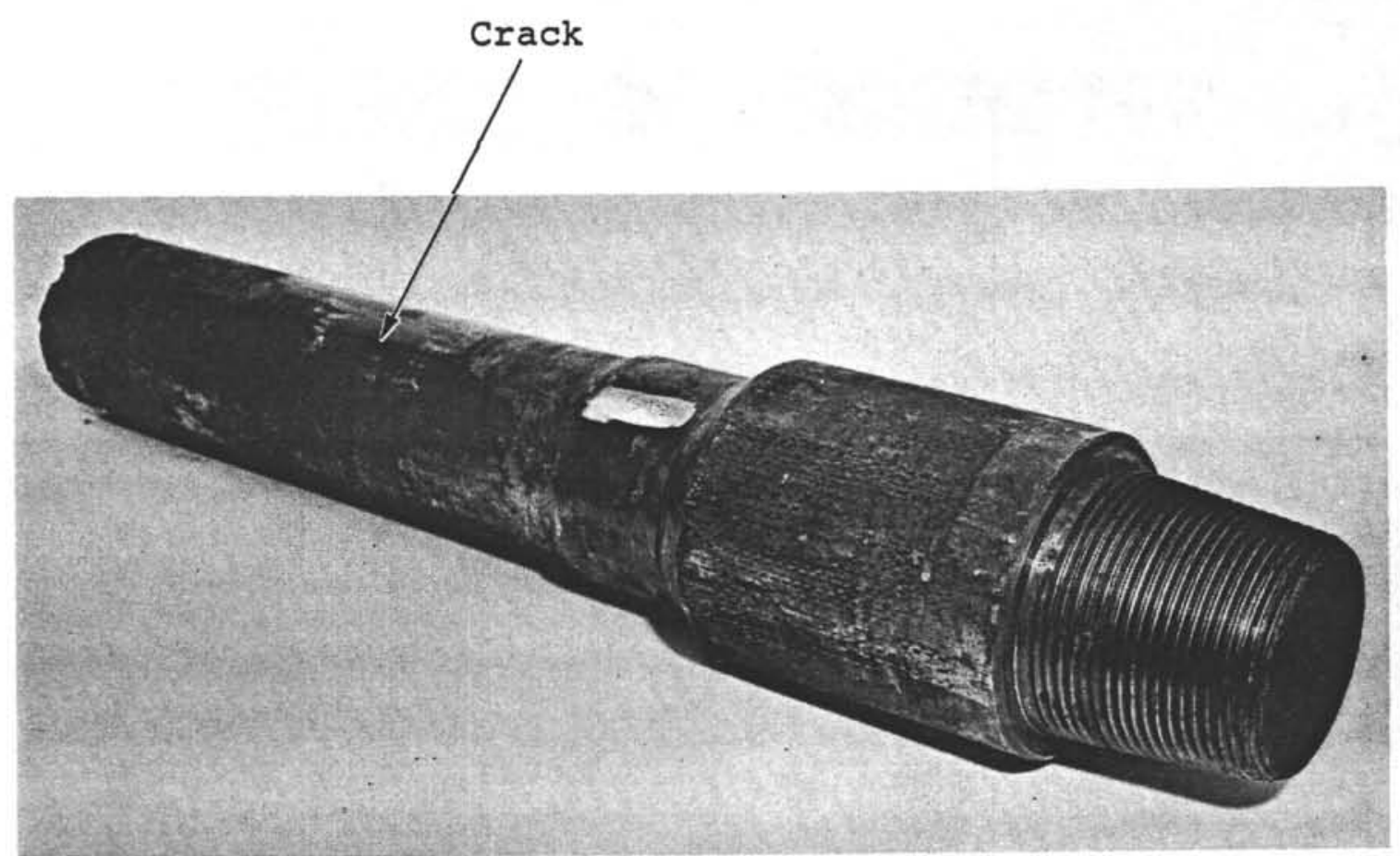

Sample C showing location of crack in relation to the pin end. 


\section{Outside surface}

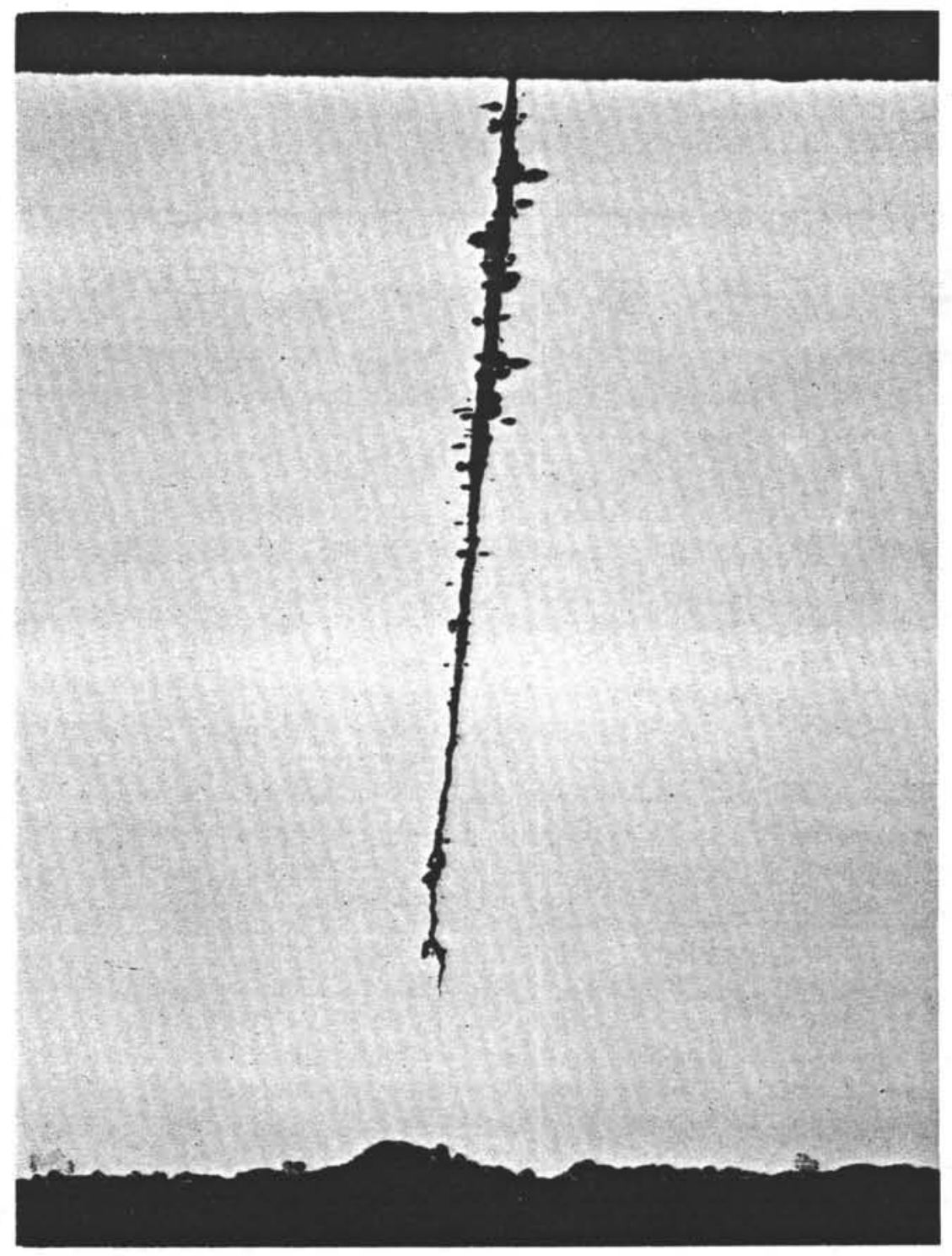

Inside surface

Crack in Sample C showing lateral pitting corrosion. Not etched. X15. 


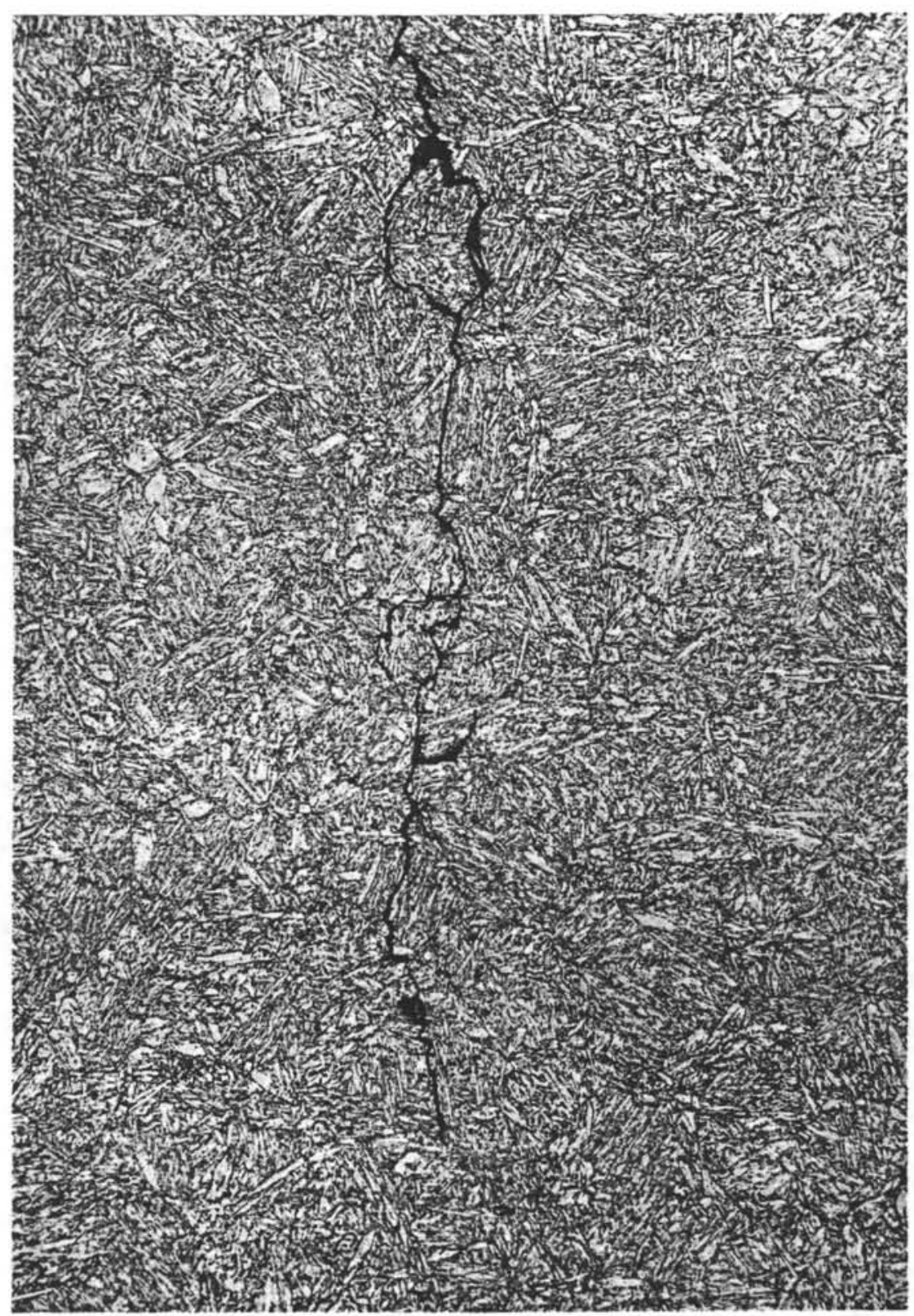

Tip of the crack shown in Figure 16. Etched in super picral. $\times 500$. 


\section{Outside surface}

Inside surface

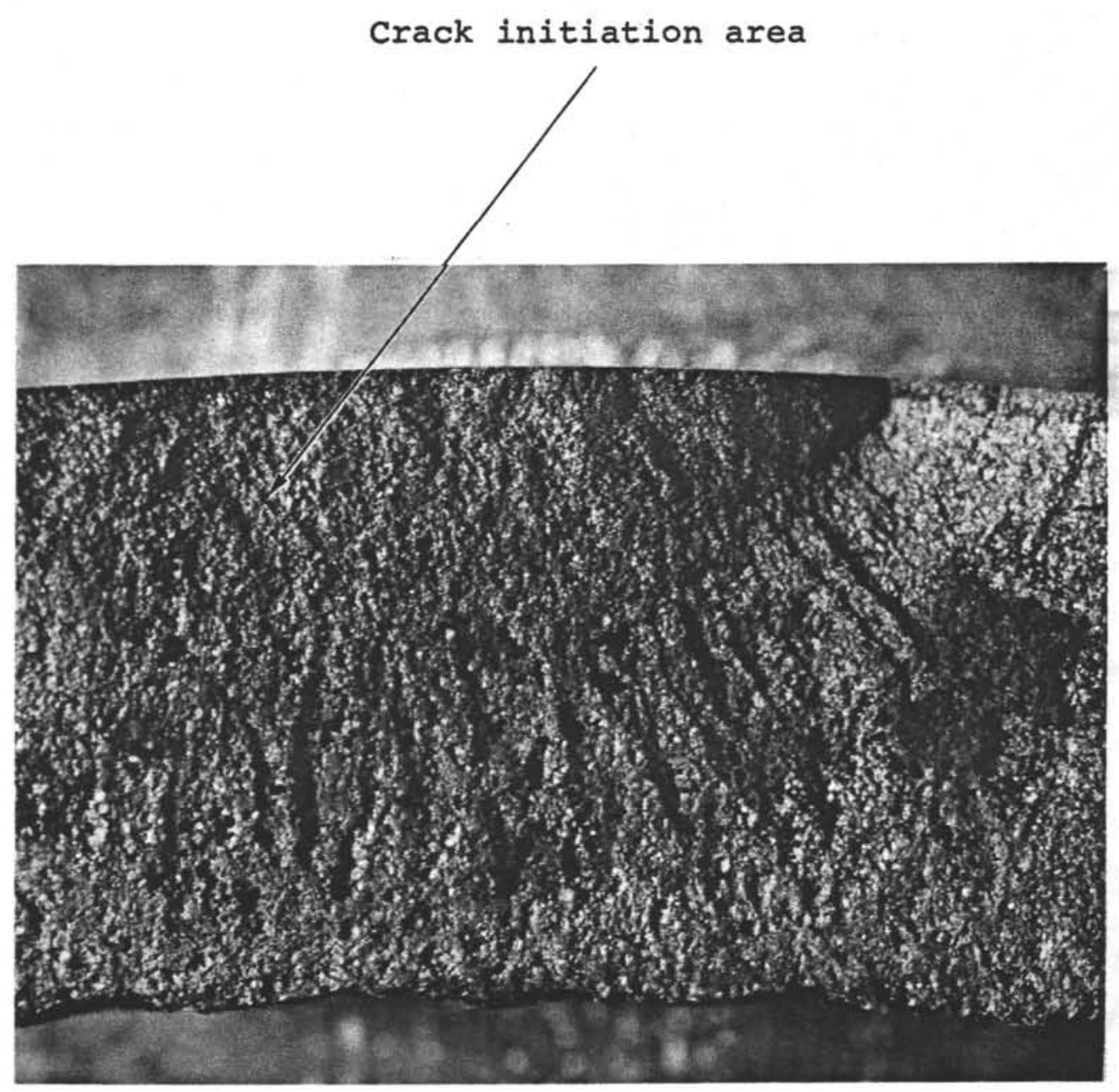

Fracture surface at crack initiation site after removal of corrosion product from Sample C. Sections shown in Figures 16 and 17 were taken at an area adjacent to the right edge of this picture. About 9X. 


\section{APPENDIX B-3}

DOCKSIDE PRELIMINARY EXAMINATION OF

FAILED S-135 STEEL DRILL PIPE FROM

D/V GLOMAR CHALLENGER AND ASSOCIATED

METALLURGICAL FAILURE ANALYSIS OF

FRACTURED DRILL PIPE, LEG 83, HOLE 504B 


\title{
REPORT
}

on

\author{
DOCKSIDE PRELIMINARY EXAMINATION OF \\ FAILED S-135 STEEL DRILL PIPE FROM \\ D. Y.V. GLOMAR CHALLENGER AND ASSOCIATED \\ METALLURGICAL FAILURE ANALYSIS OF \\ FRACTURED DRILL PIPE \\ LEG 83, HOLE 504B \\ Contract № G 12696-3058 \\ to
}

DEEP SEA DRILLING PROJECT

March 30, 1982

\author{
by \\ D. R. McIntyre \\ BATTELLE \\ Houston Operations \\ 2223 West Loop South \\ Houston, Texas
}

Battelle is not engaged in research for advertising, sales promotion, or publicity purposes, and this report may not be reproduced in full or in part for such purposes. 
Visual Examination................................. 2

Scanning Electron Microscope Fractography................. 4

Metallographic Examination........................... 4

Mechanical Properties Tests.......................... 5

Chemical Composition............................... 5

Discussion..................................... 5

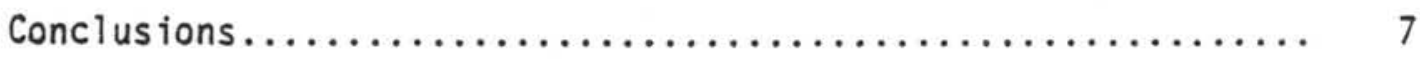

\section{LIST OF TABLES}

Table 1. Mechanical Properties of Cracked Drill Pipe (Average)

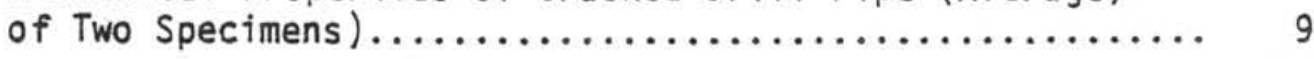

Table 2. Chemfilar Composition of Field Drill Pipe (Sample)...... 10

\section{LIST OF FIGURES}

Figure 1. Schematic of DSDP Hole $504 B \ldots \ldots \ldots \ldots \ldots \ldots \ldots \ldots . . . \ldots \ldots$

Figure 2. Fractured Pieces of Drill P.ipe................... 12

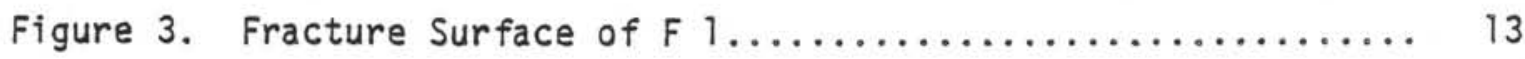

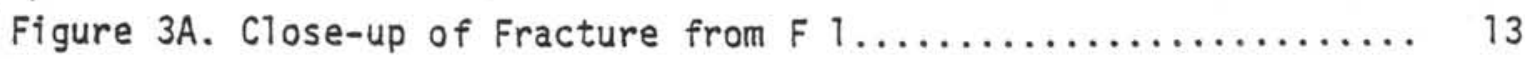

Figure 4. Fracture Surface of $F(\ldots \ldots \ldots \ldots \ldots \ldots \ldots \ldots \ldots \ldots \ldots \ldots \ldots, 14$

Figure $4 \mathrm{~A}$. Close-up of Fracture from $\mathrm{F} 2 \ldots \ldots \ldots \ldots \ldots \ldots \ldots \ldots \ldots \ldots \ldots \ldots, 14$ 


\section{TABLE OF CONTENTS}

(continued)
LIST OF FIGURES

(continued)

Page

Figure 5. Cracked Pipe Joints.......................... 15

Figure 6. Fracture Surface of Crack Exposed in Sample A.......... 16

Figure 7. Close-up of Fracture Surface from Sample A............ 16

Figure 8. Fracture Surface Exposed in Sample B.............. 17

Figure 9. Close-up of Fracture Surface from Sample B........... 17

Figure 10. Photomicrograph from a Section Through a Fracture Origin

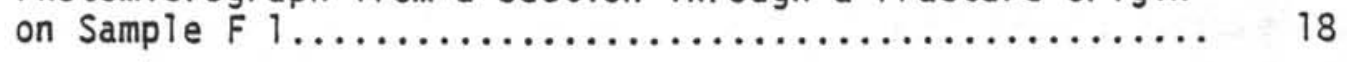

Figure 11. Higher-Magnification Photomicrograph of Origin in Figure

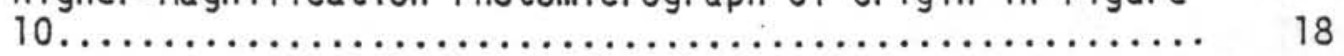

Figure 12. Photomicrograph from a Section Through a Fracture Origin

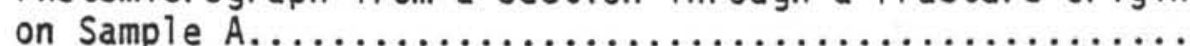

Figure 13. Higher Magnification Photomicrograph of Origin in Figure

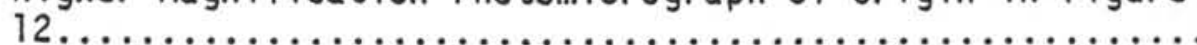




\section{SUMMARY}

Deep internal corrosion pitting led to fatigue cracks in four pieces of 5 inch I. D. S-135 drill pipe used for the Deep Sea Drilling Project (DSDP) on the D.8. GLOMAR CHALLENGER. Two of these pieces fractured during leg 83 of the DSDP. $\mathrm{H}_{2} \mathrm{~S}$ did not accelerate crack initiation or propaqation. The mechanical properties, chemistry and microstructure of the drill pipe itself were normal and within API specification 5AX. The external inorganic zinc coating was effective in preventing corrosion on the outside surface.

The root cause of these failures is the inability of the internal magnetic flux leakage inspection unit to pick up the severe general corrosion pitting and cracking present on these pieces. The drill string was inspected four months before failure; these pieces should have been retired at that time. A different inspection method which gives a more positive, quantitative measure of wall thinning, such as mechanical caliper surveys, should be used on the drill string in future.

\section{INTRODUCTION}

The Deep Sea Drilling Project analyzes geological core samples collected by the drilling ship Glomar Challenger. On November 30, 1981, the D.\$. Glomar Challenger was drilling between Panama and the Galapagos Islands on DSDP Hole No. $504 B$ in 3473 meters of water. While drilling at a bottom hole depth of 4535 meters, the drill string parted at 4048 meters. (Figure 1)

- The broken section of drill pipe was fished from the hole. Drilling continued until December 14, 1981, when the drill string parted again at a depth of 4543 meters. The bottom hole depth at the second failure was 4761 meters. When the broken string was pulled back onboard ship, water was observed leaking from three other sections of cracked pipe. The power sub, to which the string is attached at the swivel head, was al so cracked. 


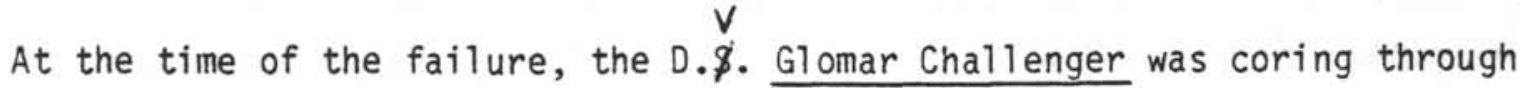
basalt under the following conditions:

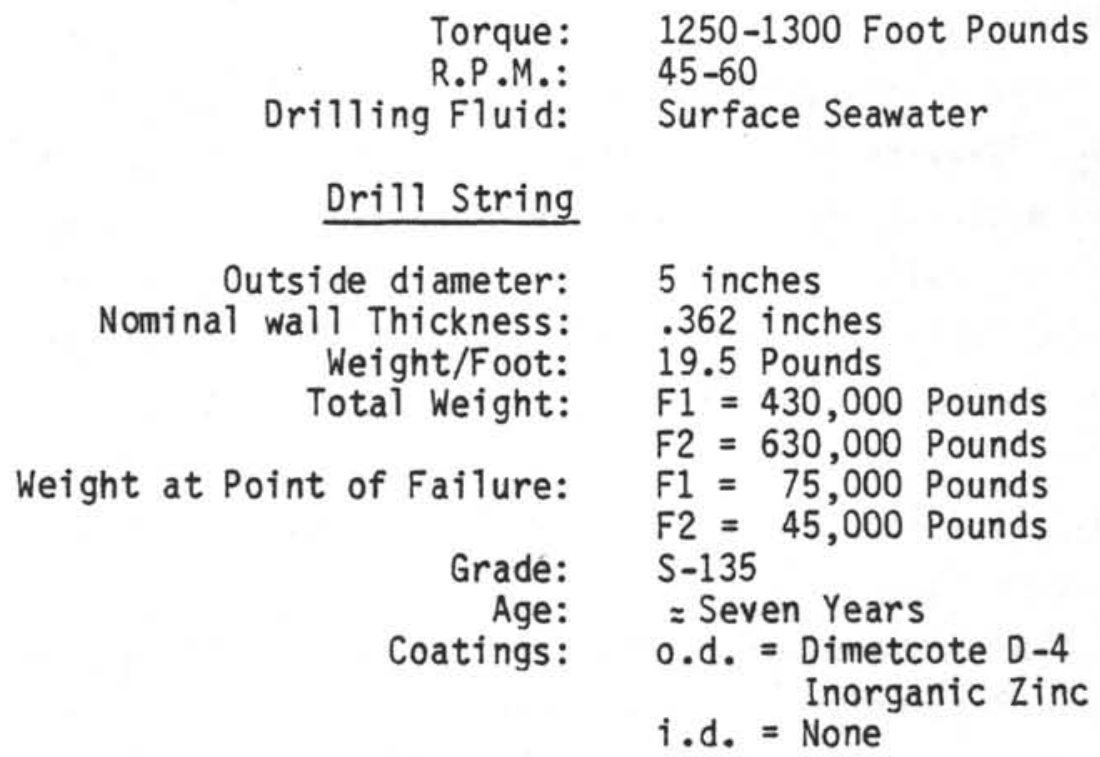

Surface seawater is pumped down the hole as a coolant and drilling fluid. Bentonite mud is used to flush the cuttings between cores.

Bottom samples of seawater returning up the outside of the drill string showed $0.5 \mathrm{ppm}-0.7 \mathrm{ppm} \mathrm{H} \mathrm{H}_{2} \mathrm{~S}$. This suggests $\mathrm{H}_{2} \mathrm{~S}$ concentrations in the formation on the order of less than or equal to $2 \mathrm{ppm}(0.01 \mathrm{psia})$. The $\mathrm{H}_{2} \mathrm{~S}$ would have been in contact only with the outside of the drill string, since surface seawater is pumped in through the inside.

After the second failure, the coring operation was abandoned and the drill string brought back onboard. As the string was being disassembled, water was observed leaking from three more joints of pipe, indicating cracks in these joints. The exact depth and location of these cracked joints was not recorded before the string was disassembled and racked.

\section{Visual Examination}

The two broken joints were labeled F1 (first fracture) and F2 (second fracture). (Figure 2) Both fractures propagated perpendicular to the 
longitudinal axis of the pipe over approximately 25 percent of the circumference of the pipe with no noticeable plastic deformation. The final fracture was in shear on both joints, with the fracture surface running at approximately 45 degrees to the longitudinal axis of the pipe.

Corrosion and mechanical damage had smoothed and obscured much of the surface on both fractures. However, "rachet marks" or radial marks, were still present indicating a series of fracture initiation sites at deep, broad corrosion pits on the inside surfaces (Figures 3 and 4 ). At the bottom of the deepest pit on $\mathrm{F} 1$, the remaining wall thickness was 0.266 in. At the bottom of the deepest pit on F2, the remaining wall thickness was 0.249 in.

The three cracked joints were labelled A, B, and C. The crack in Sample A was detected in two out of three trials during the on board inspection with the internal magnetic flux leakage unit. The cracks in joints $B$ and $C$ could not be detected with the magnetic flux leakage unit. Areas which appeared to be cracked were cut out and sent in for analysis. The three samples are shown in Figure 5.

The through-wall cracks in joints $A$ and $B$ were found with dye penetrant and broken open to expose the fracture surfaces. Figures 6 and 7 show the surface of the crack in joint A. Figures 8 and 9 show the fracture surface from joint B.

Both fractures showed essentially the same features as F1 and F2. The surfaces were heavily encrusted with corrosion products, but ratchet marks indicated a series of fracture initiation sites at the bottom of pits on the inside surface. At the thickest point the wall thickness of joint A was 0.330 inches; at the base of the pit which formed the fracture initiation site the remaining wall thickness was 0.232 inches. On Sample B, the thickest remaining area was also 0.330 inches. At the fracture origin, at the base of the pits, the remaining wall thickness was 0.240 inches.

On Sample C, dye penetrant testing revealed no cracks, even in the area with heavy slip marks. The damaged area was quartered, and each quarter was bent 
on a tensile machine to open up any cracks present. However, no cracks were found. Apparently the cracked part of the joint was not in the section sent in for examination.

\section{Scanning Electron Microscope Fractography}

The fracture surfaces from the four cracked samples were examined with scanning electron microscope. All of the fractures were covered with corrosion products. After cleaning with an alkaline ultrasonic cleaner and replicating tape, the corrosion products were removed. After cleaning the fracture surfaces were relatively flat and featureless. No intergranular facets or fatigue striations were observed during observation at 50 to $5000 x$. From the examination it was determined that the microscopic surface features on these fractures had been obliterated by corrosion. However, SEM examination confirmed that all the fractures initiated along the inside surface of the pipe.

\section{Metal lographic Examination}

Metallographic examination was performed on sections taken through fracture initiation sites on samples F1, F2, A and B. Figures 10 and 11 show the fracture profile at an initiation site from Sample F1. Heavy corrosion damage was observed along the inside edge of the pipe. The fracture profile was relatively straight, transgranular and non-branching. Figures 12 and 13 show the fracture profile from Sample A, which had a through-crack that had not separated. The crack in Sample A was similar to that shown in Figures 11 and 12 in that it initiates in a corrosion pit, propagates transgranularly, is relatively straight and non-branching.

The microstructure of the base metal on all the metallographic samples showed essentially the same features: tempered martensite of medium grain size, with no significant concentrations of anomalies which might have affected crack initiation or propagation. 


\section{Mechanical Properties Tests}

Two specimens were removed from each of the joints of drill pipe for mechanical properties tests. Table 1 presents the results. All the joints met the API $5 A X$ specification with regard to strength. One of the tensile specimens from Sample B could not be analyzed because it broke through an undetected secondary fatigue crack on the inside surface of the pipe.

\section{Chemical Composition}

Each of the pipe joints was analyzed for chemical composition using wet chemistry. Table 2 presents the results. API specification 5AX requires limits only on phosphorous and sulfur, which all the joints met.

\section{$\underline{\text { Discussion }}$}

All the fracture initiation sites on the cracked pipe joints were on the inside surface, the side which had suffered seawater corrosion damage.

The seawater used as drilling fluid is pumped from the surface down the pipe, then up around the pipe 0.D. to dissipate on the sea floor. Consequently the environment at the crack tip would be exclusively aerated seawater. The $\mathrm{H}_{2} \mathrm{~S}$ encountered in the formation would have had no effect on these fractures.

This is borne out by the fracture profiles of all the cracks. The fracture profiles are exclusively transgranular, relatively straight and nonbranching. These characteristics indicate failure by corrosion fatigue. Corrosion fatigue, of course, is the most likely fracture mode for drill pipe because of the cyclic stress environment. By contrast, sulfide stress cracking in high-strength steels is normally intergranular, with considerable crack branching.

The deep, broad pits at the fracture origins had reduced the wall thickness at the points of origin to approximately 64 percent of the original. Consequently, the stresses at these points could be expected to be at least 37 percent higher than on a new piece of pipe. The stress concentration factor 
from the pit geometry would make the effective stresses higher still.

The mechanical properties of the drill pipe met the appropriate API specifications in all respects. Yield strength, tensile strength and ductility were well beyond the specified minimums on all specimens except one from Sample B. This specimen had several service related secondary fatigue cracks which went undetected during the machining of the tensile specimen. On loading in the tensile test machine these cracks caused failure at uncharacteristically low load and elongation. However, these secondary cracks, which were not more than 0.07 inch deep, added another confirmation that the failure was due to corrosion fatigue starting on the inside surface of the pipe.

Chemistry requirements in API specification 5AX are largely left to the manufacturer's discretion with the exception of phosphorous and sulfur. On all specimens tested, these elements were well below the specification maximums. The carbon, chromium, nickel and molybdenum contents of these specimens indicate that this drill pipe was made of Carbon-manganese- 0.5 molybdenum steel.

Relatively little corrosion took place on the outside surfaces of the drill pipe. The outside surfaces had been coated with Dimetcote $D-4$ inorganic zinc coating. The zinc-rich coating provides cathodic protection to the steel during immersion or storage, preventing the corrosion damage that terminated the life of the fractured samples. In 1974, when this pipe was purchased, the technology for applying inorganic zinc coatings to the inside of smalldiameter pipe was not well developed. The replacement load of drill pipe has been zinc-coated both inside and out, which should effectively eliminate the corrosion pitting that caused these failures.

The deep pitting and general corrosion on these drill pipe joints accumulated over several years. Although all the drill pipe on the Challenger was inspected four months prior to the failure, these pitted and corroded joints were not rejected. At dockside, the 3 -inch long through-wall crack in Sample A was detected twice in three trials with the magnetic flux leakage unit. The through-wall cracks in Samples $B$ and $C$ were not detected during the dockside 
examination, nor were any of the numerous secondary cracks in Sample B found with the magnetic flux leakage unit.

Magnetic flux leakage inspection has inherent limitations in that it cannot measure remaining wall thickness. In addition, the internal inspection unit used on the Challenger generates a relatively small magnetic field compared to the external inspection units in more general commercial use. Consequently the resolution can be expected to be lower. Accurate, quantitative inspection data are crucial for making timely retirement decisions. Consequently an upgraded inspection system would definitely be a benefit.

The requirements for an inspection system for this particular application are as follows:

1. ability to inspect the pipe on board ship, in the racked, horizontal position

2. ability to quantify remaining wall thickness

3. ability to detect corrosion pitting and quantify pit depth

4. ability to locate corrosion fatigue cracks in their early stages.

Requirement one, on-board inspection, effectively prevents the use of any external inspection system since the close spacing of the pipe racks on the Challenger and the rubber drilling collars limit access to the outside surface of the pipe. However, no single internal inspection system can fulfill requirements 2,3 and 4 . Mechanical caliper surveys probably come closest in that wall thickness and pit depth can be obtained. However, mechanical calipers cannot detect corrosion fatigue cracks. An ultrasonic inspection system could be designed with a ring of multiple transducers for both anglebeam crack detection and straight-beam wall thickness measurement. However, such systems would have to be custom-built since they are not commercially available. A compromise may be necessary, using an on-board mechanical caliper survey and yearly or bi-annual dockside inspection with an external magnetic flux leakage system. 
Conclusions

1. Failure of the drill string on Leg 83 was due to corrosion fatigue.

2. The fatigue cracks initiated at deep, broad corrosion pits on the inside surface of the pipe.

3. The $\mathrm{H}_{2} \mathrm{~S}$ encountered in the formation had no effect on these failures.

4. The mechanical properties of the drill pipe met API specification 5AX.

5. The chemical composition of the drill pipe met API specification 5AX.

6. The root cause of these fractures was the failure of the internal inspection system to detect the advanced corrosion damage on the inside surface of the drill pipe.

7. The inorganic zinc coating on the exterior of the drill pipe was effective in preventing corrosion and consequently should extend the useful service life of pipe internally coated with inorganic zinc. 
TABLE 1

MECHANICAL PROPERTIES OF CRACKED DRILL PIPE

(AVERAGE OF TWO SPECIMENS)

\begin{tabular}{cccc}
\hline \hline Sample & $\begin{array}{c}\text { Yield } \\
\text { Strength, ksi }\end{array}$ & $\begin{array}{c}\text { U1timate } \\
\text { Tensile } \\
\text { Strength, ksi }\end{array}$ & $\begin{array}{c}\text { Percent } \\
\text { Elongation }\end{array}$ \\
\hline \hline F1 & 144.1 & 157.7 & 15.5 \\
F2 & 147.8 & 149.7 & 18.0 \\
A & 151.8 & 163.0 & 14.5 \\
B* & 154.4 & 164.1 & 15.0 \\
C & 145.6 & 158.2 & 15.0 \\
API & & & $9.5-$ \\
SAX & $135-165$ & 145 min & $10.5+$ \\
& & & \\
\hline \hline
\end{tabular}

* Value From One Specimen. The second specimen broke at a secondary fatigue crack.

+ Specified minimum percent elongation is calculated from the specimen crosssectional area using the formula:

$$
e_{1} \min =625.000 \frac{A^{0.2}}{U^{0.9}}
$$

where A - specimen area, $i n^{2}$ and $u=$ specified minimum UTS, psi. 
TABLE 2

CHEMICAL COMPOSITION OF FAILED DRILL PIPE

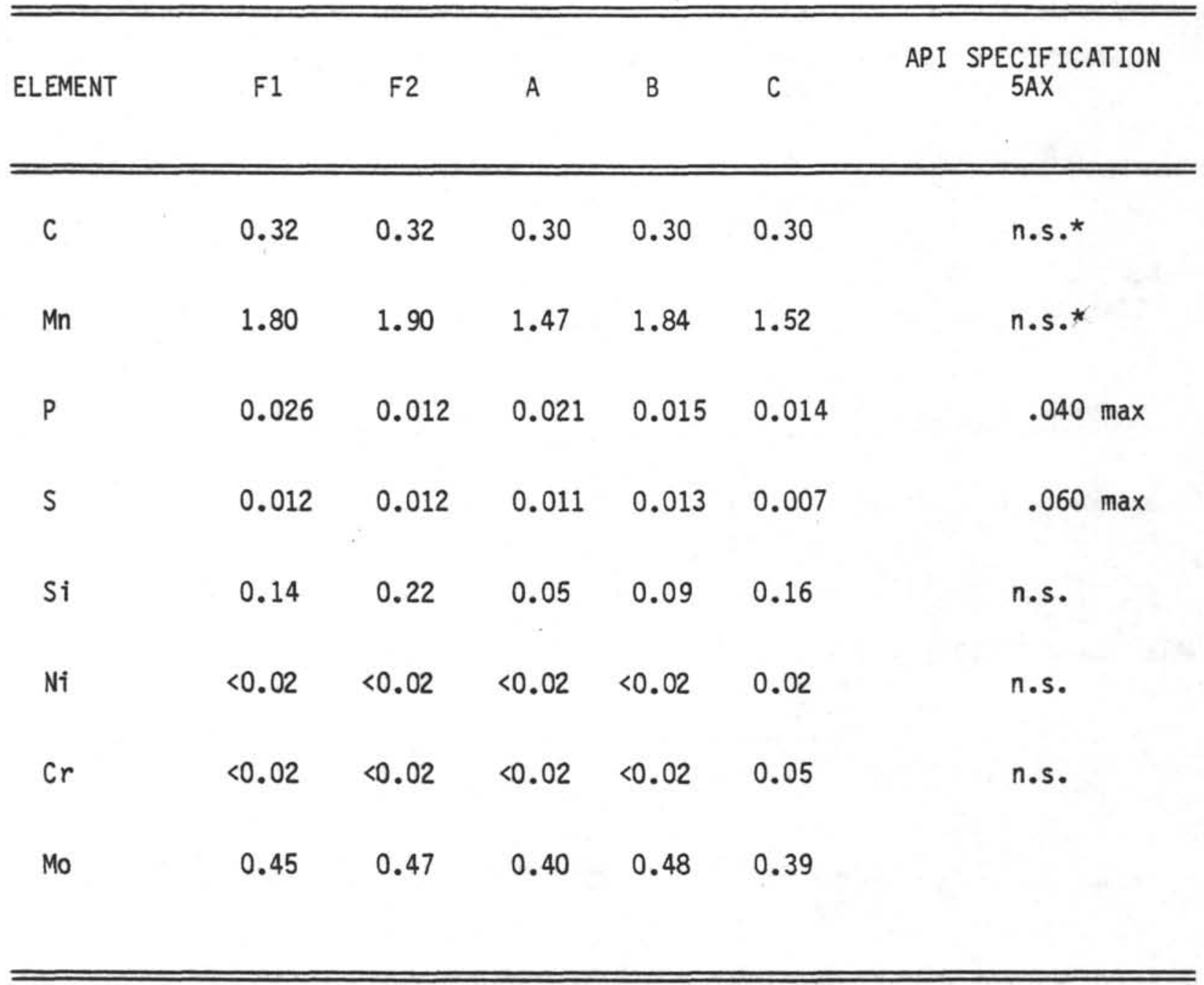

n.s. - not specified 


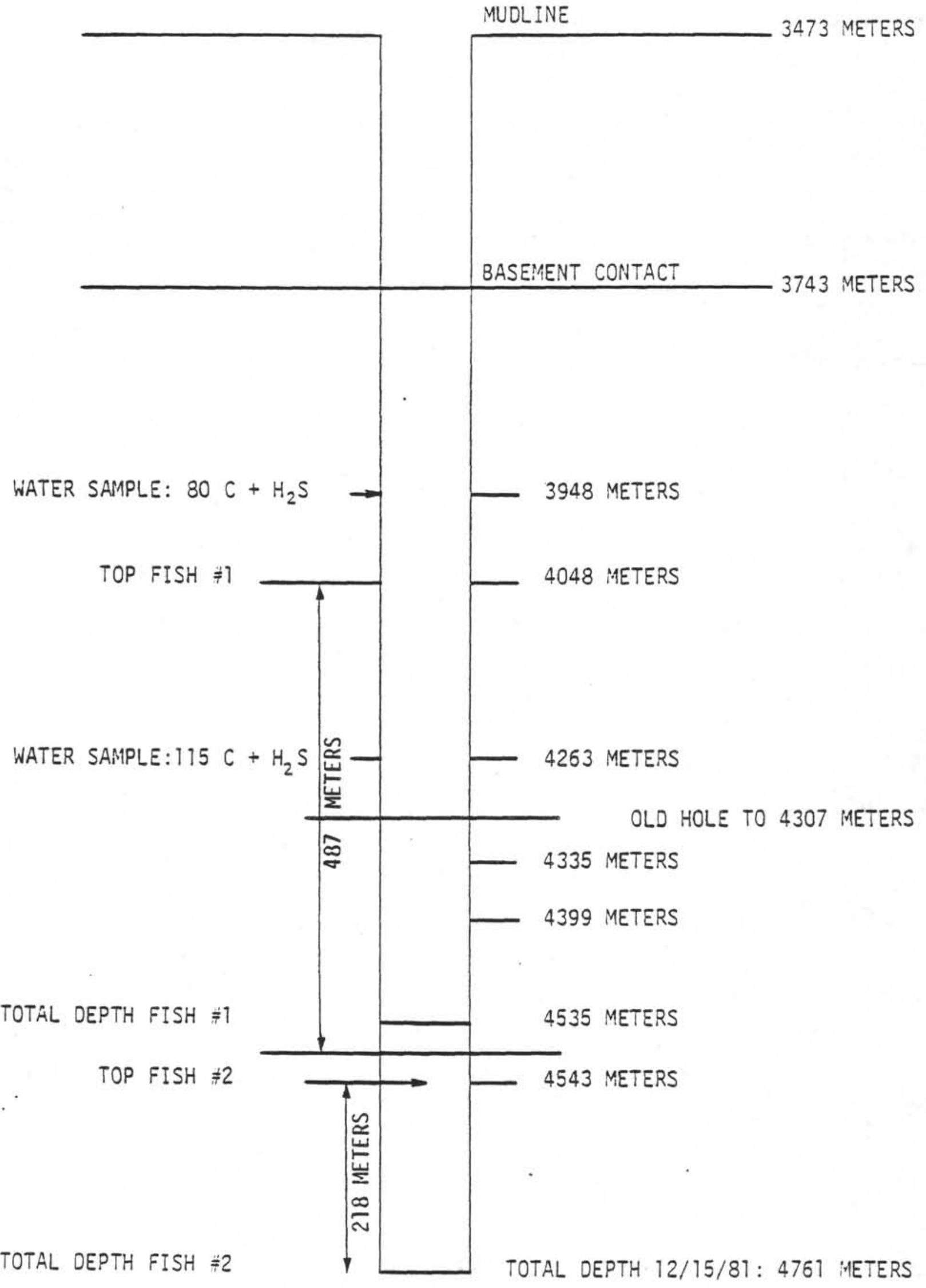

FIGURE 1. Schematic of DSDP Hole $504 B$. 


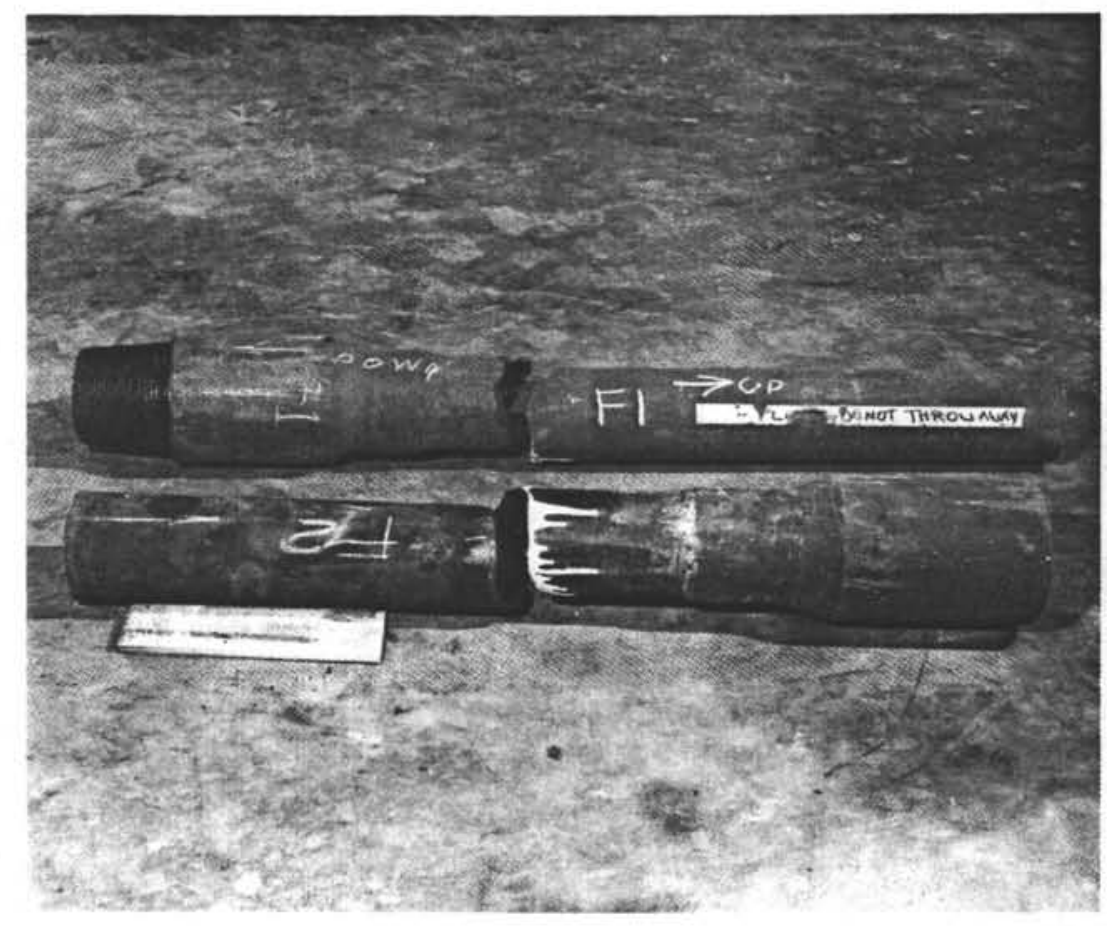

BH:O 1444-1

FIGURE 2. FRACTURED PIECES OF DRILL PIPE. (NOTE: WHITE SUBSTANCE ON F-2 BOX END FRACTURE IS SILICONE RUBBER FOR PROTECTING THE FRACTURE SURFACE) 


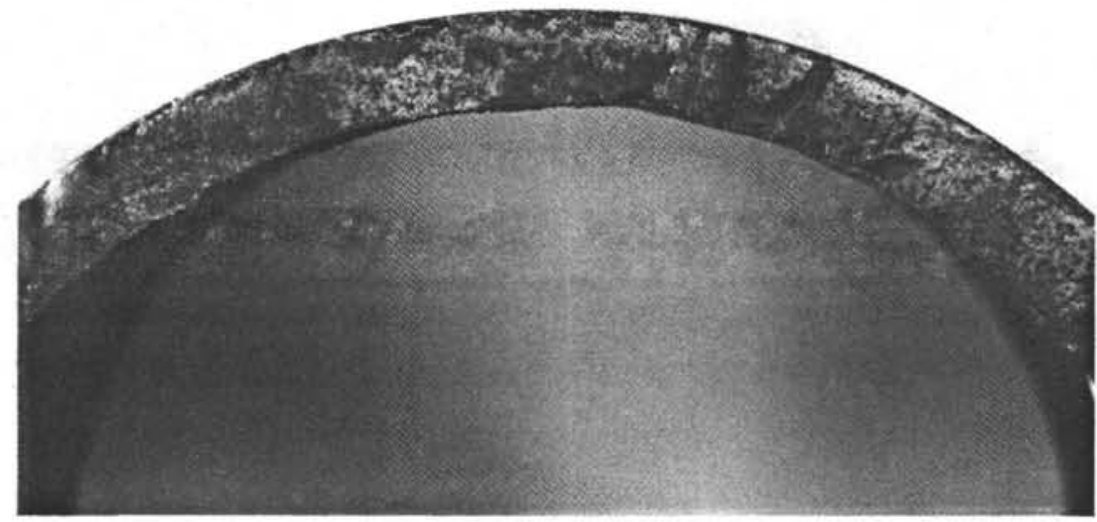

BHO 1422

FIGURE 3. FRACTURE SURFACE OF $F 1$.

$\approx 1 \times$

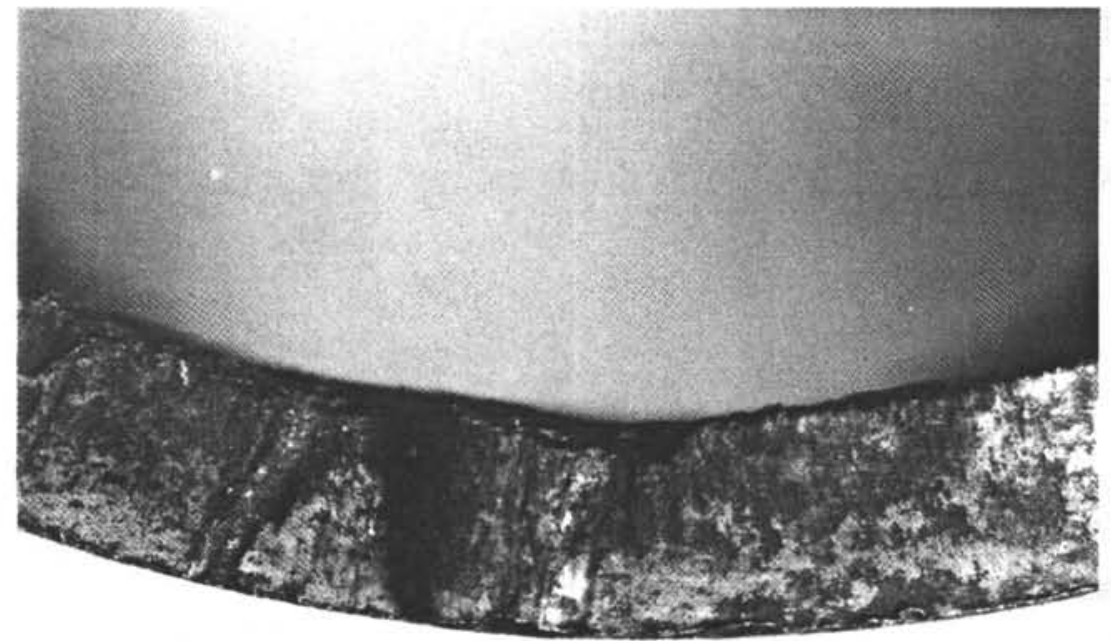

BHO 1421

FIGURE 3A. CLOSE-UP OF FRACTURE FROM F 1. RATCHET MARKS INDICATE ORIGINS ON I.D. SURFACE.

$\approx 3 \mathrm{x}$ 


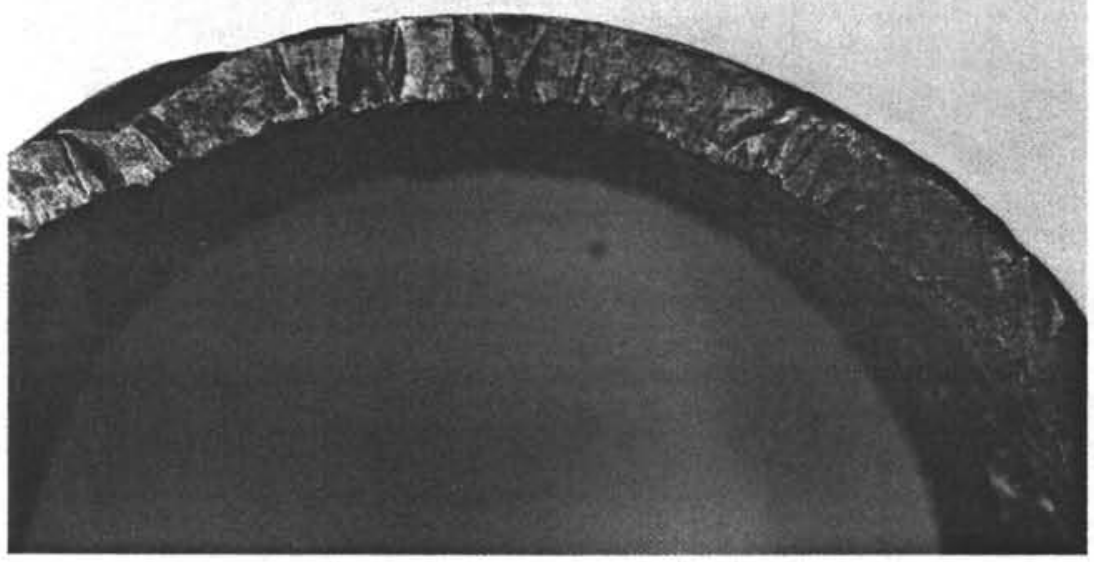

BHO 1424

FIGURE 4. FRACTURE SURFACE OF F2. $\approx 1 x$

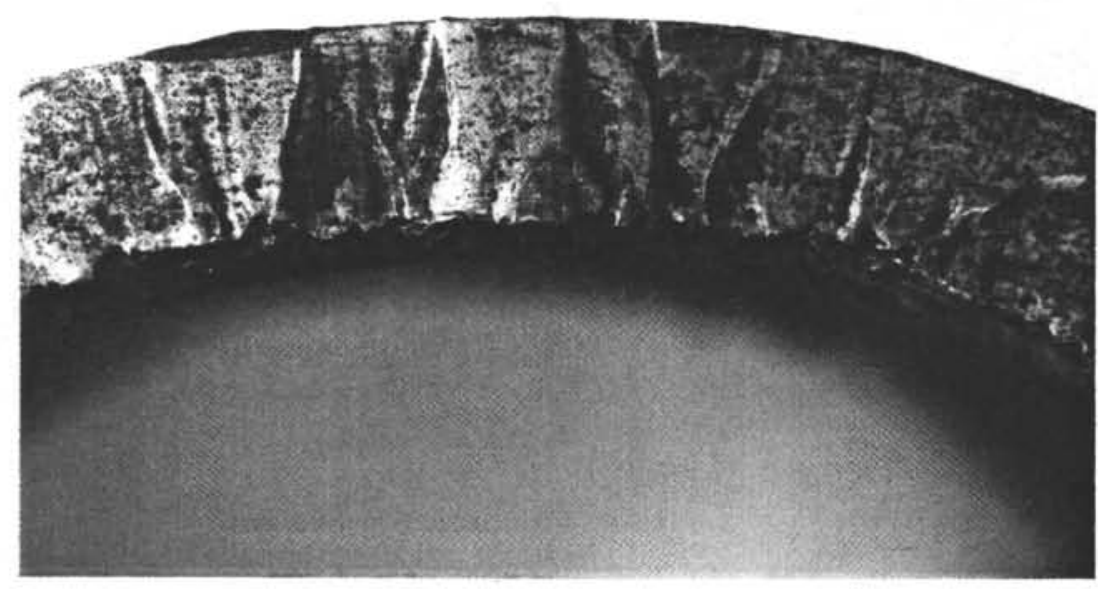

BHO 1423

FIGURE 4A. CLOSE-UP OF FRACTURE FROM F2. RATCHET MARKS. INDICATE ORIGINS AT PITS ON I.D. SURFACE. $\approx 3 x$ 


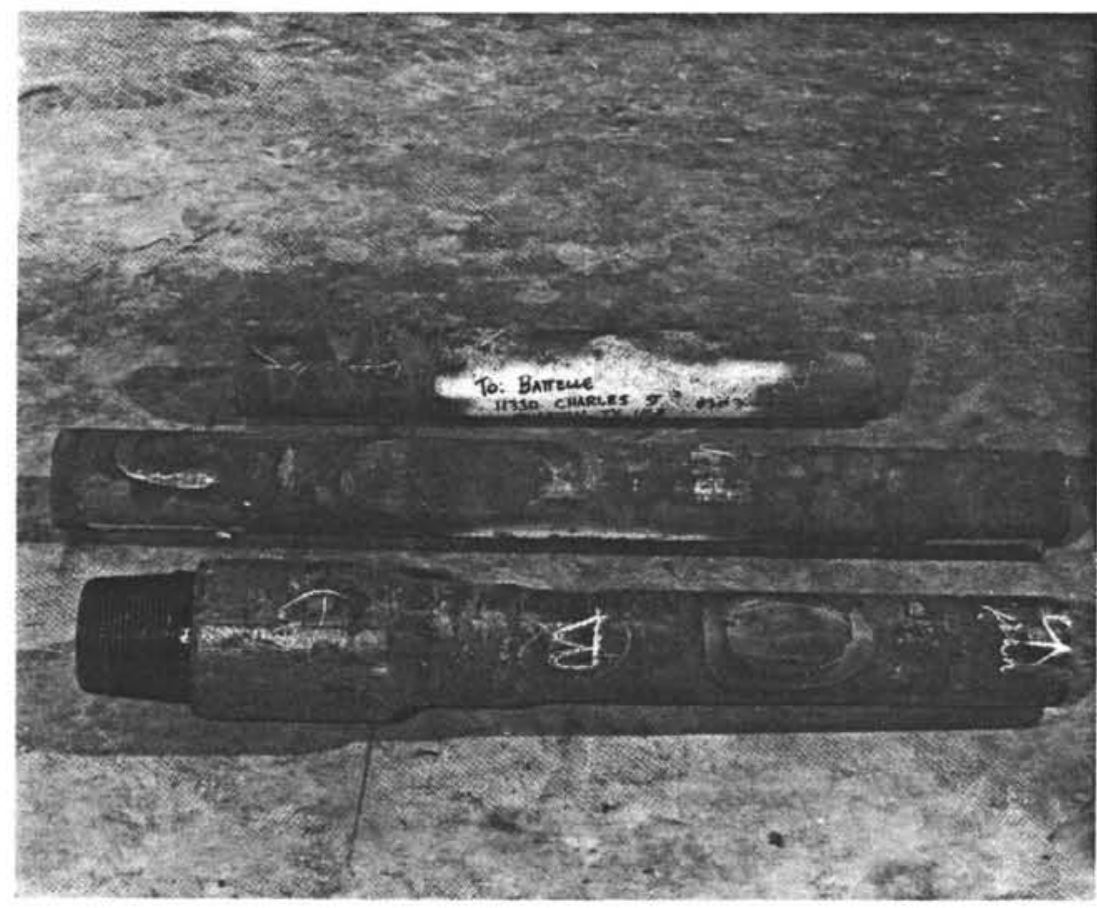

BHO 1444-5

FIGURE 5. CRACKED PIPE JOINTS. 


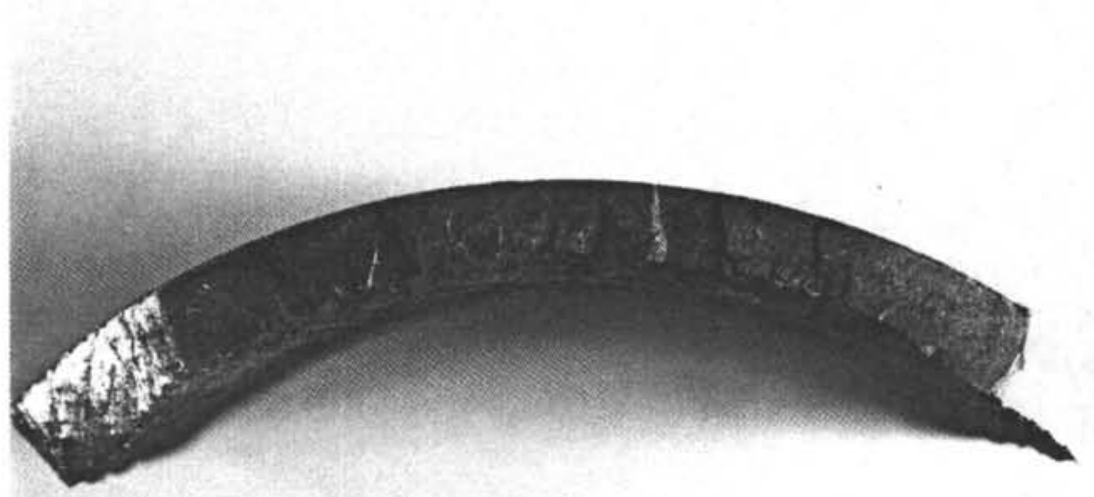

BHO 1436

FIGURE 6. FRACTURE SURFACE OF CRACK EXPOSED IN SAMPLE A. $1 \mathrm{x}$

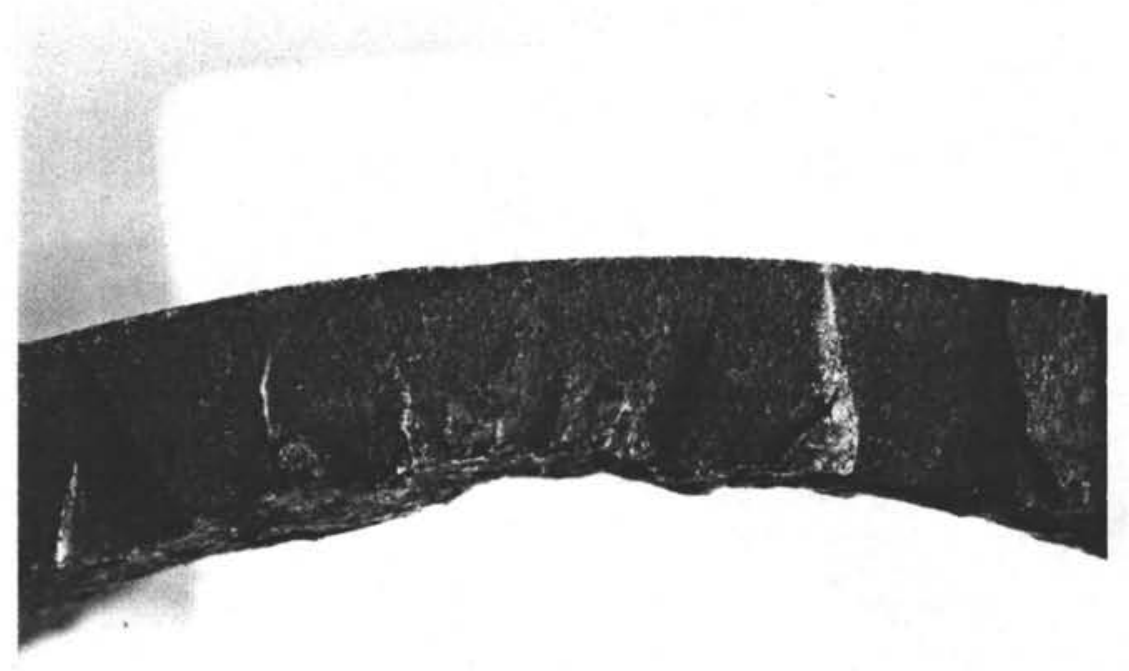

BHO 1435

FIGURE 7. CLOSE-UP OF FRACTURE SURFACE FROM SAMPLE A. $3.8 x$ 


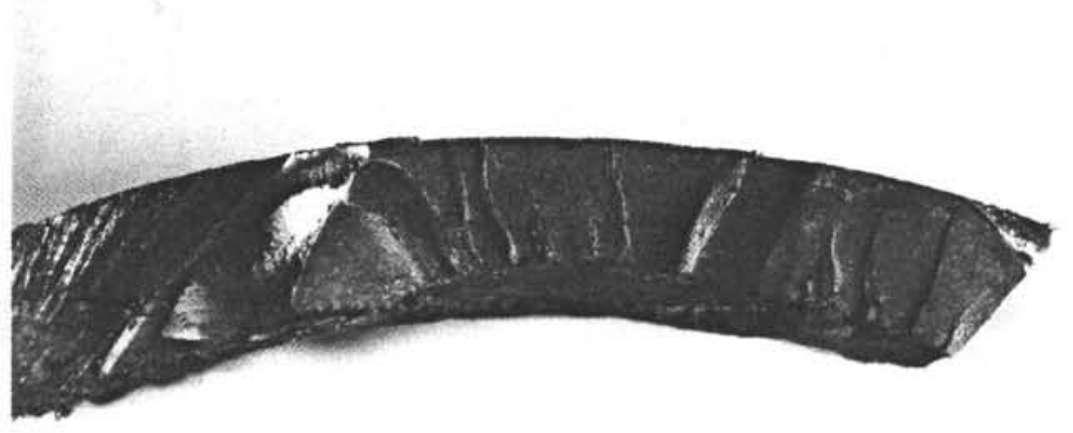

BHO 1437

FIGURE 8. FRACTURE SURFACE EXPOSED IN SAMPLE $B$. $2.2 \mathrm{x}$

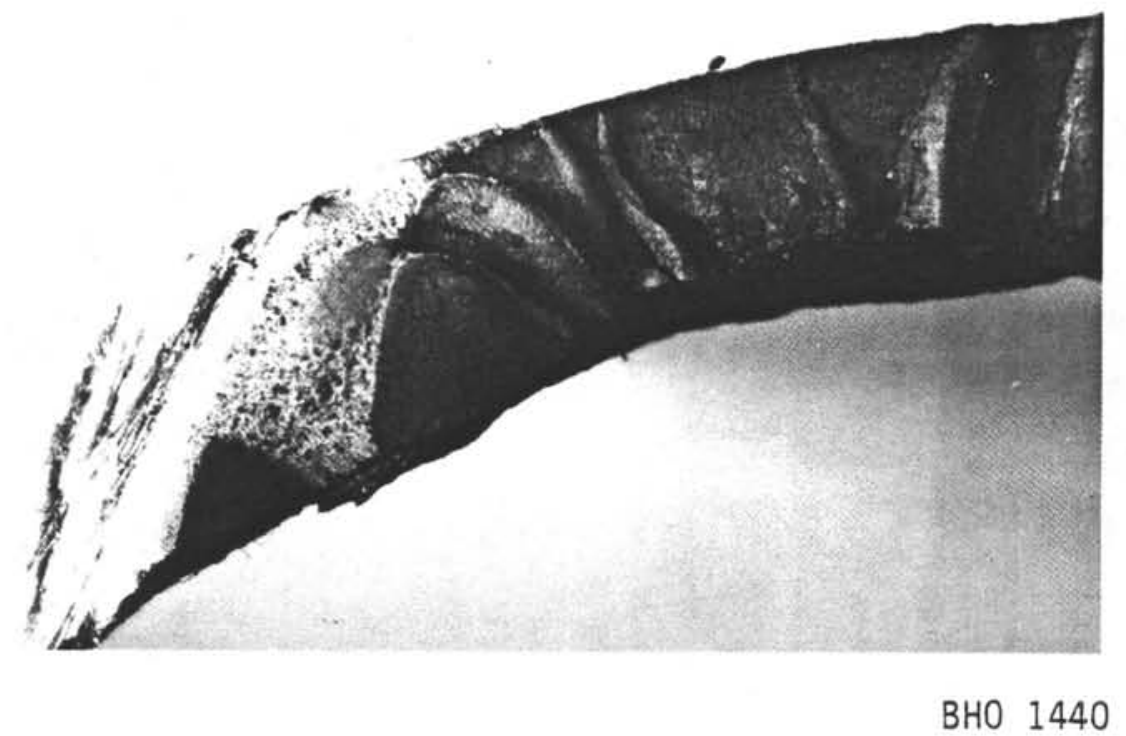

FIGURE 9. CLOSE-UP OF FRACTURE SURFACE FROM SAMPLE B. 3. $3 x$ 


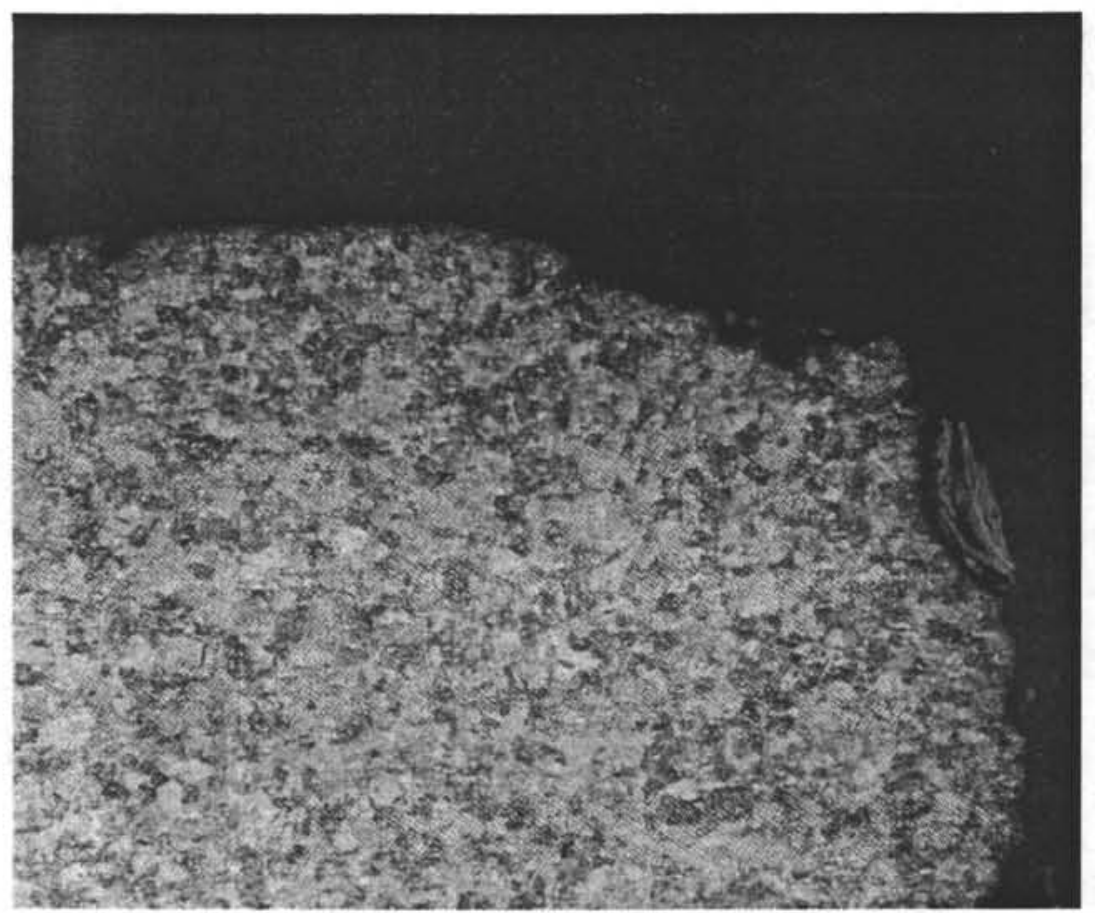

BHO 1453

FIGURE 10. PHOTOMICROGRAPH FROM A SECTION THROUGH A FRACTURE ORIGIN ON SAMPLE $F 1$.

$62.5 x$, NITAL ETCH

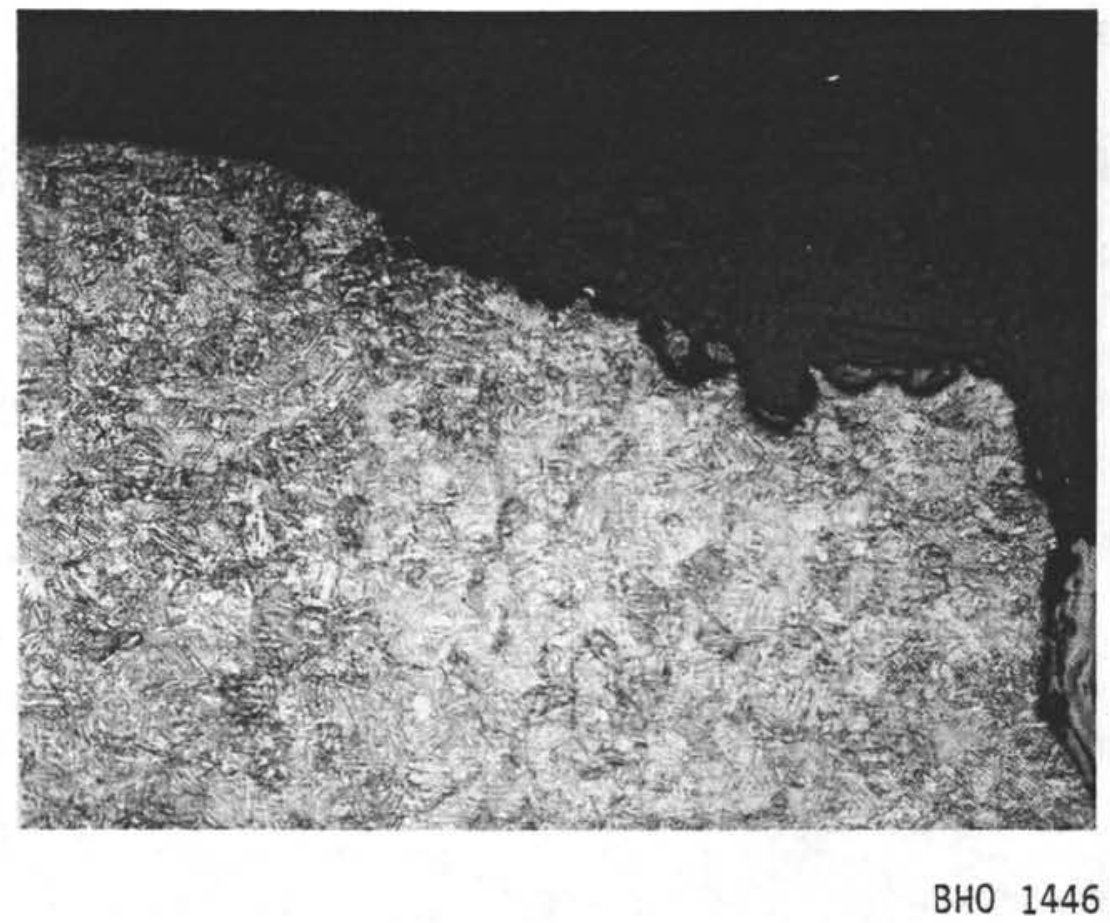

FIGURE 11. HIGHER-MAGNIFICATION PHOTOMICROGRAPH OF ORIGIN. IN FIGURE 10.

$125 x$ 


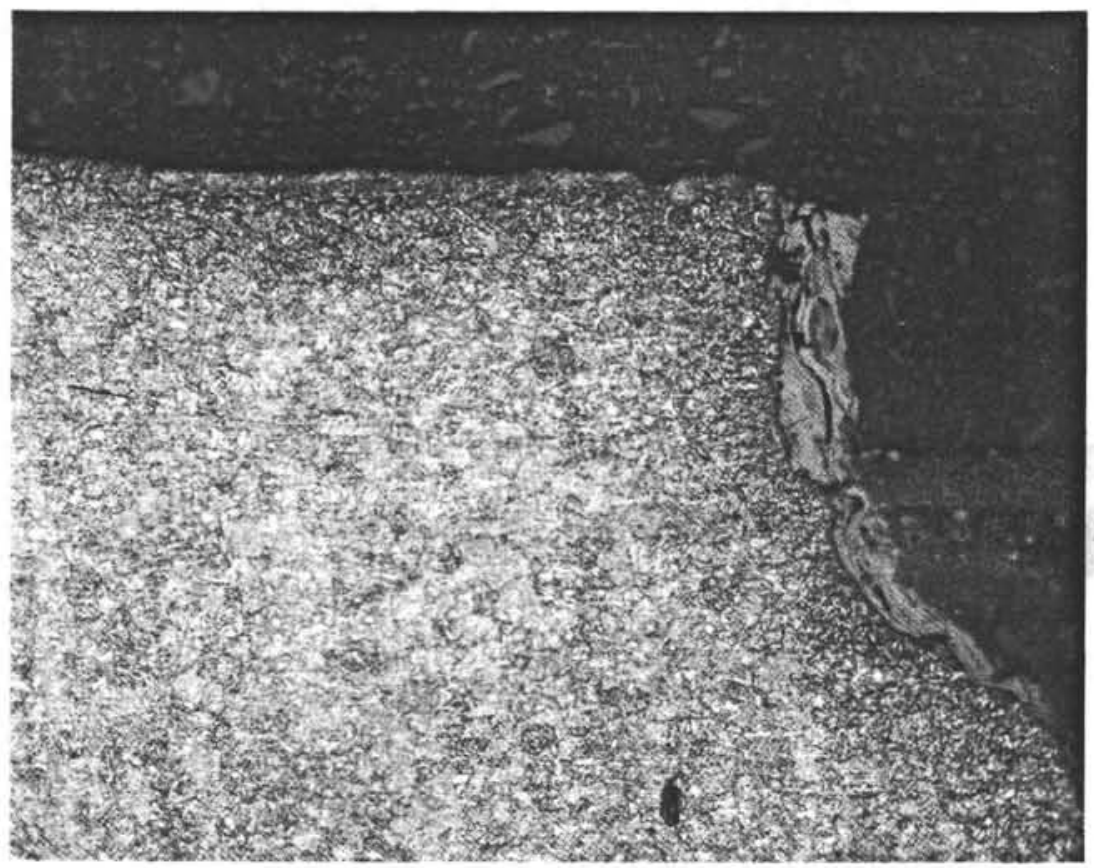

BHO 1451

FIGURE 12. PHOTOMICROGRAPH FROM A SECTION THROUGH A FRACTURE ORIGIN ON SAMPLE A. FRACTURE PROFILE IS AT TOP. -

125x, NITAL ETCH

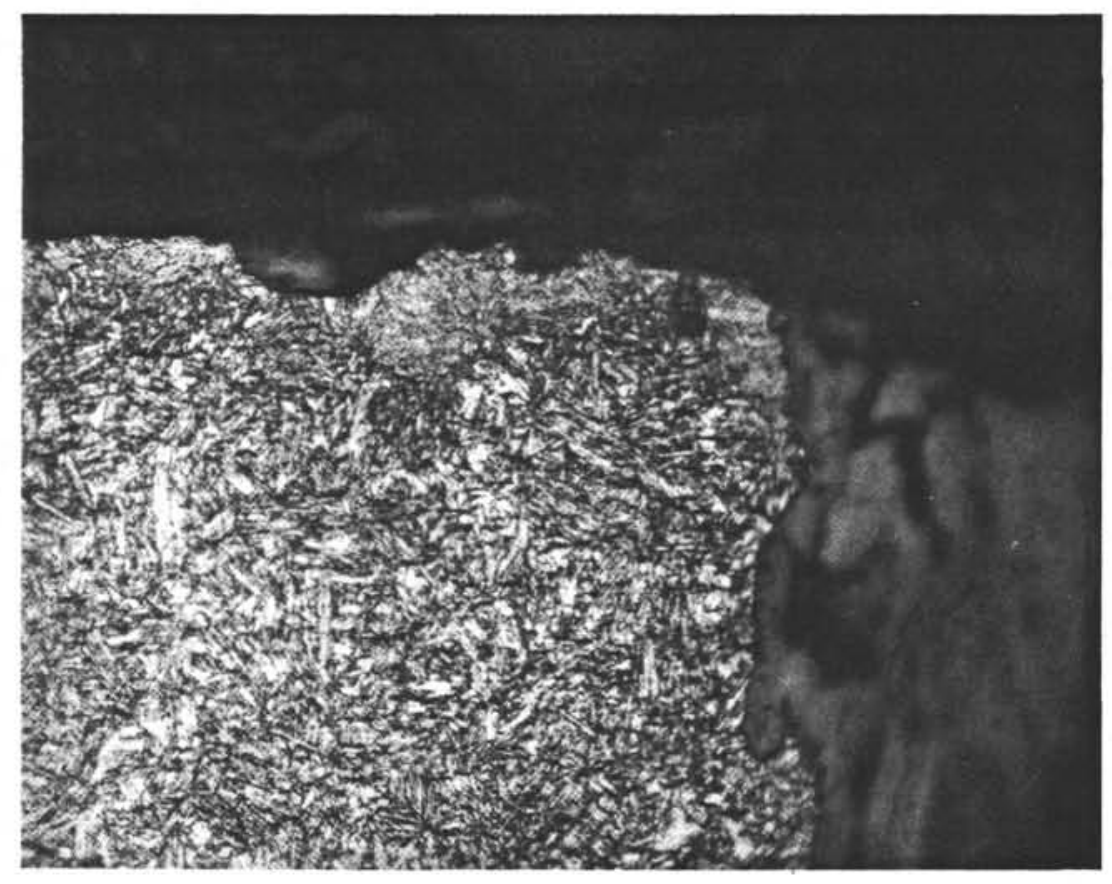

BHO 1452

FIGURE 13. HIGHER MAGNIFICATION PHOTOMICROGRAPH OF ORIGIN IN FIGURE 12.

$500 x$, NITAL ETCH 
APPENDIX B-4

FINAL REPORT

FAILURE OF DRILL STRING

DSDP LEG 84 
April 26, 1982

Houston Operations 2223 West Loop South Suite 320

Houston, Texas 77027

Telephone (713) $877-8034$

Re: Failure of Drill String, DSDP Leg 84 Contract No. G 12696-3058 Enclosed are five copies of Battelle's report on the failure of the drill string, DSDP Leg 84 . This report constitutes fulfillment of the April 30, 1982 , reporting requirement of Contract G 12696-3058.

FINAL REPORT

FAILURE OF DRILL STRING; NSDP LEG 84

\section{SUMMARY}

Excessive strength and hardness led to hydrogen embrittlement cracking of the failed joint of a 5-inch 0.D., $19.5 \mathrm{lb} / \mathrm{ft} \mathrm{S}-135 \mathrm{drill}$ pipe (DSDP identification number DP-568-7-2-82). Crack initiation was accelerated by the presence of a 1.5 inch by 0.045 inch deep lap, a rolled-in mill defect. The hydrogen which caused the embrittlement was generated by corrosion of the pipe's sacrificial zinc coating in sea water. Any remaining joints from this order of pipe should be hardness tested. Joints with hardness exceeding $R_{c} 38$ should not be used. 
BACKGROUND

On February 7, 1982, during logging operations at DSDP 567A, the drill string parted in the 18th joint below the rig floor. The failed joint was 5 -inch 0.D., $19.5 \mathrm{lb} / \mathrm{ft}$ S-135 pipe which had been internally and externally coated with inorganic zinc. The failed piece was one of 667 30-ft joints of S-135 drill pipe made by Jones and Laughl in's Youngstown mill in two different lots in June and September of 1977 for DSDP. Jones and Laughl in heat numbers for this order were 26638, 24132, 27846, 25995 (June 1977) and 32549, 27168, 27170 (September, 1977). The failed joint was loaded on the GLOMAR CHALLENGER on November 3, 1979 at Balboa, Panama. It remained in the 'tween-decks hold of the drill ship until January $16 \mathrm{th}, 1982$. The joint had spent about $81 / 2$ days deployed in the drill string with approximately 67 total rotating hours. Weather conditions assured bending stresses had been at a minimum. String weight at the failure was estimated to be 370,000 pounds which equates to a tensile stress level of approximately-70,100 psi. This value is only 52 percent of the API specified minimum yield strength (SMYS) of 135,000 psi.

A four foot section of the failed pipe joint, see Figure 1, was received at the Battelle laboratories at the end of March.

\section{VISUAL EXAMINATION}

Visual examination revealed a flat, brittle fracture which originated at a lap and propagated approximately 90 degrees around the pipe circumference. The fracture mode then changed to shear overload, evidenced by a 45 degree orientation fracture face, (Figure 2-4).

\section{Mechanical and Chemical Properties}

A section of the failed pipe joint was used to determine the mechanical and chemical properties, see Tables 1 and 2 . The yield strength was found to be higher than allowed in API Specification 5AX. Microhardness readings, which were taken across a mounted specimen, ranged in value from knoop hardness 100 $\mathrm{kg}$ number 386 to 477 , see Figure 5. These numbers roughly correspond to Rockwell hardness numbers in the $R_{C} 40-45$ range. The mechanical properties 
obtained by Battelle indicate higher strength levels than the reported mill values, see Table 1 .

Chemical properties are given in Table 2. The composition of this pipe joint meets that required in API specification $5 \mathrm{AX}$.

\section{SEM Fractography}

The fracture origin was examined in the scanning electron microscope (SEM). Region 2 (Figure 6 ) shows the origin at $11 \mathrm{X}$; the chevron marks pointing towards the point of fracture initiation are clearly evident. Higher magnification of this region reveals intergranular fracture, Figure 7 . The flat, brittle part of the fracture was exclusively intergranular cracking, with no evidence of fatigue striations. In the shear lip, the fracture mode switched to dimpled rupture.

\section{Optical Metallography}

The fracture was next sectioned and mounted to closely examine cross-sections of the origin and lap. Etching revealed the material microstructure was quenched and tempered martensite, as is expected for quenched and tempered S-135 pipe. The cross section through the origin (Section A-A) confirmed that the fracture mode was intergranular, Figure 8. Deformation was seen in grains near the surface, see Figure 9. This deformation was most likely caused after the failure. There was no evidence of high-temperature oxide on the fracture surface or in the crack branches.

The lap (Section B-B) was found to be filled with oxide. The region directly adjacent to the lap surface was decarburized (See figure 10). These fractures indicate the lap was formed during the rolling process in the mill.

\section{$\underline{\text { DISCUSSION }}$}

The drill pipe failure shows all the elements of hydrogen embrittlementcracking. Hydrogen embrittlement cracking is a form of stress corrosion cracking in which corrosion-generated hydrogen diffuses into the steel and 
causes embrittlement, resulting in cracking at stresses well below the tensile yield strength.

The high strength and hardness of this joint of drill pipe rendered it particularly susceptible to hydrogen embrittlement-cracking. High strength low alloy steels become increasingly sensitive to hydrogen embrittlementcracking as the strength is increased. Practically speaking such failures are rarely observed in sea water if the ultimate tensile strength of the material is less than about $180 \mathrm{ksi}$. This is one reason for the $165 \mathrm{ksi}$ maximum yield strength requirement in API specification $5 \mathrm{AX}$.

The lap in the surface was apparently introduced during the tube rolling operation, since there was a thin decarburized zone on its faces. This is typical of mill defects which occur during hot-rolling. The lap served as a stress raiser causing locally high stresses. API $5 A X$ specification allows imperfections such as this lap as long as they do not exceed 12.5 percent of the nominal wall thickness, which in this case would be 0.045 inch in depth. The deepest measured depth of the lap was $0.045 \mathrm{in}$. Therefore, this lap was rejectable according to API $5 A X$.

The source of the hydrogen was the corrosion of the sacrificial zinc coating on the pipe. As the zinc corrodes, hydrogen is evolved at the cathode, which in this case would be any exposed steel. Zinc-rich coatings are a standard corrosion prevention method in sea water and marine atmospheres; earlier strings of zinc coated S-135 (with lower hardness levels) gave up to seven years' service on the DSDP before failing by corrosion pitting on the uncoated inside of the pipe. However, in addition to the corrosion protection, zinc coating also greatly increases the amount of hydrogen being absorbed into the steel. If the pipe's hardness and strength are excessive, thus making it susceptible to hydrogen embrittlement-cracking, a zinc coating will cause rapid and catastrophic cracking, see Figure 11.1,2,3

Since other pipe joints from this same order may have the same high stregnth, all joints from this order are suspect. Any joints left from this order should not be used unless their strength has been tested and confirmed to fall 
within the API specification range. Direct strength evaluations, however, require destructive testing.

It is more practical to estimate the strength of drill pipe in the field by hardness testing. Hardness correlates well with ultimate tensile strength, and the ultimate tensile strength can be used to predict the yield strength. Analysis of mechanical properties data from fifty samples of S-135 drill pipe indicates that the yield strength averages 92 percent of the ultimate tensile strength, with a range of from 86 to 94 percent. This would indicate that, at the upper yield strength limit of $165 \mathrm{ksi}$, ultimate tensile strengths of from 175 to 191 ksi can be expected. High-strength low alloy steels with ultimate tensile strengths of $175 \mathrm{ksi}$ will have hardnesses of approximately $R_{C} 38.5$. Therefore, any pipe joints with hardness in excess of $R_{c} 38$ should be rejected.

\section{CONCLUSIONS}

1) The strength of the failed drill pipe exceeded the API 5AX specification, making it unusually susceptible to hydrogen embrittlement

2) The fracture initiated at a lap, a rolled-in mill defect which was rejectable by the API 5AX specification. The presence of the lap caused locally high stresses and therefore accelerated crack initiation

3) The fracture mode was intergranular, indicating failure by hydrogen embrittlement

4) The hydrogen which caused the cracking came from corrosion of the sacrificial zinc-rich coating on the pipe. However, the zinc-rich coating should be safe to use if the strength of the pipe is kept within specification

5) Any remaining pieces of drill pipe from this order should be tested for hardness. Any pieces whose hardness exceeds $R_{c} 38$ should be discarded to prevent a recurrence of this kind of failure. 
Deep Sea Drilling Project

April 26, 1982

If you have any questions concerning this report, please contact us at (713) 877-8034. It was a pleasure working with DSDP again; thank you for contacting Battelle.

Very truly yours,

Beverly guttimberg

Beverlee G. Steinberg

Research Scientist

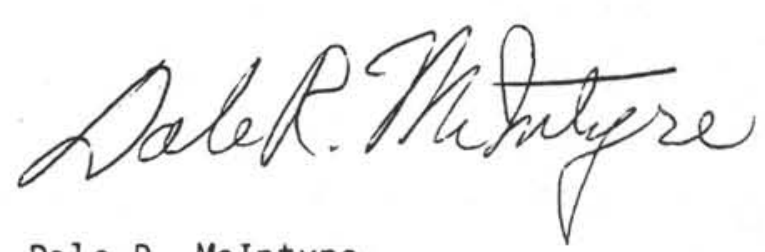

Dale R. McIntyre Principal Research Scientist

112 
References
1. "Effects of Zinc Coatings on the Stress Corrosion Cracking and
Hydrogen Embrittlement of Low-Alloy Steel," H. E. Townsend, Met.
Trans A, vol 6A, 877-833, Apr 1975.

2. "A New Model of Hydrogen-Assisted Cracking in High Strength Steels" C. D. Beachem, Met Trans A, vol 3A, Feb 1972, 437-451.

3. "Stress Corrosion Cracking of High Strength Steels," B. F. Brown, The Theory of Stress Corrosion Cracking in Alloys, edited by J. C. Scully, North Atlantic Treaty Organization Scientific Affairs Division, Brussels 1971, pp 186-204. 
TABLE 1. MECHANICAL PROPERTIES OF FAILED JOINT

\begin{tabular}{|c|c|c|c|c|}
\hline \multicolumn{2}{|c|}{$\begin{array}{c}\text { Yield Strength } \\
0.7 \% \text { of fset } \\
\text { (ksi) }\end{array}$} & $\begin{array}{l}\text { Tensile } \\
\text { Strength }\end{array}$ & $\begin{array}{l}\text { Percent } \\
\text { Elongation }\end{array}$ & $\begin{array}{l}\text { Hardness } \\
\text { (Knoop) }\end{array}$ \\
\hline Failed Sample & 170.8 & 186.3 & 16.0 & $386-477$ \\
\hline API Spec $5 A X$ & $135.0-165.0$ & $145.0 \mathrm{~min}$ & $12.5 \mathrm{~min}$ & \\
\hline $\begin{array}{l}\text { Jones-Laughl in } \\
\text { Mill Reports }\end{array}$ & $151.4-162.8$ & $166.4-177.7$ & $17-25$ & \\
\hline
\end{tabular}


TABLE 2. CHEMICAL PROPERTIES

\begin{tabular}{|c|c|c|c|c|c|c|c|c|c|c|}
\hline & C & $\mathrm{Mn}$ & $P$ & $S$ & Si & $\mathrm{Cr}$ & Mo & $\mathrm{Ni}$ & AR & V \\
\hline $\begin{array}{l}\text { Failed } \\
\text { Sample }\end{array}$ & 0.27 & 1.42 & 0.011 & 0.015 & 0.21 & 0.02 & 0.58 & $<0.02$ & & \\
\hline $\begin{array}{l}\text { API Spec. } \\
5 A X\end{array}$ & & & $0.04 *$ & $0.06 *$ & & & & & & \\
\hline $\begin{array}{l}\text { Jones } \\
\text { E-Laughl in } \\
\text { Mill Report }\end{array}$ & $\begin{array}{l}0.25- \\
0.27\end{array}$ & $\begin{array}{l}1.48- \\
1.57\end{array}$ & $\begin{array}{l}0.009- \\
0.018\end{array}$ & $\begin{array}{l}0.02- \\
0.026\end{array}$ & $\begin{array}{l}0.25- \\
0.27\end{array}$ & $\begin{array}{l}0.06- \\
0.08\end{array}$ & $\begin{array}{l}0.51- \\
0.61\end{array}$ & & $\begin{array}{l}0.046- \\
0.065\end{array}$ & $\begin{array}{l}0.038- \\
0.041\end{array}$ \\
\hline & & & & & - & & & & & \\
\hline
\end{tabular}

*maximum 


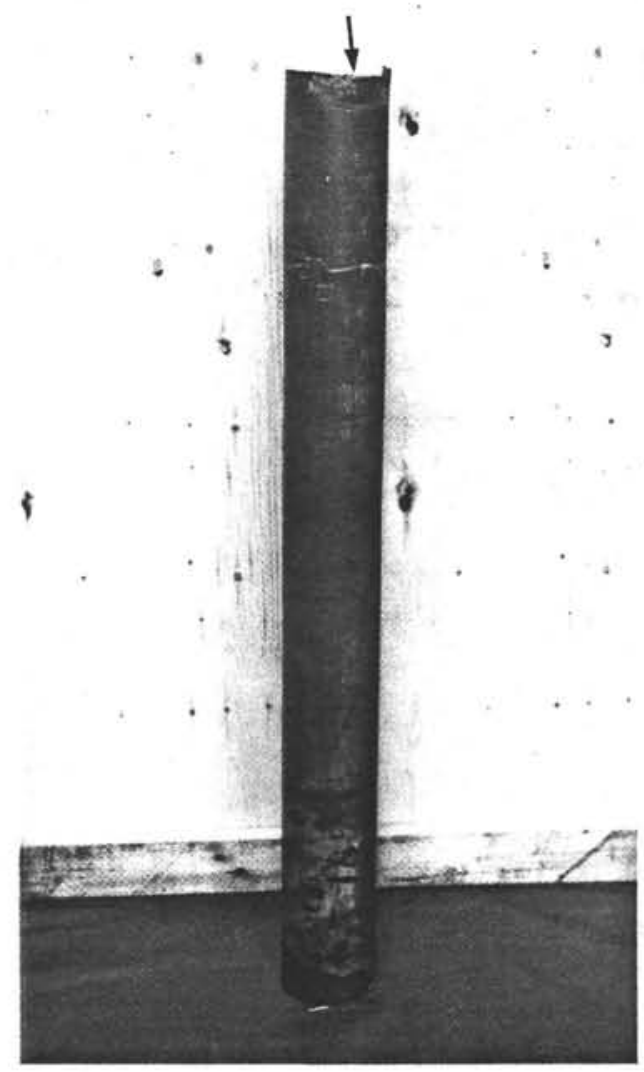

BHO 1470

FIGURE 1. AS RECEIVED PHOTOGRAPH OF FAILED JOINT. THE ARROW POINTS TO THE FRACTURE ORIGIN AND THE ROLLED IN LAP. 


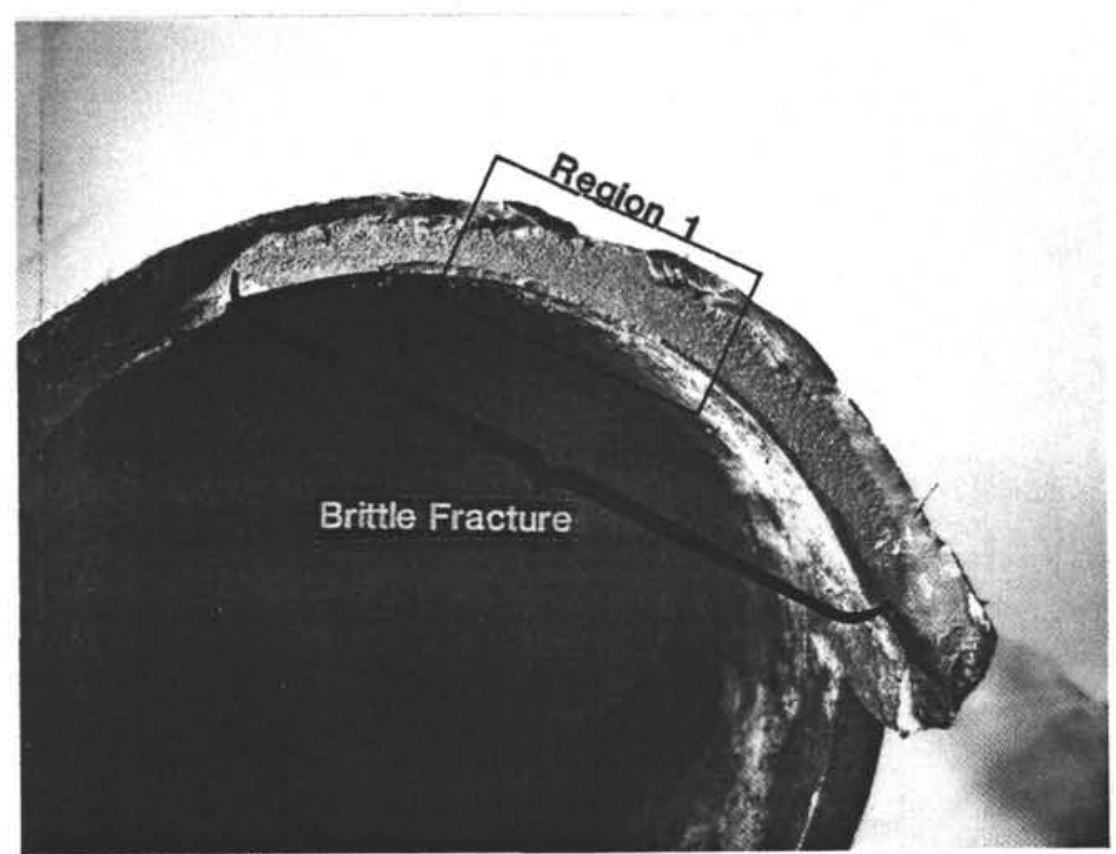

BHO 1471

FIGURE 2. THE BRITTLE FRACTURE EXTENDED APPROXIMATELY 90 DEGREES AROUND THE CIRCUMFERENCE OF THE PIPE. THE BOXED IN AREA, REGION 1, IS SHOWN MAGNIFIED IN FIGURE 3.

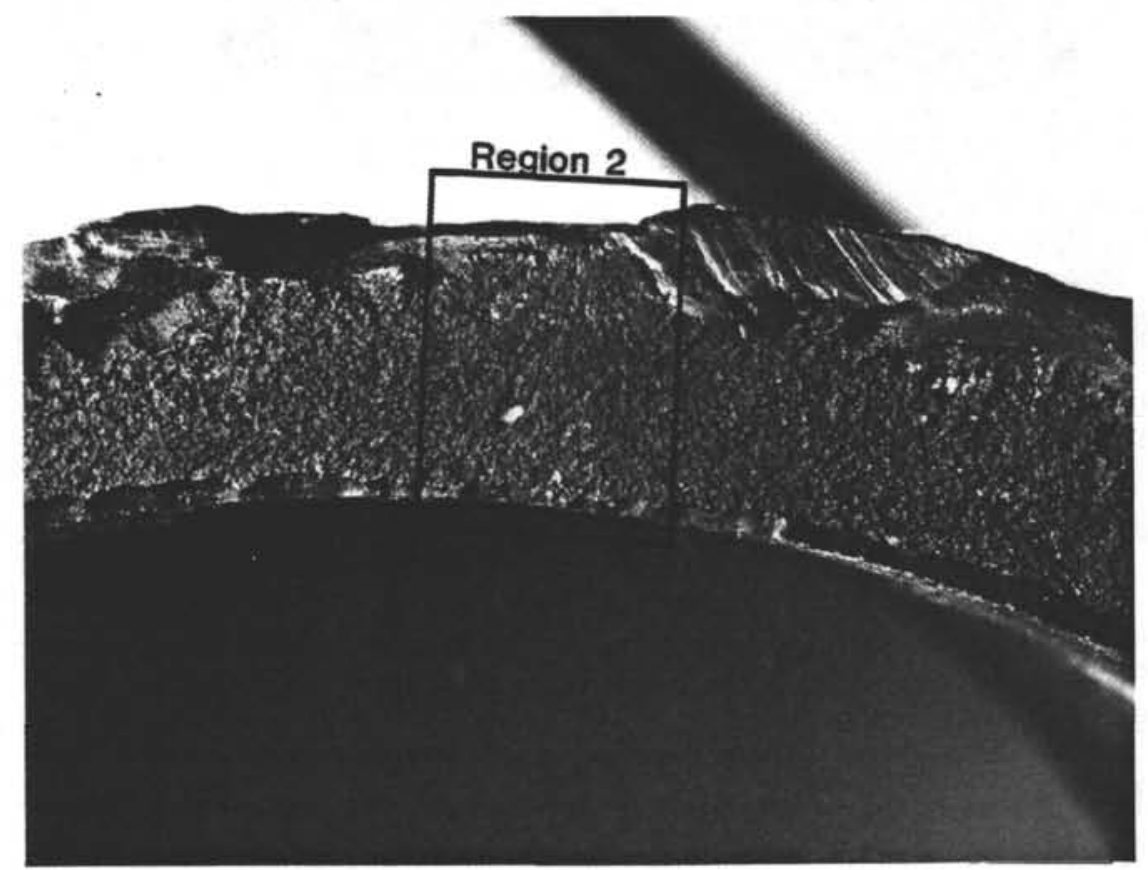

BHO 1474

FIGURE 3. A DISTINCT ORIGIN IS SEEN WITHIN THE BOXED AREA. THIS AREA, REGION 2, IS SHOWN MAGNIFIED IN FIGURE 6. 


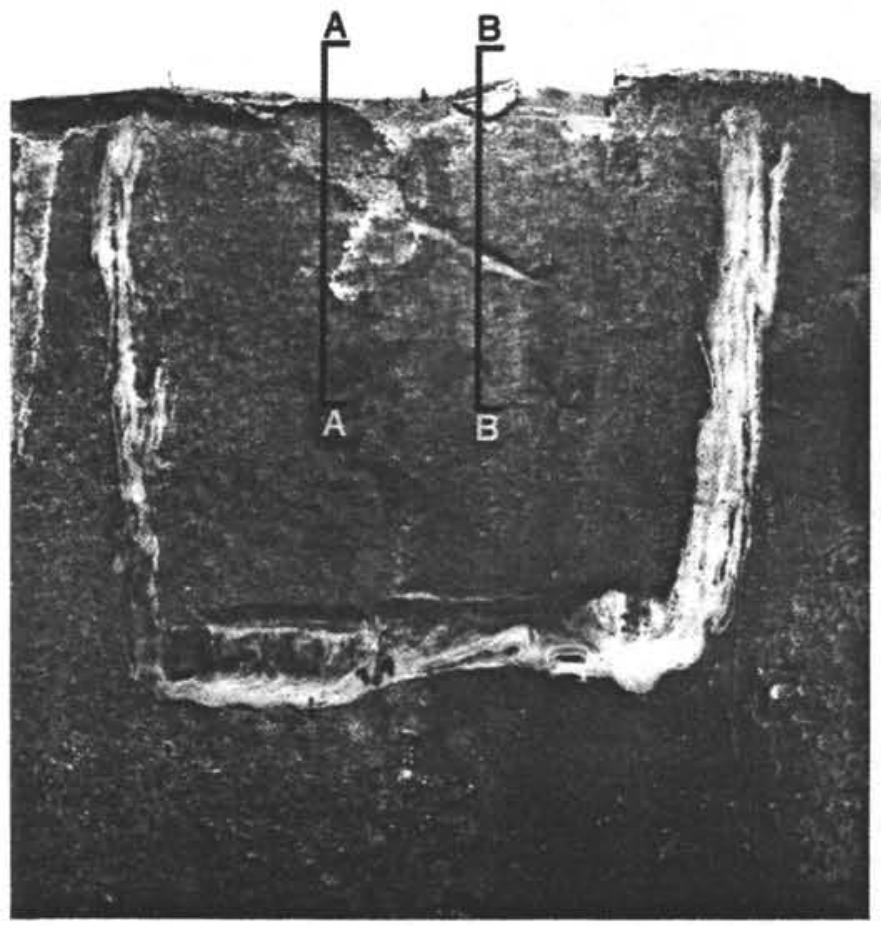

BHO 1468

FIGURE 4. A ROLLED IN LAP IS CLEARLY SEEN IN THIS PHOTOGRAPH. SECTION A-A IS AT THE ORIGIN AND DENOTES THE LOCATION USED FOR OPTICAL METALLOGRAPHIC STUDIES. SECTION B-B DENOTES THE LOCATION USED FOR THE LAP METALLOGRAPHY. 

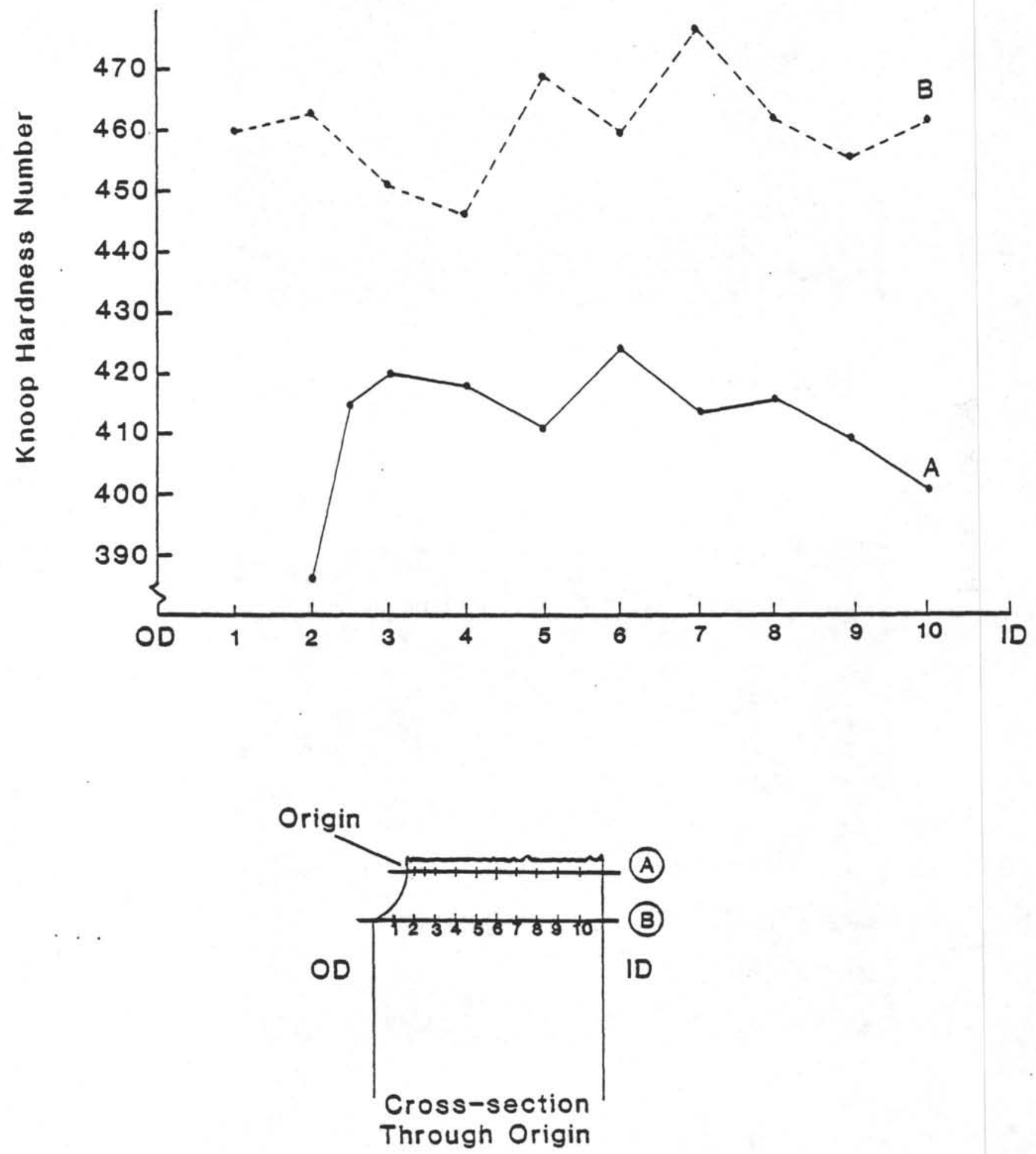

FIGURE 5. MICROHARDNESS TRANSVERSE ACROSS THE WALL THICKNESS NEAR THE ORIGIN. 


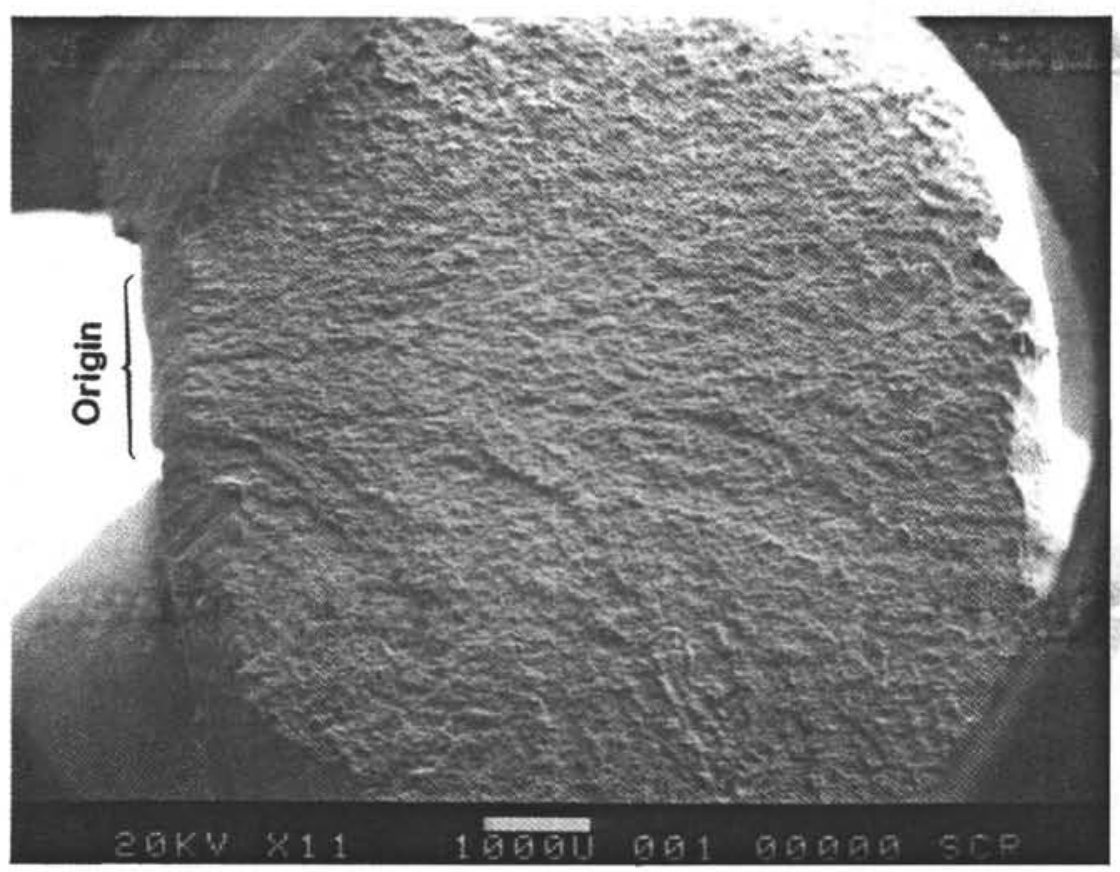

BHO 1493

FIGURE 6. SEM MICROGRAPH OF REGION 2 CLEARLY SHOWS CHEVRON MARKS POINTING TO ORIGIN (BRACKETED REGION), $11 X$.

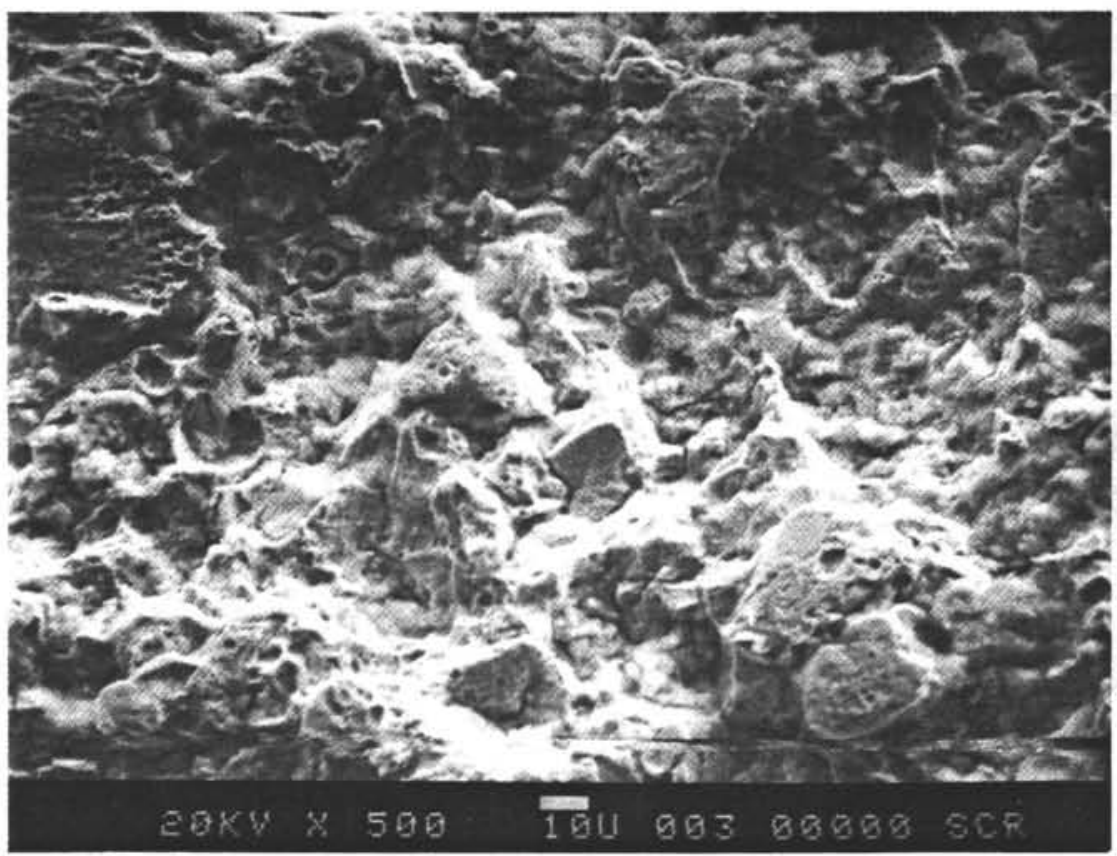

BHO 1494

FIGURE 7. A HIGH MAGNIFICATION (500X) VIEW NEAR THE ORIGIN REVEALS AN INTERGRANULAR MODE OF FRACTURE. THIS FRACTURE MODE IS TYPICAL OF HYDROGEN EMBRITTLEMENT. 


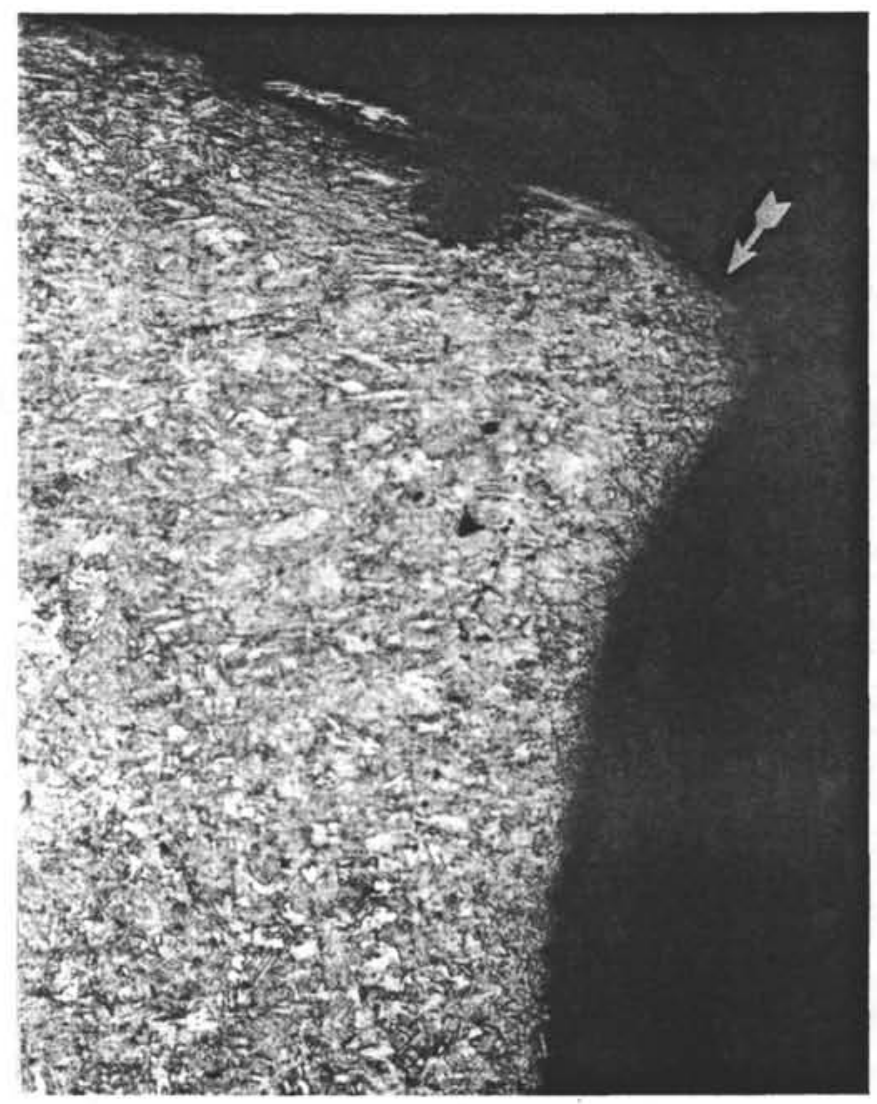

BHO 1483

FIGURE 8. SECTION A-A THROUGH THE ORIGIN OF FAILURE. THE TOP OF THE PHOTOGRAPH IS THE FRACTURE FACE. THE DEFORMATION OF THE GRAINS NEAR THE FRACTURE FACE PROBABLY OCCURRED AFTER THE FAILURE. THE ARROW POINTS TO THE AREA OF THE ORIGIN. THE RIGHT EDGE WAS THE LAP FACE. WHEN THE PIPE WAS RECEIVED AT BATTELLE, THE LAP WAS BROKEN OFF HERE, SEE FIGURE 4.

NITAL ETCH, 250X 


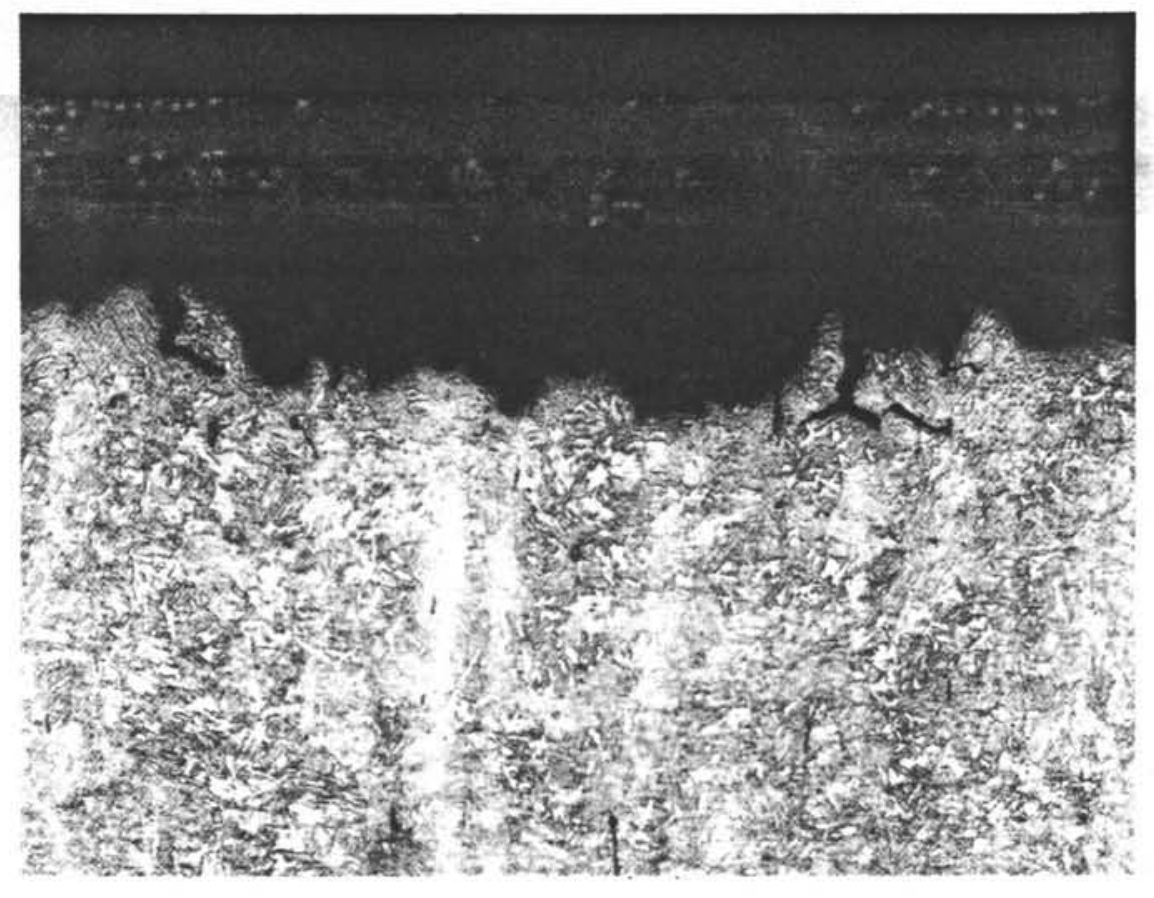

$\mathrm{BHO}$

FIGURE 9. AN INTERGRANULAR CRACKING MODE OF FAILURE CAN BE SEEN AT THE FRACTURE SURFACE.

NITAL, $250 X$ 


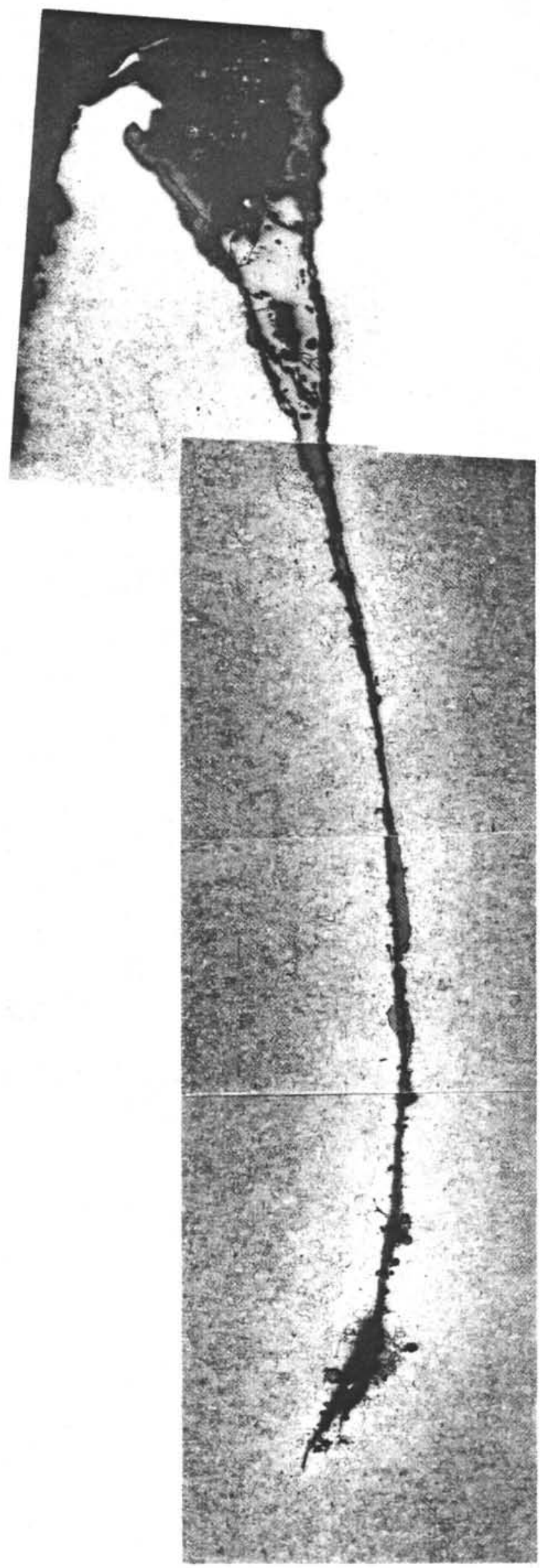

BHO 1484, 1485, 1486, 1487

FIGURE 10. SECTION B-B REVEALED A LAP WHICH WAS FILLED WITH OXIDE AND DECARBURIZED THROUGH MOST OF ITS LENGTH. THE RIGHT SIDE OF THE PHOTOGRAPHY IS THE O.D. SURFACE.

NITAL ETCH, 125X 


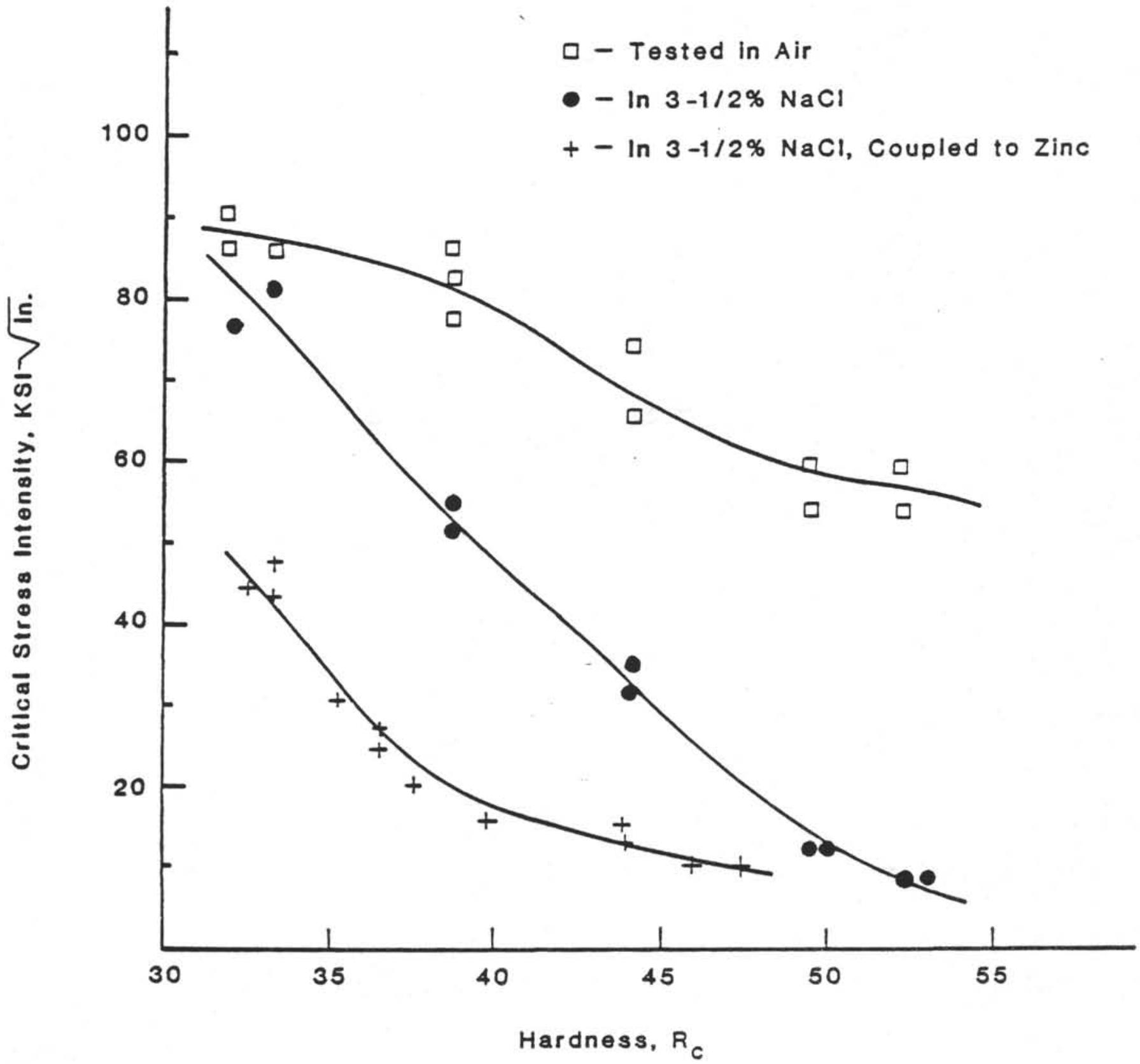

FIGURE 11. HARDIESS VERSUS CRITICAL STRESS INTENSITY FOR 4340 STEEL. 


\section{APPENDIX B-5}

FAILURE ANALYSIS OF KELLY COCK SUB (LEG 93) 
September 19, 1983

Presented herein is Battelle's report on the failure analysis of Global Marine's Kelly Cock sub from the Glomar Challenger.

\section{SUMMARY}

The Kelly Cock sub failed by brittle fracture initiating at numerous shallow fatigue cracks at the base of the last engaged thread. The fatigue cracks began at corrosion pits which had developed over the sub's fourteen year life. The fatigue cracks themselves appeared to be relatively recent; their number and shape suggest a recent, relatively short period of high-stress operation. The sudden and complete separation of the sub was due to brittle fracture initiating at these shallow (average $1 / 8$ th inch deep) fatigue cracks. That brittle fracture should result from such short, shallow cracks indicates that the toughness of the steel was very low. This was confirmed on metallography; the microstructure was a mixture of ferrite, pearlite and tempered martensite which would be very poor in toughness even though the hardness was only just below specification. To prevent recurrence of this catastrophic failure, replacement subs could be made of through-hardened 4340 steel for higher toughness.

\section{INTRODUCTION}

This Kelly Cock sub had seen approximately 14 years' service on the M. V. Glomar Challenger, a drill ship used for the Deep Sea Drilling Project. During June of 1983 the project was drilling an exceptionally deep hole in hard rock; three drill collars failed due to fatigue. At a total hole depth of 6219.3 meters the Kelly Cock sub fractured. At the time of failure operation and weather conditions were normal. The pipe was being raised after closing the heave compensator. The vessel roll was three degrees and the pitch two degrees. Drill string weight at fracture was 428,495 pounds.

The Kelly Cock sub is 8-7/8 inch outer diameter, with a 7-5/8 inch regular box and pin. The inside diameter is six inches. The material is AISI $4145 \mathrm{H}$ stee1, grade S-135, heat-treated to Brinnell 285-341, with a $120 \mathrm{ksi}$ minimum yield strength specification.

After torch-cutting for removal the fractured Kelly Cock sub was sent to Battelle Petroleum Technology Center in Houston for analysis. 
VISUAL EXAMINATION

The fractured Kelly Cock sub is shown in Figure 1 as received. Failure occurred in the box, in the circumferential plane, following the last engaged thread. There was no extensive plastic deformation.

Beachmarks on the fracture surface indicated a series of long, shallow fatigue zones following the root of the thread. The deepest of these fatigue zones by chance was immediately adjacent to the torch cut made during removal; at its maximum, this fatigue zone was approximately .25 inch deep (Figure 2). A number of shallower fatigue zones were observed essentially all the way around the root of the last engaged thread. These small fatigue zones averaged about 0.125 inches deep.

Chevron marks pointing back to the fatigue zones indicated that final fracture was by catastrophic brittle cleavage. Some of the chevron marks appeared to initiate on the outer surface, at deep slip marks, indicating that once final fracture began from the internal fatigue cracks, additional brittle fractures began on the outer surface and propagated inward to meet the internal cracks.

$$
\text { METALLOGRAPHIC EXAMINATION }
$$

Sections taken through the deepest fatigue zone and another, more typical shallow fatigue zone were polished and etched for metallographic

examination. Photomicrographs from these sections are shown in Figures 3 and 4. Both cracks initiated at corrosion pits at the root of the thread; both showed the characteristic straight, transgranular path characteristic of fatigue failures.

The microstructure on both sections was mixed, showing a combination of ferrite, pearlite and tempered martensite typical of $4145 \mathrm{H}$ alloy quenched and tempered in thick sections.

The hardness of the sub was uniform at the root of the thread, averaging $R_{c} 28$ in five measurements. This is equivalent to approximately 272 Brinnell, just below the required minimum of 285 . Empirical correlations between hardness and tensile strength suggest that steel with a hardness of $R_{c} 28$ would have a tensile strength of approximately $135 \mathrm{Ksi}$. If, as is typica\}, the ratio of yield strength to ultimate tensile strength for this item was 0.9 , this would suggest a yield strength of approximately $121.5 \mathrm{ksi}$, slightly above the required minimum of $120 \mathrm{ksi}$.

\section{DISCUSSION}

Items which fail in fatigue after a high number of cycles at low stresses normally show relatively few fatigue initiation sites, since cracking at one or two places relieves the stresses elsewhere. Fatigue failures produced by relatively high stresses or high stress-concentrations for relatively few cycles often show a number of fracture initiation sites around the edye of the item. This is the pattern seen on the Kelly Cock sub fracture. 
For an item to develop high-stress, relatively low-cycle fatigue cracks after fourteen years in service suggests that recent operations have been relatively high-stress. Such appears to have been the case with the Kelly Cock sub, since failure of several other drill string components had recently been observed.

The sudden, catastrophic development of propagating brittle fractures from such shallow fatigue cracks indicates that the toughness of the material is low. Assuming that the Kelly Cock sub behaves like a cylindrical rod with a disc-shaped central crack of radius 3.125 (thread root diameter plus average fatigue crack depth), end loaded with 428,495 pounds and having a yield strength of $121.5 \mathrm{ksi}$, the critical plane strain fracture toughness ( $\mathrm{K}_{\mathrm{IC}}$ ) can be calculated as

$$
K_{I C}=\left[\frac{K_{I}}{K_{0}}\right]\left[2 \sigma \sqrt{\frac{\alpha}{\pi}}\right]
$$

where $\sigma=$ nominal applied tensile stress, $a=$ crack radius $=3.125 \mathrm{inch}$, and the ratio $\mathrm{K}_{\mathrm{I}} / \mathrm{K}_{0}$ is taken from the graph of correction factors to $\mathrm{K}_{0}$ published by Rooke and Cartwright for plane circular cracks in cylindrical bars (from Compendium of Stress Intensity Factors, by D. P. Rooke and D. J. Cartwright, p. 249, HMSO, Uxbridye, Middlesex, UK, 1976) for the appropriate ratio of outer diameter to crack radius. For an outer diameter of $8-7 / 8$ ths, this ratio is 1.25 .

The load on the sub at failure was 428,495 pounds, and its cross-sectional area was $33.6 \mathrm{in}^{2}$, yiving a nominal tensile stress of $12,758 \mathrm{psi}$.

Substituting into the equation given above indicates a critical stress intensity for brittle fracture, $K_{\text {IC }}$ of $31,810 \mathrm{ksi} \sqrt{\mathrm{in}}$.

For a steel of this hardness level such a fracture toughness can be related to Charpy impact energy using empirical correlations based on the equation

$$
C V N=\frac{K_{I C}}{5 \sigma_{y}}+\frac{\sigma_{y}}{20}
$$

Substituting for the assumed values of $K_{I C}$ and $\sigma_{y}$ for the Kelly Cock sub gives a calculated room temperature Charpy $V$-notch energy of approximately 8 foot-pounds.

Such a low level of toughness is due primarily to the mixed microstructure observed on the sub. For optimum toughness a structure of tempered martensite is necessary; the mixture of ferrite, pearlite and martensite observed on the Kelly Cock sub is very much inferior to a completely tempered martensite structure. However, a mixed microstructure is inevitable on $4145^{\circ}$ alloy steel items which exceed about one-half inch in thickness. On 4145 steel the austenite-to-ferrite reaction is so fast that even with a severe quench during heat treatment some formation of ferrite and pearlite is inevitable. For optimum toughness more highly alloyed steels such as AISI $4340 \mathrm{H}$, with its slower austenite-to-ferrite reaction, are required. 


\section{CONCLUSIONS}

1) The Kelly Cock sub failed by brittle fracture initiated at fatigue cracks in the root of the last engaged thread.

2) The fatigue cracks began at corrosion pits in the thread root and were apparently associated with a recent period of relatively highstress operation.

3) The hardness of the Kelly Cock sub was slightly below the 285 Brinnell minimum required by the purchase specification. However, the yield strength is believed to be at or slightly above the specified minimum.

4) The toughness of the Kelly Cock sub, although not specified, is apparently quite low due to the presence of a mixed microstructure.

5) The low toughness caused the formation and propagation of catastrophic brittle fractures from the very shallow fatigue cracks.

6) To prevent similar brittle catastrophic failures a tougher material, such as quenched and tempered 4340 steel, will be required for replacement subs.

If there are any questions on this report, please call or write. I enjoyed working with you on this job. Thank you for calling Battelle.

Best regards,

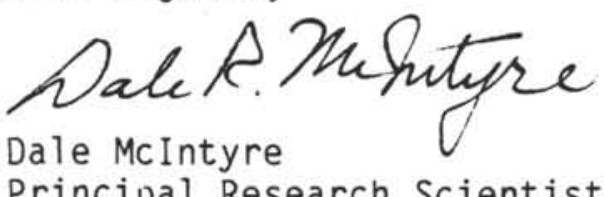

DRM:C Iw 


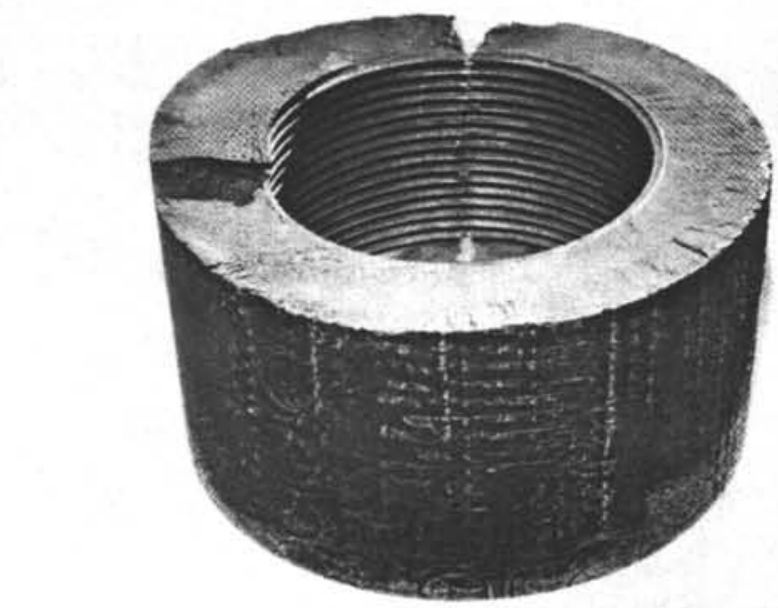

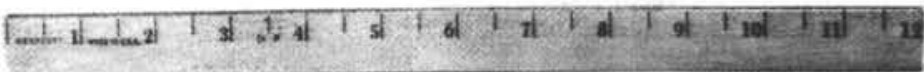

BHO 2671
FIGURE 1. Kelly Cock sub as received.

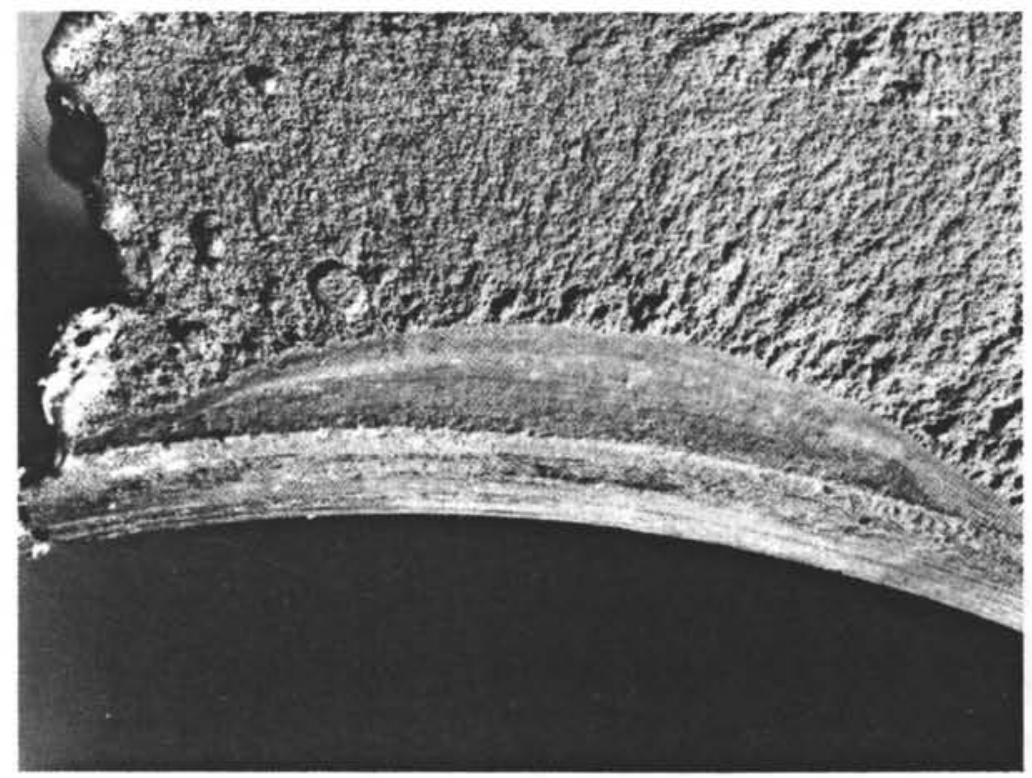

BHO 2672
FIGURE 2. Largest fatigue zone on the fracture surface. $\approx 1.5 X$ 


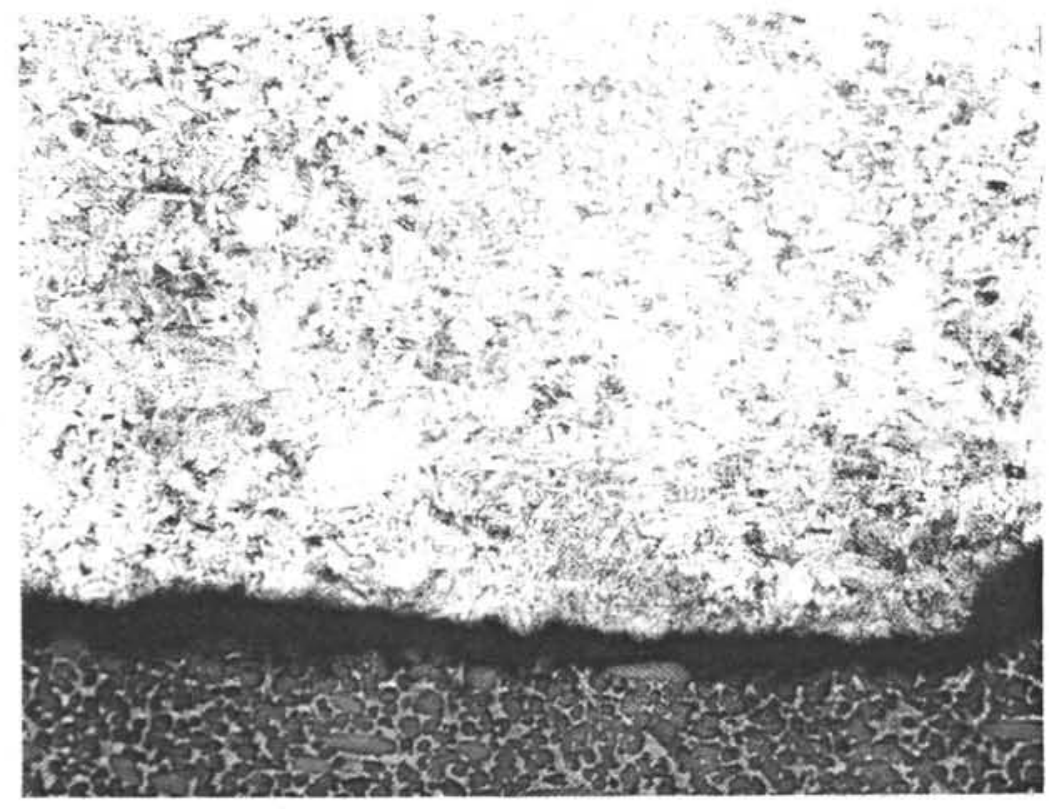

BHO 2709

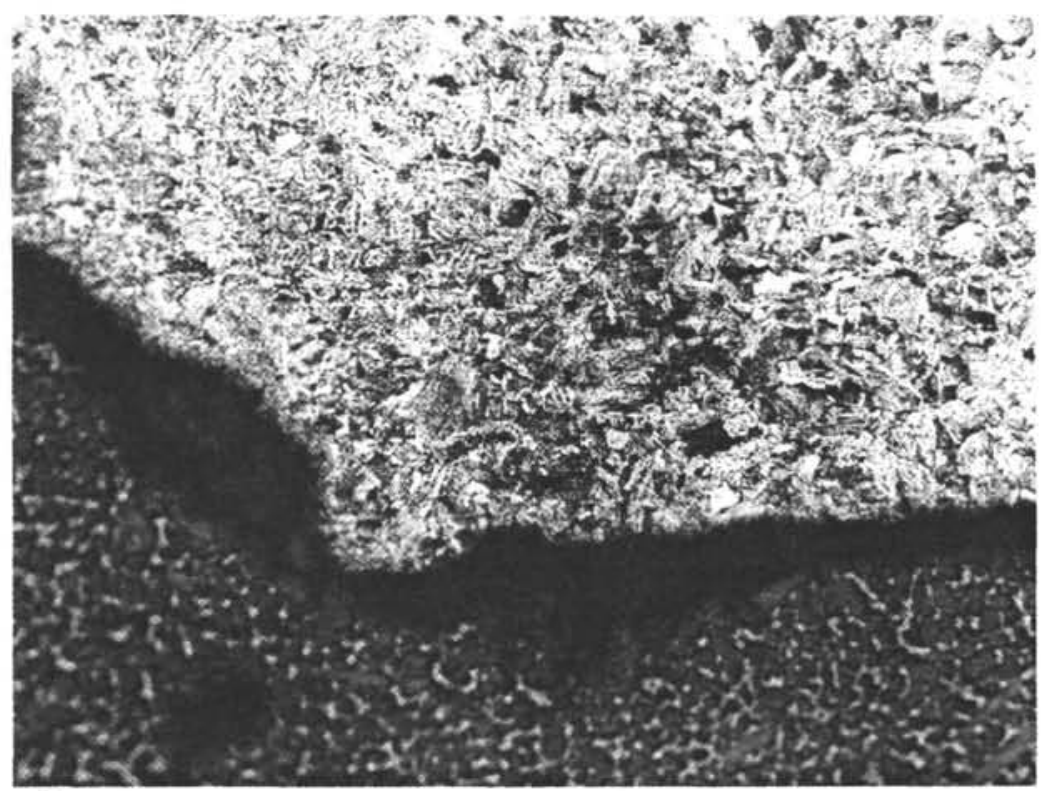

BHO 2711
FIGURE 3. Photomicrograph of section taken through the largest fatigue origin. Note mixed microstructure. 200X Nital etchant
FIGURE 4. Photomicrograph of section taken through a secondary origin approximately 3 inches away from the origin in Figure 3. Note mixed microstructure, corrosion pitting at thread root. 200X Nital etch 
APPENDIX C

FAILURE ANALYSIS OF DRILL PIPE

FROM HOLE 581A

(LEG 88) 


\section{REPORT}

on

FAILURE ANALYSIS OF DRILL PIPE FROM HOLE 581A

Contract No. Gl 3274-3058

to

DEEP SEA DRILLING PROJECT

February 7, 1983

by

D. R. McIntyre

R. J. 01 son

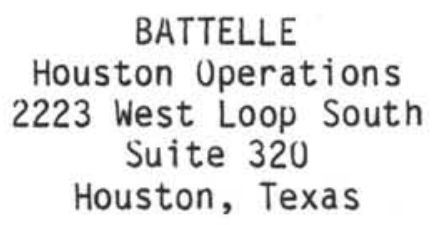

Battelle is not engaged in research for advertising, sales promotion, or publicity purposes, and this report may not be reproduced in full or in part for such purposes. 


\author{
REPURT \\ on \\ FAILURE ANALYSIS OF DRILL PIPE FROM HOLE $581 \mathrm{~A}$ \\ CONTRACT NO.: G13274-3058 \\ to \\ DEEP SEAL DRILLING PROJECT \\ by \\ Dale R. McIntyre \\ R.J. 01 son \\ from \\ BATTELLE \\ Houston Uperations \\ February 7, 1983
}

\begin{abstract}
SUMMARY
The drill pipe in DSDP hole 581A failed due to buckling followed by fatigue and final fracture by ductile rupture. The buckling apparently took place some time before the drill pipe became stuck while retrieving core No. 1 and was most likely caused by insufficient tension on the drill string. The mechanical properties and chemical composition of the drill pipe joint met the requirements of API $5 A X$ in all respects.

\section{INTRODUCTION}

On August 25, 1982, The Deep Sea Drilling Project began work on hole No. 581A, lowering a re-entry cone and $72.15 \mathrm{~m}$ of 16 -inch casing to the sea floor in $5483 \mathrm{~m}$ of water on a 5 inch, 19.5 pound/ft S-135 drill pipe running string with a 15-inch core bit.
\end{abstract}


The cone and the 16-inch casing washed in without difficulty for approximately $60 \mathrm{~m}$. at which point progress slowed considerably. It was thought that the difficulties with washing in and re-entering the cone may have resulted in setting down the string either on the edge of the cone or on hard bottom at some point. With the casing shoe at $5552 \mathrm{~m}$. below rig floor no further progress could be made. The cone was released from the running string at this point.

A 15-inch hole was washed and drilled to $364 \mathrm{~m}$. below the sea floor, at which point continuous coring began. Torquing of up to $8000 \mathrm{ft}$-pounds, the 1 imit set on the Bowen power swivel, was experienced during this drilling operation. While retrieving the first core sample, the drill pipe became stuck and required some 15 minutes and overpul ls of 70,000 pounds (the maximum allowable under existing conditions of drill string weight) before coming free.

Torquing through the cored interval ranged consistently between 6000 and 8000 foot-pounds. The hole struck basalt some 360 meters below the mudline ( 5840 m) . Coring was stopped 14.8 meters into basalt and a short pipe trip to the 16-inch casing shoe was made to check the hole condition before running $113 / 4$ inch casing.

With the bit approximately $8 \mathrm{~m}$. below the casing shoe, the travelling block was set down while the drilling line was slipped and cut. When the travelling block had been picked up again, the pipe was run back to total depth. No resistance was noted and it was assumed that the hole was thus clear. Three hundred barrels of 9.0 pound/gallon mud were displaced to fill the hole and maintain hole stability for running the $113 / 4$ inch casing. When the drill pipe was recovered it was found that the joint immediately above the bottom nole assembly had fractured approximately 0.5 meters from the pin end, leaving the bottom-hole assembly in the hole. Careful examination of the drilling recorder chart revealed that the pipe had parted during the time the drilling line was being cut and slipped. 


\section{Visual Examination}

Figure 1 shows the broken sample of drill pipe as received. As Figures 2, 3 and 4 show, the fractured end showed extensive plastic deformation. Around the circumference of the fracture, material at the twelve and six 0-clock positions had been deformed inward while at the three and nine o'clock positions the pipe wall had bulged outward. Two longitudinal splits had occurred on opposite sides of the pipe at the two and eight o'clock positions (Figures 2 and 3 ). The split at the two o'clock position ran parallel to the longitudinal axis of the pipe for approximately six inches before turning ninety degrees and running perpendicular to the longitudinal axis. (Figure 4)

Virtually all of the fracture surfaces on the broken pipe end were shear fractures propagating at approximately 45 degrees to the pipe wall thickness. At the edges of the areas which had bulged outward, two small half-moon-shaped zones suggestive of fatigue were observed (Figures 5 and 6 ) Radial marks in these zones suggested origins on the outer surface of the pipe (arrows, Figure 7). A secondary crack under the fatigue zone at the three o'clock position also appeared to be due to fatigue.

\section{Metallographic Examination}

A section taken through the fatigue zone at the three o'clock position (Figure 7) was polished and etched for metallographic examination. Figure 8 presents a photomicrograph of the fracture origin. Although damaged by cold-work and corrosion, the fracture profile appeared to be predominantly transgranular and non-branching.

Nume rous secondary cracks were observed on both the inside and outside surface of the drill pipe section. Most of these cracks were relatively blunt, transgranular and filled with corrosion products. 


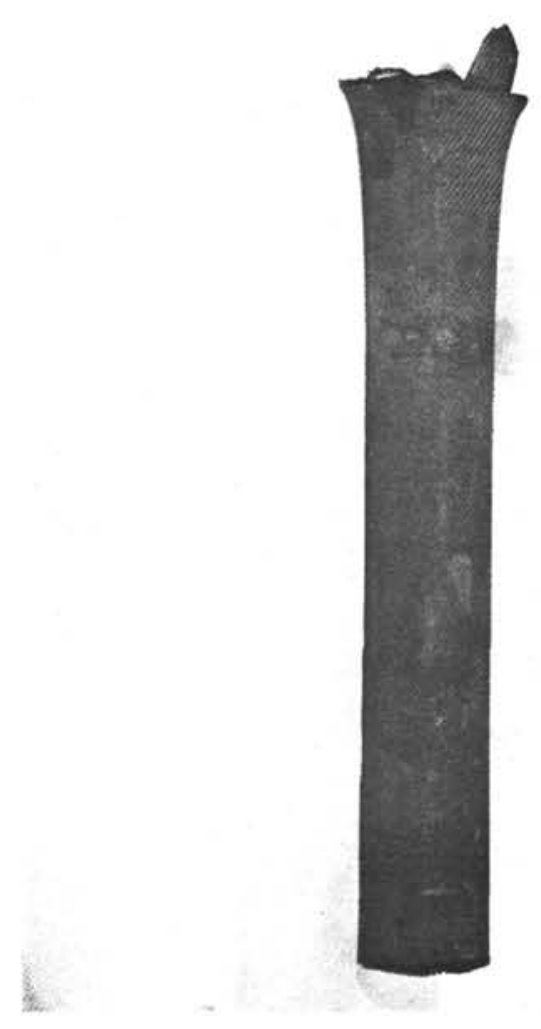

BHO 2233

FIGURE 1. FAILED DRILL PIPE SECTION AS RECEIVED 


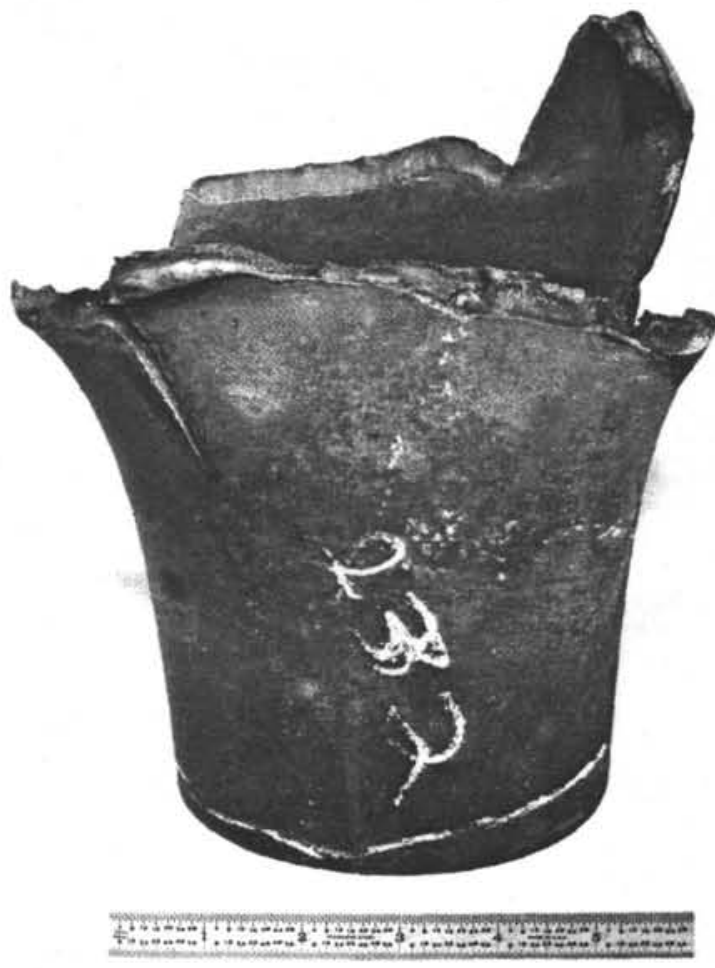

BHO 2270

FIGURE 2. FRACTURED DRILL PIPE END, LOOKING AT THE CENTER OF THE BUCKLED ZONE. 


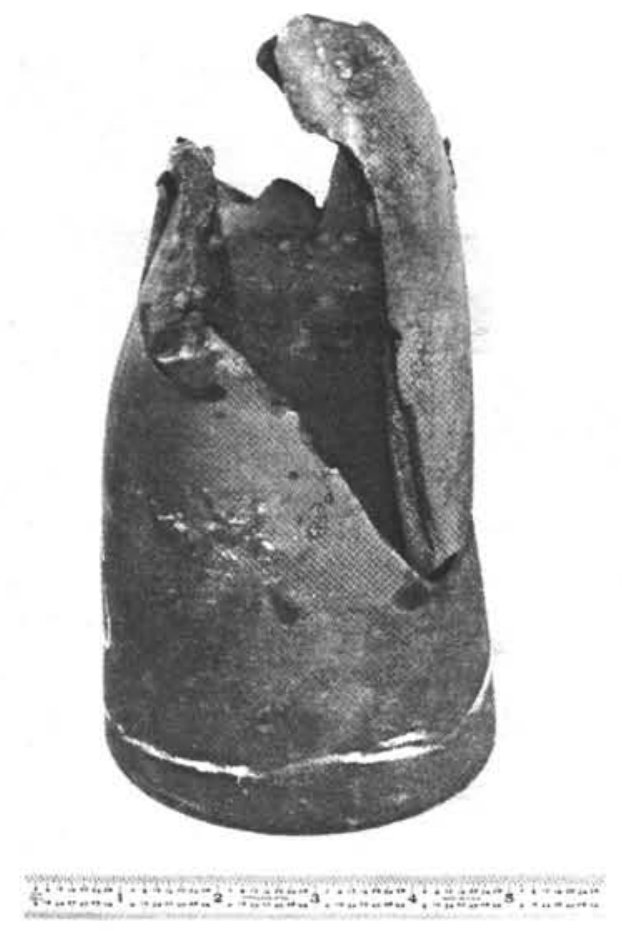

BHO 2268

FIGURE 3. SIDE VIEW OF THE BUCKLE. NOTE THE LONGIGUDINAL SPLIT. 


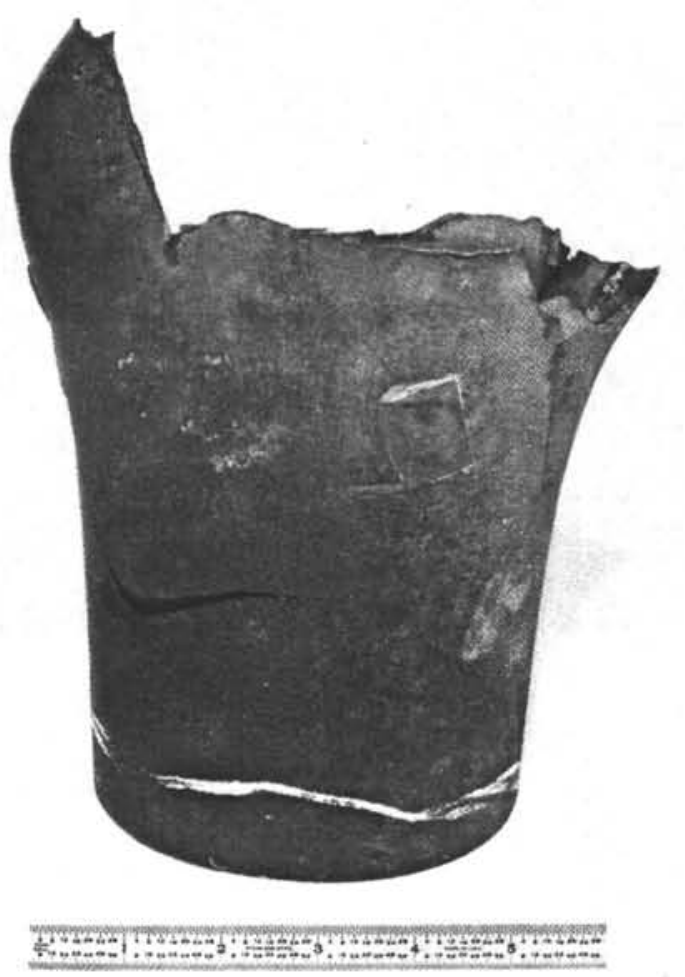

BHO 2269

FIGURE 4. BACK VIEW OF THE BUCKLE. THE LONGITUDINAL SPLIT IN FIGURE 3 TURNS $90^{\circ}$ AND RUNS PERPENDICULAR TO THE LENGTH OF THE DRILL PIPE. 


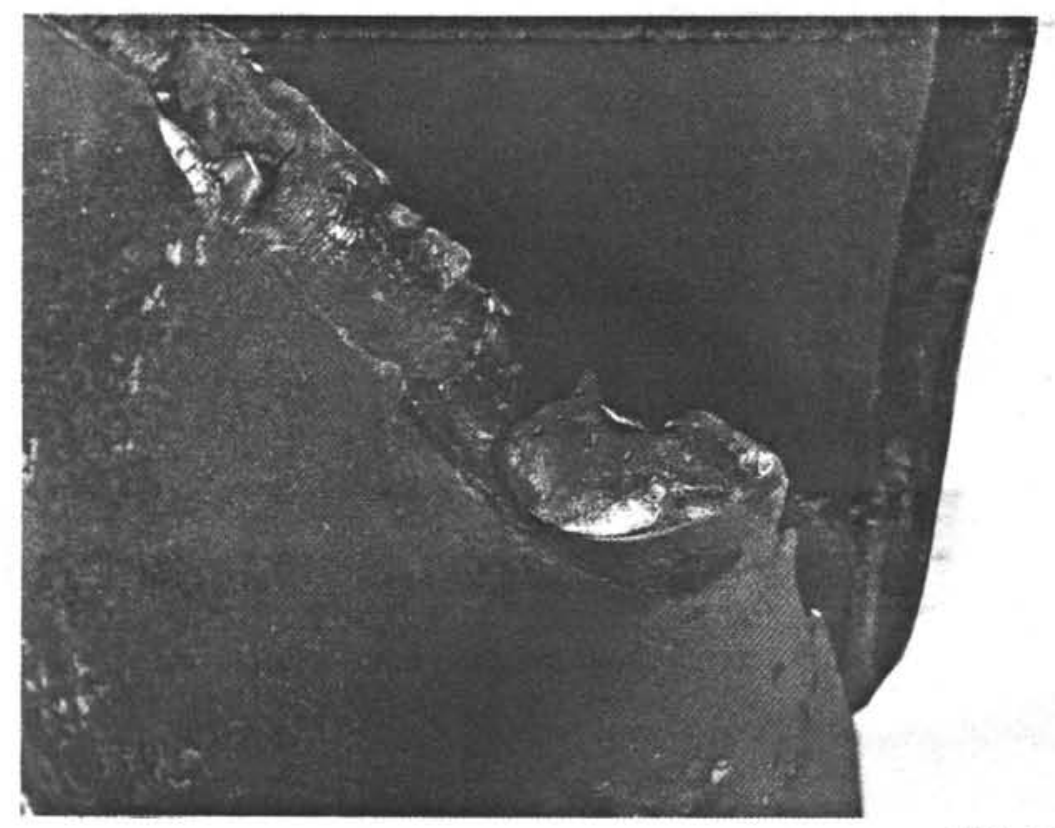

BHO 2271

FIGURE 5. FATIGUE ZONE AT THE OUTER EDGE OF THE BUCKLE. NOTE THE SECONDARY CRACK BELOW THE FATIGUE ZONE.

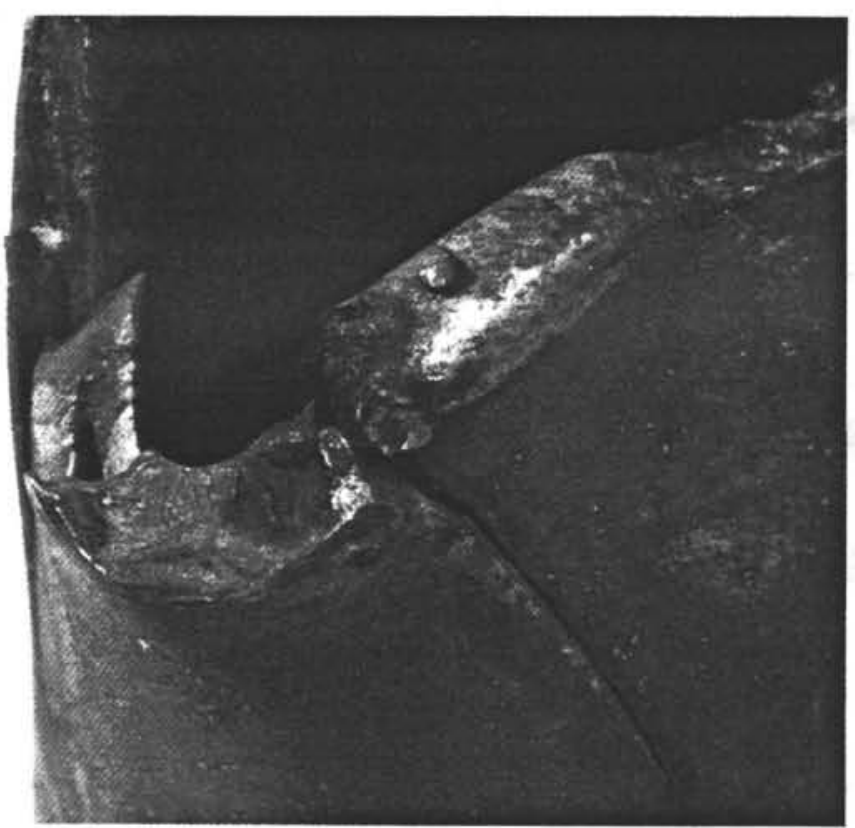

BHO 2267

FIGURE 6. FATIGUE ZONE AT THE OUTER EDGE OF THE BUCKLE, ON THE OPPOSITE SIDE AS THAT SHOWN IN FIGURE 5. 


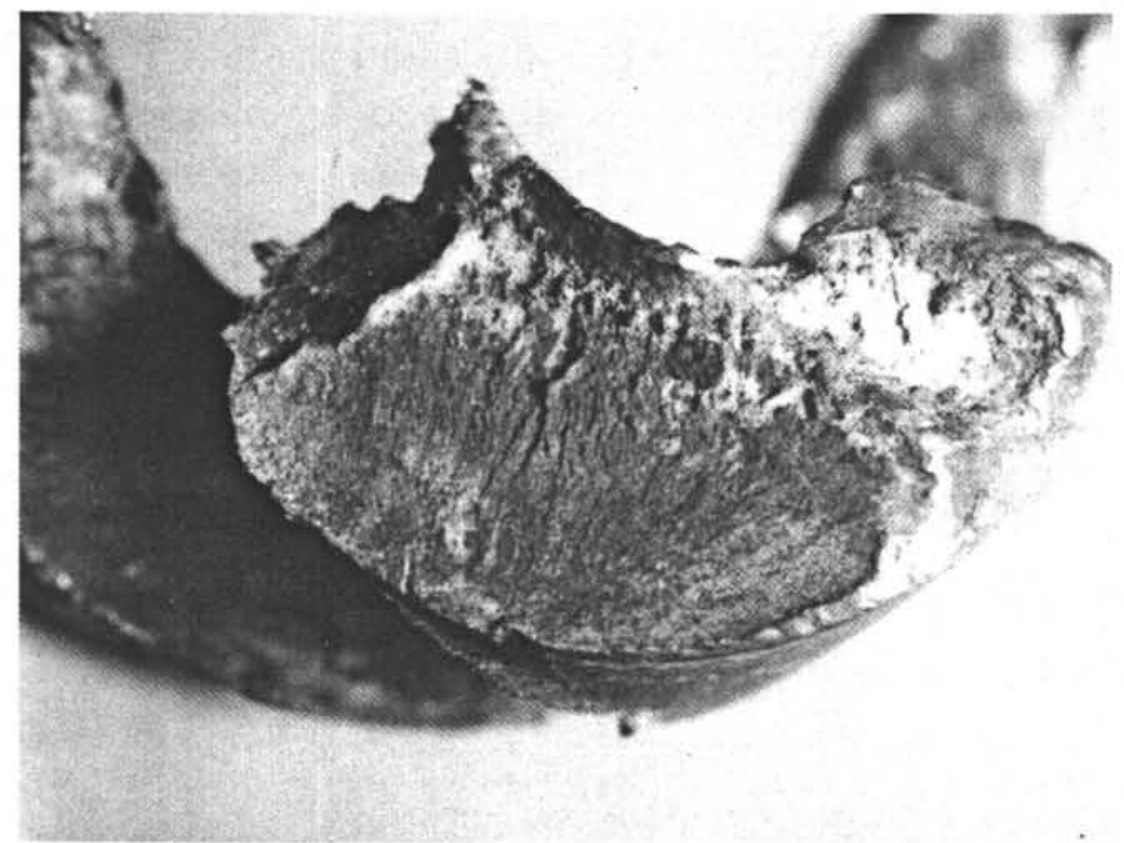

BHO 2309

FIGURE 7. CLOSE-UP OF FATIGUE ZONE IN FIGURE 5. NOTE THE RADICAL MARKS INDICATING INITIATION AT THE OUTER EDGE.

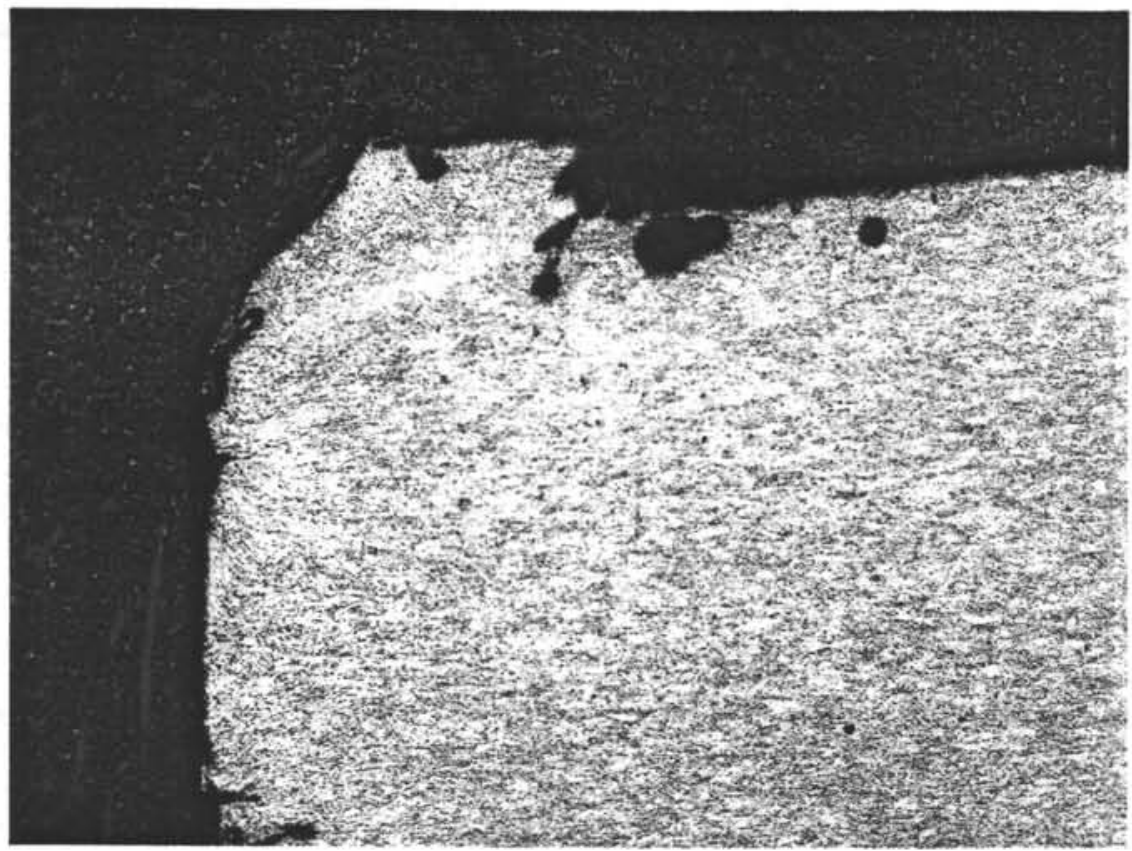

$\mathrm{BHO} 2324$

FIGURE 8. A METALLOGRAPHIC SECTION TAKEN THROUGH THE FATIGUE ZONE IN FIGURE 7. THE FRACTURE SURFACE IS AT TOP: THE PIPE OUTER SURFACE IS AT LEFT. 
On the section through the fatigue crack, the structure was tempered martensite with some evidence of cold-work. Longitudinal and transverse sections were taken well away from the fractured end to check the structure of the base metal. (Figures 9 and 10) The base metal also showed a tempered martensite structure but with no evidence of cold-work. Microhardness tests near the fatigue zone averaged $K H_{500 g} 432$ (approximately $R_{c} 42.5$ ) while the base metal well away from the fracture averaged $\mathrm{KHN}_{500 \mathrm{~g}} 388$ (approximately $\left.R_{C} 38.5\right)$.

\section{Mechanical Properties}

Duplicate tensile specimens were taken from the broken drill pipe in an area well away from the fractured end. Average mechanical properties obtained were as follows:

\begin{tabular}{|c|c|c|c|c|}
\hline & $\begin{array}{c}\text { Yield } \\
\text { Strength } \\
\text { ksi }\end{array}$ & $\begin{array}{l}\text { Ultimate } \\
\text { Tensile } \\
\text { Strength, ksi }\end{array}$ & $\begin{array}{l}\text { Percent } \\
\text { Elongation } \\
\text { in } 2 \text { inches }\end{array}$ & $\begin{array}{l}\text { Percent } \\
\text { Reduction } \\
\text { in Area }\end{array}$ \\
\hline Fractured Drill & & & & \\
\hline Pipe & 163.3 & 173.5 & 17.5 & 59.0 \\
\hline $\begin{array}{l}\text { API } 5 A X \\
\text { Specification } \\
\text { Grade S- } 135\end{array}$ & $135-165$ & $145 \mathrm{~min}$ & $12.5 \mathrm{~min}$ & n.s. \\
\hline
\end{tabular}

n.s. - not specified

Although the yield strength of the failed drill pipe is near the high end of the allowable range, the mechanical properties meet the API 5AX specification in all respects. 


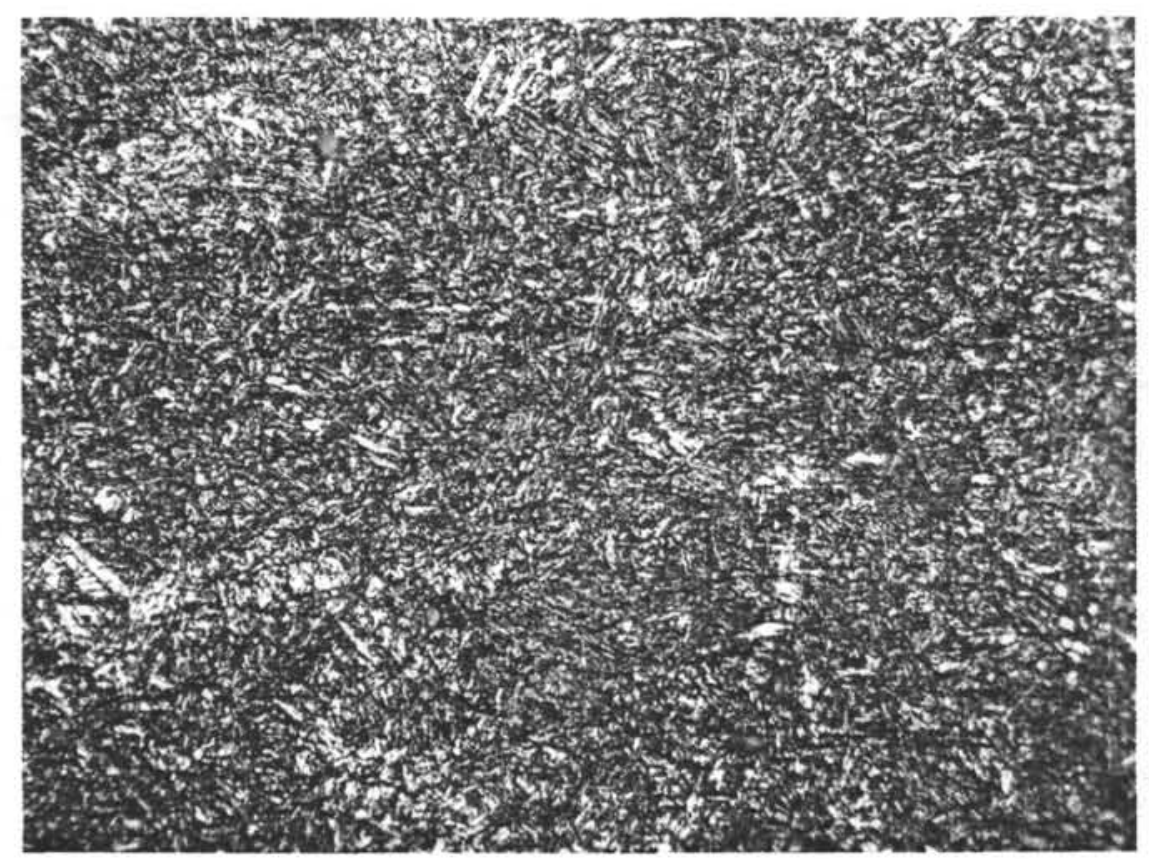

BHO 2325

FIGURE 9. TYPICAL TRANSVERSE MICROSTRUCTURE OF THE DRILL PIPE IN THE BASE METAL, APPROXIMATELY TWO FEET AWAY FROM THE BUCKLE.

400X NITAL ETCH

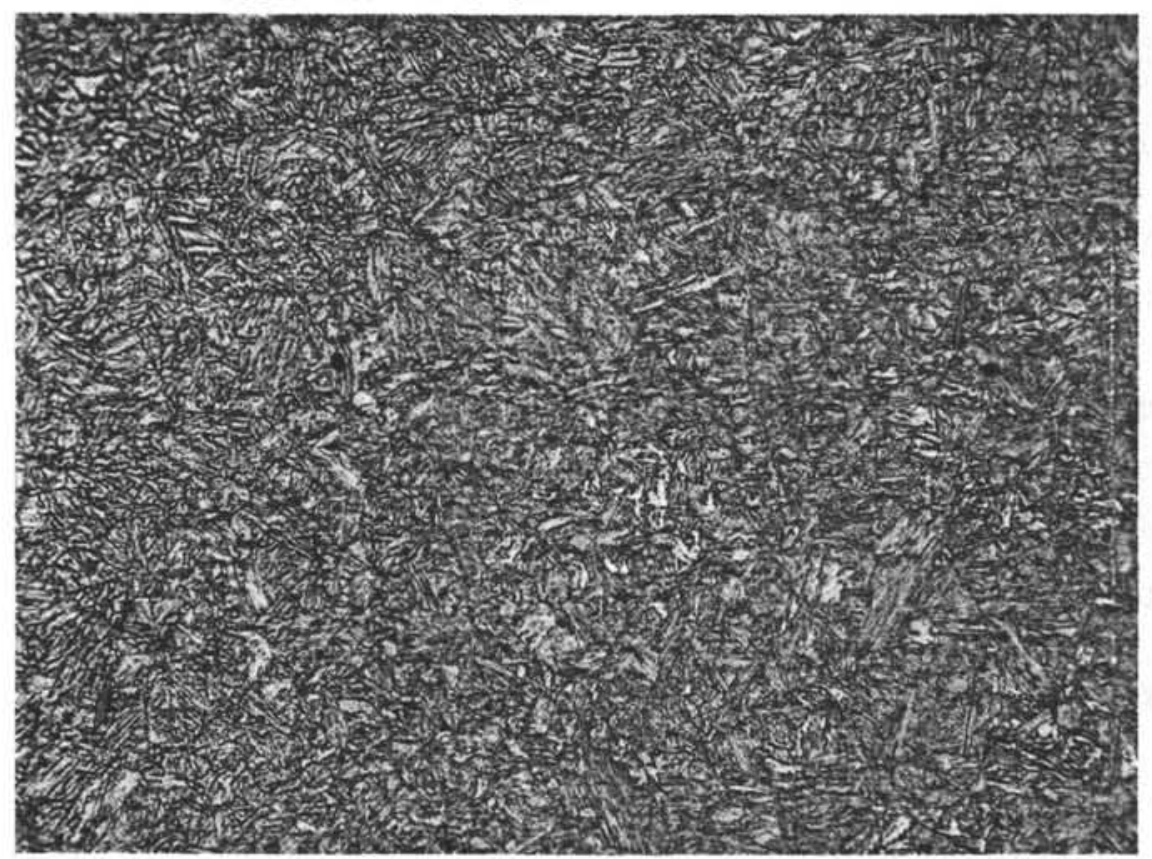

BHO 2326

FIGURE 10. TYPICAL LONGITUDINAL MICROSTRUCTURE OF THE DRILL PIPE, TAKEN ON A SECTION APPROXIMATELY TWO FEET AWAY FROM THE BUCKLE.

400X NITAL ETCH 


\section{Chemical Composition}

Spectrographic analysis of a sample from the failed drill pipe gave the following results:

API $5 A X$

Failed Drill Pipe Specification

\section{Carbon}

Manganese

Phosphorus

Sulfur

Nickel

Chromium

Mol ybdenum

Vanadi um

\subsection{1}

0.96

0.011

0.015

0.025

0.10

0.008

0.055 n.s.

n.s.

$0.04 \max$

$0.06 \max$

n.s.

n.s.

n.s.

n.s.

n.s. - not specified

The API 5AX specification is extremely non-restrictive with regard to chemistry. The failed drill pipe meets the limits for phosphorous and sulfur, the only two elements listed in the specification. However, the drill pipe is unusual in that it is essentially a plain carbon steel, with none of the elements (chromium, molybdenum or nickel) normally added to improve hardenability. 


\section{$\underline{\text { DISCUSSIUN }}$}

The mechanical properties of the failed drill pipe met API specification $5 A X$ in all respects.

The failed joint was of plain carbon steel rather than low-alloy steel. Lowalloy steels are normally used for S-135 drill pipe because the alloy additions insure that the structure is transformed to martensite all the way through the pipe wall when the item is quenched during heat treating. With incomplete transformation an undesireable mixed structure forms, of martensite plus bainite or martensite plus ferrite and pearlite, which has poor toughness. However, in thin sections even plain carbon steels can be transformed completely to martensite if quenched rapidly enough. Since the failed drill pipe showed a completely tempered-martensite structure, since the failure involved considerable plastic deformation, and since the phosphorous and sulfur levels were within specification, the chemistry of the failed joint apparently had no effect on this failure.

The overall appearance of the fractured pipe is indicative of a dent or buckle - the cross-section is flattened and appears to have been creased at the failure site. As denting or buckling begins, the cross-section becomes elliptical, which in turn puts the outer wall at the ends of the major axis of the ellipse in tension. If the defornation becomes severe enough, this tension can cause longitudinal splits at the outer wall.

Three possible scenarios can be hypothesized which could cause the observed deformation of the pipe:

1. The pipe, just above the bottom hole assembly, impacts the moon pool or reentry cone causing a dent.

2. With the bottom hole assembly in the reentry cone, station keeping is lost and the vessel drifts excessivly causing the 
drill string to bend. Such bending, if large enough could cause a local buckle (collapse) of the pipe cross-section. (Figure 11)

3. While lowering the drill string, the bottom hole assembly lands on the sea floor or edge of the reentry cone causing a bifurcation buckle (column instability). (Figure 12)

Since any of these three scenarios is possible, each was considered in more detail.

Denting. The denting scenario seems very unlikely. If the pipe, just above the bottom hole assembly had impacted on the moon pool, it would have had to have been inclined at a very large angle. This probably could not occur except in extreme weather conditions. Since drilling was in progress, the weather must have been reasonably calm. Considering denting of the pipe by impact on the reentry cone, since the bottom hole assembly is over 350 feet long and the top of the cone was only 35 feet above the sea floor, it would not be possible to dent the pipe on the reentry cone.

Collapse. In order to judge the likelihood of the collapse scenario, two pieces of data were required: 1) the local bending moment at collapse of the pipe and 2) the global bending moments of the drill string when the vessel was offset. To generate these data, two computer programs COLAPS[1] a combined bending moment, tension and pressure pipe collapse program, and DWRSR[2], a marine riser analysis program, were used. Tables 1 and 2 present the salient features of the two analyses. The yield moment for the pipe is 40900 footpounds while the bending moment at collapse is 68850 foot-pounds. A vessel offset of 2500 feet in calm water results in a bending moment in the damaged pipe section of 8600 foot-pounds.

Column Buckling. To determine the likelihood of column buckling, a critical buckling load analysis was performed using the DWRSR marine riser analysis 


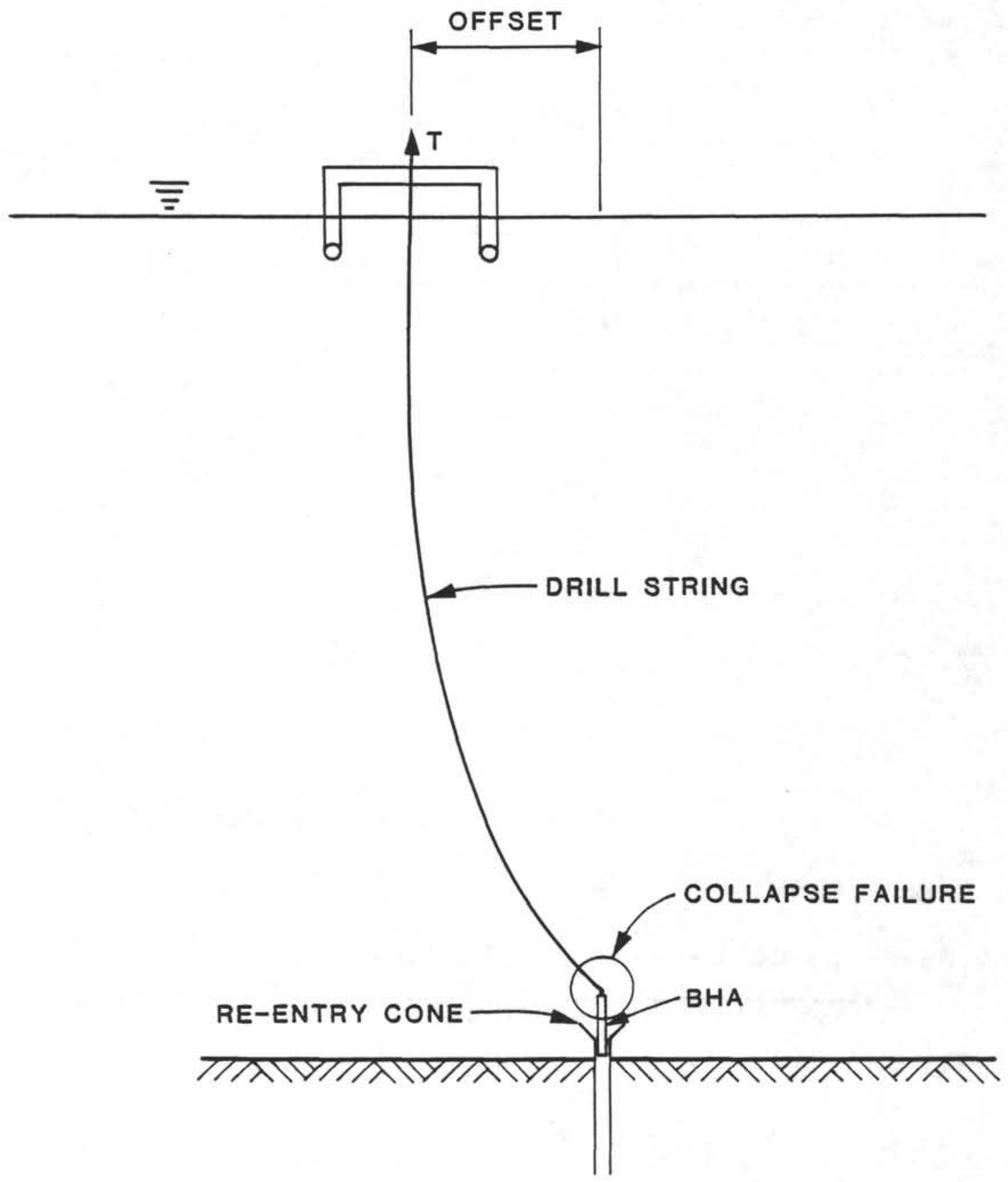

Figure 11- SCHEMATIC FOR COLLAPSE FAILURE SCENARIO 


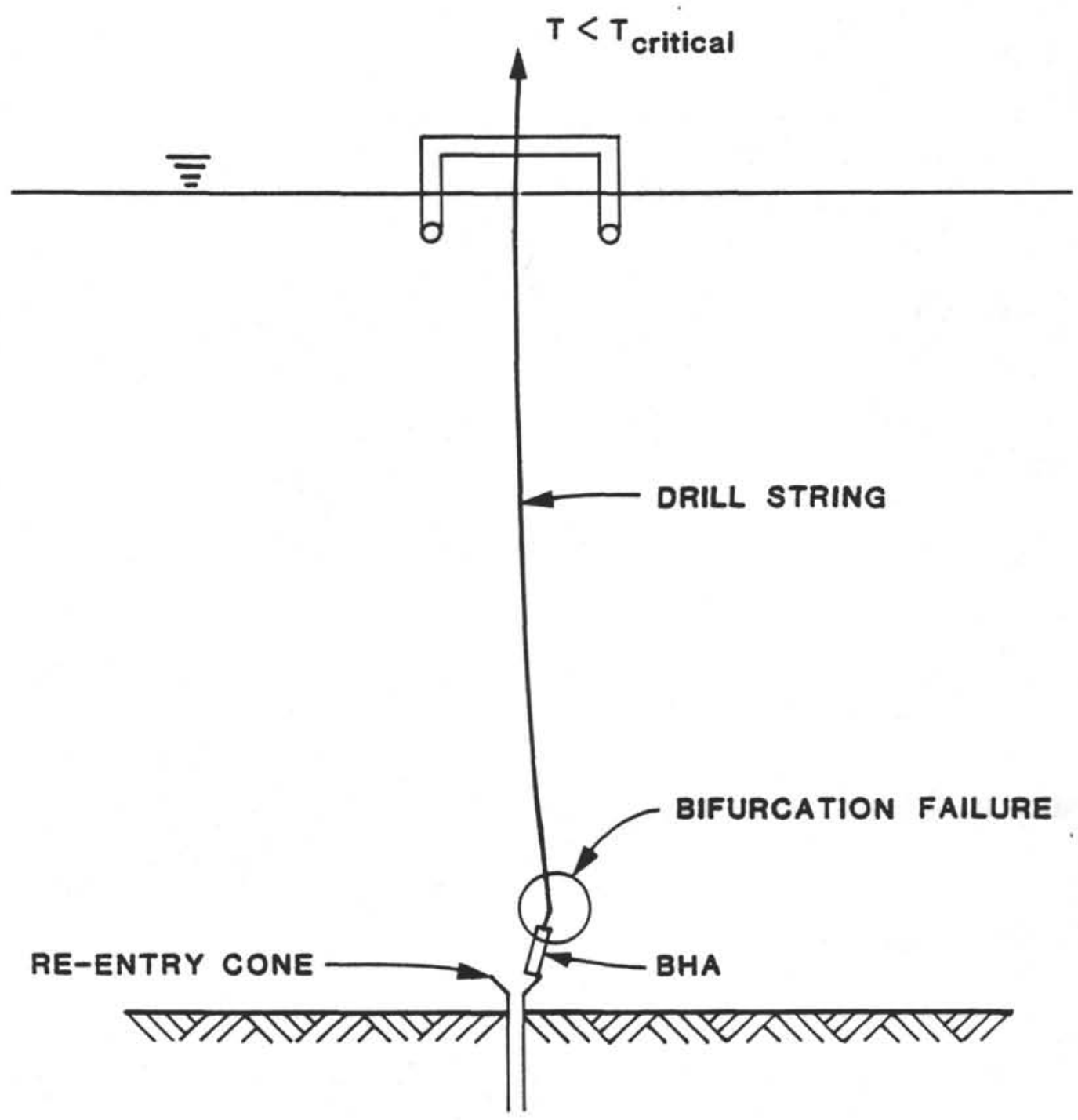

Figure 12- SCHEMATIC FOR BIFURCATION (COLUMN INSTABILITY) FAILURE SCENARIO 
TABLE 1. COLLAPSE ANALYSIS

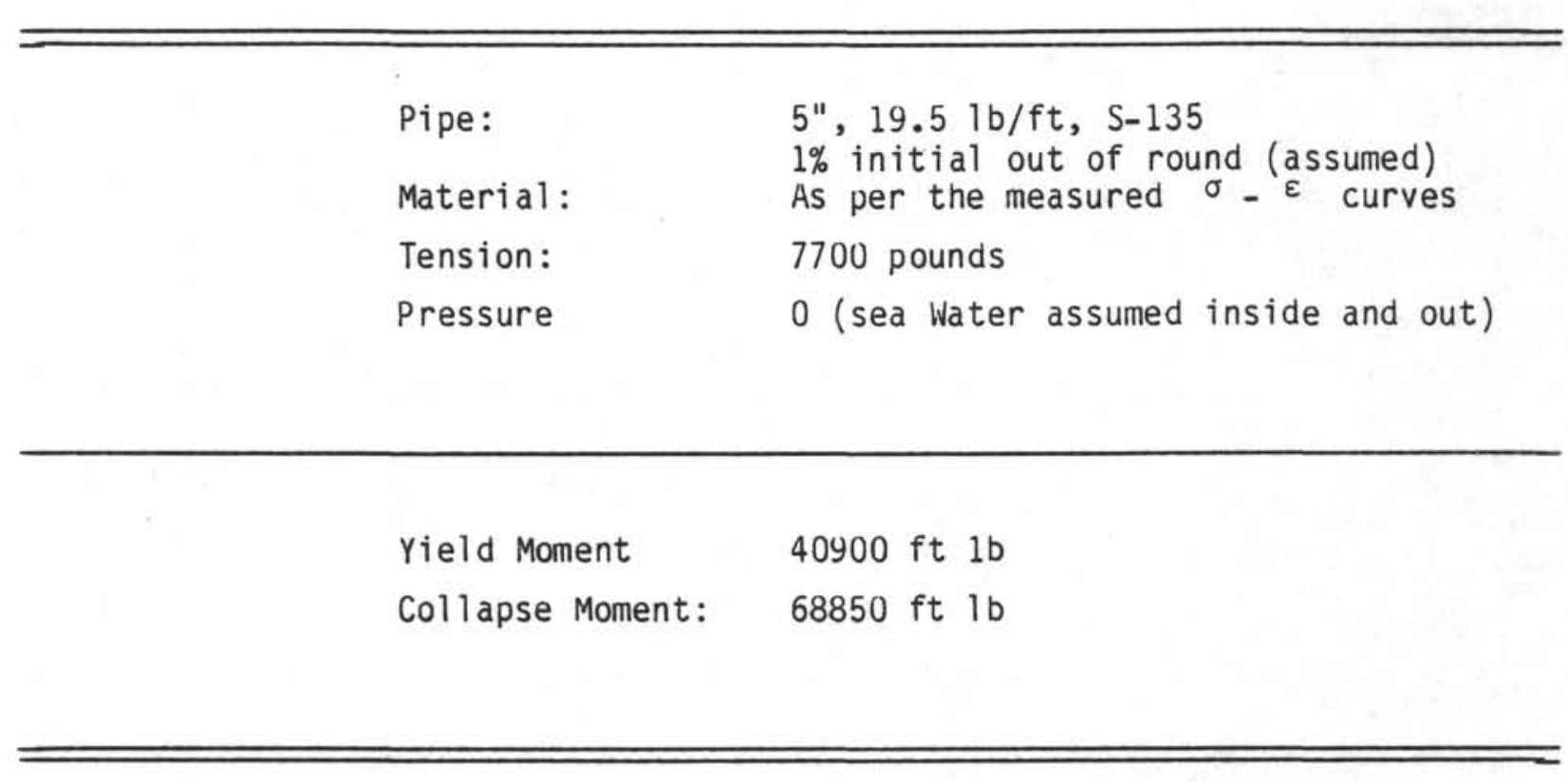


TABLE 2. VESSEL OFFSET ANALYSIS

Pipe:

BHA :

Top Tension:

uffset:

Model:
5", $19.5 \mathrm{lb} / \mathrm{ft}, \mathrm{S}-135$

As per BHA-01 drawing

$400000 \mathrm{lb}$

$2500 \mathrm{ft}$

402 tension/compression beam finite

elements

Boundary Conditions: bottom - fixed top - lateral roller with ball joint

Bending Moment at Collapsed Section: $8600 \mathrm{ft}-1 \mathrm{~b}$ 
program. The relevant data for this analysis is shown in Table 3 . The buckling load, 325,000 pounds is the minimum tension that must be applied to the top of the drill string to prevent buck1ing.

Considering all three possible causes for the initial damage to the drill pipe, column instability seems to be the most likely cause of the failure. Denting has been ruled out as physically unlikely. Collapse, while physically possible, is deemed unlikely because of the fact that to even approach the yield moment would require an offset in excess of 2500 feet. Column buckling on the other hand, seems quite reasonable - the buckling tension is very near the operating tension (400000 pounds) and the buckling mode shape results in the occurrence of the maximum moment in the drill stem at the pipe joint just above the bottom hole assembly. It should be noted that in the analyses performed, conditions have been idealized in that no waves, no current were considered and a shell approximation for collapse analysis was used. Such sea state and vessel offset data are unavailable for a more detailed analysis. The inclusion of such effects as the dynamic tension variation due to vessel heave and the influence of initial curvature due to waves and current would likely aggravate the buckling problem. In view of these analyses, the evidence strongly favors loss of tension due to drill string loads on the reentry cone as the initial cause of the ovalization or buckling damage to the pipe.

After it buckled, the drill pipe did not part immediately. The fatigue zones on the outer edges of the buckled area suggest that after buckling, the drill pipe continued to operate for perhaps several thousand cycles. During this time at least three fatigue cracks initiated and began to grow on the outer edges of the buckled zone. The heavy overpulls necessary to free the stuck drill pipe probably caused some of the remaining ligament to part. Final fracture occurred by ductile rupture in tension when the string was lifted to be slipped and cut. 
TABLE 3. COLUMN BUCKLING ANALYSIS

\begin{tabular}{ll}
\hline Pipe: & $5^{\prime \prime}, 19.51 \mathrm{~b} / \mathrm{ft}, \mathrm{S}-135$ \\
BHA: & As per BHA-01 drawing \\
Offset: & 0. \\
Tension & Variable \\
Model: & 402 tension/compression finite elements \\
& $\begin{array}{l}\text { Boundary Conditions: bottom - pinned } \\
\text { top - lateral roller with ball joint }\end{array}$ \\
& \\
& \\
Buckling Load: & 325000 pounds \\
Max Moment & lower end of piece of drill pipe just \\
in Pipe: & above BHA \\
\end{tabular}


This evidence suggests that the buckle which initiated this failure occurred some time before the drill pipe became stuck while retrieving core No. 1 .

\section{CONCLUSIONS}

1. The failure of the drill pipe in DSDP hole $581 \mathrm{~A}$ was initiated by a buckling of the drill pipe.

2. Buckling apparently took place some time before the drill pipe became stuck while attempting to retrieve core No. 1 . It is likely that it occurred during the setting of the 16 inch casing.

3. The buckle which initiated this failure was probably caused by insufficient tension in the drill string resulting from setting of the pipe on the sea floor or edge of the reentry cone.

4. After buckling the drill pipe did not part immediately. Several thousand cycles of rotation occurred while fatigue cracks formed at the coldworked outer edges of the buckled zone. Final fracture occurred by ductile rupture in tension.

5. The mechanical properties of the failed drill pipe joint met the API specification $5 A X$ in all respects.

6. The chemical composition of the drill pipe met the API 5AX specification limits for phosphorous and sulfur, the only elements required. Although the failed drill pipe joint was of plain carbon steel rather than lowalloy steel, the chemical composition apparently had no effect on this failure. 


\section{REFERENCES}

1. Kingel, et al.; Summary Report on the Inelastic Collapse and Buckling of Deep Water Pipelines Under Combined Movement, Pressure, and Axial Tension; Report to Battelle's Deep Water Offshore Pipeline Group; March, 1976.

2. Olson, et al.; Applications Manual for DWRSR Riser Analysis Program; Report to Battelle's Deep Water Marine Riser Group; June, 1982. 


\section{APPENDIX D}

OPERATIONS DURING SEVERE WEATHER 
OPERATIONS DURING SEVERE WEATHER

(EXCERPTED FROM DSDP OPERATIONS PLAN, $8 / 25 / 82$ )

The following operational limits and procedures have been established to protect personnel and equipment during severe weather conditions:

1. Drill pipe shall not be run when anticipated sea conditions will cause the ship to pitch and/or roll in excess of seven degrees single amplitude.*

2. Drilling operations, including running of drill pipe, may continue on the basis of a maximum pitch and/or roll of seven degrees single amplitude.*

3. The drill string shall be pulled if occasional pitch and/or roll exceeds nine degrees single amplitude.

4. If personnel safety considerations require that pulling/ running the drill string be stopped due to weather, a minimum of three heavy drilling joints should be picked up. Then the drill string should be slowly pulled up and down over a six meter interval so that the pipe located at the keel of the vessel is moved. Avoid having a connection within 5 feet of keel.

5. Positioning, when moving the ship with drill pipe extended, bending of the drill pipe shall be held to less than seven degrees as indicated by cutouts on the horn. During such operations, the drill pipe shall be moved vertically, frequently. The ship should not be moved at a speed greater than one knot and should be moved only as far an offset from vertical as a positioning beacon permits. Sufficient time must be allowed for the drill string to resume its generally vertical position before spudding.

6. If the presence of a strong current is indicated by the handling characteristics of the ship while positioning over the beacon on a new site, time should be taken to obtain a reasonably accurate estimate of current velocity before commencing to lower the drill string. If a current in excess of three knots, or excessive drill string vibration is encountered, regardless of wind direction and speed, consideration will be given to the selection of another site.

If wind, current, and sea forces are combined in one direction, the ship can operate in up to 15 foot swells, 40 knot winds and 3 knot currents. However, where these forces are not in the same direction (and wind or current may change direction on short notice), operations may have to be halted with much less wind and/or current.

* Limitation is five degrees for drill string in excess of 6860 meters. 
APPENDIX E

MECHANICAL AND METALLURGICAL EVALUATION OF $S-135$ DRILL PIPE 


\title{
REPORT
}

on

\section{MECHANICAL AND METALLURGICAL \\ EVALUATION OF S-135 DRILL PIPE}

Contract No. 613068-3058

to

DEEP SEA DRILLING PROJECT

August 30,1982

\author{
by \\ D. R. McIntyre \\ BATTELLE \\ Houston Operations \\ 2223 West Loop South \\ Houston, Texas
}

Battelle is not engaged in research for advertising, sales promotion, or publicity purposes, and this report may not be reproduced in full or in part for such purposes. 
SUMMARY $\ldots \ldots \ldots \ldots \ldots \ldots \ldots \ldots \ldots \ldots \ldots \ldots \ldots \ldots \ldots \ldots \ldots \ldots, 1$

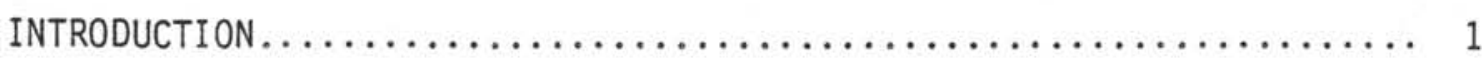

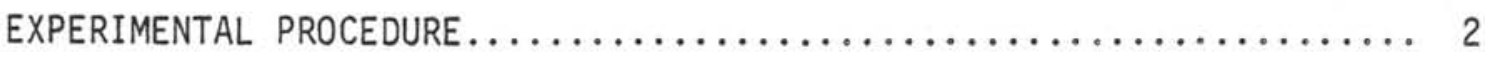

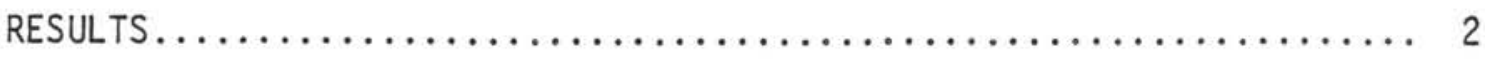

Dimensional Measurements........................... 2

Chemical Composition............................... 3

Mechanical Properties.............................. 3

Toughness Tests.................................. 3

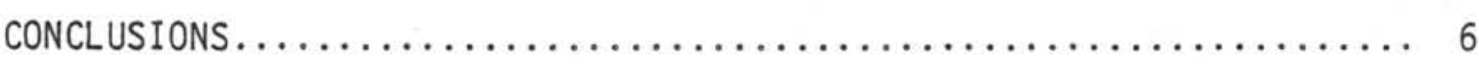

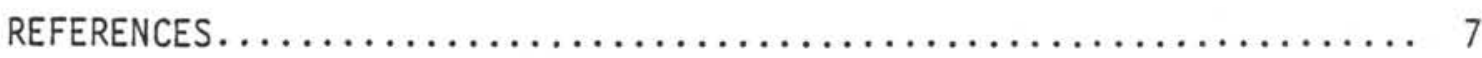

\section{LIST OF TABLES}

Table 1. Dimensional Measurements of Drill Pipe Sample.......... 8

Table 2. Chemical Analysis of Drill Pipe.................... 9

Table 3. Mechanical Properties of Drill Pipe.................. 10

Table 4. Toughness of Drill Pipe Sample...................... 11 


\section{REPORT}

on

MECHANICAL AND METALLURGICAL EVALUATION OF S-135 DRILL PIPE

CONTRACT NO.: 613068-3058

to

DEEP SEA DRILLING PROJECT

by

Dale R. McIntyre

from

BATTELLE

Houston Operations

August 30,1982

\section{SUMMARY}

A sample of 5 inch diameter $19.51 \mathrm{~b} / \mathrm{ft} \mathrm{S}-135 \mathrm{drill}$ pipe was evaluated for toughness, alloy content, dimensional tolerance and mechanical properties. Fracture mechanics analysis suggests that the toughness of the pipe is adequate to fulfill the leak-before-break criterion under typical drilling service conditions. The sample met API 5 AX specification in all respects.

\section{$\underline{\text { INTRODUCTION }}$}

Deep Sea Drilling Project uses API 5AX, 5 inch diameter, $19.5 \mathrm{lb} / \mathrm{ft}$ grade S135 drill pipe for obtaining geological core samples in deep water from the drill-ship D. V. GLOMAR CHALLENGER. DSDP has purchased a new lot of drill pipe from Japan for future use. In the past, drill pipe failures due to fatigue and hydrogen embrittlement have caused expensive project delays. Battelle was requested to assess the mechanical and metallurgical condition of samples from the new lot of pipe in the light of anticipated service 
conditions. A three-foot length of drill pipe from the new lot was sent to Battelle-Houston's Charles Street laboratory for evaluation.

\section{EXPERIMENTAL PROCEDURE}

The sample was subjected to the following tests:

1. Dimensional measurements of 0.D., I.D. and wall thickness using calipers at four locations on the sample.

2. Wet chemical analysis of triplicate samples for

Carbon

Manganese

Phosphorous

Silicon

Chromium

Mol ybdenum

3. Mechanical properties detemination on triplicate samples at room temperature. Properties measured were:

ultimate tensile strength

yield strength at 0.7 percent offset

percent elongation in two inches

4. Toughness determination on two sets of triplicate Charpy V-notch specimens tested at $32 \mathrm{~F}$ and room temperature.

\section{RESULTS}

\section{Dimensional Measurements}

Results of the dimensional measurements are shown presented in Table 1 . The 
sample received met the API $5 A X$ specification for outer diameter tolerance, wall thickness tolerance, and ovality at all the locations tested.

\section{Chemical Composition}

Results of the wet chemical analysis on three samples from the drill pipe specimen are presented in Table 2. The API 5AX specification places limits only on phosphorous and sulfur, leaving the balance of the composition to the manufacturer's discretion. The samples analyzed easily met the required phosphorous and sulfur limits. The balance of the composition is indicative of a typical low-alloy steel roughly equivalent to AISI 4030 steel.

\section{Mechanical Properties}

Table 3 presents the results of mechanical properties tests on triplicate oneinch wide full thickness strip tensile specimens. The yield strength, ultimate tensile strength and ductility met the API 5AX specification in all respects. The ratio of yield strength to ultimate tensile strength averaged .93 , which is within the range of .86 to .94 typical for S-135 drill pipe. Hardness of the pipe sample was Rc 34.

\section{Toughness Tests}

Table 4 presents the results of Charpy impact tests on triplicate threequarter size specimens broken at room temperature and freezing temperature. There is no API specification for toughness on drill pipe. However, impact tests across the range of anticipated service temperatures can indicate whether or not brittle fracture might be a problem in service.

The toughness of the six specimens from this piece of drill pipe was good at both room temperature and freezing. The values for percent shear suggest that the ductile-to-brittle transition temperature of this material is well below freezing. 
The specimens used were three-quarter size since the pipe wall thickness was too thin to permit the use of the standard ten millimeter wide Charpy specimen. The ASTM standards which allow the use of both ten-millimeter and three-quarter size Charpy specimens typically use a ratio of 0.80 for comparing the absorbed energy values of low-alloy steels. Thus 20 foot-pounds of absorbed energy in a standard ten-millimeter Charpy corresponds to 16 footpounds of energy in a three quarter size Charpy. 1,2 This correlation is perforce approximate and may not be valid for all materials at all yield strengths. However, using this ratio, the observed average absorbed energy values would correspond to full-size impact values of 49 . 6 foot-pounds at room temperature and 37 foot-pounds at freezing temperature.

For drill pipe, there are no toughness criteria specified in API 5AX specification. However, the level of toughness required for satisfactory service can be estimated as follows:

The most desirable service requirement for drill pipe is that any fatigue cracks which form should leak before they break, allowing detection before the string parts. The leak-before-break criterion means that the pipe must be able to sustain a circumferential through-thickness crack without catastrophic brittle failure. The stress intensity generated by a circumferential throughthickness crack twice as long as the wall thickness can be approximated with the relationship:

$$
K=\sigma \sqrt{\pi}
$$

Where $\sigma=$ the applied stress, $T=$ the wall thickness, and $K=$ the stress intensity. ${ }^{3}$ At the specified minimum yield strength of S-135, a $2 T$ throughthickness circumferential crack would generate

$$
135000(\pi \times 0.362)^{1 / 2}=143,000 \mathrm{ksi} \sqrt{\mathrm{in}}
$$

of stress intensity. 
The critical stress intensity a material can sustain without brittle fracture, $K_{I C}$, can be estimated from the Charpy impact values using Barsom, Rolfe and Novak's empirical correlations between $\mathrm{K}_{\mathrm{IC}}$ and Charpy test results on the upper shelf and in the transition region between brittle and ductile behaviour. 4

At room temperature, the calculated full-size Charpy impact value averaged 49.6 foot-pounds. Fracture was 100 percent ductile, so the upper shelf equation from Barsom, Rolf and Novak applies.

$$
\left(\frac{K_{I C}}{\gamma}\right)^{2}=5\left[\frac{C_{v}}{\gamma}-0.05\right]
$$

For $g=152 \mathrm{ksi}, C_{v}=49.6 \mathrm{ft}-1 \mathrm{bs}$, the calculated $K_{I C}-179 \mathrm{ksi}$ in. Therefore, the drill pipe sample could sustain a 2T through-thickness circumferential crack at any stress up to and beyond the yield strength with no danger of brittle fracture.

At freezing temperature, the calculated full-size Charpy impact values average 37 foot-pounds. Some cleavage fracture was present on the specimens, so the material is in the transition region and the following correlation between $\mathrm{K}_{\mathrm{I}} \mathrm{C}$ and CVN can be used:

$$
\frac{K_{I C}{ }^{2}}{E}=2\left(C_{V}\right)^{3 / 2}
$$

If $C_{v}-37 \mathrm{ft}-1 \mathrm{bs}$ and $E=29,000,000 \mathrm{psi}, K_{I C}=114 \mathrm{ksi} \sqrt{\mathrm{in}}$.

Therefore at freezing temperature this material could sustain a 2T throughthickness circumferential crack up to stresses of:

$$
\sigma=114,000 /(\pi \times 0.362)^{1 / 2}=107,000 \mathrm{psi} \text {. }
$$

In 5 inch 0.D. $19.5 \mathrm{lb} / \mathrm{ft}$ drill pipe this would be equivalent to a total string weight of 583,000 pounds. If through-thickness fatigue cracks are present at freezing temperatures with total load in excess of 583,000 pounds, then brittle fracture is possible. 
These calculations are approximate and based on two empirical correlations rather than direct measurement of the drill pipe toughness. However, they indicate that this material's toughness is entirely adequate at ambient temperatures under any elastic loading condition. At $0^{\circ} \mathrm{C}$ the material's toughness is adequate up to 80 percent of the specified minimum yield strength. At stresses above this level fatigue cracks might not leak before the string parts.

\section{CONCLUSIONS}

1. The drill pipe sample submitted met the API $5 A X$ dimensional requirements in all respects.

2. The sample submitted met the chemical composition requirements of API 5AX and is typical of low-alloy steels in widespread use for this service.

3. The sample submitted met the API $5 A X$ mechanical properties requirements in all respects.

4. The room temperature toughness of the sample submitted was sufficient to ensure leakage of any crack before brittle fracture at any load up to the specified minimum yield strength.

5. The toughness of the sample submitted was still good at $0^{\circ} \mathrm{C}$, although cracks might not leak before breaking if the pipe is stressed in excess of 80 percent of the specified minimum yield strength. 


\section{REFERENCES}

1. ASTM A320-80B, "Alloy Steel Bolting Material for Low-Temperature Service" American Society for Testing and Materials, 1981 Annual Book of ASTM Standards, Part 1, p.231-240.

2. ASTM A333-79, "Seamless and Welded Steel Pipe for Low-Temperature Service" American Society for Testing and Materials, 1981 Annual Book of ASTM Standards, Part 1, p. 241-249.

3. "Stress-Intensity Factor for a Circumferential Through-wall Crack in a Straight Pipe," Gilman, J. D. Report GEAP-5557 General Electric Co. APED, San Jose, Cal if, 1968.

4. "Use of Correlations between $K_{I C}$ and Charpy V-notch Test Results in the Transition-Temperature Range" Barsom, J. M. and Rolfe, S. T., Impact Testing of Metals, ASTM STP 466, American Society for Testing and Materials, 1970, pp 3-20. 
TABLE 1. DIMENSIONAL MEASUREMENTS OF DRILL PIPE SAMPLE

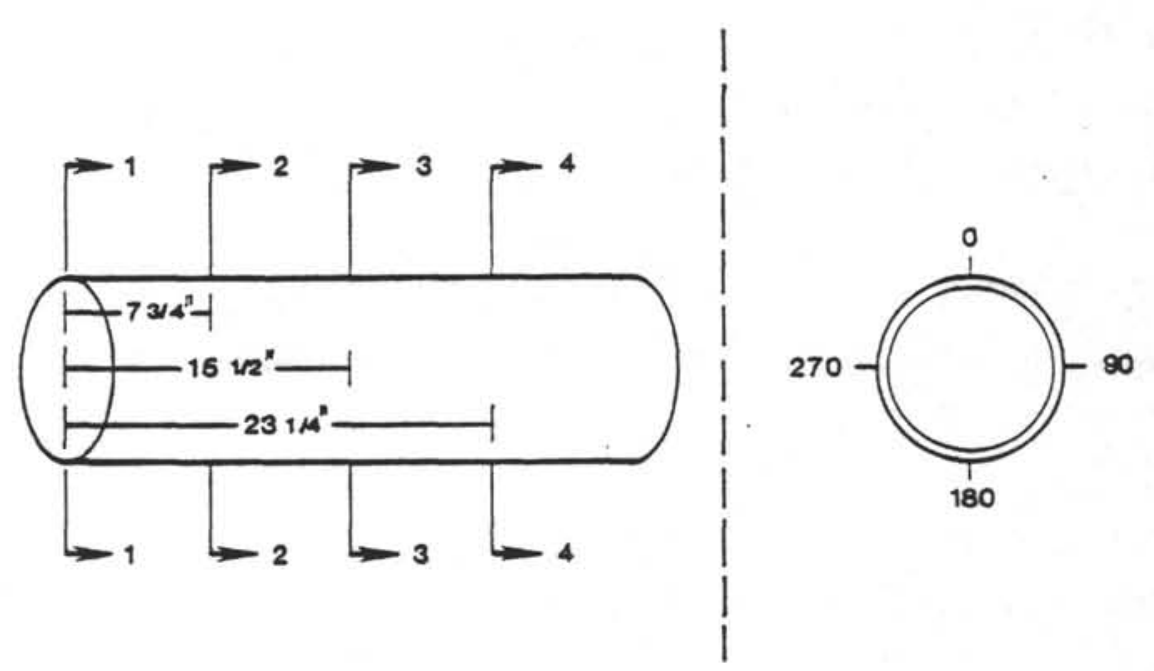

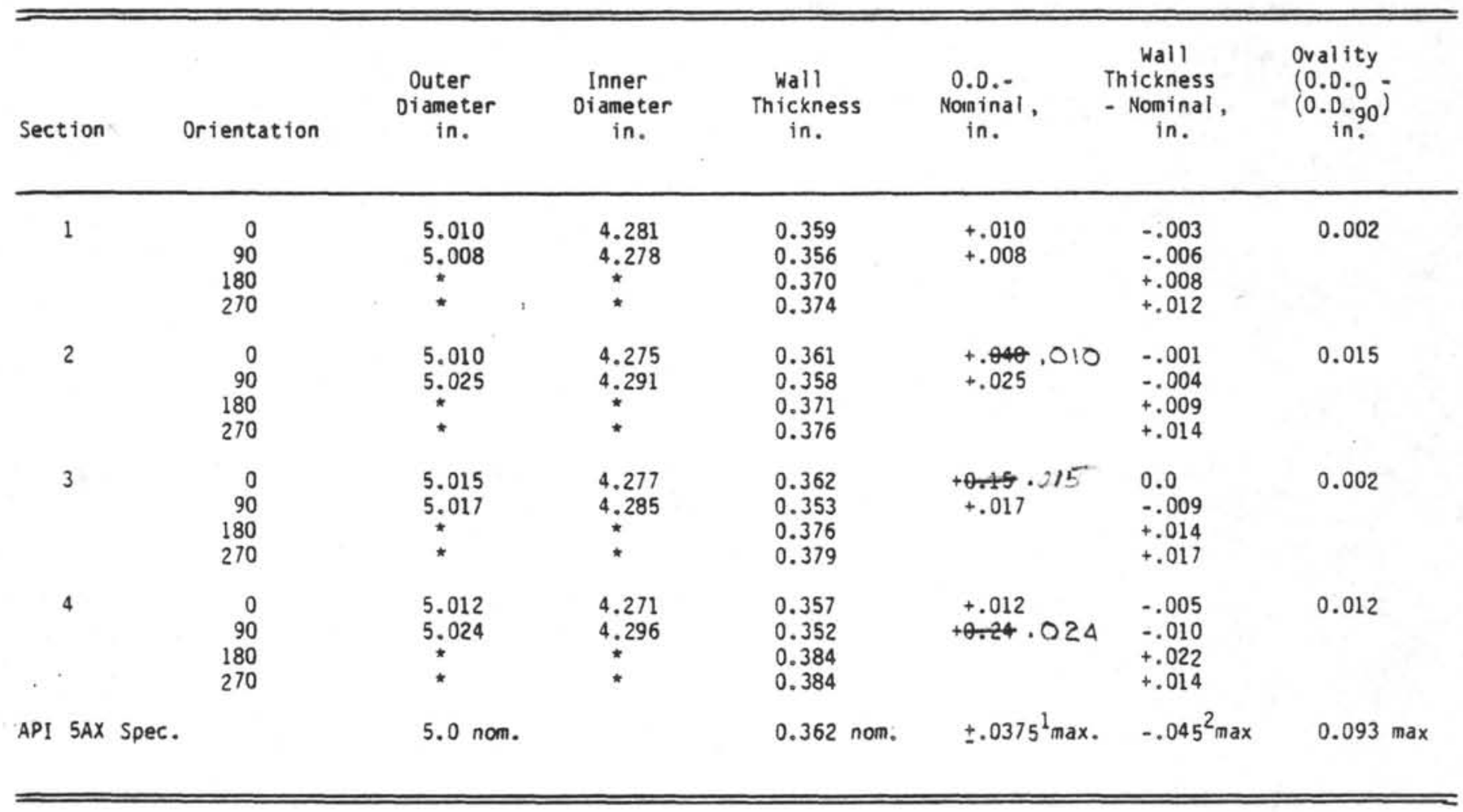

* diameter measurements were taken from 0 to $180^{\circ}$ and 90 to $270^{\circ}$ so the $0^{\circ} 0.0$. reading will be identical to the $180^{\circ}$ reading and the $90^{\circ}$ reading is identical to the $270^{\circ}$ reading.

$1 \pm 0.75$ percent

2 - 12.5 percent 
TABLE 2. CHEMICAL ANALYSIS OF DRILL PIPE

All Values are in Weight Percent

\begin{tabular}{|c|c|c|c|c|}
\hline Sample No. & 1 & 2 & 3 & $\begin{array}{c}\text { API } 5 A X \\
\text { Specification }\end{array}$ \\
\hline Carbon & 0.28 & 0.28 & 0.28 & n.s. \\
\hline Manganese & 1.37 & 1.38 & 1.38 & n.s. \\
\hline Phosphorus & 0.020 & 0.020 & 0.021 & $0.040 \max$ \\
\hline Sulfur & 0.010 & 0.009 & 0.010 & $0.060 \max$ \\
\hline Silicon & 0.15 & 0.16 & 0.17 & n.s. \\
\hline Chromium & 0.25 & 0.26 & 0.26 & n.s. \\
\hline Mol ybdenum & 0.38 & 0.39 & 0.38 & n.s. \\
\hline
\end{tabular}

* n.s. - not specified 
TABLE 3. MECHANICAL PROPERTIES OF DRILL PIPE

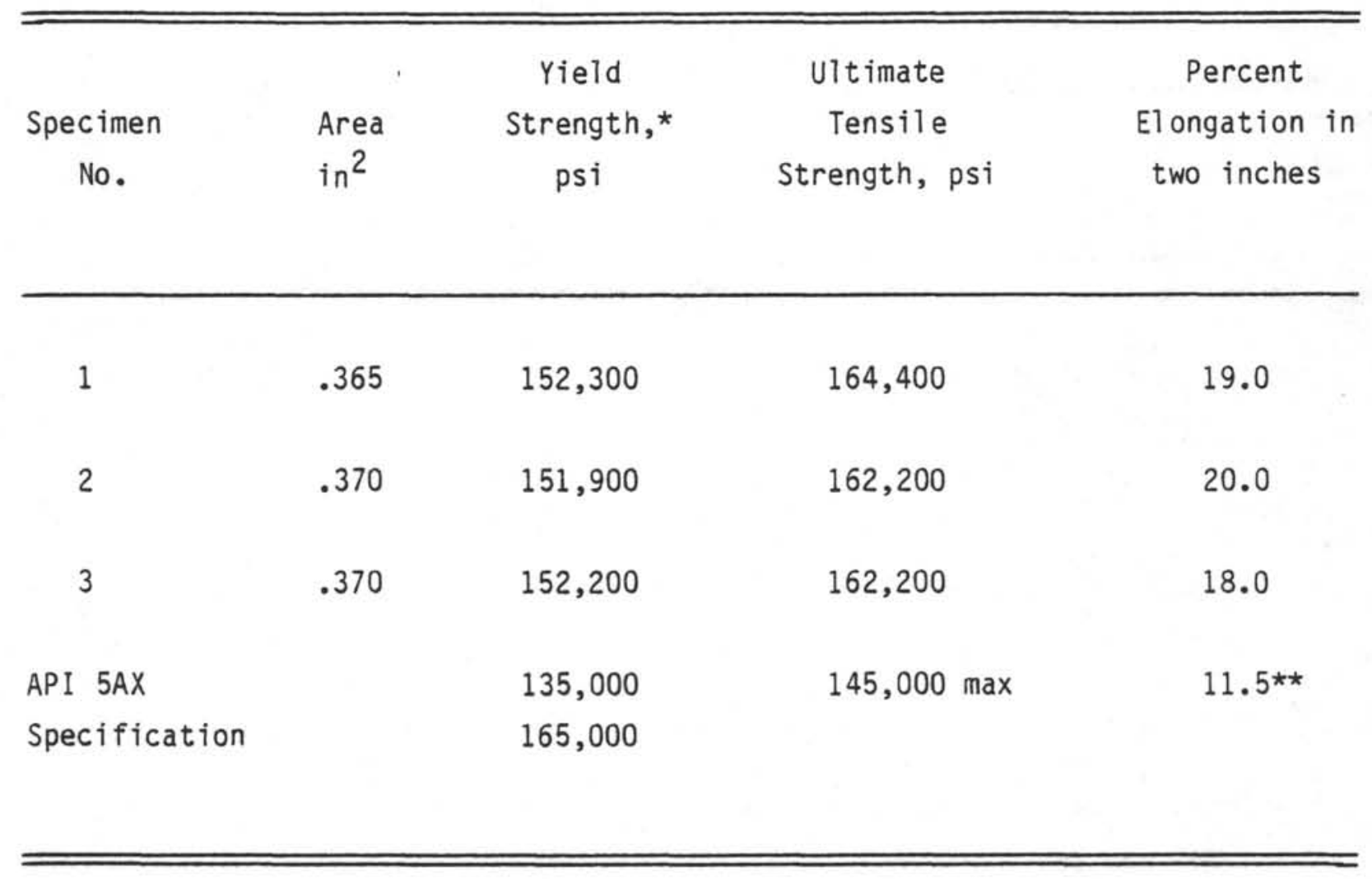

* $\quad .7 \%$ Total Extension

** API $5 A X$ required minimum elongation varies with specimen size and is based on the formula:

where:

$$
e=625,000 \frac{A^{0.2}}{U^{0.9}}
$$

$$
\begin{aligned}
& \mathrm{e}=\text { minimum elongation } \\
& \mathrm{a}=\text { specimen area, } i \mathrm{n}^{2} \\
& \mathrm{u}=\text { specified minimum tensile strength, psi }
\end{aligned}
$$


TABLE 4. TOUGHNESS OF DRILL PIPE SAMPLE.

Values are from $3 / 4$ Size Specimens

\begin{tabular}{cccc}
\hline \hline Specimen No. & Test Temp & Impact Value (ft-1bs.) & Percent Shear \\
\hline 1 & $+73^{\circ} \mathrm{F}$ & 38.5 & 100 \\
2 & $+73^{\circ} \mathrm{F}$ & 42.0 & 100 \\
3 & $+73^{\circ} \mathrm{F}$ & 38.5 & 100 \\
4 & $+32^{\circ} \mathrm{F}$ & 27.0 & 79 \\
5 & $+32^{\circ} \mathrm{F}$ & 30.0 & 86 \\
6 & $+32^{\circ} \mathrm{F}$ & 32.0 & \\
\hline \hline
\end{tabular}

